\title{
Surface chemistry of carbon dioxide revisited
}

\author{
William Taifan, ${ }^{1}$ Jean-François Boily ${ }^{2, *}$ and Jonas Baltrusaitis ${ }^{1, *}$ \\ ${ }^{1}$ Department of Chemical and Biomolecular Engineering, Lehigh University, B336 Iacocca Hall, \\ 111 Research Drive, Bethlehem, PA 18015, USA \\ ${ }^{2}$ Department of Chemistry, Umeå University, SE-901 87 Umeå, Sweden
}

\begin{abstract}
This review discusses modern developments in $\mathrm{CO}_{2}$ surface chemistry by focusing on the work published since the original review by H. J. Freund and M.W. Roberts two decades ago (Surface Science Reports 25 (1996) 225-273). It includes relevant fundamentals pertaining to the topics covered in that earlier review, such as conventional metal and metal oxide surfaces and $\mathrm{CO}_{2}$ interactions thereon. While UHV spectroscopy has routinely been applied for $\mathrm{CO}_{2}$ gas-solid interface analysis, the present work goes further by describing surface- $\mathrm{CO}_{2}$ interactions under elevated $\mathrm{CO}_{2}$ pressure on non-oxide surfaces, such as zeolites, sulfides, carbides and nitrides. Furthermore, it describes salient in situ techniques relevant to the resolution of the interfacial chemistry of $\mathrm{CO}_{2}$, notably infrared spectroscopy and state-of-the-art theoretical methods, currently used in the resolution of solid and soluble carbonate species in liquid-water vapor, liquid-solid and liquid-liquid interfaces. These techniques are directly relevant to fundamental, natural and technological settings, such as heterogeneous and environmental catalysis and $\mathrm{CO}_{2}$ sequestration.
\end{abstract}




\section{Table of Contents}

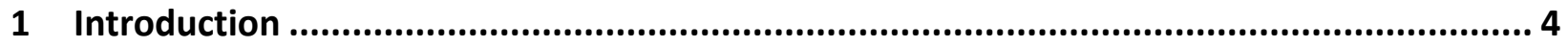

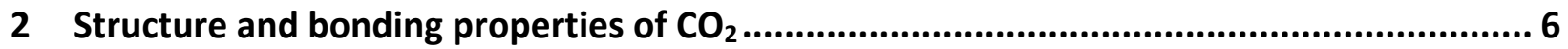

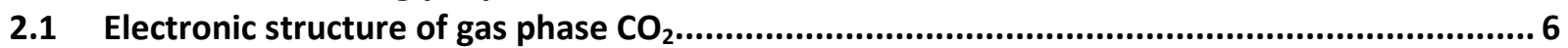

2.2 Molecular structure and electronic properties of the excited state and anionic $\mathrm{CO}_{2} \ldots \ldots \ldots \ldots . . . . .8$

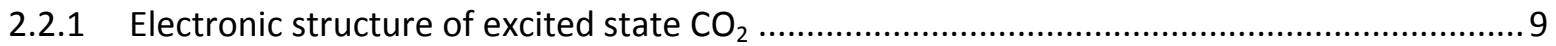

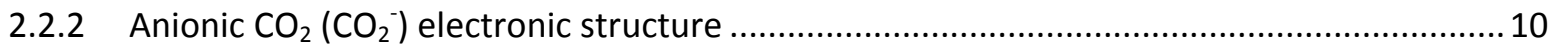

3 Experimental techniques for $\mathrm{CO}_{2}$ surface chemistry analysis ...................................... 12

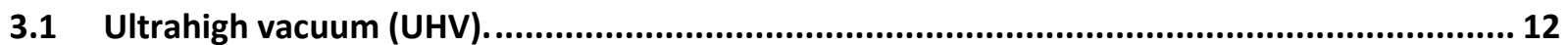

3.1.1 Surface analysis techniques based on electron-surface interactions. .............................. 16

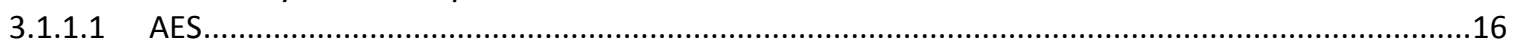

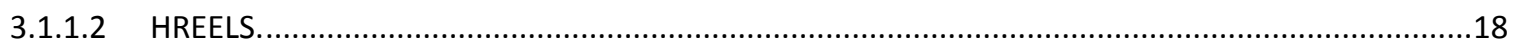

3.1.2 Surface analysis techniques based on photon-surface interactions. ................................. 19

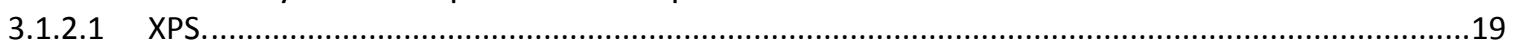

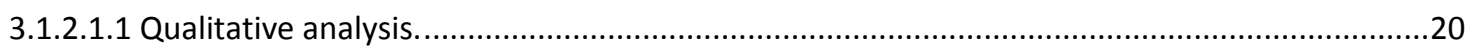

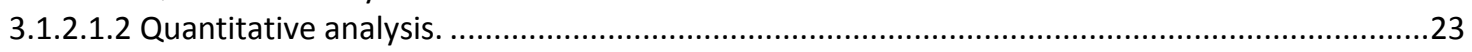

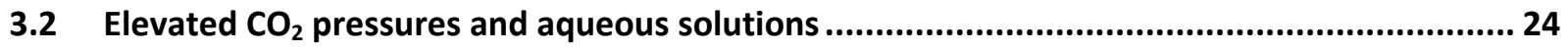

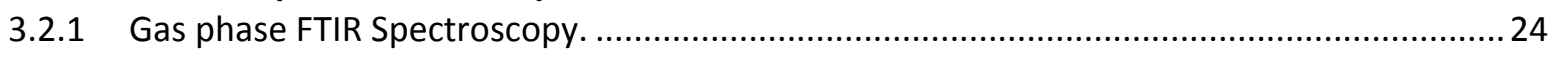

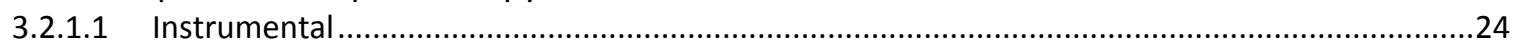

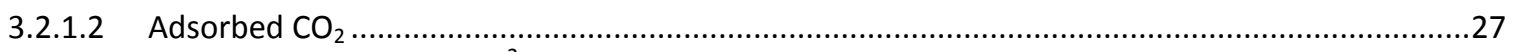

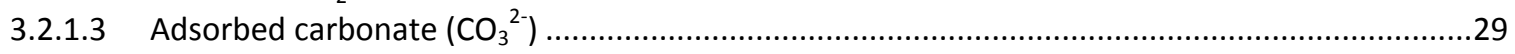

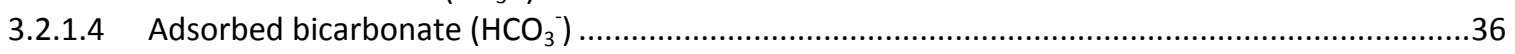

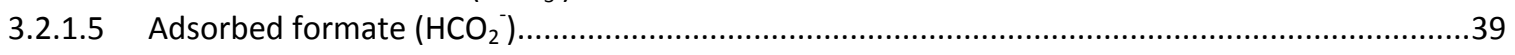

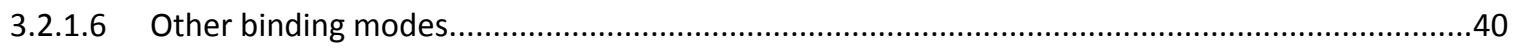

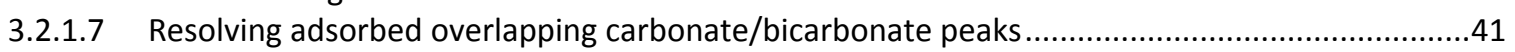

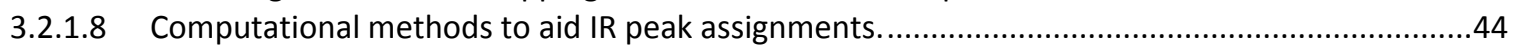

3.2.2 Instrumental designs to monitor $\mathrm{CO}_{2}$ adsorption and uptake ......................................50

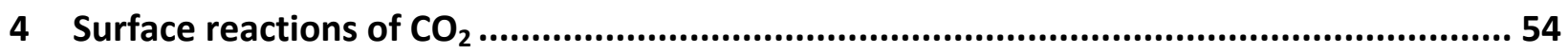

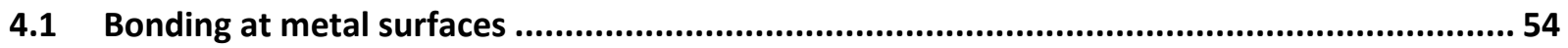

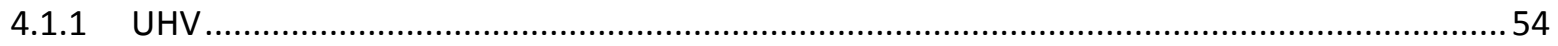

4.1.2 $\mathrm{CO}_{2}$ interactions with co-adsorbing gas on metal surfaces .............................................68

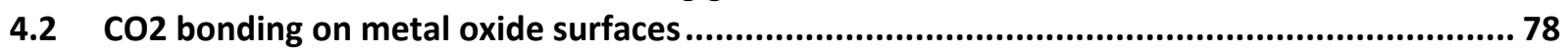

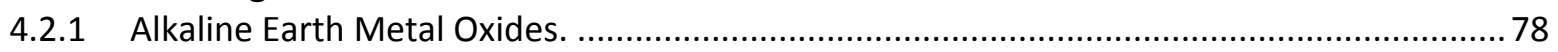

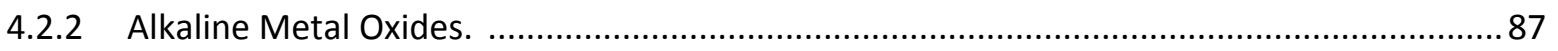

4.2.3 Other Metal Oxides (Pure and Doped Al2O3, ZrO2, Cr2O3, TiO2, ZnO, Ga2O3) ................. 91

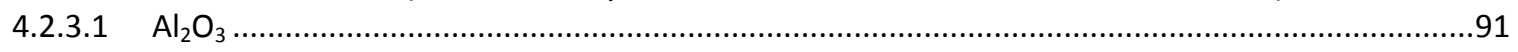

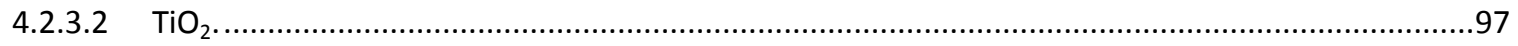

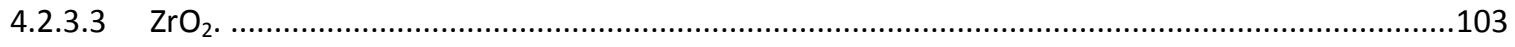

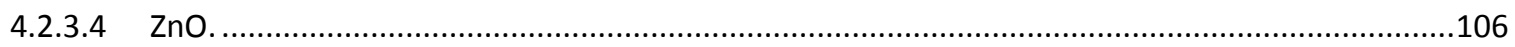

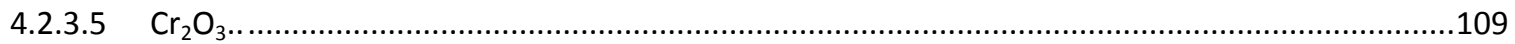

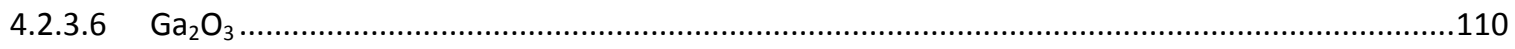

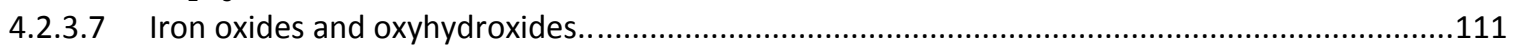

4.2.3.8 PdO.

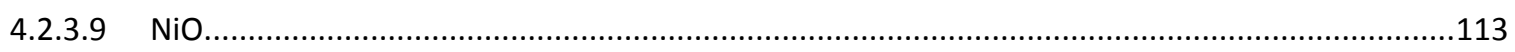

4.2.4 $\mathrm{CO}_{2}$ adsorption on metal oxide surfaces in the presence of coadsorbing molecules .........114

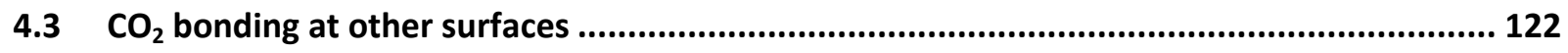

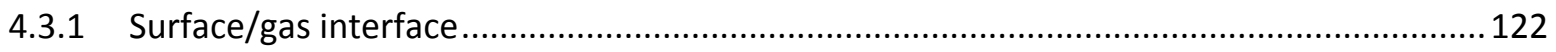




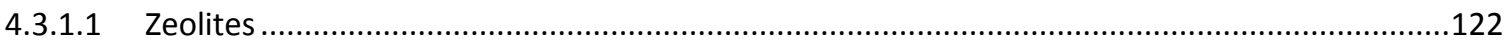

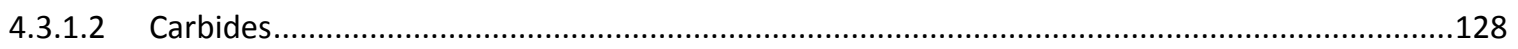

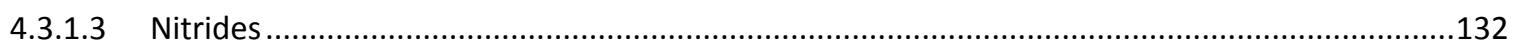

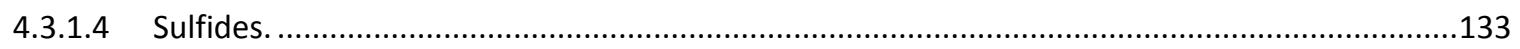

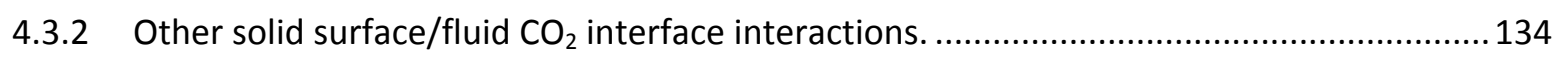

4.4 Carbonate $/ \mathrm{H}_{2} \mathrm{O}$ vapor or fluid interfaces .................................................................. 139

4.4.1 Solid metal carbonate/gas interface ............................................................... 139

4.4.1.1 Metal carbonate surfaces in the presence of significant humidity 136

4.4.1.2 Metal carbonate surfaces in the presence of acidic gases 140

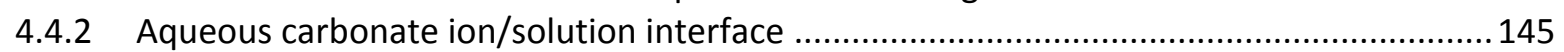

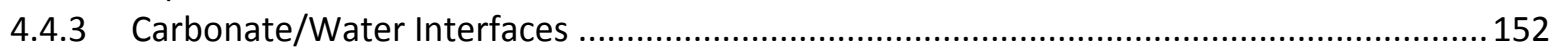

4.4.4 Metal Oxide/Aqueous Carbonate Ion Interface ...................................................... 156

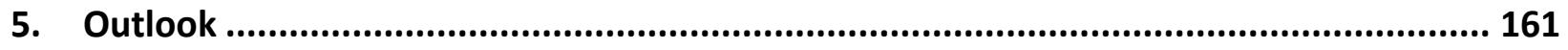

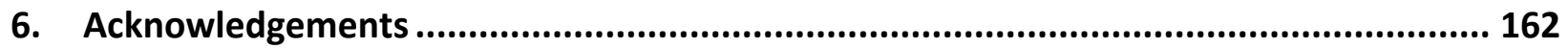

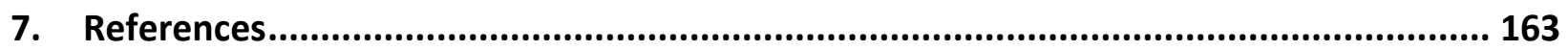


Increasing levels of atmospheric $\mathrm{CO}_{2}[1,2]$ have prompted numerous studies dedicated to solid and liquid surface-facilitated chemical reactions leading to the fixation of carbon from $\mathrm{CO}_{2}$ as a feedstock. These studies range from natural processes in the atmosphere $\left(\mathrm{CO}_{2}\right.$ partitioning into the oceans [3] or on mineral dust aerosols [4] under environmentally relevant conditions of pressure, temperature and co-reactants, such as $\mathrm{H}_{2} \mathrm{O}$ vapor [5]) to high temperature and pressure catalytic processes, such as industrial $\mathrm{CH}_{3} \mathrm{OH}$ synthesis [6]. $\mathrm{CO}_{2}$ activation and upgrading to value added chemicals has been extensively reviewed [6-12] with the focus on finding the most feasible catalysts that possess (a) high single pass conversion while (b) selectively yielding desired hydrocarbons or the corresponding oxygenates. Simple thermodynamic considerations $(\Delta \mathrm{H}$ and $\Delta \mathrm{G})$ suggest that a number of catalytic reactions shown in Table 1, below are thermodynamically and exergonically favorable, and even proceed on the same catalysts as the equivalent $\mathrm{CO}$ hydrogenation processes ( $\mathrm{rxn} 3$ to form $\mathrm{CH}_{3} \mathrm{OH}$ on $\mathrm{Cu} / \mathrm{ZnO}$ based catalysts).

Table 1. Thermodynamic consideration of various reactions of $\mathrm{CO}_{2}$ to molecules at $298 \mathrm{~K}$. Reproduced with permission from [11]. Copyright (2013) PCCP Owner Societies.

\begin{tabular}{|c|c|c|c|l|}
\hline Rxn & Reactions & $\begin{array}{c}\Delta \mathbf{H}, \\
(\mathbf{k J} / \mathbf{m o l})\end{array}$ & $\begin{array}{c}\Delta \mathbf{G}, \\
(\mathbf{k J} / \mathbf{m o l})\end{array}$ & \multicolumn{1}{|c|}{ Catalyst } \\
\hline 1 & $\mathrm{CO}_{2}+\mathrm{H}_{2} \rightleftharpoons \mathrm{CO}+\mathrm{H}_{2} \mathrm{O}$ & 41.2 & 28.6 & $\begin{array}{l}\mathrm{Cu}-\mathrm{Cu} / \mathrm{ZnO}-, \mathrm{Fe}-\text {, and Ce- } \\
\text { based catalysts }\end{array}$ \\
\hline 2 & $\mathrm{CO}_{2}+\mathrm{H}_{2} \rightleftharpoons \mathrm{HCOOH}$ & -31.2 & 33 & $\begin{array}{l}\text { Rh-, Ru-, and Ir-based } \\
\text { organometallic catalysts }\end{array}$ \\
\hline 3 & $\mathrm{CO}_{2}+3 \mathrm{H}_{2} \rightleftharpoons \mathrm{CH}_{3} \mathrm{OH}+\mathrm{H}_{2} \mathrm{O}$ & -131 & -9 & $\begin{array}{l}\text { Cu-, Cu/ZnO-, Fe-, and Ce- } \\
\text { based catalysts }\end{array}$ \\
\hline 4 & $\mathrm{CO}_{2}+4 \mathrm{H}_{2} \rightleftharpoons \mathrm{CH}_{4}+2 \mathrm{H}_{2} \mathrm{O}$ & -164.9 & -113.5 & $\begin{array}{l}\text { Ni-based, supported Ru and } \\
\text { Rh catalysts }\end{array}$ \\
\hline 5 & $\mathrm{CO}_{2}+\mathrm{CH}_{4} \rightleftharpoons 2 \mathrm{CO}+2 \mathrm{H}_{2}$ & 247.3 & 170.7 & $\begin{array}{l}\text { Rh-, Ru-, and Ni-based } \\
\text { catalysts }\end{array}$ \\
\hline
\end{tabular}


Selectivity issues however prohibited practical implementation of catalytic $\mathrm{CO}_{2}$ conversion. For example, the reverse water-gas shift reaction 1 and methanol formation reaction 3 take place over the same catalyst. Formation of water also presents a challenge to the active catalyst material and the support, in addition to increasing separation costs [7]. Furthermore, converting $\mathrm{CO}$ into methanol is much more efficient than $\mathrm{CO}_{2}$. Even though labeling experiments show that surface carbonate and formate species, resulting from $\mathrm{CO}_{2}$, not from $\mathrm{CO}$, are the main intermediates, the catalysts for $\mathrm{CO}$ to $\mathrm{CH}_{3} \mathrm{OH}$ lose their catalytic activity, when $\mathrm{CO}_{2}$ is used instead of $\mathrm{CO}$ [7]. The deactivation of the catalyst is apparently due to the formation of water in the $\mathrm{CO}_{2}$ case, which is not encountered when one starts with $\mathrm{CO}$ [8]. This interesting interplay between favorable thermodynamics and low observed yields suggests catalyst surface controlled reactivity.

The hitherto methods for identifying the best combinations of catalysts have not provided a detailed understanding of the underlying, fundamental surface phenomena. Furthermore, during the recent decades, theoretical methods, such as the Density Functional Theory (DFT), and calculations developed rapidly, now provide a superior tool for understanding the combined reaction mechanism involved. These advances aid in the design of new catalysts, rather than tediously exhausting all the possible combinations of the existing transition metals and oxides. New models and improved algorithms, as well as the introduction of van der Waals contributions to adequately describe weak substrate-adsorbate interactions, are expected to become the main protagonists in understanding $\mathrm{CO}_{2}$ surface based transformations. Combined with the instrument developments for in situ experimental surface analysis at the operating temperature and pressure, advances in theoretical approach could help overcome the selectivity challenges. A comprehensive review of the computational approach for $\mathrm{CO}_{2}$ upgrade to $\mathrm{CO}, \mathrm{CH}_{4}, \mathrm{CH}_{3} \mathrm{OH}$, and 
$\mathrm{HCOOH}$, in addition to photocatalysis and electrocatalysis, is provided by Cheng et al. [11] and will not be discussed here. Instead, molecular level surface fundamentals in $\mathrm{CO}_{2}$ adsorption, binding and resulting molecular structure perturbation will be broadly covered using both Ultra High Vacuum (UHV) and controlled temperature and pressure conditions via both experimental and theoretical approaches. At the same time, this review builds upon the one by H.-J. Freund and M.W. Roberts published in 1996 [13] and includes relevant fundamentals pertaining to $\mathrm{CO}_{2}$ chemistry and techniques needed for resolution of the interfacial chemistry of $\mathrm{CO}_{2}$ that are of central importance to the topics covered in this review. As such, the overarching goal of this review is to provide an overview of the salient achievements in the interfacial chemistry of $\mathrm{CO}_{2}$ during the past two decades, yet it cannot fully cover the entirety of the contributions made by the vast and interconnected chemical, geochemical, and atmospheric communities. Still, it is our hope that this review will provide early career to seasoned physical scientists with the necessary overview needed to grasp the rich interfacial chemistry undergone by $\mathrm{CO}_{2}$, and that it will pave the way for future developments for this engaging greenhouse gas of scientific, engineering and societal importance.

\section{Structure and bonding properties of $\mathrm{CO}_{2}$}

\subsection{Electronic structure of gas phase $\mathrm{CO}_{2}$}

$\mathrm{CO}_{2}$ is a linear molecule that has two equivalent $\mathrm{C}=\mathrm{O}$ bond lengths, with a $\angle \mathrm{O}-\mathrm{C}$-O bond angle of $180^{\circ}$. The ground state electronic configuration of a carbon atom is $1 \mathrm{~s}^{2} 2 \mathrm{~s}^{2} 2 \mathrm{p}^{2}$, whereas an

oxygen atom has a ground state electronic configuration of $1 s^{2} 2 s^{2} 2 p^{4}$. This indicates that the carbon atom needs four electrons to reach the octet configuration, while an oxygen atom needs 
two more electrons. A linear combination of atomic orbitals can express molecular orbitals of the $\mathrm{CO}_{2}$ (LCAO-MO) wave function in the general form as

$\psi=c_{1} 2 s_{O 1}+c_{2} 2 s_{O 2}+c_{3} 2 s_{C}+c_{4} 2 p x_{O 1}+c_{5} 2 p x_{O 2}+c_{6} 2 p x_{C}+c_{7} 2 p y_{O 1}+c_{8} 2 p y_{O 2}+$ $c_{9} 2 p y_{C}+c_{10} 2 p z_{O 1}+c_{11} 2 p z_{O 2}+c_{12} 2 p z_{C}$

The 1s shells of the $\mathrm{C}$ and $\mathrm{O}$ atoms are non-bonding orbitals, and hence do not contribute to the bonding of $\mathrm{CO}_{2}$, as shown in Figure 1, below. The $2 \mathrm{p}_{\mathrm{x}}$ and $2 \mathrm{p}_{\mathrm{y}}$ orbitals are located in the same plane, hence three doubly degenerate molecular orbitals, $1 \pi_{\mathrm{g}}$ (non-bonding), $1 \pi_{\mathrm{u}}$, and $2 \pi_{\mathrm{u}}{ }^{*}$, are formed. The former does not contain a contribution from the $\mathrm{C}$ atom, as the $2 \mathrm{p}$ orbitals of the $\mathrm{O}$ atoms are out of phase and contain lone pairs electrons. The $2 \mathrm{p}_{z}$ and $2 \mathrm{~s}$ atomic orbitals combine to form six $\sigma$ molecular orbitals labeled as $3 \sigma_{\mathrm{g}}, 2 \sigma_{\mathrm{u}}, 4 \sigma_{\mathrm{g}}, 5 \sigma_{\mathrm{g}}{ }^{*}, 3 \sigma_{\mathrm{u}}$, and $4 \sigma_{\mathrm{u}}{ }^{*}$. Not counting the core electrons, the $\mathrm{CO}_{2}$ molecule shares 16 electrons in the molecular orbitals, with eight electrons occupying four $\sigma$ orbitals, and the other eight in two $\pi$ orbitals [13]. 


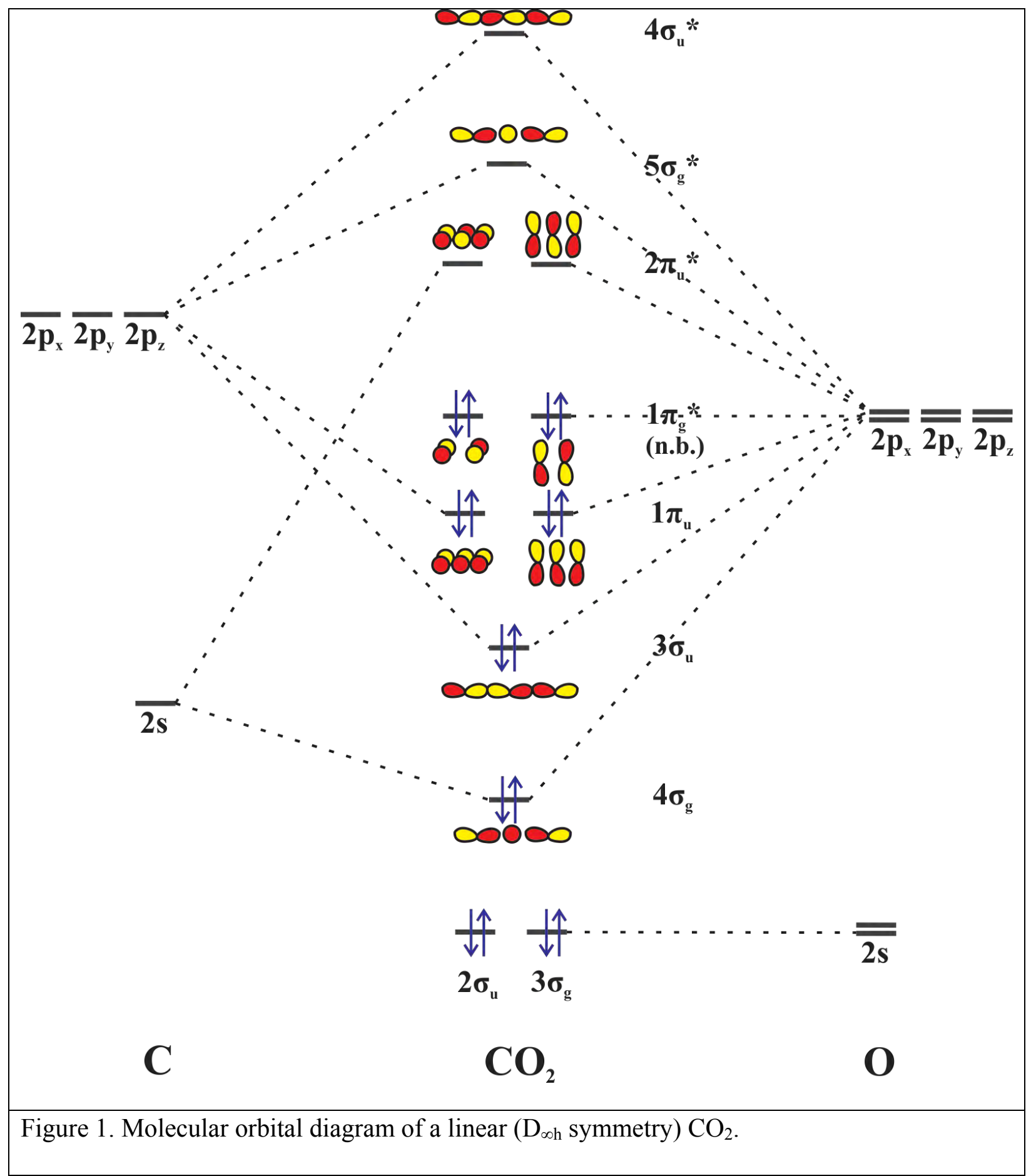

\subsection{Molecular structure and electronic properties of the excited state and anionic $\mathrm{CO}_{2}$.}

The $\pi_{\mathrm{u}}$ MOs have contributions from all the atoms involved. However, electron sharing is only permitted when the two orbitals have equal binding energy. Oxygen has considerably greater 
electronegativity than carbon, and hence, two lower-energy degenerate $\pi$ orbitals $\left(1 \pi_{\mathrm{u}}\right.$ and $\left.1 \pi_{\mathrm{g}}{ }^{*}\right)$ are localized on the oxygen atoms, whereas the higher energy one, $2 \pi_{\mathrm{u}}{ }^{*}$, is more localized on carbon [14]. Two of these three MOs, $1 \pi_{\mathrm{g}}{ }^{*}$ (non-bonding) and $2 \pi_{\mathrm{u}}{ }^{*}$ ' constitute, in turn, the highest occupied (HOMO) and lowest unoccupied (LUMO) molecular orbitals of this molecule. Bonding electrons are distributed throughout $4 \sigma_{\mathrm{g}}$ to $1 \pi_{\mathrm{u}}$, where electrons occupying $4 \sigma_{\mathrm{g}}$ and $3 \sigma_{\mathrm{u}}$ form $\sigma$ $\mathrm{CO}$ bonds, and those occupying the doubly degenerate $1 \pi_{\mathrm{u}}$ form the $\pi$-CO bonds. Because the ground-state $\mathrm{CO}_{2}$ molecule contains 16 valence electrons, it is expected to be linear.

\subsubsection{Electronic structure of excited state $\mathrm{CO}_{2}$}

In its first excited state, analogous to $\mathrm{NO}_{2}$, the electrons are promoted to the $2 \pi_{\mathrm{u}}{ }^{*}$ molecular orbital, resulting in a smaller population of electrons for stabilizing the linear form. The molecule is consequently expected to be bent. Full-valence Complete Active Space CAS $(16,12)$ /def2TZVP calculations show that the $\mathrm{S} 0$ ground state of $\mathrm{CO}_{2}$ possesses minor multi-reference character ( $92 \%$ one reference state). All orbitals are doubly occupied with calculated degenerate HOMO orbitals containing $1.96 \mathrm{e}^{-}$and degenerate LUMO containing $0.06 \mathrm{e}^{-}$. Calculated CM5 charges are +0.44 on $\mathrm{C}$ and -0.22 on each $\mathrm{O}$ atom. On the other hand, the $\mathrm{S} 1$ excited state structure exhibits a very different molecular structure with a C-O1 bond of $1.22 \AA$ and a C-O2 bond of $1.46 \AA$ and an O-C-O angle of $150.0^{\circ}$ (Figure 2). Still, only a minor multi-reference character is observed $(90 \%$ one reference state). The singly occupied molecular orbitals (SOMOs) involved in excited state transitions are shown in Figure 2. SOMO1 is mainly localized on the $\mathrm{p}_{z}$ orbital of $\mathrm{O} 2$ while $\mathrm{SOMO} 2$ is localized on the $\mathrm{p}_{\mathrm{y}}$ orbital of $\mathrm{C}$. This is different from the ground state HOMO/LUMO orbital populations also shown in Figure 2, below, where the former is localized on both $\mathrm{O}$ atoms equally and the latter, symmetrically on $\mathrm{C}$. Calculated CM5 charges are +0.25 on $\mathrm{C},-0.16$ on $\mathrm{O} 1$ and -0.09 on $\mathrm{O} 2$. The $\mathrm{CO}_{2}$ molecule in the S1 state should consequently contain a much less electrophilic C, but O1 of nearly the same nucleophilicity as in S0, and an essentially neutral $\mathrm{O} 2$. 


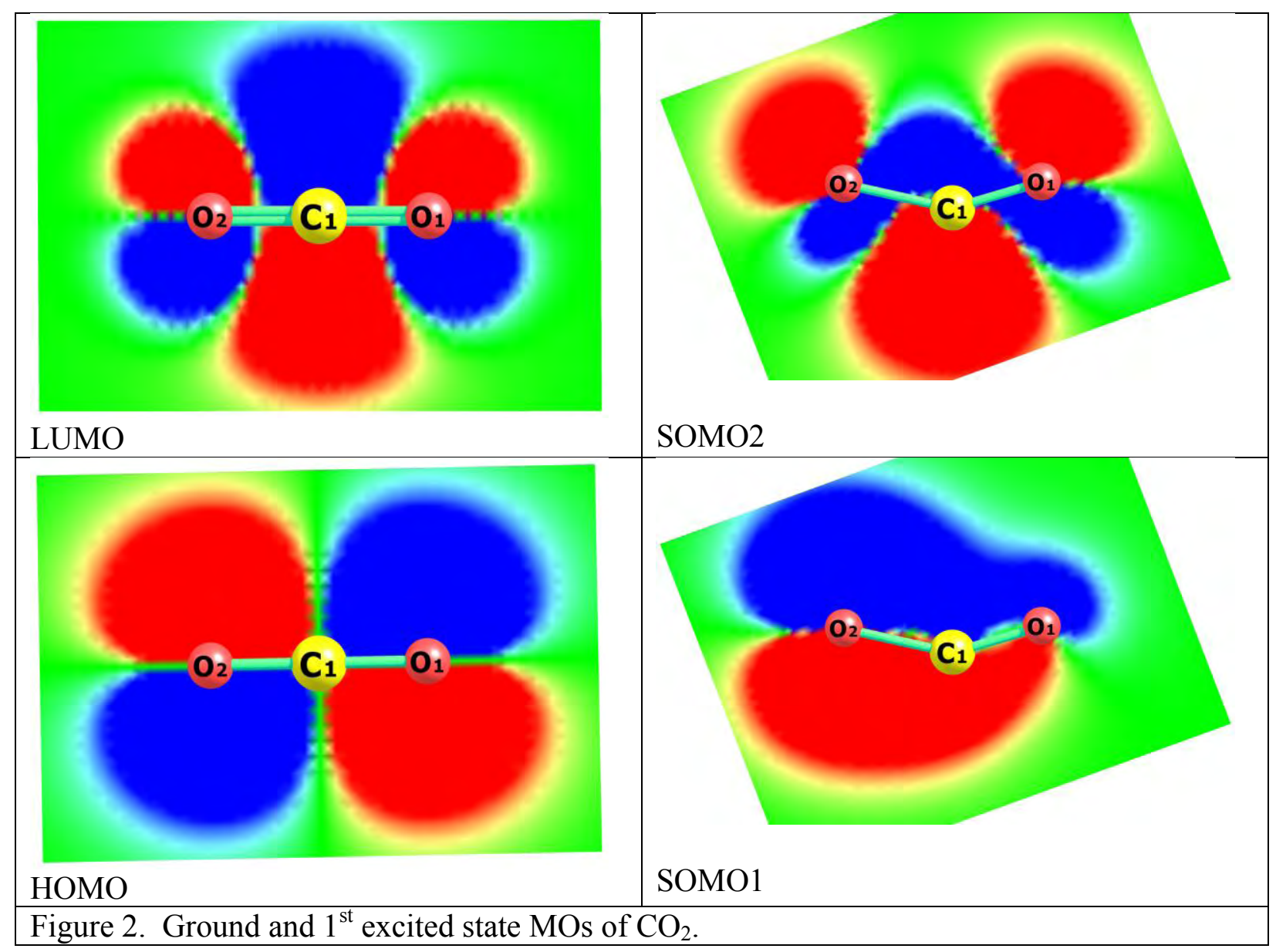

\subsubsection{Anionic $\mathrm{CO}_{2}\left(\mathrm{CO}_{2}^{-}\right)$electronic structure}

The anionic $\mathrm{CO}_{2}$ molecule has a negative charge, and 17 electrons in the valence orbitals can form via transfer of an electron from the substrate upon adsorption. It will also exhibit a bent structure (Figure 3). 


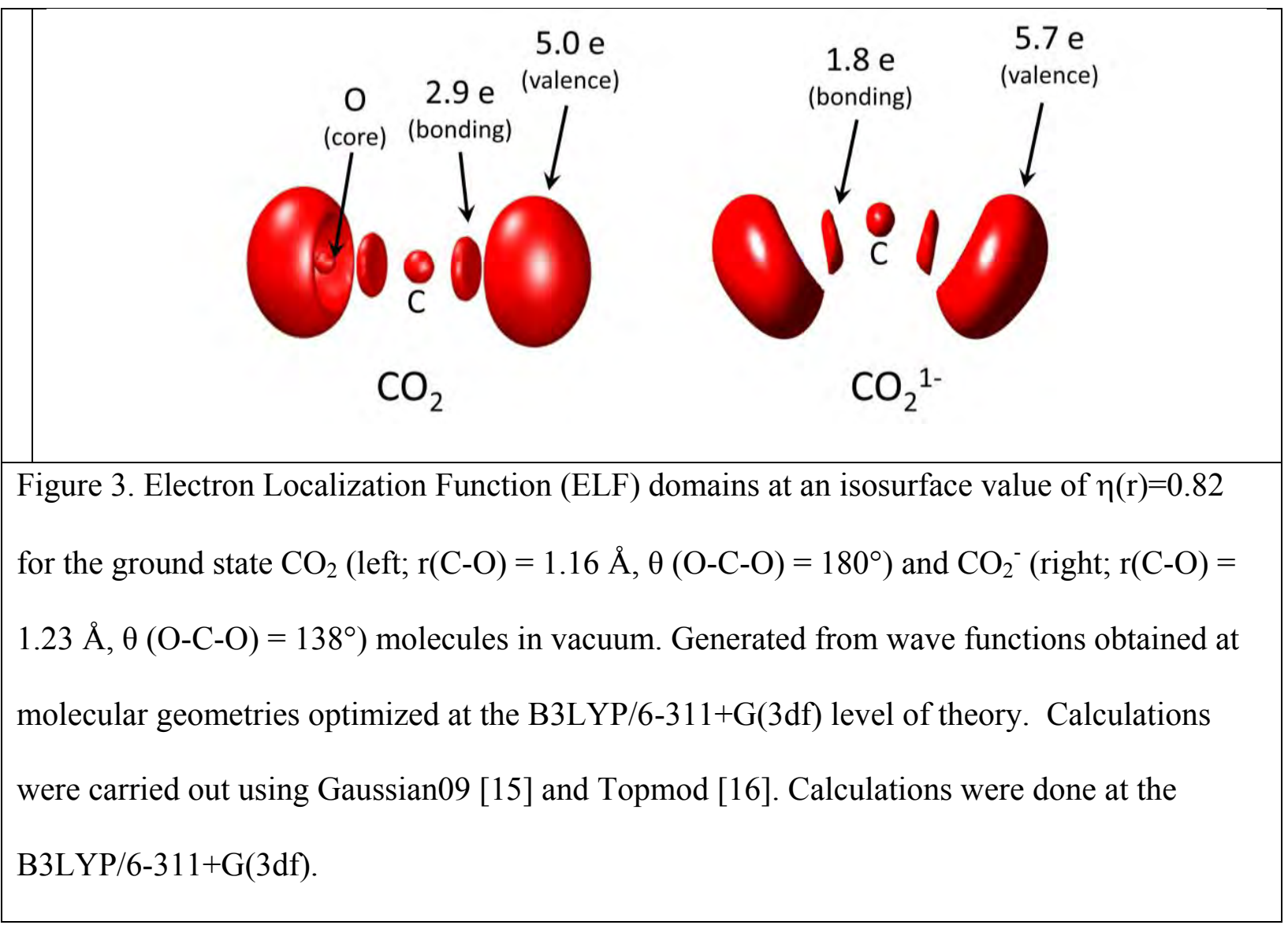

B3LYP/6-311+G(3df) level calculations show that $\mathrm{CO}_{2}$ is indeed linear (22 total electrons total, calculated $\mathrm{C}-\mathrm{O}=1.16 \AA$, $v($ bend $)=677 \mathrm{~cm}^{-1} ; v($ sym $)=1372 \mathrm{~cm}^{-1} ; v \quad($ asym $\left.)=2405 \mathrm{~cm}^{-1}\right)$. Calculated Electron Localization Function (ELF) [17] domains show electron populations in bonding basins of 2.93-2.85 $\mathrm{e}^{-}$per basin with electron populations in a valence shell of $\mathrm{O}=4.95$ $4.99 \mathrm{e}^{-}$per basin. A strong cross-relation between the electron populations of the valence shell of $\mathrm{O}$ and the bonding electrons can also be observed. When $\mathrm{CO}_{2}$ obtains an additional electron, its structure becomes bent ( 23 electrons in total; $\mathrm{C}-\mathrm{O}=1.23 \AA$, optimal bond angle $=138^{\circ}, v$ (bend) $=664 \mathrm{~cm}^{-1} ; v(\mathrm{sym})=1213 \mathrm{~cm}^{-1} ; v($ asym $\left.)=1764 \mathrm{~cm}^{-1}\right)$. Electron populations in the bonding orbitals are 1.80-1.82 $\mathrm{e}^{-}$per basin, while electron populations in the valence shell of $\mathrm{O}=5.73$ $5.75 \mathrm{e}^{-}$per basin. There is also a strong cross-relation between electron populations of the valence shell of $\mathrm{O}$ and the bonding electrons. Hence, the $\mathrm{CO}_{2}^{-}$molecular anion has an extra 
electron which results in the bending of the $\mathrm{O}-\mathrm{C}-\mathrm{O}$ angle to $135^{\circ}$ and shifts the electron population from the bonding basin to the $\mathrm{O}$ valence basin. This is important because the oxygen atoms in a bent structure are more negatively charged and the carbon is more prone to nucleophilic attack. Both excited state and anionic $\mathrm{CO}_{2}$ are much more reactive than linear $\mathrm{CO}_{2}$ and the degree of their apparent reactivity will be elucidated throughout this paper, as inferred from their molecular shape, electronic and vibrational properties.

\section{Experimental techniques for $\mathrm{CO}_{2}$ surface chemistry analysis}

The surface chemistry of $\mathrm{CO}_{2}$ at UHV conditions is a topic of perennial interest $[13,18,19]$, and can be effectively probed by a range of surface sensitive experimental techniques. UHV techniques typically focus on very surface sensitive measurements, where $\mathrm{CO}_{2}$ is adsorbed as a monolayer coverage. Other techniques, such as infrared spectroscopy, are routinely utilized at $\mathrm{CO}_{2}$ pressures ranging from a few mTorr to several atmospheres. Similarly, solid-liquid interfaces are probed routinely using various modes of infrared spectroscopy.

\subsection{Ultrahigh vacuum (UHV).}

Historically, vacuum based techniques have been used extensively to probe $\mathrm{CO}_{2}$-surface interactions. UHV is the main prerequisite in these types of studies and is now routinely attained in the laboratory using complex pumping systems, as shown in Table 2. Low vacuum is routinely achieved using rotary vane pumps, although diaphragm pumps are gaining increased popularity because they are cleaner. Momentum transfer based pumps, such as diffusion or turbomolecular, are used to move molecules from the low to the high vacuum side to achieve high vacuums. For UHV studies, pumping systems typically include a combination of pumps for different stages with entrapment pumps, such as ion or cryogenic. To achieve that last stage, 
system -bakig" - degassing of the chemisorbed water molecules from chamber walls - is necessary.

Table 2. Degrees of vacuum and the pumping equipment employed for attaining them

\begin{tabular}{|l|l|l|}
\hline Vacuum & Pressure, Torr & Pumping equipment \\
\hline Low & $20-10^{-3}$ & $\begin{array}{l}\text { Rotary vane, diaphragm } \\
\text { pumps }\end{array}$ \\
\hline Medium & $10^{-3}-10^{-5}$ & Diffusion pumps \\
\hline High & $10^{-5}-10^{-9}$ & $\begin{array}{l}\text { Turbomolecular, diffusion } \\
\text { pumps }\end{array}$ \\
\hline Ultrahigh & $<10^{-9}$ & $\begin{array}{l}\text { Ion, cryo pumps (backing } \\
\text { required) }\end{array}$ \\
\hline
\end{tabular}

The reasons for implementing UHV are typically to:

a. Maintain atomically clean surfaces for the duration of the experiment,

b. Permit low energy probes, including electrons, photons and ions, to be used without interference due to gas phase scattering,

c. Ensure stability, longevity and safety for the typical high energy electronics used.

The Langmuir ( $L$; where $1 \mathrm{~L}=10^{-6}$ Torr) is a commonly-used unit to quantify the time window available before the surface inside the instrument is completely covered with residual gas. In this context, a sticking coefficient of 1 implies that complete surface coverage $\left(10^{-6}\right.$ Torr $)$ by residual gases will be achieved in 1s. Hence, for a surface science experiment to be accomplished in the presence of the desired gas molecule, a vacuum of $10^{-8}$ Torr should provide a time window of at least $100 \mathrm{~s}$. A UHV vacuum of $10^{-10}$ Torr provides a convenient time window of $10,000 \mathrm{~s}$.

Commonly used techniques for surface-sensitive $\mathrm{CO}_{2}$ analysis can be grouped into the following probe-surface based interactions between

a. Electron and surface,

b. Photon and surface, 
c. Ion and surface.

They are summarized in Table 3.

Table 3. Conventional UHV CO 2 -surface interaction analysis techniques

\begin{tabular}{|l|l|}
\hline Electron-surface interactions & Photon-surface interactions \\
\hline Auger Electron Spectroscopy (AES) & $\begin{array}{l}\text { X-ray Photoelectron Spectroscopy (XPS) } \\
\text { High Resolution Electron Energy Loss }\end{array}$ \\
$\begin{array}{l}\text { Photon Stimulated Desorption (PSD) } \\
\text { Spectroscopy (HREELS) }\end{array}$ & $\begin{array}{l}\text { Ultraviolet Photoelectron Spectroscopy } \\
\text { Electron-Stimulated Desorption (ESD) } \\
\text { Low Energy Electron Diffraction (LEED) } \\
\text { Scanning Tunneling Microscopy (STM) }\end{array}$ \\
\cline { 1 - 1 } Ion-surface interactions & \\
\cline { 1 - 2 } Secondary Ion Mass Spectroscopy (SIMS) & \\
Low Energy Ion Scattering (LEIS) & \\
\hline
\end{tabular}

UHV techniques based on electron-surface interactions include Auger Electron Spectroscopy (AES), Electron-Stimulated Desorption (ESD), High Resolution Electron Energy Loss Spectroscopy (HREELS), Scanning Tunneling Microscopy (STM), and Low Energy Electron Diffraction (LEED). Those based on photon-surface interactions include X-ray Photoelectron Spectroscopy (XPS), Photon Stimulated Desorption (PSD), and Ultraviolet Photoelectron Spectroscopy (UPS). Those based on ion-surface interactions include Secondary Ion Mass Spectroscopy (SIMS) and Low Energy Ion Scattering (LEIS). This list is not exhaustive, because a plethora of other light and electron based methods typically used to investigate $\mathrm{CO}_{2}$ interactions in UHV cannot be considered strictly surface techniques, as the signal can originate from the atoms within the bulk. This can be readily seen from Figure 4. Surface sensitivity from within a few monolayers can be achieved utilizing either low energy excitation sources or shallow escape depths, which are based on the inelastic mean free path of the electron. The strongly contrasting penetration depths of photons $(1 \mu \mathrm{m})$, electrons $(20 \AA)$ and ions (10 $\mathrm{A})$ under a given beam energy also imply that the damage to the sample surface should, in principle, be lowest for ions [20]. The definition of the sampling depth, however, is not straightforward, 
nor is that of a monolayer. We will consequently attempt to define this surface sensitivity for the methods to be described in the following sections to compare and contrast their surface sensitivity and analytical capabilities.

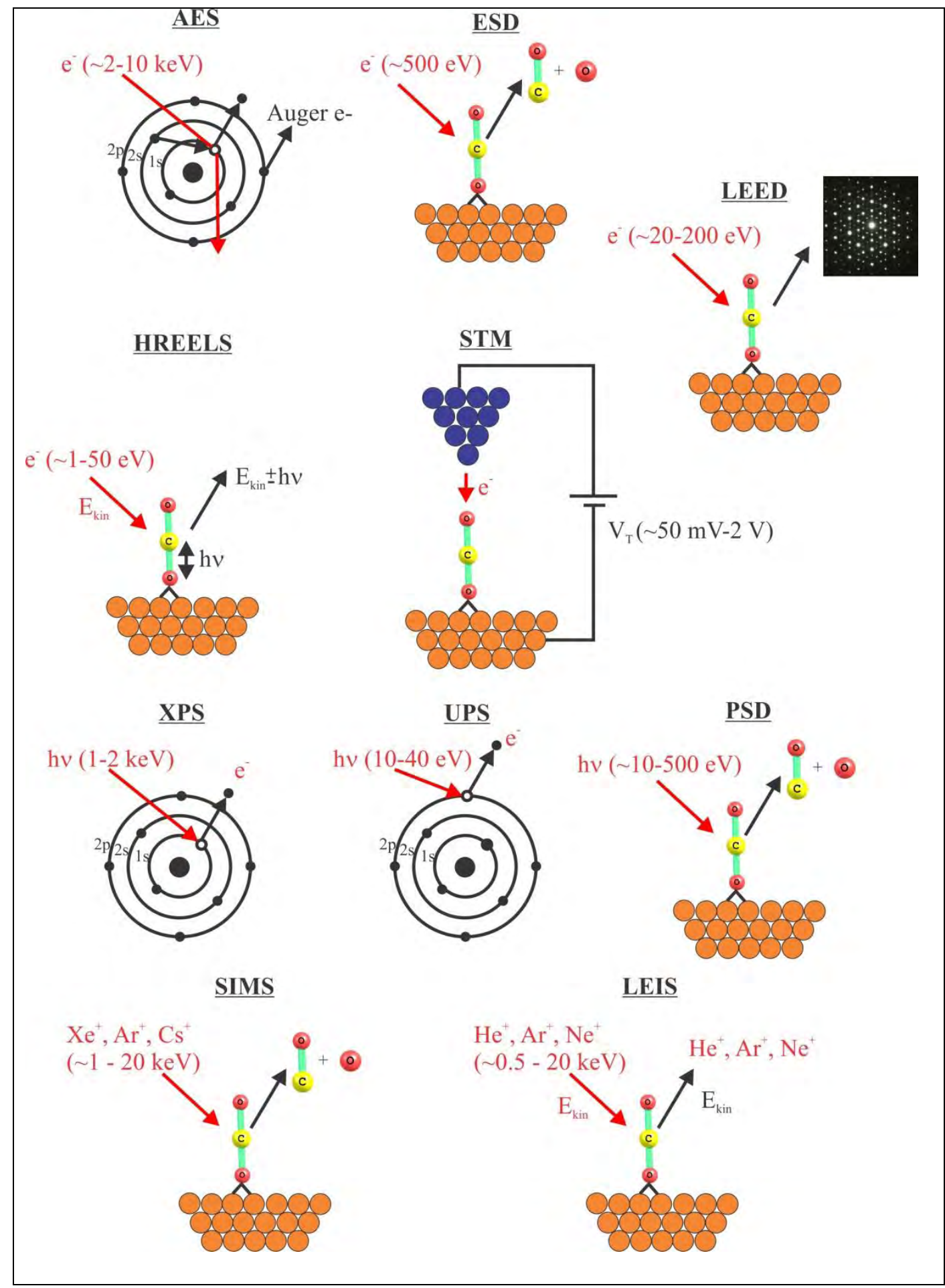


Figure 4. Surface sensitive UHV techniques used for $\mathrm{CO}_{2}$ surface chemistry analysis.

\subsubsection{Surface analysis techniques based on electron-surface interactions.}

3.1.1.1. AES. Auger electron spectroscopy (AES) is based on the interaction of an electron beam with the sample to initiate the Auger electron emission. The initial step is the excitation of an atom followed by the removal of its core electron. These core electron excitations can be similarly induced by an incident photon or ion. Relaxation ensues by one of the two competing processes. One process can proceed via a less tightly bound electron dropping to substitute for the empty core level followed by a photon emission to compensate for the energy difference between the two levels. This process is X-ray fluorescence and dominates when the excited core levels are of high binding energy, such as for heavier elements. The other process involves the excess energy carried away by a third electron from less tightly bound levels via a radiation-free Auger process. The kinetic energy of the emitted electron is then, for example,

$\mathrm{E}_{\mathrm{KLL}}=\mathrm{E}_{\mathrm{K}}-\mathrm{E}_{\mathrm{L} 2}-\mathrm{E}_{\mathrm{L} 3}-\Phi$, 
where $\Phi$ is the work function of the surface and the peaks are labeled as such $(\mathrm{C}(\mathrm{KLL}))$. The Auger de-excitation process is predominant for the lighter elements, with the lightest element detectable being $\mathrm{Li}$ due to the need for at least three involved electrons. The resulting emitted electron kinetic energy is measured and shows energy specific peaks superimposed on a large background, due to the
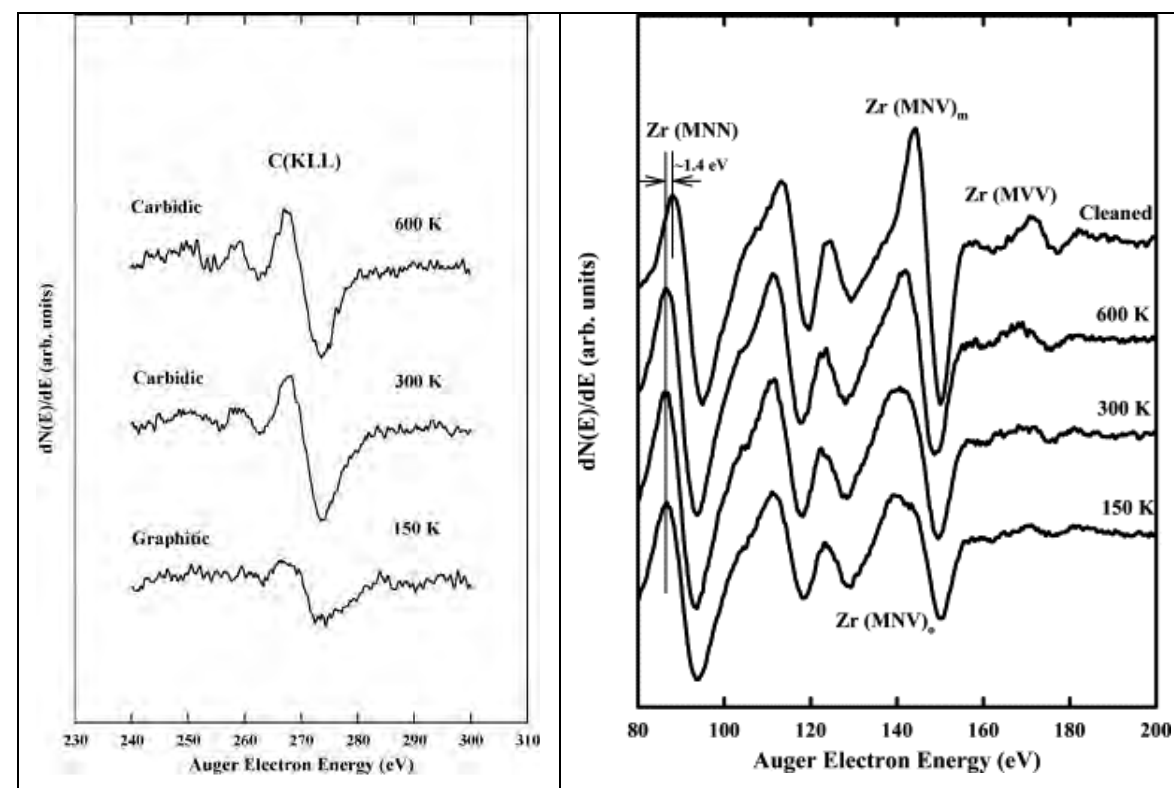

Figure 5. Derivative mode AES spectra showing the C(KLL) and $\mathrm{Zr}(\mathrm{MNN})$ transitions as a function of $\mathrm{CO}_{2}$ adsorption temperature on $\mathrm{Zr}$ alloy. In all three cases an exposure surface to $\mathrm{CO}_{2}$ of $5 \times 10^{14} / \mathrm{cm}^{2}$ is used. Upon $\mathrm{CO}_{2}$ adsorption at $150 \mathrm{~K}$ the $\mathrm{C}(\mathrm{KLL})$ line shape resembles that of graphitic carbon, whereas in the 300 and $600 \mathrm{~K}$ cases the carbidic-like phase dominates. Reprinted with permission from Elsevier [21].

secondary electrons generated via a multitude of inelastic scattering processes. It provides for both qualitative and quantitative elemental analysis with about $1 \%$ monolayer sensitivity. First or second derivatives of the spectra with respect to energy can also be used to accentuate spectral peaks. The resulting spectra are most commonly compared with samples of known composition to assess the nature of the surface species formed and their chemical environment by (a) peak position shift and (b) peak shape resemblance. For example, $\mathrm{CO}_{2}$ adsorption on zirconium alloy 
was performed at 150,300 and $600 \mathrm{~K}$ and a $1.4 \mathrm{eV}$ shift was observed in $\operatorname{Zr}(\mathrm{MNN})$ with concomitant changes in $\operatorname{Zr}(\mathrm{MNV})$ shape [21], as shown in Figure 5. This was attributed to the effect of oxygen on the dissociative $\mathrm{CO}_{2}$ adsorption. Then, the diffusion of the oxygen formed into the subsurface followed, with the domains of the graphitic $(150 \mathrm{~K})$ and carbidic (300 and $600 \mathrm{~K})$ carbon formed on the surface, as confirmed by the C(KLL) peak shapes. The $\mathrm{Zr}$ metal feature $\mathrm{Zr}(\mathrm{MNV})_{\mathrm{m}}$ decreases in intensity at lower temperatures due to the electron donation from zirconium to oxygen atoms. While such fingerprinting contributes significant knowledge, other spectroscopies, such as XPS, can provide greater levels of detailed molecular (chemical) information. Also, non-conductive surfaces are challenging for Auger, because the negative charge buildup resulting from the electron beam eventually prohibits the flux of the emitted Auger electrons. To this extent, XPS is much more useful, as charging induced with soft X-rays can readily be mitigated by the low energy electron supply. The larger energy of the incoming electrons in Auger also damages the sample more so than in XPS.

3.1.1.2 HREELS. Measuring energy loss of inelastically backscattered, low-energy electrons provides information on vibrational modes of the adsorbed species on the surface. It also provides information on the physisorbed and chemisorbed adsorbate states as well as adsorbate adsorbate interactions. The process is not restricted by selection rules, and in combination with dipole scattering, all vibrational modes may be discernable. To this extent, in a dipole scattering regime HREELS provides complimentary information to that obtained using infrared spectroscopy. However, very high surface sensitivity, approximately. $0.01 \%$ of a monolayer, is obtained, which is much greater than that of IR. At the typical electron emitting cathode temperature, $\sim 2,000 \mathrm{~K}$, the width of the thermal energy distribution of the emitted electrons, $\mathrm{k}_{\mathrm{B}} \mathrm{T}$ is in the hundreds of $\mathrm{meV}$ resolution without energy filtering, somewhat akin to the acronym of the technique. Full width at half maxima (FWHM) of a few meV can be achieved by selecting the energy of the beam at a certain pass energy. The highest achievable resolution is $0.5 \mathrm{meV}$ (4 $\left.\mathrm{cm}^{-1}\right)$ for a total spectral range of $0-1,000 \mathrm{meV}\left(0-8,000 \mathrm{~cm}^{-1}\right)$. Importantly, electronic 
transitions of both surface and the corresponding adsorbates can be obtained, providing a complete surface picture. However, rather flat and mostly conducting surfaces are needed to fully utilize the advantages provided by HREELS. $\mathrm{CO}_{2}$ adsorption on $\mathrm{RuO}_{2}(110)$ at $85 \mathrm{~K}$ yields a complex

HREEL spectra with species identified that are difficult to observe using FTIR, including physisorbed $\mathrm{CO}_{2}$, several forms of chemisorbed $\mathrm{CO}_{2}{ }^{\delta-}$, carbonate $\mathrm{CO}_{3}{ }^{\delta-}$ and dimerized modes $\mathrm{CO}_{2} \cdot \mathrm{CO}_{2}{ }^{\delta-}[22]$. At $1 \mathrm{~L}$ coverage, low temperatures facilitated formation of the $\mathrm{CO}_{2} \cdot \mathrm{CO}_{2}{ }^{\delta-}$ dimers, where linear $\mathrm{CO}_{2}$ is bound to the chemisorbed $\mathrm{CO}_{2}{ }^{\delta-}$, with gradual transition into carbonate species at and above $260 \mathrm{~K}$ (Figure 6). Annealing to $350 \mathrm{~K}$ resulted in carbonate losses due to the formation of $\mathrm{O}_{\text {ads }}$ and gaseous $\mathrm{CO}_{2}$. The formation of adsorbate carbonate is typically observed when $\mathrm{CO}_{2}$ is exposed to metal oxides [18].

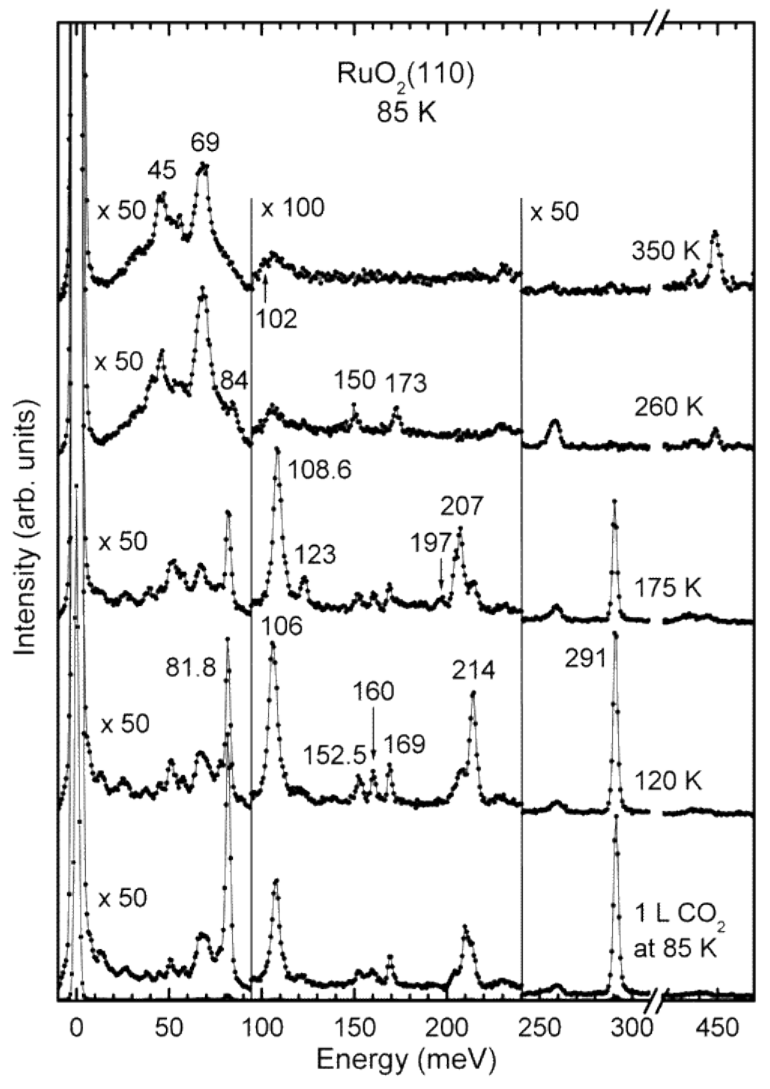

Figure 6. HREELS of $1 \mathrm{~L} \mathrm{CO}_{2}$ on $\mathrm{RuO}_{2}(110)$ at various temperatures. Reprinted with permission from [22]. Copyright (2002) American Chemical Society.

\subsubsection{Surface analysis techniques based on photon-surface interactions.}

3.1.2.1 XPS. Photons of specific energy are used to excite the electronic states of the sample, which results in ejected (photo)electrons. These electrons are filtered in a hemispherical 
analyzer and their intensity for the particular energy window is measured by a detector. Binding energy of the electron in $\mathrm{eV}$ is then obtained by

$$
\mathrm{E}_{\mathrm{B}}=\mathrm{h} v-\mathrm{E}_{\mathrm{K}}-\Phi,
$$

where $E_{B}$ is the binding energy of the electron in the atom, hv-is the energy of the photon and $E_{K}$ is the kinetic energy of the photoelectron measured. The work function term in equation (3) is important when dealing with solids, whereas gas phase molecule binding energy will be identical to the ionization potential of the particular electron. Importantly, Auger peak kinetic energy is independent of the hv term, and altering the photon energy by changing the X-ray anode material will cause Auger lines and photoelectron peaks to change in energy with respect to each other. While X-rays can penetrate several microns into the sample, only electrons from within up to $\sim 10 \mathrm{~nm}$ can escape from the sample without losing their energy. This is defined as the inelastic mean free path (IMFP) of the electron. IMFPs for the kinetic energies from 20 to $1000 \mathrm{eV}$ is about 5 to $20 \AA$, while outside that range IMFP values increase [23]. Sampling depth is $\sim 3$ monolayers with the elemental sensitivity in the order of $0.1 \%$. Furthermore, the spatial resolution of XPS is by the wavelength of the X-rays $(\sim 600 \mathrm{~nm})$ compared to that limited by the diameter of the electron beam $(\sim 5 \mathrm{~nm})$ in AES. Finally, we note that $\mathrm{H}$ and $\mathrm{He}$ cannot be detected by XPS.

3.1.2.1.1 Qualitative analysis. In principle, XPS relies on the knowledge of well-defined binding energies, as defined by the corresponding electronic state of the atom. These are tabulated for specific compounds and can be found in literature references or online databases [24]. The theoretical models for the calculation of the core-level binding energies (CEBEs) within the DFT approximation have also been used and can be classified in three major groups, namely, (a) based on the complete screening picture, (b) the transition state model and (c) the 
initial state approximation [25]. In the initial state approximation, screening of the core hole in the core-excited state is neglected, whereas in the final state approximation, the core hole is completely screened. In a transition state model, partial orbital occupations are introduced to describe the excitation process. Since charge transfer is poorly described by gradient corrected functionals, adsorbed molecule CEBEs can be underestimated so the fraction of Fock exchange needs to be added via PBE0 functional [26].

Of paramount importance in XPS qualitative analysis are so called chemical shifts, which arise due to the changes in binding energy of a core electron. This is caused by the change in the chemical bonding (environment) of that element. Since core binding energy is an electrostatic interaction between the electron and the nucleus, it will be affected by the change in shielding of the nuclear charge by removal/addition of the electronic charge as a result of bonding. In general, withdrawal of the valence charge of electrons will cause an increase in CEBEs, whereas an addition will decrease it. This means that typical binding interactions of $\mathrm{CO}_{2}$ on solid surfaces can be monitored using XPS and adsorbed species bonding information can be obtained. Conventional XPS is limited to UHV conditions due to the elastic and inelastic scattering of the photoelectrons by the gas molecules. This causes the attenuation of the signal, which is proportional to $\mathrm{e}^{(-\mathrm{z \sigma op} / \mathrm{kT})}$, where $\sigma$ is the electron scattering cross-section and $\mathrm{z}$ is the distance the electrons have to travel at pressure $\mathrm{p}$. This strongly implies that the electron travel distance in an elevated pressure environment needs to be minimized. Such conditions allow imaging of liquids [27,28]. Ambient pressure XPS (APXPS) utilizes a combination of a high intensity X-ray source, differential pumping system and electrostatic focusing, thus allowing operation under elevated pressures of several mbars [29]. Both gas and adsorbed species information can be obtained using modern XPS instruments. Tabulated CEBEs of the species pertaining to $\mathrm{CO}_{2}$ surface 
chemistry in the $\mathrm{C} 1 \mathrm{~s}$ region are shown in Figure 7. These include adsorbed $\mathrm{CO}[30,31], \mathrm{CO}_{3}{ }^{2-}$ [31-36], carboxylate [31,33,35,37], oxalate [33,34], graphite/adventitious carbon $[31,33,35]$, formate [37] and gas phase $\mathrm{CO}[38]$ and $\mathrm{CO}_{2}[33,37]$.

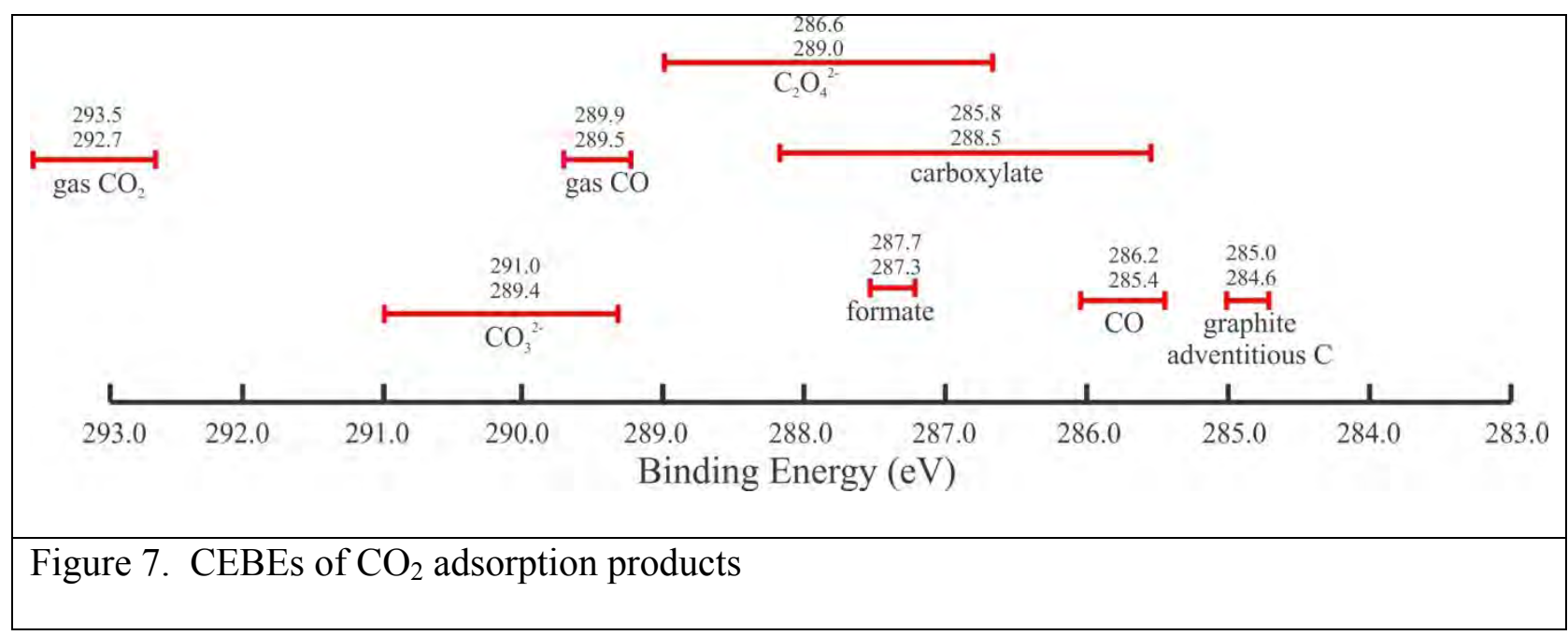

For high-resolution qualitative analysis, a FWHM of the resulting peaks needs to be as small as possible to facilitate their separation and assignment. Spectral peaks are broadened due to the (a) X-ray line broadening, (b) the width of the analyzer energy window, and (c) the natural line width of the orbital in the atom. The latter cannot be altered as it is inherent to the transition considered. The main improvements that can be made come by reducing the line width of the source. Most often used is $\mathrm{Al} \mathrm{K}_{\alpha} 1486.7 \mathrm{eV}$ radiation with $0.85 \mathrm{eV}$. With the monochromator it can be reduced to $0.26 \mathrm{eV}$ [39]. A monochromator also removes X-ray satellite peaks and Bremsstrahlung radiation, thus improving the overall appearance of the spectra. On the other hand, it also removes the total X-ray flux to the sample, thus reducing the corresponding photoemission signal. However, to resolve small peak differences due to the chemical shifts in the adsorbed $\mathrm{CO}_{2}$ products and unambiguously interpret them, a monochromated beam or low temperature experiments are necessary. 
3.1.2.1.2 Quantitative analysis. Gathering atomic concentrations from the XPS spectrum involves isolating emission peaks, one per element, and then performing a sequence of corrections to these intensities leading to the normalized values representative of the amount of substance sampled via XPS. Quantification of the XPS spectra needs to account for the electrons belonging to a certain transition. This is typically performed via subtracting the background due to the scattering events other than those of the elastically scattered transition of interest. Background subtraction is typically performed using the Shirley [40] or Tougaard [41] methods. Although for the peaks due to the $\mathrm{C} 1 \mathrm{~s}$ and O1s electronic transitions for materials which have relatively large bandgaps, where no significant amount of inelastically scattered electrons proceeds, linear subtraction is sometimes acceptable. Exceptions do exist (for example, graphite) where C1s transition is often modeled using the Shirley background. Peak areas are then computed from the background-subtracted data and serve as the basis for quantification. Relative sensitivity factors (RSF) are then used to scale measured peak areas to obtain an atomic concentration. The underlying assumption is that the number of electrons recorded in the spectrum is proportional to the number of the atoms via

$A_{i}=\frac{I_{i}}{T\left(E_{i}\right) R S F_{i} E_{i}^{n}}$

Here, $\mathrm{I}_{\mathrm{i}}$ is the peak area, $\mathrm{T}(\mathrm{E})_{\mathrm{I}}$, the transmission function at the peak position, $\mathrm{RSF}_{\mathrm{i}}$ is the relative sensitivity factor, $\mathrm{E}_{\mathrm{i}}$ is the kinetic energy of the electron and $\mathrm{n}$ is the escape depth exponent. RSF values of elements are relative to a specified transition. The purpose of RSF is to correct peak intensities to account for differences resulting from the photoemission process. Traditionally, Wagner et al. [42] used RSF values relative to F1s; hence, for Wagner/PHI/Kratos/Thermo tables the RSF values have F1s RSF $=1$. Scofield cross-sections [43] used by SPECS/Thermo/Kratos Amicus/Scienta/Omicron are used relative to C 1s, e.g. RSF C1s $=1$. 
Scofield cross-sections are theoretically derived using Hartree-Slater approximations and do not account for angular distribution variations in the effective cross-section, as a consequence of instruments detecting electrons in a specific direction relative to the photon source. This transmission (ratio of electrons leaving the sample to the number of electrons recorded at the detector) varies as a function of the kinetic energy of the emitted electrons. These are incorporated by specific instrument manufacturers, who have their own RSF values that also account for the transmission function, $\mathrm{T}(\mathrm{E})_{\mathrm{i}}$ of that particular instrument. These include Kratos Axis Ultra and Kratos Axis Nova and can have either C1s or F1s as a reference. They are tabulated in Table 4, as follows:

Table 4. Tabulated RSF parameters commonly used for $\mathrm{CO}_{2}$ adsorption product quantification.

$\begin{array}{llll}\text { Core level } & \text { Wagner [42] } & \text { Scofield [43] } & \text { Kratos } \\ \text { C1s } & 0.25 & 1 & 0.278 \\ \text { O1s } & 0.66 & 2.93 & 0.78\end{array}$

It is noteworthy that, provided the entire RSF table is converted the same way, the peak selected as the reference (e.g. C 1s or F 1s) for tabulating the sensitivity factors is arbitrary. However, no standard RSF values exist over the XPS instruments. Therefore care must be taken so no RSF values from two different libraries are applied.

\subsection{Elevated $\mathrm{CO}_{2}$ pressures and aqueous solutions}

\subsubsection{Gas phase FTIR Spectroscopy.}

\subsubsection{Instrumental}

Infrared (IR) spectroscopy is based on radiation absorption by the characterized compounds. When an IR beam is passed through a sample, the compound absorbs radiation at a specific wavelength, resulting in a decrease of the transmitted radiation. In the spectra, the absorption is 
reflected as a dip in transmission or a peak in absorbance. Upon absorbing the IR radiation, the molecules' oscillation amplitude will increase, hence the molecule is excited to a higher vibrational state. Vibrational states are quantized energy levels, and the particular wavelength of absorption by a specific bond depends on the energy difference between the ground level and the excited state. Thus, different bonds produce different peaks/dips, which also vary depending on the different oscillation modes in the IR spectra at different wavenumbers.

Monitoring the molecular events taking place at a certain reaction temperature or pressure, i.e. in situ IR spectroscopy, is now possible and widely used. A substrate, or catalyst, can be put into a reaction chamber, where a reactant is passed over it. IR spectroscopy is then used to continuously monitor the surface species present on the substrate, while the surface is heated up to a certain desired temperature. This characterization method is very powerful, because it provides information about the bonds created or destroyed during the temperature ramping, which, when properly analyzed, can give information on the possible transition states during the reaction.

Vibration spectroscopic measurements of the solid/gas interface can be effectively carried out using a reaction chamber equipped with optical windows enabling measurements in transmission mode, attenuated total reflectance (ATR) and total or diffuse reflectance modes. Fourier transform infrared spectroscopy (FTIR) is generally limited to powdered (submicron-sized) materials, given the limitations in throughput. Single crystals are, on the other hand, best studied by reflectance-based measurements, such as reflectance-absorbance infrared spectroscopy (RAIRS) [44], provided that the sample is conducting. FTIR studies of $\mathrm{CO}_{2}$ binding with powdered materials have, however, been considerably more popular, given the relative ease with which measurements can be conducted and the relevance of nanoparticles and colloids to 
environmental and technological research. Experimental setups using closed or open-loop flowthrough cells have facilitated automated measurements of $\mathrm{CO}_{2}$ adsorption isotherms (Figure 8). Systems for the study of supercritical $\mathrm{CO}_{2}$ interactions with solid surfaces have also been developed in recent years, with a surge of studies prompted by the prospect of geological storage of $\mathrm{CO}_{2}$. We note that the study of mixed $\mathrm{CO}_{2}-\mathrm{H}_{2} \mathrm{O}$ gases requires careful spectral processing of contributions from atmospheric $\mathrm{H}_{2} \mathrm{O}$ and/or gas phase vibrations of the reacting molecules. Dominant strategies include (1) an internal referencing method, by which the gas-phase is monitored by shifting the solid sample away from the optical path [45] and (2) by spectral subtraction using a chemo-metric methodology [46].

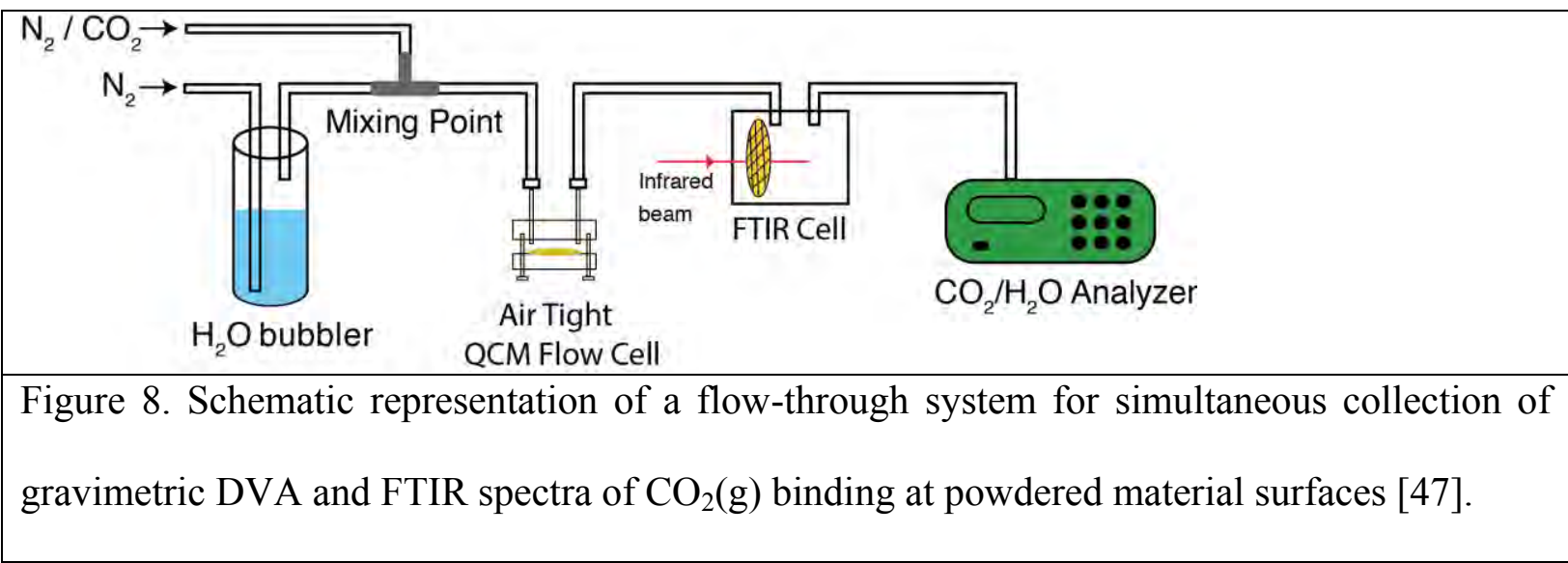

The instrumental design shown in Figure 8 has been very widely used in the transmission of FTIR measurements of $\mathrm{CO}_{2}$ interaction with solid surfaces, with and without the presence of coadsorbing gases [5,48-52]. The use of this type of spectral subtraction in this particular case was facilitated by the fact that the dominant gaseous $\mathrm{CO}_{2}$ IR vibration at $2349 \mathrm{~cm}^{-1}$ does not overlap with any dominant adsorption product vibrations, such as adsorbed carbonates $\left(\mathrm{CO}_{3}{ }^{2-}\right)$, bicarbonates, $\left(\mathrm{HCO}_{3}^{-}\right)$, adsorbed formate $\left(\mathrm{HCO}_{2}^{-}\right)$and others typically observed in the 1700$1000 \mathrm{~cm}^{-1}$ region. 


\subsubsection{Adsorbed $\mathrm{CO}_{2}$}

$\mathrm{CO}_{2}$ is a linear $\mathrm{D}_{\infty \mathrm{h}}$ molecule with three fundamental vibrations: one is a Raman active symmetric $v_{1}$ stretch at $1388 \mathrm{~cm}^{-1}$ and the other two are an infrared active double degenerate $v_{2}$ (deformation) at $667 \mathrm{~cm}^{-1}$ and a $v_{3}$ asymmetric stretch at $2349 \mathrm{~cm}^{-1}$ [53]. Upon adsorption, IR inactive modes are typically activated, after which double degenerate modes split, resulting in a complex spectral envelope. Isostructural organometallic reference compounds, and vibrations calculated based on first principles, are often used to assign observed IR peaks in complex reactive systems. Various organometallic compounds are readily available for differently configured adsorbed $\mathrm{CO}_{2}$ species. In particular, there are at least 13 different configurations represented by numerous organometallic compounds, as shown in Figure 9. Distinct trends in fundamental asymmetric and symmetric stretching vibrations are difficult to unambiguously assign between all the species with the apparent asymmetric stretch $\left(2349 \mathrm{~cm}^{-1}\right.$ fundamental frequency) significantly shifting towards lower wavenumbers and symmetric stretch $\left(1388 \mathrm{~cm}^{-1}\right.$ fundamental frequency) becoming IR active. In general, the magnitude of the asymmetric stretch shift can be correlated with the number of metal atoms involved into coordination providing a varying degree of O-C-O bond distortion. Tabulated standard deviations (Table 5) from the pool of organometallic compounds range within ca. $\pm 60 \mathrm{~cm}^{-1}$, providing confidence that a certain binding mode will take place, regardless of the intrinsic electronic properties of the metal itself. Assignments of the different $\mathrm{CO}_{2}$ related ligands in organometallic compounds have been discussed extensively by Sumida et al., Gibson, Leitner, and Aresta [54-57]. In this report, we provide a summary of their collective assignments for different types of metal complex- $\mathrm{CO}_{2}$ ligands. 


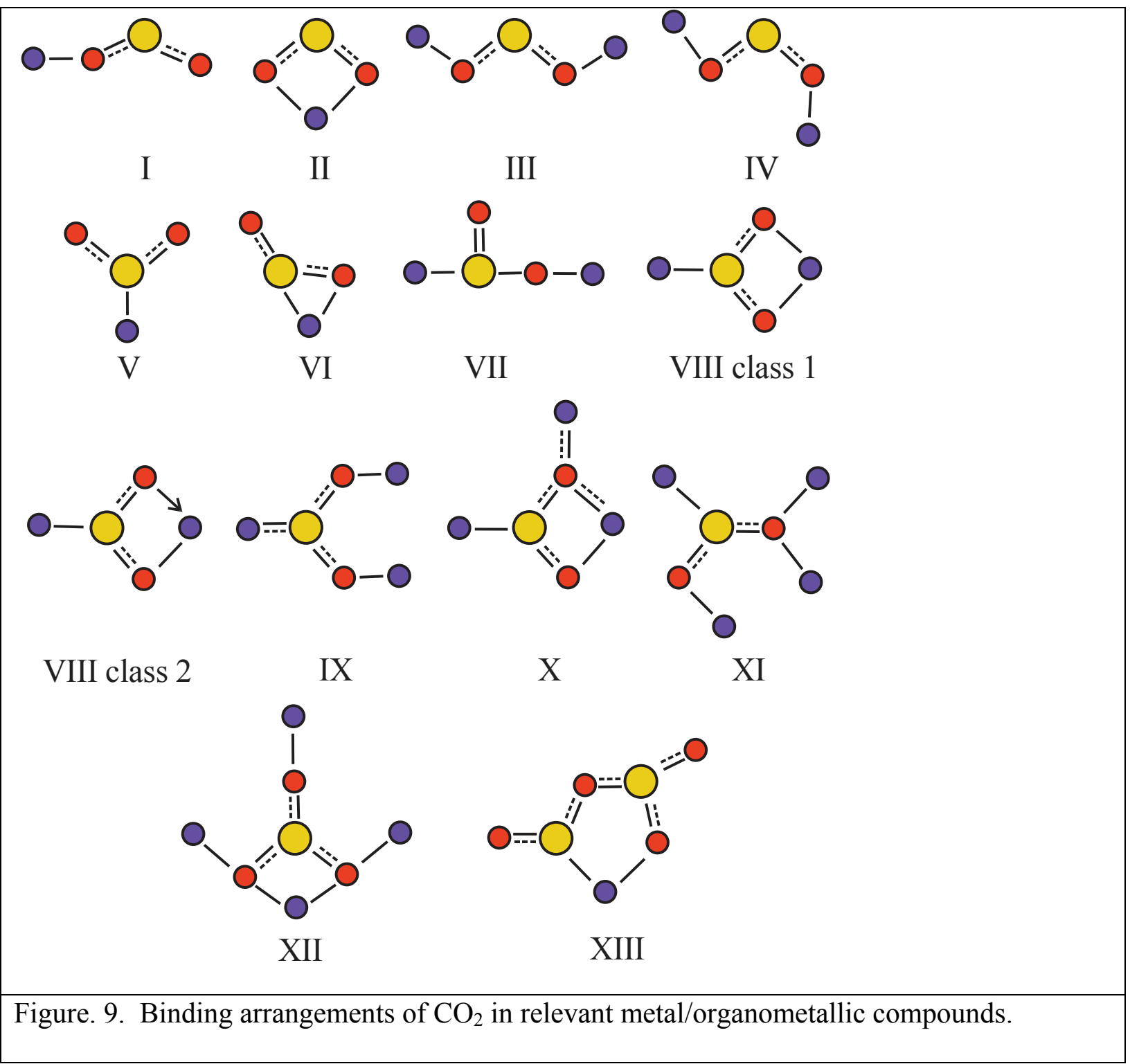

Table 5. IR peak assignments for $\mathrm{CO}_{2}$ binding with the corresponding standard deviation provided, where available.

\begin{tabular}{|c|c|c|c|c|c|}
\hline Metal sites & Type & v as & v s & Note & Reference \\
\hline 1 & I & $\begin{array}{c}1780-1751 ; \\
2188\end{array}$ & $1221-1146$ & Li, Al, U & \\
\cline { 1 - 5 } 1 & II & $1576 \pm 80$ & $1238 \pm 84$ & $\begin{array}{c}\text { Li, Cs, Al, Ni, Re, } \\
\text { Pd, Mo }\end{array}$ & [57] \\
\hline 2 & III & 1341 & 1174 & Cs & \\
\hline 2 & IV & $1448 ; 1335$ & $984 ; 1018$ & Li, Cs & [56,57] \\
\hline 1 & V & $1610 ; 1550$ & $1230-1210$ & Ir and Rh & \\
\hline
\end{tabular}




\begin{tabular}{|c|c|c|c|c|c|}
\hline & & & & & \\
\hline & & & & complexes & \\
\hline 1 & VI & $1675 \pm 40$ & $1135 \pm 39$ & $\begin{array}{c}16 \text { organometallic } \\
\text { complexes }\end{array}$ & {$[56,57]$} \\
\hline 2 & VII & $1549 \pm 64$ & $1136 \pm 63$ & $\begin{array}{c}30 \text { organometallic } \\
\text { complexes }\end{array}$ & \\
\hline 2 & VIII class I & $1372 \pm 45$ & $1269 \pm 30$ & $\begin{array}{c}19 \text { organometallic } \\
\text { complexes }\end{array}$ & {$[55-57]$} \\
\hline 2 & VIII class II & $1452 \pm 56$ & $1165 \pm 42$ & $\begin{array}{l}16 \text { organometallic } \\
\text { complexes }\end{array}$ & \\
\hline 3 & IX & $1380 ; 1365$ & $1295-1260$ & $\begin{array}{c}\mathrm{Re}, \mathrm{Rh} \text { and } \mathrm{Co} \\
\text { complexes }\end{array}$ & {$[55,57]$} \\
\hline 3 & $\mathrm{X}$ & 1650 & $1280 ; 1215$ & Co complex & \\
\hline 4 & XI & 1428 & 1242 & Ru water complex & {$[577$} \\
\hline 4 & XII & 1280 & $1260-1250$ & $\begin{array}{c}\text { Rh Zn THF } \\
\text { complex }\end{array}$ & ] \\
\hline Carboxylate & XIII & $1696 \pm 66$ & $1339 \pm 51$ & $\begin{array}{l}\text { K-Ru and Ir } \\
\text { complex }\end{array}$ & {$[53,58]$} \\
\hline
\end{tabular}

Some of the bridged carbonate ions (vide infra) also exhibit vibrations in 1600-1700 and 1200-

$1300 \mathrm{~cm}^{-1}$ ranges due to the split in double degenerate $v_{3}$ vibrational mode. However, adsorbed $\mathrm{CO}_{2}$, sometimes referred to as carboxylate or strongly perturbed (bent) $\mathrm{CO}_{2}$ molecules, also have vibrations in the same spectra regions, as shown in Table 5. Bent $\mathrm{CO}_{2}$ is of approximately $\mathrm{C}_{2 \mathrm{v}}$ symmetry, with all three vibrations infrared and Raman active [53]. Assignment of the vibrational bands needs to be based on the particular substrate (metal or oxide) and the nature of the corresponding metal ion.

\subsubsection{Adsorbed carbonate $\left(\mathrm{CO}_{3}{ }^{2-}\right)$}

Application of IR spectroscopy on $\mathrm{CO}_{2}$ capture has been in existence for many years. Busca and Lorenzelli compiled and assigned IR vibrations for different $\mathrm{CO}_{2}$ adsorption configurations on the surfaces of different metal oxides and metal complexes [53]. They did so by comparing them with those on well characterized organometallic compounds. Adsorption of $\mathrm{CO}_{2}$ on metal oxide surfaces yields mostly carbonates and bicarbonates. Carbonates formed on a surface via reactive $\mathrm{CO}_{2}$ binding come in different configurations. There are symmetrical (I), monodentate (II-III), 
bidentate (IV), bridged (V-VI), and polydentate configurations (VII-XIII), as shown in Figure 10 [53]. Carbonate in its free ion form has a Raman active vibration of $1063 \mathrm{~cm}^{-1}$ due to the symmetric C-O stretching $\left(v_{1}\right)$, an IR active vibration of $879 \mathrm{~cm}^{-1}$ due to out-of-plane deformation $\left(\mathrm{v}_{2}\right)$, and two Raman-IR active vibrations of 1415 and $680 \mathrm{~cm}^{-1}$, due to CO asymmetric stretching $\left(v_{3}\right)$ and in-plane deformation $\left(v_{4}\right)$, respectively [53]. Changes in molecular symmetry brought by electrostatic, hydrogen and covalent binding induce important shifts as well as the doubly degenerate $v_{3}$ and $v_{4}$ split. These recorded vibrational frequencies can, based on empirical evidence in previous literature data assignments and/or theoretical frequency predictions, be indicators for the coordination environment of the carbonate species, the prevalent $\mathrm{CO}_{2}$ adsorption product. IR-activation of the symmetric stretching mode, and the splitting of both $v_{3}$ and $v_{4}$, with each adsorption configuration exhibiting different values of splitting induced by changes in molecular symmetry. The splitting of $v_{3}$ is the one routinely used to identify binding modes, such as monodentate, bidentate, and bridged with the approximate splitting values of 100,300 , and $\geq 400 \mathrm{~cm}^{-1}$, respectively [53]. For more complicated irregular carbonate structures, i.e., the polydentate configurations, splitting of $v_{3}$ is usually much smaller, sometimes even smaller than that of monodentate, leading to the discrepancy among several authors in assigning specific $v_{3}$ peaks to either monodentate or polydentate carbonates. 


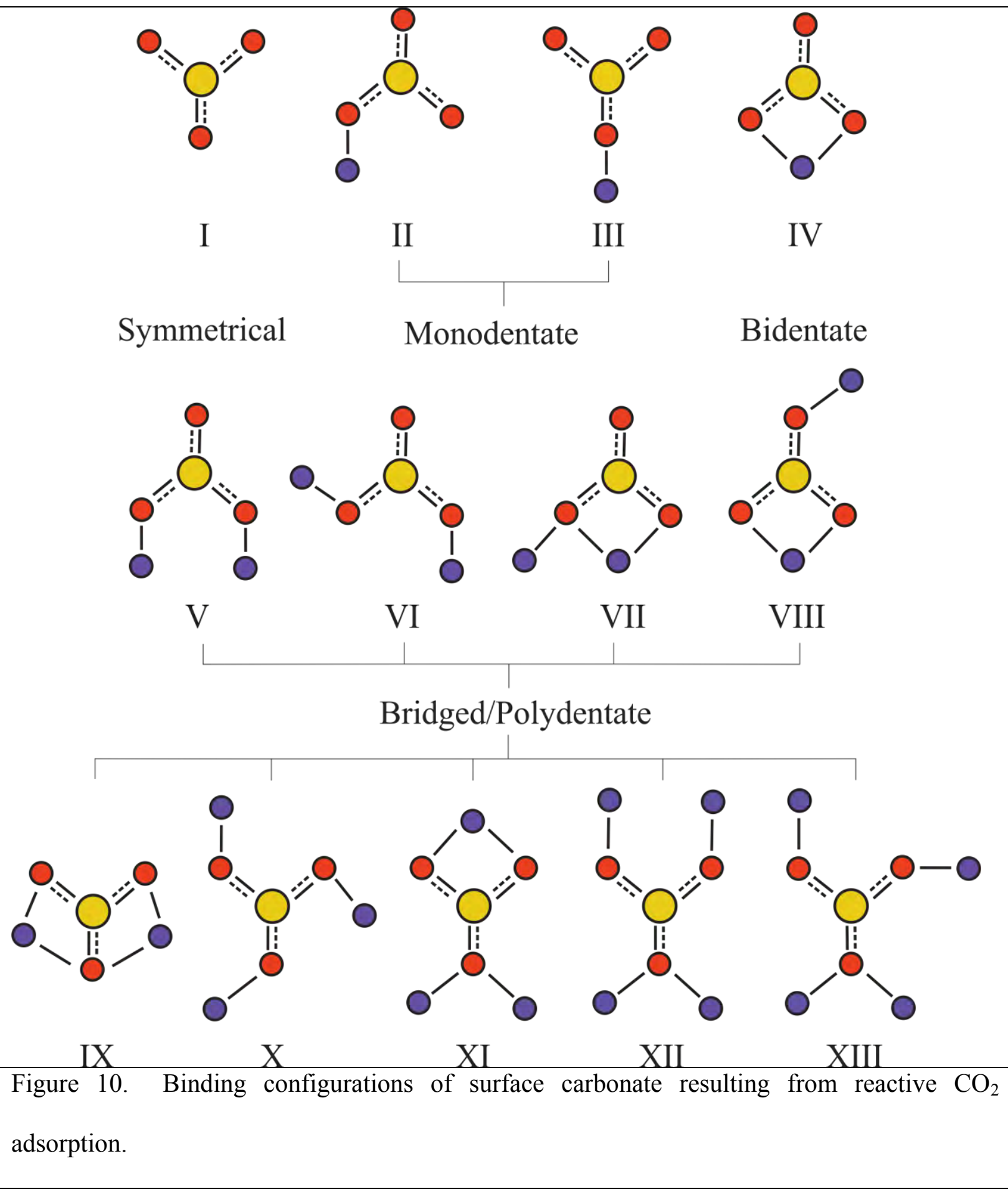

With the data presented so far, binding modes of the adsorbed carbonates for the pure metal oxide surfaces can be referenced against those measured for the organometallic compounds and the binding configuration assigned. This was performed and displayed in Table 6. It can be seen that in a prevalent number of cases mono- and bidentate binding modes take place, with just a few exceptions for alumina $\left(\mathrm{Al}_{2} \mathrm{O}_{3}\right)$ polymorphs, $\mathrm{Ga}_{2} \mathrm{O}_{3}$ and yttria. 
Table 6. Experimental values for peak assignments of carbonates on various metal oxides.

\begin{tabular}{|c|c|c|c|c|c|c|c|c|c|c|c|}
\hline \multirow[b]{2}{*}{ Oxide } & \multicolumn{10}{|l|}{ Type } & \multirow[b]{2}{*}{ Ref } \\
\hline & Symmetrical & $\begin{array}{l}\text { IR } \\
\text { modes }\end{array}$ & Monodentate & $\begin{array}{l}\text { IR } \\
\text { modes }\end{array}$ & Bidentate & $\begin{array}{l}\text { IR } \\
\text { modes }\end{array}$ & $\begin{array}{l}\text { Bridged } \\
(\mathrm{V}-\mathrm{VI})\end{array}$ & $\begin{array}{l}\text { IR } \\
\text { modes }\end{array}$ & $\begin{array}{l}\text { Bridged } \\
\text { Polydentate } \\
\text { (VII-XIII) }\end{array}$ & $\begin{array}{l}\text { IR } \\
\text { modes }\end{array}$ & \\
\hline \multirow{2}{*}{$\mathrm{BeO}$} & 1440 & $v_{3}$ & & & 1640 & $v_{3}$ as & & & & & \multirow{2}{*}{$\begin{array}{l}{[53] \text { and ref }} \\
\text { therein }\end{array}$} \\
\hline & & & & & 1220 & $v_{3} s$ & & & & & \\
\hline \multirow{4}{*}{$\mathrm{MgO}$} & & & $\begin{array}{l}1520 / 1550 \\
1506 ; 1526\end{array}$ & $v_{3}$ as & $\begin{array}{l}1655 / 1670 / \\
1660 ; \\
1673 ; 1778\end{array}$ & $v_{3}$ as & & & & & \multirow{4}{*}{$\begin{array}{l}{[53] \text { and ref }} \\
\text { therein; } \\
{[51,59] ;}\end{array}$} \\
\hline & 1410 & $v_{3}$ & $\begin{array}{l}\text { 1390/1410; } \\
1415-1418\end{array}$ & $v_{3} \mathrm{~s}$ & $\begin{array}{l}1325 / 1320 / \\
1307 / 1315 / \\
1330 ; \\
1361 ; 1243\end{array}$ & $v_{3} \mathrm{~s}$ & & & & & \\
\hline & & & $\begin{array}{l}1050 ; 1067- \\
1072\end{array}$ & $v_{1}$ & $\begin{array}{l}\text { 1005/1000; } \\
1091 ; 932\end{array}$ & $v_{1}$ & & & & & \\
\hline & & & 860 & $v_{2}$ & $850 ; 847$ & $v_{2}$ & & & & & \\
\hline \multirow{4}{*}{$\mathrm{CaO}$} & $\begin{array}{l}\text { 1520-1490; } \\
1415\end{array}$ & $v_{3}$ & $\begin{array}{l}1635-1550 ; \\
1603\end{array}$ & $v_{3}$ as & & $v_{3}$ as & $1781 / 1776$ & $v_{3}$ as & & & \multirow{4}{*}{$\begin{array}{l}{[53] \text { and ref }} \\
\text { therein; } \\
{[59]}\end{array}$} \\
\hline & & & $\begin{array}{l}\text { 1308-1302; } \\
1314\end{array}$ & $v_{3} \mathrm{~s}$ & & $v_{3} \mathrm{~s}$ & & & & & \\
\hline & 1060 & $v_{1}$ & 1035 & $v_{1}$ & & $v_{1}$ & & & & & \\
\hline & 860 & $v_{4}$ & 876 & $v_{2}$ & & $v_{2}$ & & & & & \\
\hline \multirow{3}{*}{$\begin{array}{l}\alpha- \\
\mathrm{Al}_{2} \mathrm{O}_{3}\end{array}$} & & & $1610-1570$ & $v_{3}$ as & $\begin{array}{l}1710 / \\
1675-1660\end{array}$ & $v_{3}$ as & 1810 & $v_{3}$ as & 1810 & $v_{3}$ as & \multirow{3}{*}{$\begin{array}{l}{[53] \text { and ref }} \\
\text { therein }\end{array}$} \\
\hline & & & $1385-1350$ & $v_{3} \mathrm{~s}$ & $1310 / 1345$ & $v_{3} \mathrm{~s}$ & 1730 & $\mathrm{v}_{3}$ as & 1730 & $v_{3} \mathrm{~s}$ & \\
\hline & & & & & & & 1310 & $v_{3}$ & & & \\
\hline $\begin{array}{l}\gamma- \\
\mathrm{Al}_{2} \mathrm{O}_{3}\end{array}$ & & & 1530 & $v_{3}$ as & $\begin{array}{l}1730- \\
1660 ; 1640 \\
\end{array}$ & $v_{3}$ as & $\begin{array}{l}1900- \\
1750 \\
\end{array}$ & $v_{3}$ as & & & $\begin{array}{l}\text { [53] and ref } \\
\text { therein; }\end{array}$ \\
\hline
\end{tabular}




\begin{tabular}{|c|c|c|c|c|c|c|c|c|c|c|c|}
\hline & & & $1370 ; 1383$ & $v_{3} \mathrm{~s}$ & $\begin{array}{l}1270- \\
1230 ; 1355\end{array}$ & $v_{3} \mathrm{~s}$ & 1180 & $v_{3} s / v_{1}$ & & & \multirow[t]{2}{*}[50]{} \\
\hline & & & 1040 & $v_{1}$ & 1010 & $v_{1}$ & & & & & \\
\hline \multirow{2}{*}{$\begin{array}{l}\eta- \\
\mathrm{Al}_{2} \mathrm{O}_{3}\end{array}$} & & & $1630-1600$ & $v_{3}$ as & 1710 & $v_{3}$ as & $\begin{array}{l}1900- \\
1750\end{array}$ & $v_{3}$ & & & \multirow{2}{*}{$\begin{array}{l}{[53] \text { and ref }} \\
\text { therein }\end{array}$} \\
\hline & & & $1515-1470$ & $v_{3} \mathrm{~s}$ & 1315 & $v_{3} \mathrm{~s}$ & 1180 & $v_{3} s / v_{1}$ & & & \\
\hline \multirow{2}{*}{$\begin{array}{l}\kappa- \\
\mathrm{Al}_{2} \mathrm{O}_{3}\end{array}$} & 1460 & $v_{3}$ & & & 1652 & $v_{3}$ as & & & & & \multirow{2}{*}{$\begin{array}{l}{[53] \text { and ref }} \\
\text { therein }\end{array}$} \\
\hline & & & & & 1234 & $v_{3} \mathrm{~s}$ & & & & & \\
\hline \multirow[b]{2}{*}{$\mathrm{SnO}_{2}$} & & & 1440 & $v_{3}$ as & 1580 & & & & 1760 & $v_{3}$ as & \multirow{2}{*}{$\begin{array}{l}{[53] \text { and ref }} \\
\text { therein }\end{array}$} \\
\hline & & & 1380 & $v_{3} \mathrm{~s}$ & & & & & 1740 & $v_{3} \mathrm{~s}$ & \\
\hline & & & & & & & & & & & \\
\hline \multirow{2}{*}{$\mathrm{Sc}_{2} \mathrm{O}_{3}$} & 1140 & $v_{1}$ & & & 1635 & $v_{3}$ as & & & & & \multirow{2}{*}{$\begin{array}{l}{[53] \text { and ref }} \\
\text { therein }\end{array}$} \\
\hline & & & & & 1220 & $v_{3} s$ & & & & & \\
\hline \multirow{3}{*}{$\mathrm{TiO}_{2}$} & & & $1461 ; 1510$ & $v_{3}$ as & $\begin{array}{l}1579 ; \\
1691 ; 1566\end{array}$ & $v_{3}$ as & & & & & \multirow{3}{*}[60,61]{} \\
\hline & & & 1392 & $\mathrm{v}_{3} \mathrm{~s}$ & $\begin{array}{l}1319 ; \\
1265 ; 1355\end{array}$ & $v_{3} s$ & & & & & \\
\hline & & & 1076 & $v_{1}$ & & & & & & & \\
\hline \multirow{2}{*}{$\begin{array}{l}\mathrm{TiO}_{2} \\
\text { Rutile }\end{array}$} & & & & & 1485 & $v_{3}$ as & 1706 & $v_{3}$ as & & & \multirow{2}{*}{$\begin{array}{l}{[53] \text { and ref }} \\
\text { therein; } \\
{[62]}\end{array}$} \\
\hline & & & & & 1325 & $v_{3} \mathrm{~s}$ & & & & & \\
\hline \multirow{3}{*}{$\begin{array}{l}\mathrm{TiO}_{2} \\
\text { anatase }\end{array}$} & & & $1590-1575$ & $v_{3}$ as & $\begin{array}{l}1580 / 1670 ; \\
1589\end{array}$ & $v_{3}$ as & & & & & \multirow{3}{*}{$\begin{array}{l}{[53] \text { and ref }} \\
\text { therein; } \\
{[5,62]}\end{array}$} \\
\hline & & & $\begin{array}{l}\text { 1370-1320; } \\
1377\end{array}$ & $v_{3} \mathrm{~s}$ & $\begin{array}{l}\text { 1320/1243; } \\
1315\end{array}$ & $v_{3} \mathrm{~s}$ & & & & & \\
\hline & & & & & 1055 & $v_{1}$ & & & & & \\
\hline \multirow[t]{2}{*}{$\mathrm{ZrO}_{2}$} & & & $1490 / 1450$ & $v_{3}$ as & $\begin{array}{l}1575 / 1550 / \\
1595 / 1573 / \\
1559\end{array}$ & $v_{3}$ as & & & 1450 & $v_{3}$ as & \multirow[t]{2}{*}{ [63-66] } \\
\hline & & & $1395 / 1425$ & $v_{3} \mathrm{~s}$ & $\begin{array}{l}1325 / 1355 / \\
1315 / 1354 /\end{array}$ & $v_{3} \mathrm{~s}$ & & & 1430 & $v_{3} \mathrm{~s}$ & \\
\hline
\end{tabular}




\begin{tabular}{|c|c|c|c|c|c|c|c|c|c|c|c|}
\hline & & & & & 1310 & & & & & & \\
\hline & & & & & 1065 & $v_{1}$ & & & & & \\
\hline \multirow{3}{*}{$\begin{array}{l}\alpha- \\
\mathrm{Cr}_{2} \mathrm{O}_{3}\end{array}$} & 1440 & $v_{3}$ & 1490 & $v_{3}$ as & $\begin{array}{l}1635 / 1590 / \\
1560 / 1650\end{array}$ & $v_{3}$ as & 1740 & $v_{3}$ as & & & \multirow{3}{*}{$\begin{array}{l}{[53] \text { and ref }} \\
\text { therein; } \\
\text { [67] }\end{array}$} \\
\hline & & & 1365 & $v_{3} \mathrm{~s}$ & $\begin{array}{l}1285 / 1305 / \\
1340 / 1240\end{array}$ & $v_{3} \mathrm{~s}$ & & & & & \\
\hline & & & & & 850 & $v_{2}$ & & & & & \\
\hline \multirow{3}{*}{$\begin{array}{l}\alpha- \\
\mathrm{Fe}_{2} \mathrm{O}_{3}\end{array}$} & 1450 & $v_{3}$ & 1460 & $v_{3}$ as & $\begin{array}{l}1610 / 1550 / \\
1553\end{array}$ & & 1760 & $v_{3}$ as & & & \multirow{3}{*}{$\begin{array}{l}{[53] \text { and ref }} \\
\text { therein; } \\
{[52]}\end{array}$} \\
\hline & 850 & $v_{2}$ & 1400 & $v_{3} s$ & $\begin{array}{l}1290 / 1340 / \\
1316\end{array}$ & & & & & & \\
\hline & & & 1050 & $v_{1}$ & & & & & & & \\
\hline \multirow{3}{*}{$\mathrm{Co}_{3} \mathrm{O}_{4}$} & & & 1440 & $v_{3}$ as & 1545 & $v_{3}$ as & & & & & \multirow{3}{*}{$\begin{array}{l}{[53] \text { and }} \\
\text { ref therein }\end{array}$} \\
\hline & & & 1408 & $v_{3} \mathrm{~s}$ & 1324 & $v_{3} s$ & & & & & \\
\hline & & & 876 & $v_{2}$ & 1134 & $v_{1}$ & & & & & \\
\hline \multirow{3}{*}{$\mathrm{NiO}$} & & & 1640 & $v_{3}$ as & $\begin{array}{l}1670 ; \\
1620 ; 1625\end{array}$ & $v_{3}$ as & 1730 & $v_{3}$ as & & & \multirow{3}{*}{$\begin{array}{l}{[53] \text { and ref }} \\
\text { therein; } \\
{[68]}\end{array}$} \\
\hline & & & $1390 / 1263$ & $\mathrm{v}_{3} \mathrm{~s}$ & & & 1160 & $v_{3} s / v_{1}$ & & & \\
\hline & & & 910 & $v_{2}$ & & & & & & & \\
\hline \multirow{2}{*}{$\mathrm{CuO}$} & 1445 & $v_{3}$ & & & 1500 & $v_{3}$ as & & & & & \multirow{2}{*}{$\begin{array}{l}{[53] \text { and ref }} \\
\text { therein }\end{array}$} \\
\hline & 845 & $v_{1}$ & & & & & & & & & \\
\hline \multirow{5}{*}{$\mathrm{ZnO}$} & 1430 & & $1543-1520$ & $v_{3}$ as & $\begin{array}{l}1665- \\
1580 ; 1621\end{array}$ & $v_{3}$ as & & & 1466 & $v_{3}$ as & \multirow{5}{*}{$\begin{array}{l}{[53] \text { and ref }} \\
\text { therein }\end{array}$} \\
\hline & & & $1323-1313$ & $v_{3} s$ & $\begin{array}{l}1348- \\
1303 ; 1292\end{array}$ & $v_{3} s$ & & & 1386 & $v_{3} \mathrm{~s}$ & \\
\hline & & & & & $1007-999$ & $v_{1}$ & & & & & \\
\hline & & & & & $852-841$ & $v_{2}$ & & & & & \\
\hline & & & & & $680-677$ & $v_{4}$ & & & & & \\
\hline \multirow{2}{*}{$\mathrm{La}_{2} \mathrm{O}_{3}$} & & & 1500 & $v_{3}$ as & 1565 & $v_{3}$ as & & & & & \multirow{2}{*}{$\begin{array}{l}{[53] \text { and ref }} \\
\text { therein, }\end{array}$} \\
\hline & & & 1390 & $v_{3} s$ & 1310 & $v_{3} s$ & & & & & \\
\hline
\end{tabular}




\begin{tabular}{|c|c|c|c|c|c|c|c|c|c|}
\hline & 1060 & $v_{1}$ & & & & & & & [69] \\
\hline & 850 & $\mathrm{v}_{2}$ & & & & & & & \\
\hline \multirow{4}{*}{$\mathrm{ThO}_{2}$} & & & 1610 & $v_{3}$ as & & & & & \multirow{4}{*}{$\begin{array}{l}{[53] \text { and ref }} \\
\text { therein }\end{array}$} \\
\hline & & & 1290 & $v_{3} \mathrm{~s}$ & & & & & \\
\hline & & & 1030 & $v_{1}$ & & & & & \\
\hline & & & 840 & $v_{2}$ & & & & & \\
\hline \multirow{2}{*}{$\mathrm{Ga}_{2} \mathrm{O}_{3}$} & & & 1587 & $v_{3}$ as & 1680 & $v_{3}$ as & 1460 & $v_{3}$ as & \multirow{2}{*}{ [70] } \\
\hline & & & 1325 & $v_{3} \mathrm{~s}$ & 1280 & $v_{3} \mathrm{~s}$ & 1406 & $v_{3} \mathrm{~s}$ & \\
\hline \multirow{2}{*}{$\mathrm{Y}_{2} \mathrm{O}_{3}$} & & & & & 1585 & $v_{3}$ as & & & \multirow{2}{*}{ [71] } \\
\hline & & & & & 1334 & $v_{3} \mathrm{~s}$ & & & \\
\hline
\end{tabular}


An interesting comparison of $v_{3}$ vibrational frequencies can be made for the samples where basic oxides $\left(\mathrm{MgO}, \mathrm{CaO}\right.$ and $\left.\mathrm{Na}_{2} \mathrm{O}\right)$ are supported on $\mathrm{Al}_{2} \mathrm{O}_{3}$, as is typical of solid oxide sorbents for $\mathrm{CO}_{2}$ capture (Table 7). The values observed do not necessarily coincide exactly with those of pure metal oxides shown in Table 6. Also, the exact identity of the binding site cannot be unambiguously determined by FTIR spectroscopy. Some binding modes observed for $\mathrm{CaO} / \mathrm{Al}_{2} \mathrm{O}_{3}$, identified as bidentates, do not typically appear in pure $\mathrm{CaO}$ but can instead be associated with $\mathrm{Al}_{2} \mathrm{O}_{3}$ adsorption of $\mathrm{CO}_{2}$. Complex polydentate binding can then be postulated due to the availability of inhomogeneous adsorption sites, as in the case of $\mathrm{Na}_{2} \mathrm{O} / \mathrm{Al}_{2} \mathrm{O}_{3}(\mathrm{Table}$ 7).

Table 7. Experimental values for peak assignments of carbonates on doped $\mathrm{Al}_{2} \mathrm{O}_{3}$.

\begin{tabular}{|c|c|c|c|c|c|c|c|}
\hline \multirow[b]{2}{*}{ Dopants } & \multicolumn{6}{|c|}{ Type } & \multirow[b]{2}{*}{ Ref } \\
\hline & Monodentate & $\begin{array}{l}\text { IR } \\
\text { modes } \\
\end{array}$ & Bidentate & $\begin{array}{l}\text { IR } \\
\text { modes } \\
\end{array}$ & Polydentate & $\begin{array}{l}\text { IR } \\
\text { modes } \\
\end{array}$ & \\
\hline \multirow{2}{*}{$\mathrm{MgO}$} & $1574 / 1591$ & $v_{3}$ as & $1708 / 1610$ & $v_{3}$ as & 1675 & $v_{3}$ as & \multirow{4}{*}[72-74]{} \\
\hline & $1420 / 1506$ & $\mathrm{v}_{3} \mathrm{~s}$ & $1330 / 1380 / 1340$ & $v_{3} \mathrm{~s}$ & & & \\
\hline \multirow{2}{*}{$\mathrm{CaO}$} & 1518 & $v_{3}$ as & 1600 & $v_{3}$ as & & & \\
\hline & 1300 & $v_{3} s$ & 1350 & $v_{3} \mathrm{~s}$ & & & \\
\hline \multirow{2}{*}{$\mathrm{Na}_{2} \mathrm{O}$} & & & $\begin{array}{l}\text { 1672-1677; } \\
1618-1631\end{array}$ & $v_{3}$ as & 1571 & $v_{3}$ as & \multirow{2}{*}{ [75] } \\
\hline & & & $\begin{array}{l}\text { 1361-1376; } \\
1311-1320\end{array}$ & $v_{3} \mathrm{~s}$ & $1353 / 1450$ & $v_{3} \mathrm{~s}$ & \\
\hline
\end{tabular}

\subsubsection{Adsorbed bicarbonate $\left(\mathrm{HCO}_{3}{ }^{-}\right)$}

Adsorbed bicarbonate species, as is true of their carbonate counterparts, exhibit several binding configurations. In its solid state bicarbonate is in a dimer form (I) with characteristic IR peaks at 2620-2450 $\mathrm{cm}^{-1}(\mathrm{v}(\mathrm{OH} \ldots \mathrm{O})), 1655-1615 \mathrm{~cm}^{-1}$ (asymmetric $\mathrm{C}=\mathrm{O}$ stretch), 1400-1370 $\mathrm{cm}^{-1}$ (symmetric $\mathrm{C}=\mathrm{O}$ stretch) and $1300 \mathrm{~cm}^{-1}$ (COH...O bending). However, for monomeric bicarbonate species, hydrogen bonding between the two dimers is not necessarily present and the 
$\mathrm{OH}$ stretch $v_{5}$ is present at much higher wavenumbers $\left(3340-3148 \mathrm{~cm}^{-1}\right)$. At the same time, though, shifts are also expected on the other peaks at $1702-1675 \mathrm{~cm}^{-1}$ for the asymmetric $\mathrm{C}=\mathrm{O}$ stretch $\left(v_{3}\right.$ as), $1346-1327 \mathrm{~cm}^{-1}$ for the symmetric $\mathrm{C}=\mathrm{O}$ stretch $\left(v_{3} \mathrm{~s}\right)$, and $1252-1205 \mathrm{~cm}^{-1}$ for the $\mathrm{OH}-\mathrm{O}$ bend $\left(\delta_{4}\right)$ [53]. There are two main types of surface bicarbonate observed on surfaces: monodentate (II) and bidentate (III). An additional structure, the bridged bicarbonate (IV) species, is rarely recognized, although an FTIR study of isotope labeling of adsorbed $\mathrm{HC}^{16} \mathrm{O}_{3}^{-}$, $\mathrm{DC}^{16} \mathrm{O}_{3}^{-}, \mathrm{HC}^{18} \mathrm{O}_{3}^{-}, \mathrm{HC}^{16} \mathrm{O}^{18} \mathrm{O}_{2}^{-}$, and $\mathrm{HC}^{18} \mathrm{O}^{16} \mathrm{O}_{2}^{-}$, combined with quantum chemical calculations, points toward its presence [50]. To facilitate this process, a proton transfer mechanism is likely to occur through an intermolecular process involving either a coadsorbed hydroxyl group and/or a carbonate ion. Figure 11 below depicts the hitherto encountered bicarbonate species.

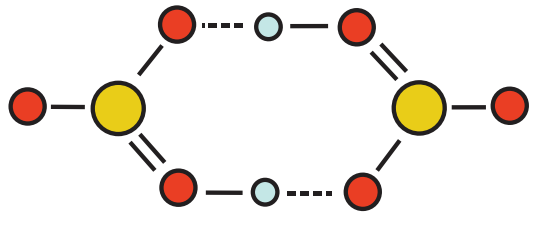

I

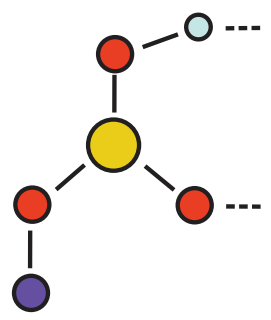

II

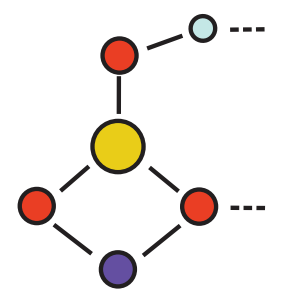

III

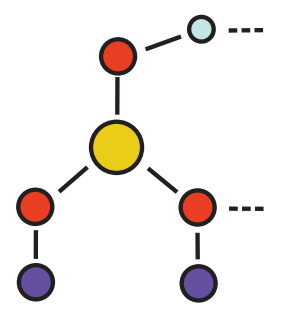

IV

Figure 11. Various configurations of surface bicarbonate observed.

Table 8. Experimental values for peak assignments of bicarbonates on various metal oxides.

\begin{tabular}{|c|c|c|c|c|c|}
\hline \multirow{2}{*}{ Oxide } & \multicolumn{3}{|c|}{ Types } & \multirow{2}{*}{ IR Modes } & \multirow{2}{*}{ Ref } \\
\hline & Monodentate (II) & Bidentate (III) & Bridged (IV) & & \\
\hline \multirow{4}{*}{$\mathrm{PdO} / \gamma-\mathrm{Al}_{2} \mathrm{O}_{3}$} & 3610 & & & $v_{5}$ & \multirow{4}{*}{ [76] } \\
\hline & 1645 & & & $v_{3}$ as & \\
\hline & 1485 & & & $v_{3} \mathrm{~s}$ & \\
\hline & 1235 & & & $\delta_{4}$ & \\
\hline \multirow{5}{*}{$\mathrm{MgO}$} & \multicolumn{3}{|l|}{$1658-1639$} & $v_{3}$ as & \multirow{5}{*}{$\begin{array}{l}{[53,59,77]} \\
{[78-80]}\end{array}$} \\
\hline & \multicolumn{3}{|c|}{$1419-1415 ; 1480-1420$} & $v_{3} \mathrm{~s}$ & \\
\hline & \multicolumn{3}{|c|}{$1250-1210$} & $\delta_{4}$ & \\
\hline & \multicolumn{3}{|l|}{1040} & $v_{1}$ & \\
\hline & \multicolumn{3}{|l|}{840} & $v_{2}$ & \\
\hline $\mathrm{CaO}$ & \multicolumn{3}{|l|}{1630} & $v_{3}$ as & [59] \\
\hline
\end{tabular}




\begin{tabular}{|c|c|c|c|c|c|}
\hline & $1360-1560$ & & & $v_{3} \mathrm{~s}$ & \\
\hline \multirow{4}{*}{$\mathrm{Al}_{2} \mathrm{O}_{3}$} & & 3620 & & $v_{1}$ & \multirow{4}{*}[5,72,75]{} \\
\hline & 1620 & 1650 & & $v_{3}$ as & \\
\hline & 1450 & $1435 ; 1436$ & & $v_{3} \mathrm{~s}$ & \\
\hline & 1230 & $1228 ; 1225$ & & $\delta_{4}$ & \\
\hline \multirow{3}{*}{$\mathrm{MgO} / \mathrm{Al}_{2} \mathrm{O}_{3}$} & $1650 ; 1675$ & & & $v_{3}$ as & \multirow{3}{*}[73,74]{} \\
\hline & 1403 & & & $v_{3} \mathrm{~s}$ & \\
\hline & 1220 & & & $\delta_{4}$ & \\
\hline \multirow{3}{*}{$\mathrm{CaO} / \mathrm{Al}_{2} \mathrm{O}_{3}$} & & 1649 & & $v_{3}$ as & \multirow{3}{*}{ [81] } \\
\hline & & 1440 & & $v_{3} s$ & \\
\hline & & 1230 & & $\delta_{4}$ & \\
\hline \multirow{2}{*}{$\begin{array}{l}\text { aminopropylsilane } \\
\text { functionalized } \\
\mathrm{TiO}_{2}\end{array}$} & & 1691 & & $v_{3}$ as & \multirow[b]{2}{*}{ [82] } \\
\hline & & 1265 & & $\delta_{4}$ & \\
\hline \multirow{2}{*}{ Anatase $\mathrm{TiO}_{2}$} & 1434 & & & $v_{3} s$ & \multirow{2}{*}{ [62] } \\
\hline & 1222 & & & $\delta_{4}$ & \\
\hline \multirow{3}{*}{$\mathrm{TiO}_{2}$} & & 1623 & & $v_{3}$ as & \multirow{3}{*}{ [5] } \\
\hline & & 1423 & & $v_{3} \mathrm{~s}$ & \\
\hline & & 1222 & & $\delta_{4}$ & \\
\hline \multirow{4}{*}{$\mathrm{ZrO}_{2}$} & 3607 & & & $v_{5}$ & \multirow{4}{*}{ [63-66] } \\
\hline & $1620 ; 1610 ; 1613$ & & & $v_{3}$ as & \\
\hline & 1453,1443 & & & $v_{3} \mathrm{~s}$ & \\
\hline & $1225,1224,1243$ & & & $\delta_{4}$ & \\
\hline \multirow{3}{*}{$\mathrm{Ga}_{2} \mathrm{O}_{3}$} & $1619 ; 1630$ & & & $v_{3}$ as & \multirow{3}{*}[70,83]{} \\
\hline & $1456 ; 1463$ & $1431 ; 1432$ & & $v_{3} \mathrm{~s}$ & \\
\hline & 1231 & 1229 & & $\delta_{4}$ & \\
\hline \multirow{5}{*}{$\mathrm{Fe}_{2} \mathrm{O}_{3}$} & & 3619 & & $v_{5}$ & \multirow{5}{*}[5,52]{} \\
\hline & & $1629 ; 1622$ & & $v_{3}$ as & \\
\hline & & 1410 & & $v_{3} s$ & \\
\hline & & $1222 ; 1220$ & & $\delta_{4}$ & \\
\hline & & 1010 & & $v_{1}$ & \\
\hline \multirow{4}{*}{$\mathrm{Y}_{2} \mathrm{O}_{3}$} & 3658 & 3625 & & $v_{5}$ & \multirow{10}{*}{ [71] } \\
\hline & 1674 & 1652 & 1585 & $v_{3}$ as & \\
\hline & 1397 & 1419 & 1334 & $v_{3} \mathrm{~s}$ & \\
\hline & 1223 & 1223 & & $\delta_{4}$ & \\
\hline \multirow{3}{*}{ Y-stabilized $\mathrm{ZrO}_{2}$} & & 1646 & & $v_{3}$ as & \\
\hline & & 1429 & 1305 & $v_{3} s$ & \\
\hline & & 1225 & & $\delta_{4}$ & \\
\hline \multirow{3}{*}{$\mathrm{ZrO}_{2}$} & 1628 & & & $v_{3}$ as & \\
\hline & 1431 & & & $v_{3} \mathrm{~s}$ & \\
\hline & 1223 & & & $\delta_{4}$ & \\
\hline
\end{tabular}




\subsubsection{Adsorbed formate $\left(\mathrm{HCO}_{2}{ }^{-}\right)$}

As in the case of carbonate and bicarbonate, surface formate species also exhibit different binding configurations, such as monodentate (I), bidentate (II), bridged (III-V), and even more complicated bridged structures (VI-VII), as shown in Figure 12. The characteristic IR peaks of a typical formate ion usually lie at $2841,1567,1377$, and $1366 \mathrm{~cm}^{-1}$, corresponding to $\mathrm{CH}$ stretch, asymmetric $\mathrm{CO}$ stretch, $\mathrm{CH}$ bend, and symmetric $\mathrm{CO}$ stretch, respectively.

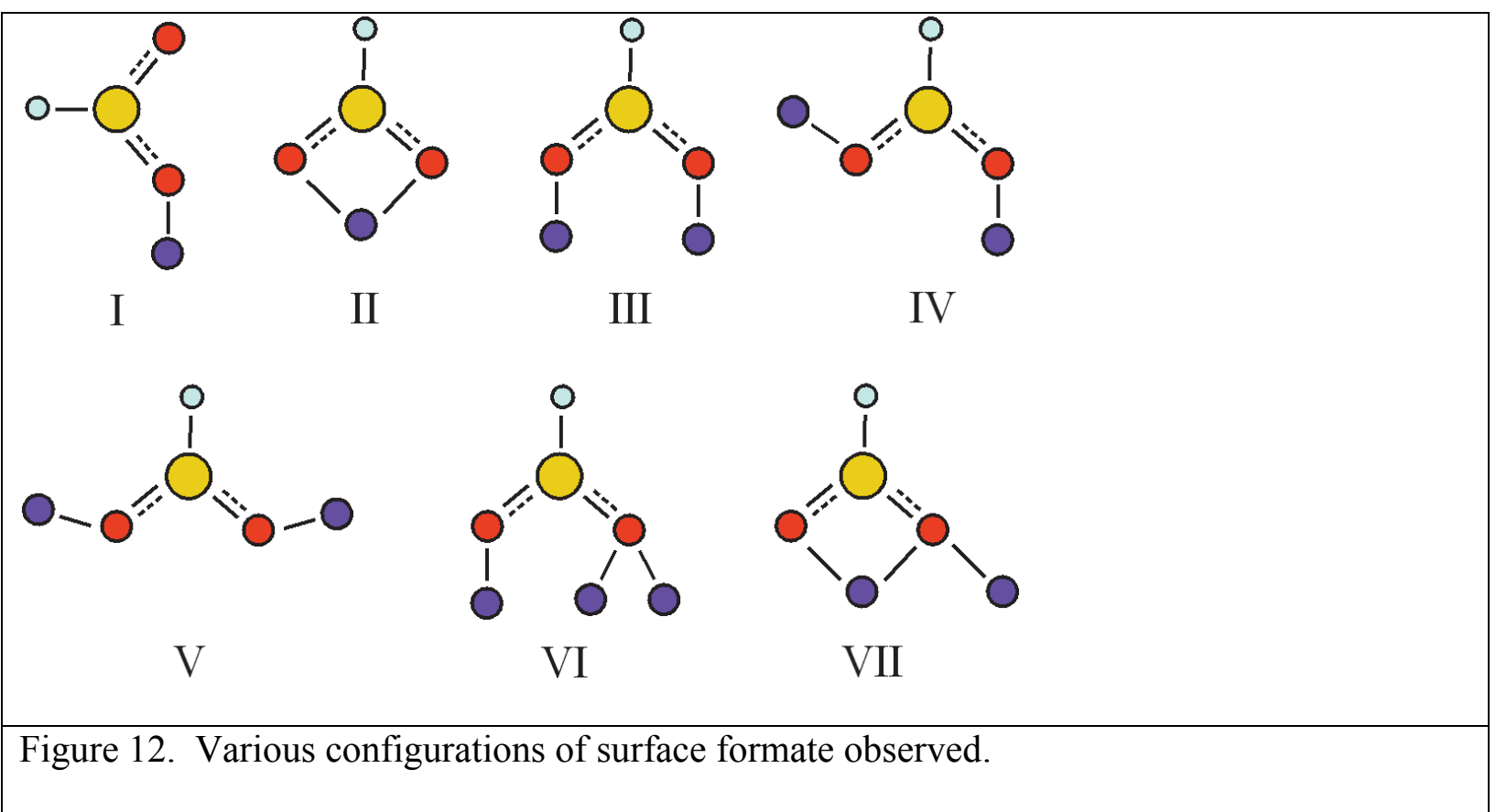

The wavenumber value of the peaks in the adsorbed formate should again be referenced in the same, exact manner as the organometallic model compound, thus providing the ability to infer a particular binding mode. However, multiple problems may still persist if several binding configurations are simultaneously present with the peaks in the vicinity of each other. For example, when type XIII carboxylate and type III $\mathrm{CO}_{2}$ adsorptions are present at the same time a peak at $\sim 1340 \mathrm{~cm}^{-1}$ will appear. This peak could arise from the asymmetric $v$ OCO $\left(v_{3}\right.$ as) for the former and symmetric $v$ OCO $\left(v_{3} s\right)$ from the latter. Another drawback from assigning peaks using organometallic compounds is that organometallic compounds are measured in their non- 
adsorbed, rather directly bonded, state. Adsorption of a molecule by a surface can perturb its vibrations to the extent that it is different from that of the direct bonding interaction. Shifts of the vibrational frequencies are expected in these cases from the values that are reported for organometallics.

\subsubsection{Other binding modes.}

This subsection deals with $\mathrm{CO}_{2}$ binding modes encountered in adsorption on a metal organic framework (MOF), where $\mathrm{CO}_{2}$ adsorbs in a linear fashion using one of its oxygen atoms. Recently, a DFT work combined with IR revealed that on M2L (M=Mg, and transition metals; $\mathrm{L}=2,5$-dioxidobenzene-1,4-dicarboxylate) a blue shift was observed in the $\mathrm{CO}_{2} \mathrm{v}_{3}$ mode for $\mathrm{M}=\mathrm{Mg}$, while a red shift took place on $\mathrm{M}=$ transition metals [84]. The cause was the perturbation arising from the electrostatic and charge transfer effect typical in transition metal complexes. For this reason, an anomalous blue shift in the case for $\mathrm{M}=\mathrm{Mg}$ is remarkable. The anomalous blue shift was explained when the binding mode of $\mathrm{CO}_{2}$ was investigated theoretically. A nearcomplete cancellation of the opposing local mode contributions to the observed frequency shift was observed in the case of $\mathrm{Mg}$, leaving the shift to originate solely from the electrostatic effect [84]. The absence of $\mathrm{d}$ valence electrons in $\mathrm{Mg}$ prevented back-bonding (electron density donation to $\mathrm{CO}_{2} \pi^{*}$ orbital) and resulted in anomalously equal red and blue local shifts. The same research group also observed a new peak at a much lower temperature, which they attribute to an alternate, localized orientation of $\mathrm{CO}_{2}$ adsorbed to the metal site.

Shifts in the $v_{3}$ mode of $\mathrm{CO}_{2}$ were also observed in MIL-100(Cr), MIL-100(V) and MIL-100(Sc) (where MIL is a metal(III) carboxylate built from trimers of metal octahedra sharing a common oxygen atom and are linked together by trimesate rigid ligands) with respect to the gas phase molecule vibrations of 8,7 , and $11 \mathrm{~cm}^{-1}$, respectively [85]. MIL-100 and MIL-101 (Cr, V, Sc, 
Fe) have lately become important for carbon capture purposes [85-87]. Llewellyn et al., reported high uptakes of $\mathrm{CO}_{2}$ using chromium(VI)-based MIL-100 and MIL-101 as characterized by FTIR [86]. Cr-MIL-100 strongly adsorbed $\mathrm{CO}_{2}$ gas and produced peaks at $2351\left(\mathrm{v}_{3}\right)$ and 1271 $\mathrm{cm}^{-1}\left(2 \mathrm{v}_{2}\right.$ overtone Fermi resonance). These peaks characterized a class of coordination, where the end oxygen atom was bound to the metal site. For MIL-101, there was only one single sharp peak at $2196 \mathrm{~cm}^{-1}$ due to $v(\mathrm{CO})$, which was explained by the difference in acidity between the two adsorbing surfaces [86]. Leclerc et al. revealed that the oxidation state of the iron metal sites on MIL-100 did not affect the $\mathrm{CO}_{2}$ uptake, nor adsorbed $\mathrm{CO}_{2}$ configuration on the surface as demonstrated by the spectra. The spectra exhibited a doublet peak at ca 2333 and $2344 \mathrm{~cm}^{-1}$, characteristic of end-on $\mathrm{CO}_{2}$ configuration [87].

\subsubsection{Resolving adsorbed overlapping carbonate/bicarbonate peaks}

The spectral region corresponding to $\mathrm{C}-\mathrm{O}$ stretching vibrations attributable to $\mathrm{CO}_{2}$ adsorption products spans from 1700 to $1200 \mathrm{~cm}^{-1}$ and very quickly becomes complex and very difficult to interpret. This is due to (a) the variety of the $\mathrm{CO}_{2}$ adsorption products (vide supra) and (b) the close overlap of the resulting peaks that are routinely used to fingerprint the particular species. 


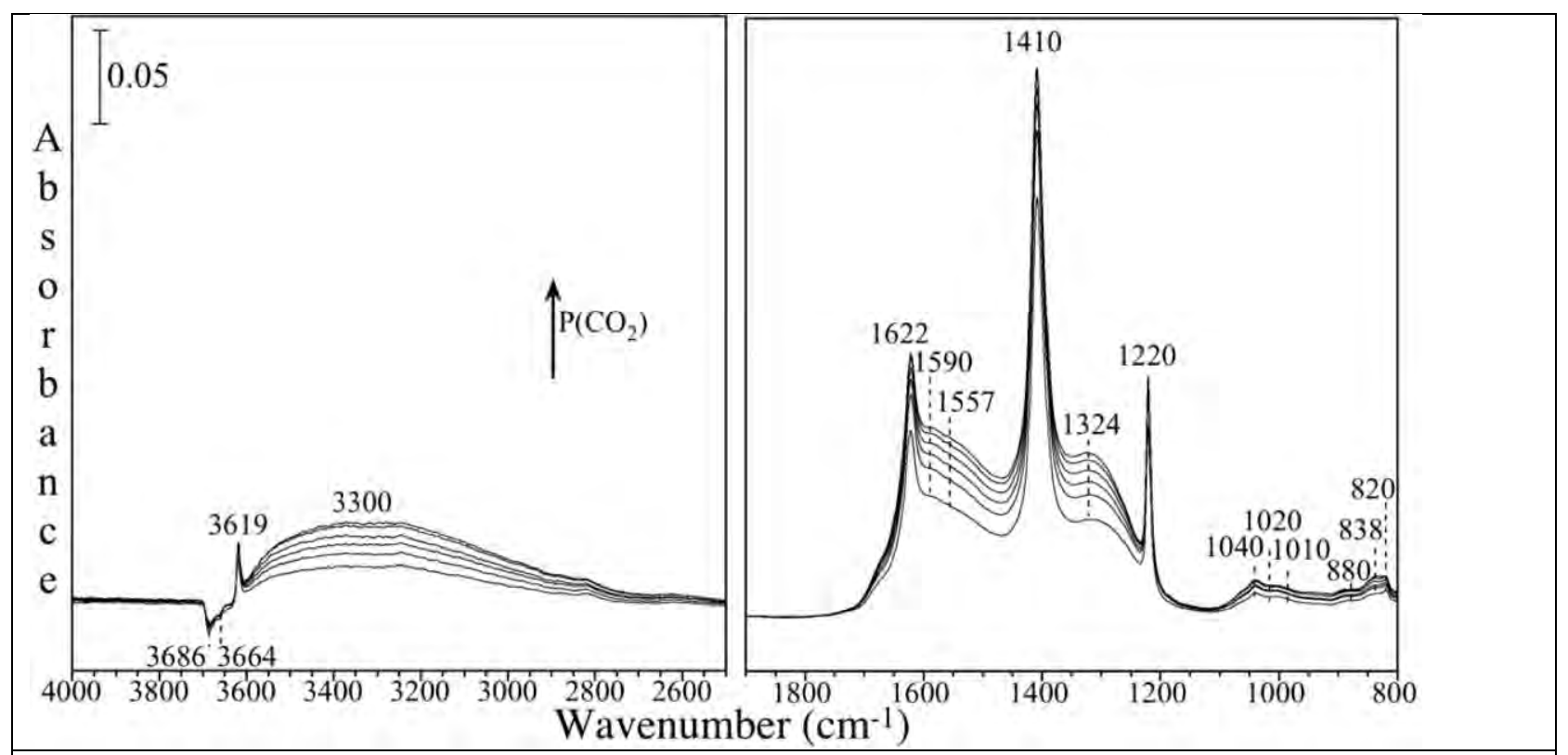

Figure 13. Transmission FTIR spectra of nanoparticulate $\mathrm{Fe}_{2} \mathrm{O}_{3}$ recorded following exposure to increasing pressures of $\mathrm{CO}_{2}(51,110,156,201,251$, and 274 mTorr). All spectra were recorded in the presence of gas-phase $\mathrm{CO}_{2}$. Reprinted with permission from [50]. Copyright (2006) American Chemical Society.

For example, $\mathrm{CO}_{2}$ adsorption on $\mathrm{Fe}_{2} \mathrm{O}_{3}$ as a function of pressure is shown in Figure 13 [50]. Intrinsically strong and sharp adsorbed bicarbonate ion vibrations at 1622,1410 and $1220 \mathrm{~cm}^{-1}$ interfere with the assignment of the broader adsorbed carbonate peaks observed in the same spectral region. The sharp peak at $3619 \mathrm{~cm}^{-1}$ is indicative of the $\mathrm{OH}$ stretching vibration in bicarbonate and coincides with the decrease of isolated 3686 and $3664 \mathrm{~cm}^{-1}$ surface hydroxyl groups. A combination of temperature programmed desorption with in situ FTIR monitoring of the adsorbed species was applied to facilitate adsorbed carbonate peak assignment. Temperature or vacuum treatment can be used interchangeably, while the resulting peaks need to be fit with synthetic components to determine the exact wavenumber value, as well as the relative population, as inferred from the corresponding area under the peak. These experiments can also provide kinetics data on the stability of certain carbonate/bicarbonate species, as shown in Figure 14. 

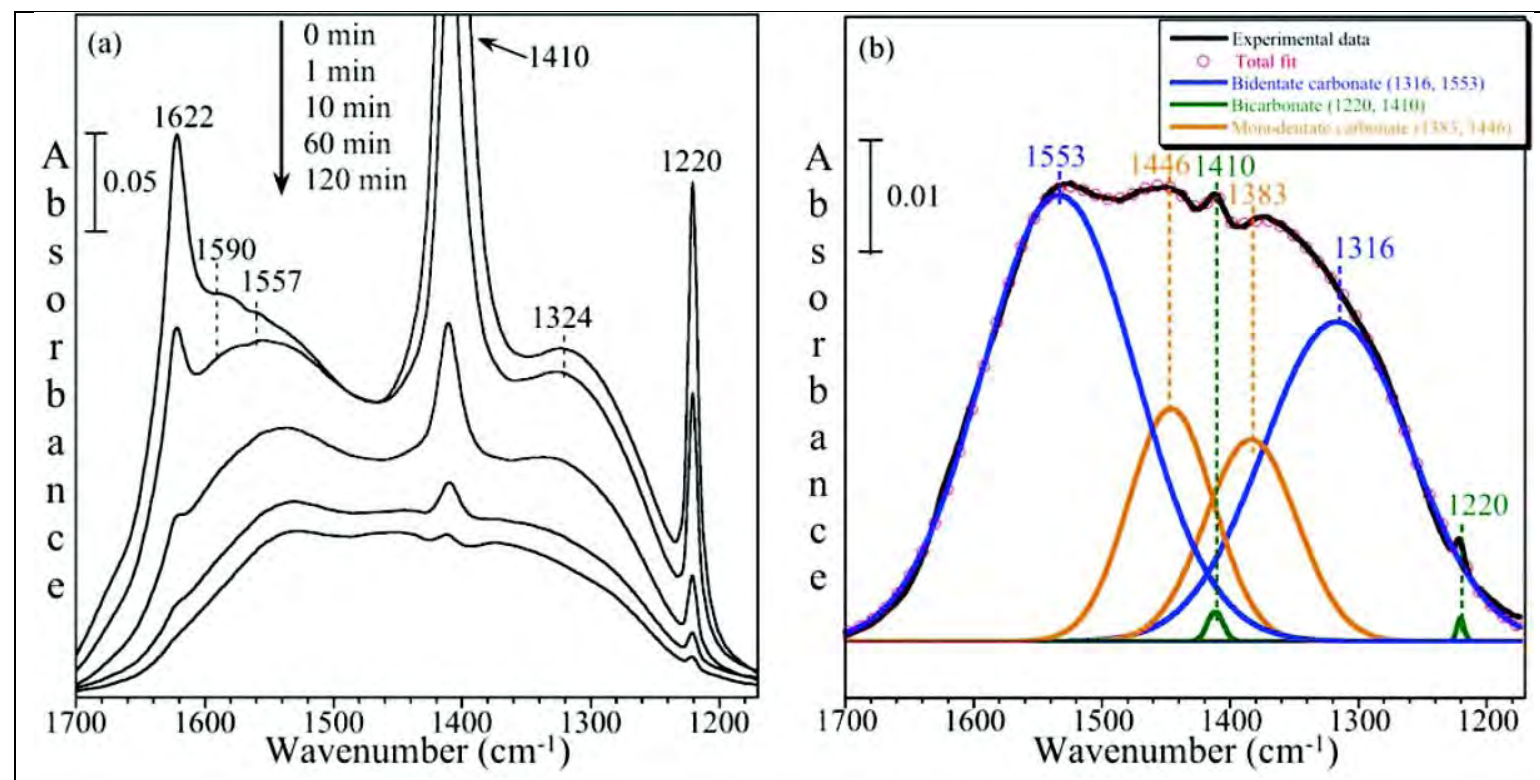

Figure 14. Transmission FTIR spectra recorded for nanoparticulate $\mathrm{Fe}_{2} \mathrm{O}_{3}$ particles following exposure to $274 \mathrm{mT}$ Torr of $\mathrm{CO}_{2}$ as a function of evacuation time from 0 to $120 \mathrm{~min}(0,1,10,60$, and $120 \mathrm{~min}$ ). (b) Gaussian curve fit for the transmission FTIR spectrum of nanoparticulate $\mathrm{Fe}_{2} \mathrm{O}_{3}$ recorded after exposure of nanoparticulate $\mathrm{Fe}_{2} \mathrm{O}_{3}$ to 274 mTorr of $\mathrm{CO}_{2}$ and then evacuated for $120 \mathrm{~min}$. The data are fit to three surface species - monodentate carbonate (1383 and 1446 $\left.\mathrm{cm}^{-1}\right)$, bidentate carbonate (1316 and $\left.1553 \mathrm{~cm}^{-1}\right)$, and bicarbonate $\left(1221\right.$ and $\left.1411 \mathrm{~cm}^{-1}\right)$. The correlation coefficient for the total fit is 0.99964. Reprinted with permission from [50]. Copyright (2006) American Chemical Society.

A very new approach, recently used to accurately interpret XPS data that is routinely comprised

of overlapping peaks in the spectra, was model spectral envelopes created using vector based analysis, thus avoiding synthetic spectral components [88]. Titled informed amorphous sample model (IASM), it was created and implemented into Casa XPS analysis software [89]. The the concept is however published in a public domain. It creates spectral components by incorporating key information of the sample obtained experimentally. It was tested on the particularly challenging case of elucidating molybdenum oxide oxidation states in the presence of X-ray exposure and resulted in (1) complex shapes for the Mo (VI) and Mo (V) spectral component, accounted for without the need to identify synthetic line shapes and (2) spectral forms introduced as a shape constraint into the model, which guided further introduction of synthetic line shapes necessary to complete data reproduction by the model. Casa XPS is easily 
interfaced with FTIR and Raman data and changes in the adsorbed carbonate/bicarbonate envelope as a function of sample temperature, gas partial pressure, and evacuation time can possibly be used so as to utilize IASM to interpret and assign complex overlapping peaks.

\subsubsection{Computational methods to aid IR peak assignments.}

Another method to assign peaks from the complex $\mathrm{CO}_{2}$ adsorption systems is by using DFT calculations. DFT can calculate every single vibrational frequency that might appear on the spectra. For instance, monodentate and bidentate carbonate species on different defect sites on $\mathrm{MgO}$ can be discriminated using this method [90]. This is particularly useful for assigning peaks due to several surface species present simultaneously on the surface (as typically exhibited by the overlapping peaks that need accurate interpretation via peak fitting), even determining at which sites these molecules are adsorbed. However, just like any other assignment method, DFT has its own drawback. Vibrational energy levels calculated using DFT and harmonic approximation will exhibit a parabolic curve. Hence, a correction/scaling factor is needed. Determining the scaling factor itself requires some work and one should apply the same method of computation used on a model compound for which the IR peaks are sophisticatedly characterized. While generic scaling factors are available for the specific functional and basis set used [91], the approach of calculating factors for a specific molecule from the calculated values and the gas phase fundamental vibrational frequencies is preferred [50]. In this procedure, experimental vibrational frequencies $\left(v_{\mathrm{i}}\right)$ and the calculated vibrational frequencies $\left(\omega_{\mathrm{i}}\right)$ were used to determine the scaling factor $\mathrm{c}$ according to this equation:

$c=\sum\left(v_{i} \omega_{i}\right) / \sum\left(\omega_{i}^{2}\right)$

The calculated scaling factor $\mathrm{c}$ for the gas phase bicarbonate ion was 0.9506 , different from 0.9613 by Wong [92], which was averaged over many compounds at B3LYP/6-31+G(d) level of 
theory. Figure 15 summarizes the pros and cons of employing the two different methods. These are organometallic model compound and DFT, intended to assign measured vibrational frequencies.

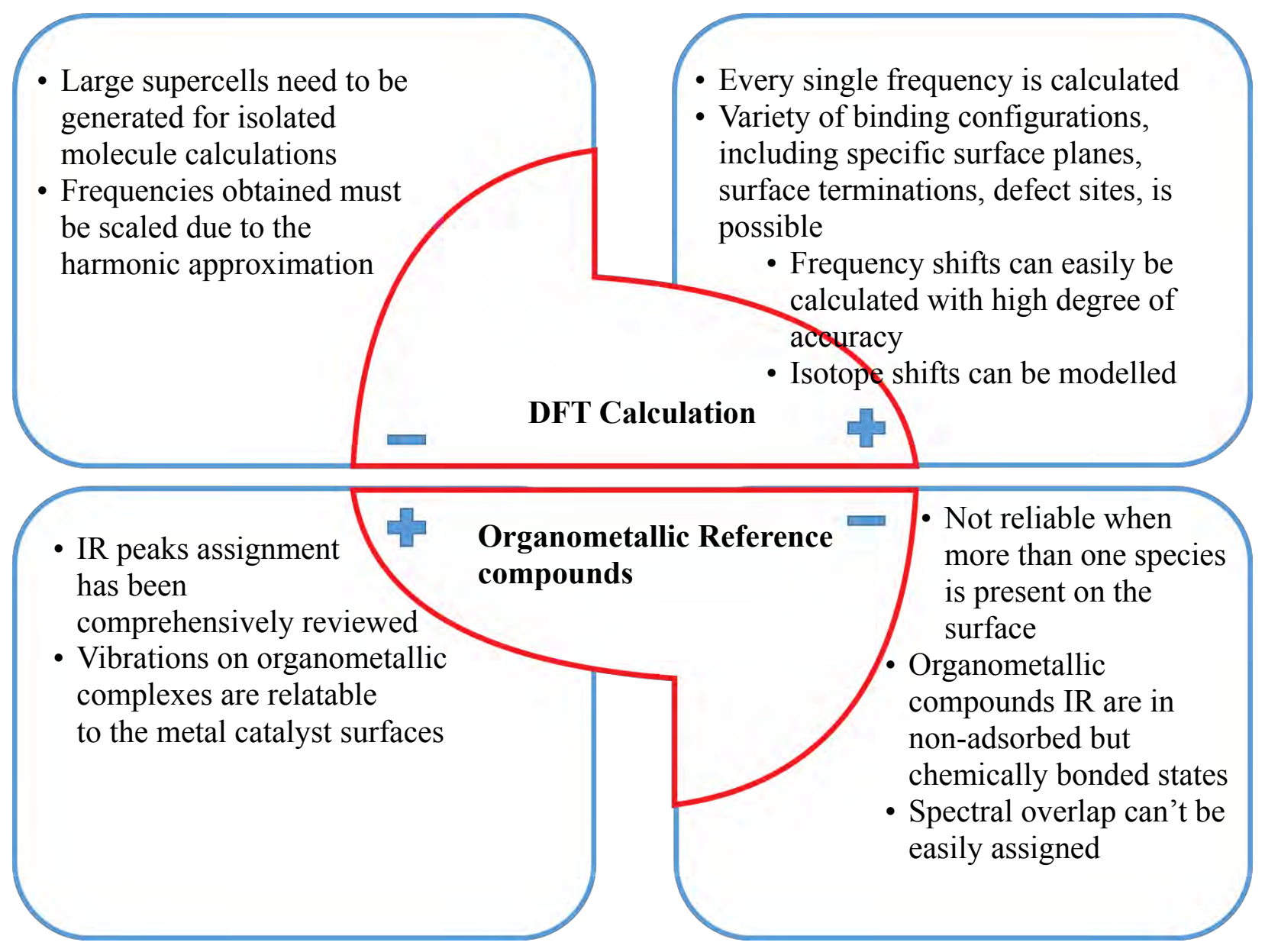

Figure 15. Pros and cons of the two major methods currently used in vibrational frequency assignment of adsorbed $\mathrm{CO}_{2}$ products.

DFT based adsorbed $\mathrm{CO}_{2}$ product peak assignments are relatively new and there are not a lot of publications, as in organometallics. However, several investigators have done work sufficient to give reference for others to assign peaks in the IR spectra, with or without scaling factors [50,90,93-98]. Tables 9 and 10 summarize the assignments of carbonate and bicarbonate IR peaks predicted by DFT calculation on various metal oxide surfaces. 
Table 9. Adsorbed carbonate vibrational frequencies on various metal oxide surfaces as calculated by DFT

\begin{tabular}{|c|c|c|c|c|c|c|c|c|c|}
\hline \multirow{2}{*}{ Oxide } & \multicolumn{6}{|c|}{ Type } & \multirow{2}{*}{$\begin{array}{c}\text { Computational } \\
\text { Details }\end{array}$} & \multirow{2}{*}{$\begin{array}{l}\text { Scaling } \\
\text { factor }\end{array}$} & \multirow{2}{*}{ Ref } \\
\hline & I & II & III & IV-V & VI-XIII & Mode & & & \\
\hline \multirow{4}{*}{$\mathrm{MgO}$} & & $\begin{array}{l}1703 ; 1440^{d} \\
(1520 / 1550 ; \\
1506 ; 1526)\end{array}$ & $\begin{array}{l}1778 ; 1730-1650^{\mathrm{d}} \\
(1655 / 1670 / 1660 ; 1673 ; \\
1778)\end{array}$ & - & $\begin{array}{l}1650- \\
1600^{\mathrm{d}} \\
1560^{\mathrm{d}}\end{array}$ & $v_{3}$ as & \multirow{8}{*}{$\begin{array}{l}\text { B3LYP, } \\
\text { Gaussian 03; 6- } \\
311+\mathrm{G}(\mathrm{d}) \text { and 6- } \\
31 \mathrm{G} / 6-31 \mathrm{G}(\mathrm{d}) \\
\text { PW91, VASP; } \\
\text { PAW-generated } \\
\text { pseudopotential }^{\mathrm{d}}\end{array}$} & \multirow{8}{*}{$\mathrm{n} / \mathrm{a}$} & \multirow{8}{*}[90,94]{} \\
\hline & $(1410)$ & $\begin{array}{l}1327 ; 1378^{d} \\
(1390 / 1410 \\
1415-1418)\end{array}$ & $\begin{array}{l}1243 ; 1200-1125^{\mathrm{d}} \\
(1325 / 1320 / 1307 / 1315 / 1330 ; \\
1361 ; 1243)\end{array}$ & - & $\begin{array}{l}1451 \\
1300- \\
1280^{\mathrm{d}} \\
1330^{\mathrm{d}}\end{array}$ & $v_{3} \mathrm{~s}$ & & & \\
\hline & & $\begin{array}{l}1011(1050 \\
1067-1072)\end{array}$ & $932(1005 / 1000 ; 1091)$ & - & 1084 & $v_{1}$ & & & \\
\hline & & $849(860)$ & $847(850 ; 847)$ & - & 906 & $v_{2}$ & & & \\
\hline \multirow{4}{*}{$\mathrm{CaO}^{\mathrm{a}}$} & $\begin{array}{l}(1520- \\
1490)\end{array}$ & $\begin{array}{l}1664 / 1603 \\
(1635- \\
1550 ; 1603) \\
\end{array}$ & 1703 & $(1781 / 1776)$ & 1461 & $v_{3}$ as & & & \\
\hline & $(1415)$ & $\begin{array}{l}1316 / 1314 \\
(1308- \\
1302 ; 1314) \\
\end{array}$ & 1257 & & 1423 & $v_{3} \mathrm{~s}$ & & & \\
\hline & $(1060)$ & $968 / 1035$ & 944 & & 1080 & $v_{1}$ & & & \\
\hline & $(860)$ & $845 / 876$ & 845 & & 881 & $v_{2}$ & & & \\
\hline \multirow[b]{2}{*}{$\mathrm{Ga}_{2} \mathrm{O}_{3}{ }^{\mathrm{b}}$} & - & - & $1775-1755 / 1655(1587)$ & $(1680)$ & $(1460)$ & $v_{3}$ as & \multirow[b]{2}{*}{$\begin{array}{l}\text { PBE, VASP; } \\
\text { PAW-generated } \\
\text { pseudopotential }\end{array}$} & \multirow[b]{2}{*}{$\mathrm{n} / \mathrm{a}$} & \multirow[b]{2}{*}{ [93] } \\
\hline & - & - & $1292-1203 / 1233(1325)$ & $(1280)$ & $(1406)$ & $v_{3} \mathrm{~s}$ & & & \\
\hline \multirow{4}{*}{$\begin{array}{l}\mathrm{ZnO} \\
(0001)\end{array}$} & $(1430)$ & $\begin{array}{l}(1543- \\
1520)\end{array}$ & 1713 & $\begin{array}{l}(1665-1580 ; \\
1621)\end{array}$ & $(1466)$ & $v_{3}$ as & \multirow{4}{*}{$\begin{array}{l}\text { First principle, } \\
\text { VASP; PAW- } \\
\text { generated } \\
\text { pseudopotential }\end{array}$} & \multirow{4}{*}{$\mathrm{n} / \mathrm{a}$} & \multirow{4}{*}[95]{} \\
\hline & & $\begin{array}{l}(1323- \\
1313) \\
\end{array}$ & 1281 & $\begin{array}{l}(1348-1303 ; \\
1292)\end{array}$ & $(1386)$ & $v_{3} \mathrm{~s}$ & & & \\
\hline & & & & $(1007-999)$ & & $v_{1}$ & & & \\
\hline & & & & $(852-841)$ & & $v_{2}$ & & & \\
\hline
\end{tabular}




\begin{tabular}{|c|c|c|c|c|c|c|c|c|c|}
\hline & & & & $(680-677)$ & & $v_{4}$ & & & \\
\hline \multirow{2}{*}{$\begin{array}{l}\mathrm{CeO}_{2} \\
(331)\end{array}$} & - & - & - & 1759 & - & $v_{3}$ as & & & \\
\hline & - & - & - & 1183 & - & $v_{3} \mathrm{~s}$ & & & \\
\hline \multirow{2}{*}{$\begin{array}{l}\mathrm{ZnO} / \\
\mathrm{CeO}_{2} \\
(111)\end{array}$} & 1556 & - & - & - & - & $v_{3}$ as & & & \\
\hline & 1428 & - & - & - & - & $v_{3} \mathrm{~s}$ & & & \\
\hline \multirow{4}{*}{$\begin{array}{l}\mathrm{TiO}_{2} \\
\text { anatase }\end{array}$} & & $\begin{array}{l}1584 \\
(1590- \\
1575) \\
\end{array}$ & $1802(1580 / 1670 ; 1589)$ & & & $v_{3}$ as & \multirow{4}{*}{$\begin{array}{l}\text { PBE0, } \\
\text { CRYSTAL09; } \\
\text { TZ-P/ Hay-Wadt } \\
\text { pseudopotential }\end{array}$} & \multirow{4}{*}{0.9525} & \multirow{4}{*}{ [96] } \\
\hline & & $\begin{array}{l}1378 \\
(1370- \\
1320 ; 1377) \\
\end{array}$ & $\begin{array}{l}1125 / 1105 \quad(1320 / 1243 ; \\
1315)\end{array}$ & & & $v_{3} \mathrm{~s}$ & & & \\
\hline & & 1058 & $(1055)$ & & & $v_{1}$ & & & \\
\hline & & 663 & 610 & & & $v_{2}$ & & & \\
\hline
\end{tabular}

${ }^{\mathrm{a}}$ monodentate values represent adsorption on (edge/corner) sites

${ }^{\mathrm{b}}$ represents vibrational modes on different hydrated surface schemes

${ }^{c}$ values in brackets represent experimental values for comparison

d two calculation results for $\mathrm{MgO}$ case

Table 10. Adsorbed bicarbonate vibrational frequencies on various metal oxide surfaces as calculated by DFT

\begin{tabular}{|c|c|c|c|c|c|c|c|}
\hline \multirow{2}{*}{ Oxide } & \multicolumn{3}{|c|}{ Types } & \multirow{2}{*}{ Modes } & \multirow[b]{2}{*}{ Computational details } & \multirow{2}{*}{$\begin{array}{l}\text { Scaling } \\
\text { factor }\end{array}$} & \multirow{2}{*}{ Ref } \\
\hline & Monodentate (II) & Bidentate (III) & Bridged (IV) & & & & \\
\hline \multirow{6}{*}{$\begin{array}{l}\text { Hydroxylated } \\
\mathrm{Fe}_{2} \mathrm{O}_{3}\end{array}$} & & $3619(3620)$ & & $v_{5}$ & \multirow{8}{*}{$\begin{array}{l}\text { B3LYP, Spartan '04, } \\
6-31+G(d)\end{array}$} & \multirow{8}{*}{0.9506} & \multirow{8}{*}[50]{} \\
\hline & & $1622(1629)$ & & $v_{3}$ as & & & \\
\hline & & $1410(1410)$ & & $v_{3} \mathrm{~s}$ & & & \\
\hline & & $1220(1220,1222)$ & & $\delta_{4}$ & & & \\
\hline & & $(1010)$ & & & & & \\
\hline & & & & $v_{1}$ & & & \\
\hline \multirow{2}{*}{$\begin{array}{l}\text { Hydroxylated } \\
\alpha-\mathrm{Al}_{2} \mathrm{O}_{3}\end{array}$} & & $3623(3620)$ & & $v_{5}$ & & & \\
\hline & $(1620)$ & $1648(1650)$ & & $v_{3}$ as & & & \\
\hline
\end{tabular}




\begin{tabular}{|c|c|c|c|c|c|c|c|}
\hline & $(1450)$ & $1438(1435 ; 1436)$ & & $v_{3} \mathrm{~s}$ & & & \\
\hline & (1230) & $1231(1228 ; 1225)$ & & $\delta_{4}$ & & & \\
\hline \multirow{3}{*}{$\mathrm{Ga}_{2} \mathrm{O}_{3}$} & $1619 ; 1630$ & $1595-1586 / 1591$ & & $v_{3}$ as & \multirow{3}{*}{$\begin{array}{l}\text { PBE, VASP; PAW-generated } \\
\text { pseudopotential }\end{array}$} & \multirow{3}{*}{$\mathrm{n} / \mathrm{a}$} & \multirow{3}{*}{ [93] } \\
\hline & $1456 ; 1463$ & $\begin{array}{l}\text { 1421-1448/1417 } \\
(1431 ; 1432)\end{array}$ & & $v_{3} s$ & & & \\
\hline & 1231 & $(1229)$ & & $\delta_{4}$ & & & \\
\hline \multirow{4}{*}{$\begin{array}{l}\text { Defective } \\
\text { rutile } \quad 110 \\
\mathrm{TiO}_{2}\end{array}$} & & 1804 & & $v_{3}$ as & \multirow{4}{*}{$\begin{array}{l}\text { PBE-TS, VASP; PAW-generated } \\
\text { pseudopotential }\end{array}$} & \multirow{4}{*}{$\mathrm{n} / \mathrm{a}$} & \multirow{4}{*}{ [97] } \\
\hline & & 1240 & & $\delta_{4}$ & & & \\
\hline & & 1103 & & $v_{1}$ & & & \\
\hline & & 873 & & $v_{2}$ & & & \\
\hline \multirow{4}{*}{$\mathrm{In}_{2} \mathrm{O}_{3}$} & & 3677 & 3653 & $v_{5}$ & \multirow{4}{*}{$\begin{array}{l}\text { PBE, VASP; PAW-generated } \\
\text { pseudopotential }\end{array}$} & \multirow{4}{*}{$\mathrm{n} / \mathrm{a}$} & \multirow{4}{*}{ [98] } \\
\hline & & 1541 & 1592 & $v_{3}$ as & & & \\
\hline & & 1460 & 1421 & $v_{3} s$ & & & \\
\hline & & 1177 & 1179 & $\delta_{4}$ & & & \\
\hline \multirow{5}{*}{$\mathrm{TiO}_{2}$ anatase } & 1656 & 1613 & $1625 ; 1574$ & $v_{3}$ as & \multirow{5}{*}{$\begin{array}{l}\text { PBE0, CRYSTAL09; TZ-P/ Hay- } \\
\text { Wadt pseudopotential }\end{array}$} & \multirow{5}{*}{0.9525} & \multirow{5}{*}{ [96] } \\
\hline & $1432(1434)$ & 1505 & $1497-1426$ & $v_{3} \mathrm{~s}$ & & & \\
\hline & $1052(1222)$ & 1048 & 1117-1063 & $v_{1}$ & & & \\
\hline & 664 & 713 & $670-645$ & $v_{2}$ & & & \\
\hline & 1207 & 1193 & $1230-1212$ & $\delta_{4}$ & & & \\
\hline
\end{tabular}

${ }^{\mathrm{c}}$ values in brackets represent experimental values for comparison 
As mentioned earlier, FTIR spectroscopy is an important method for characterizing surface species resulting from $\mathrm{CO}_{2}$ capture over various substrates, metal oxides in particular. Tables 610 summarize assignments of prior IR experiments concerning $\mathrm{CO}_{2}$ adsorption on metal oxides. The assignments made are mostly based on model adsorbing surfaces, such as $\mathrm{MgO}$, organometallic reference compounds, and DFT calculation.

\subsubsection{Instrumental designs to monitor $\mathrm{CO}_{2}$ adsorption and uptake}

Experimental detection of $\mathrm{CO}_{2}$ binding at solid surfaces under ambient atmospheric conditions is essential for assessing environmentally-relevant processes. It should be emphasized that the interfacial chemistry of solids equilibrated to ambient $\mathrm{pO}_{2}$ levels is dominated by (hydr)oxo terminations that can participate in $\mathrm{CO}_{2}$ binding in a variety of mechanisms, from weak van der Waals binding, to direct ligand exchange as well as nucleophilic attack. Analytical determinations of $\mathrm{CO}_{2}$ binding are challenged by the ready exchanges between the solid surface and the gas phase of the solid/gas interface or at the headspace of aqueous suspensions of solids. As such, in situ monitoring of $\mathrm{CO}_{2}$ binding is key for the determination loadings achieved at solid surfaces. Classical methods based on loss of total $\mathrm{pCO}_{2}$ in a reaction chamber (e.g. pressure, gas chromatography, infrared) require highly reactive solids and/or high specific surface area and/or large amounts of materials [99]. The Dynamic Vapor Sorption method [100], which was originally developed for water vapor binding, has extended to $\mathrm{CO}_{2}$ binding [101103]. This technique makes use of high precision balances to monitor mass changes [45]. Methods using on ultra-microbalances take samples on the order of mg and those using the Quartz Crystal Microbalance, on the order of a few $\mu \mathrm{g}$. The latter has a greater sensitivity in the

sense that it detects mass changes at the nanogram level, yet it requires a more thorough 
preparation of sufficiently viscous (non-rigid) thin solid films on Au-coated quartz electrodes. Congruent serial and parallel resonant frequencies should be achieved throughout the course of an experiment in order to be successful.

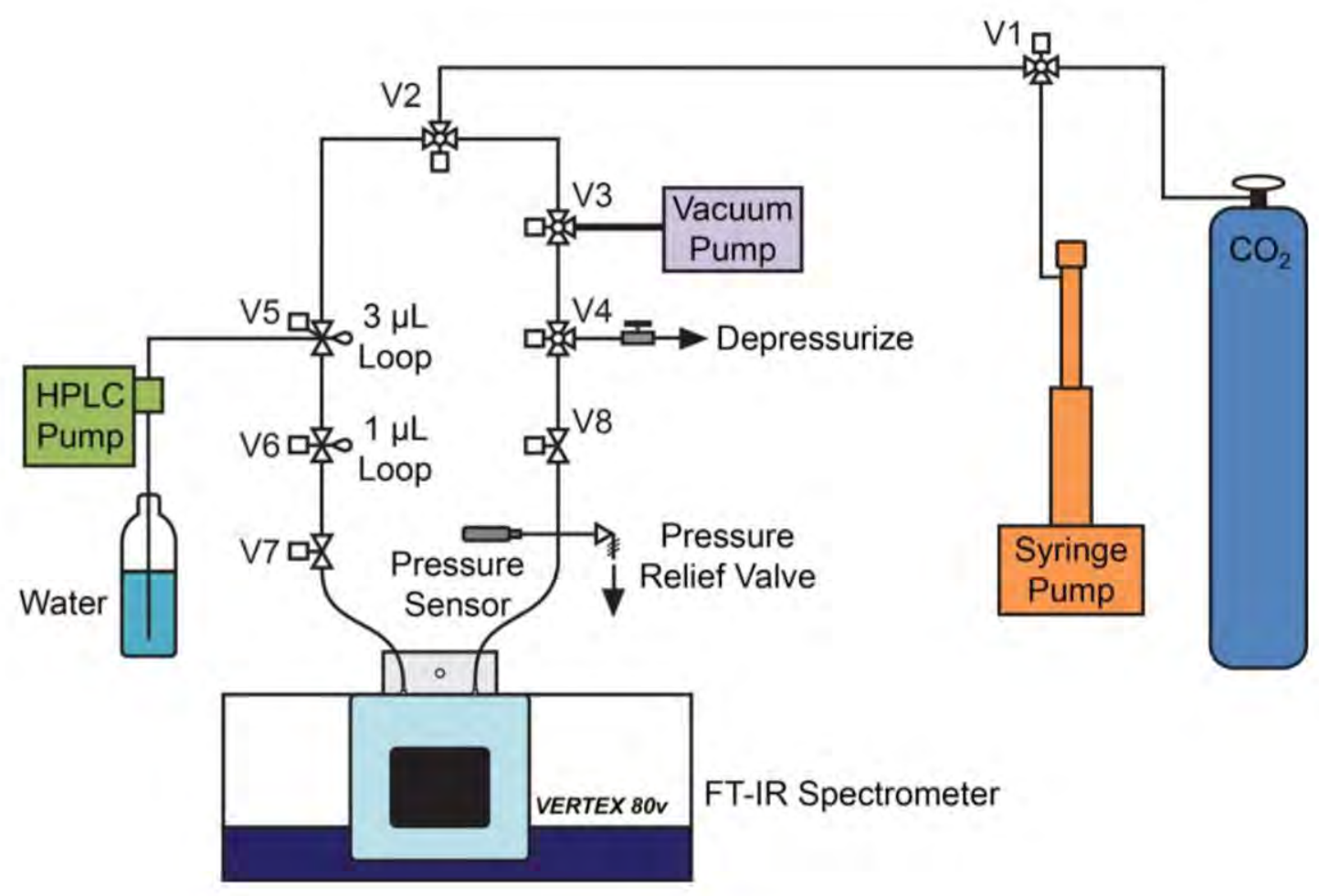

Figure 16. System for $\mathrm{scCO}_{2}$ delivery to optical chamber for in situ monitoring by vibration spectroscopy based on a high pressure fluid delivery system. Reprinted with permission from [104]. Copyright (2014), AIP Publishing LLC.

Measurements at the solid/water interface have greater limitations because of the strong absorbance of water. Many studies have thus employed the ATR-FTIR technique to attenuate these contributions, then proceed with careful spectral subtraction of the contributions of the bending mode of water at $\sim 1630 \mathrm{~cm}^{-1}$. Work with $\mathrm{D}_{2} \mathrm{O}$ provides advantages on this front, as for example in the case of carbonate binding to hematite in the study of Bargar et al. [105]. 
Characterization of $\mathrm{CO}_{2}$ adsorption in aqueous suspensions of solids also requires monitoring the gas phase as a proxy of the soluble carbonate concentrations via the relationship $\mathrm{CO}_{2}(\mathrm{~g})+\mathrm{H}_{2} \mathrm{O}$ $\rightarrow \mathrm{CO}_{2} \cdot \mathrm{H}_{2} \mathrm{O}(\mathrm{aq})\left(\right.$ e.g. $\mathrm{K}=3.4 \times 10^{-2} \mathrm{M} \cdot \mathrm{atm}^{-1}$ at $\left.298.15 \mathrm{~K}\right)$. Closed reaction vessels, such as in the one shown in Figure 17, enable adsorption experiments to be carried out, not only in a closed system but also in open systems by enabling addition of $\mathrm{CO}_{2}$ to maintain a given partial pressure $[106,107]$. Head space $\mathrm{CO}_{2}$ levels in the reaction vessels can be monitored using an infrared detector [106] or a cavity ring down spectrometer [108], provided the analytical instruments are absolutely air-tight.

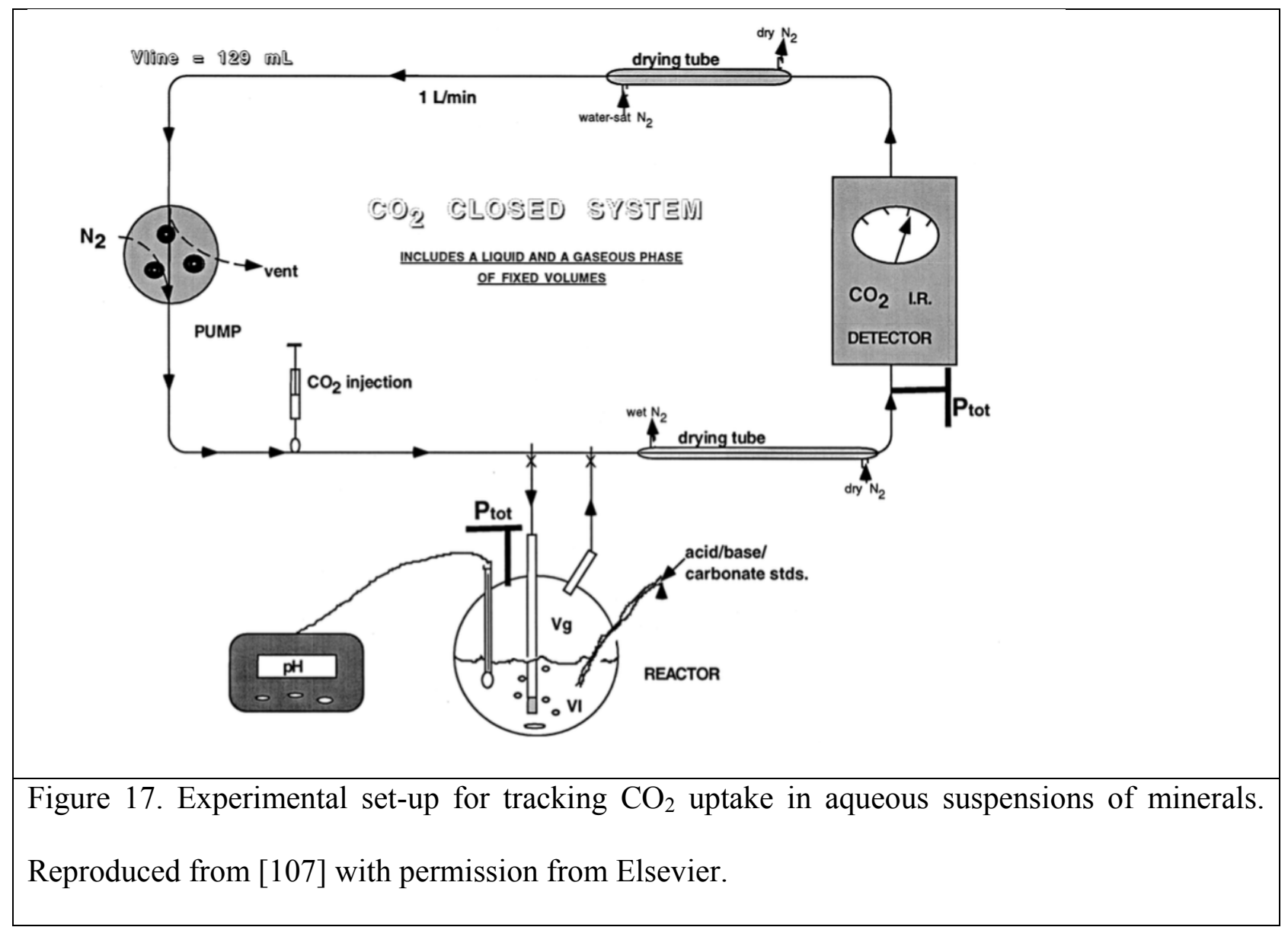

Molecular-scale resolution of $\mathrm{CO}_{2}$ species at the solid/atmosphere and solid/water interface has still relied predominantly on vibration spectroscopy. By probing the C-O stretching region of the linear (or bent) $\mathrm{CO}_{2}$ molecules and of the often-resulting carbonate species, the technique 
provides insightful details into the modes of interactions with a solid surface. This approach was very recently extended to supercritical liquids, such as $\mathrm{H}_{2} \mathrm{O}$ and $\mathrm{CO}_{2}\left(\mathrm{sCO}_{2}\right)$, both of importance as sustainable solvents. The inherent need for high pressures to attain the supercritical state were circumvented using an attenuated total reflection (ATR) cell as shown in Figure 18 [109]. This cell is based on the commercially available Golden Gate High Pressure ATR accessory from Specac Ltd. It was modified to include an ATR crystal, syringe pump, preheater system, measuring chamber and capillary restrictor. The apparatus can operate at a maximum working temperature of $350{ }^{\circ} \mathrm{C}$ and mixtures can be interrogated up to a pressure of $24 \mathrm{MPa}$.

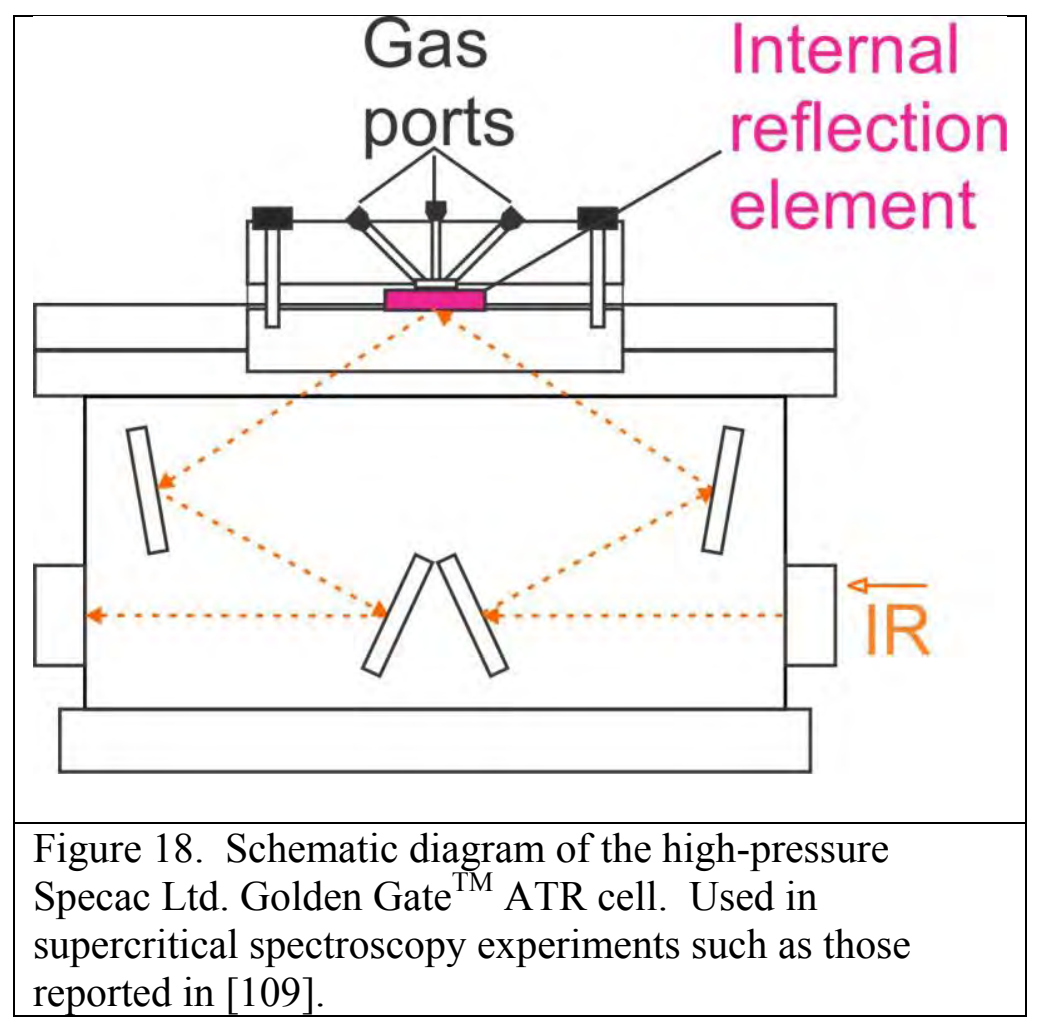

In this work phase transitions of alcohols (ethanol and methanol) were monitored owing to the fact that a condensing liquid has a much more intense IR absorption detected by the ATR crystal than a gas phase molecule. While the ATR crystal itself was used as the adsorbent, thin films or slurries of catalyst can potentially be utilized in this setup to extend the analysis beyond monitoring phase change. 


\section{Surface reactions of $\mathrm{CO}_{2}$}

\subsection{Bonding at metal surfaces}

\subsubsection{UHV}

Adsorption of $\mathrm{CO}_{2}$ on metal surfaces is widely acknowledged to result in two states of adsorbed species: a linear, inert $\mathrm{CO}_{2}$ and a bent, anionic $\mathrm{CO}_{2}$, widely recognized as a precursor to $\mathrm{CO}$ and $\mathrm{O}$ adatoms [110]. A key step for the reaction of $\mathrm{CO}_{2}$ with hydrogen on $\mathrm{Ni}(110)$ is a change in the activated molecule coordination to the metal surface [111]. At $90 \mathrm{~K}, \mathrm{CO}_{2}$ is negatively charged and chemically bonded via the carbon atom [111]. When the temperature is increased and $\mathrm{H}$ approaches, the $\mathrm{H}-\mathrm{CO}_{2}$ complex flips and binds to the surface through the two oxygen atoms, while $\mathrm{H}$ binds to the carbon atom, thus yielding formate. On a clean Ni (100) surface at $130 \mathrm{~K}$, however, no chemical activity takes place; neither physisorbed nor chemisorbed $\mathrm{CO}_{2}$ is observed [112].

Copper catalyst surfaces, when in interaction with $\mathrm{CO}_{2}$, are of paramount importance in catalysis. Polycrystalline copper foil exhibits chemisorption, yielding adsorbed carbonate, bent $\mathrm{CO}_{2}$, and even $\mathrm{C}^{0}[37]$. On clean $\mathrm{Cu}$, XPS revealed that adsorption under 0.1 Torr $\mathrm{CO}_{2}$ results in the formation of carbonate species, chemisorbed $\mathrm{CO}_{2}{ }^{-}$, and $\mathrm{C}^{0}$. The $\mathrm{C} 1 \mathrm{~s}$ peak at $289.3 \mathrm{eV}$ and $\mathrm{O}$ 1s peak at $531.9 \mathrm{eV}$ were assigned to a carbonate species; the $\mathrm{C} 1 \mathrm{~s}$ peak at $288.4 \mathrm{eV}$ and $\mathrm{O} 1 \mathrm{~s}$ peak at $531.4 \mathrm{eV}$ to chemisorbed, negatively charged $\mathrm{CO}_{2}\left(\mathrm{CO}_{2}{ }^{-}\right)$and the $\mathrm{C} 1 \mathrm{~s}$ peak at $284.4 \mathrm{eV}$ to a $\mathrm{C}^{0}$ species. Co-adsorption with $\mathrm{Zn}$, however, leads to complete conversion of all $\mathrm{CO}_{2}$ to carbonate. A comparative study between $\mathrm{Cu}$ (110) and stepped $\mathrm{Cu}$ (311) using AES and temperature desorption spectroscopy (TDS) was conducted by Fu and Somorjai [113]. While the former does not exhibit adsorption of $\mathrm{CO}_{2}$, dissociative adsorption readily takes place on the 
latter, proven by the TDS spectra. The $\mathrm{H}_{2}{ }^{18} \mathrm{O}$ is formed due to reaction between labeled $\mathrm{C}^{18} \mathrm{O}_{2}$ and background $\mathrm{H}_{2}$, which is the reverse water-gas shift reaction [113]. The TDS spectra obtained from this experiment is shown in Figure 19. These phenomena substantiate increased reactivity of metal surface planes of higher indices (lower stability) that can be prepared and stabilized under vacuum.

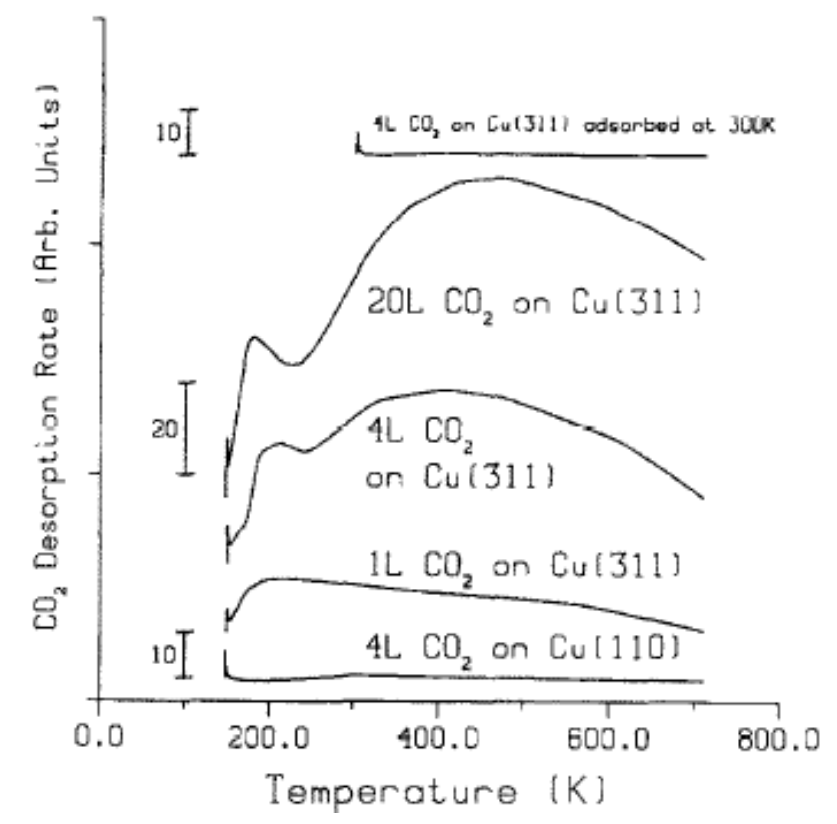

Figure 19. $\mathrm{CO}_{2}$ desorption from $\mathrm{Cu}(311)$ and $\mathrm{Cu}$ (110). Reprinted with permission from Elsevier [113].

On $\mathrm{Cu}$ (332), $\mathrm{CO}_{2}$ is also found to adsorb by dissociation as $\mathrm{CO}$ and $\mathrm{O}$ surface species, confirmed by TDS and UPS [114]. The three main desorption states deduced from the experiment are at $110 \mathrm{~K}, 130 \mathrm{~K}$, and $376 \mathrm{~K}$, while UPS confirmed the presence of adsorbed oxygen with peaks at $6.1 \mathrm{eV}$ and $9.6 \mathrm{eV}$, corresponding to $\pi_{\mathrm{g}}{ }^{*}$ and $\pi_{\mathrm{u}}$ orbitals, respectively [114]. Different $\mathrm{Cu}$ surface preparation methods apparently alter the reactivity of the surface itself, most likely due to the complex surface terminations present. Surface-enhanced Raman spectroscopy (SERS) spectra show $\mathrm{CO} 2$ adsorption on a $\mathrm{Cu}$ surface. This surface is prepared 
using a cold deposition method and exhibited peaks associated with bent anionic $\mathrm{CO}_{2}$, at 767 and $1182 \mathrm{~cm}^{-1}$ corresponding to $\delta(\mathrm{OCO})$ and the symmetric stretch mode $v_{\mathrm{s}}(\mathrm{OCO})$ [115]. At higher coverage, presumably after the surface is saturated with $\mathrm{CO}$, neutral $\mathrm{CO}_{2}$ peaks intensify, as characterized by peaks at 1261,1361 , and $2292 \mathrm{~cm}^{-1}$ assigned to $v_{\mathrm{s}}(\mathrm{OCO}), 2 \delta(\mathrm{OCO})$, and $v_{\mathrm{a}}$ (OCO) modes.

Cesium, an alkali metal, has been investigated as a dopant for carbon capture sorbents, especially $\mathrm{Cu}[116,117]$. Adsorption of $\mathrm{CO}_{2}$ at $80 \mathrm{~K}$ on the surface followed by heating up to $110 \mathrm{~K}$ was monitored using PES and valence electron energy-loss spectroscopy (VEELS). PE spectra showed two distinct peaks in $\mathrm{O} 1 \mathrm{~s}$ spectra, a broad peak at $532 \mathrm{eV}$ and a much weaker one at 536 $\mathrm{eV}$, with the latter corresponding to physisorbed $\mathrm{CO}_{2}$. In the VEEL spectra, losses were found at $295,660,1460,1660$, and a weaker feature at $1975 \mathrm{~cm}^{-1}$. Assignment of the peaks was as follows: a peak at $660 \mathrm{~cm}^{-1}$ was assigned to $\delta_{2}(\mathrm{OCO})$ of $\mathrm{CO}_{2}$, while peaks at 1460 and $1660 \mathrm{~cm}^{-1}$ were symmetric and asymmetric vibrational modes of ionic $\mathrm{CO}_{2}{ }^{\delta-}$. Binding energy at $532 \mathrm{eV}$ was assigned to bent ionic $\mathrm{CO}_{2}$. Peaks at 295 and $1975 \mathrm{~cm}^{-1}$ were associated with gaseous and surface CO, respectively, at a very low concentration. Surface carbonate was formed upon heating the system to $298 \mathrm{~K}$ as peaks at $1510\left(v_{3}\right), 1060\left(v_{1}\right), 700\left(v_{4}\right)$ and $350 \mathrm{~cm}^{-1}(\mathrm{v}(\mathrm{Cu}-\mathrm{O}))$ increased, while the PE spectra exhibited a peak at $531 \mathrm{eV}$ [116]. On a Cs-doped $\mathrm{Cu}$ (110) surface, photoelectron spectra revealed the formation of carbonates even after heating up to 350 $\mathrm{K}$, evident from the peaks at 5.54, 9.58 and $12.02 \mathrm{eV}$ corresponding to $\mathrm{CO}_{3}{ }^{-}$orbitals [117]. A physisorbed molecule was also detected from a peak found at $15 \mathrm{eV}$, while a bent $\mathrm{CO}_{2}$ molecule was represented by the peak at $6.9 \mathrm{eV}$.

The effect of $\mathrm{K}$ promotion on cold deposited $\mathrm{Cu}$ film, $\mathrm{Cu}(110), \mathrm{Cu}(115)$ and $\mathrm{Cu}(100)$ changed the reactivity of the supposedly inert surface $[115,118-121]$. The K-doped, cold deposited $\mathrm{Cu}$ 
film demonstrated the formation of $\mathrm{CO}$ and carbonates, in addition to the other species existing on the surface of its clean counterpart. On this surface, bending mode and symmetric vibration of the bent $\mathrm{CO}_{2}$ exhibited peaks at 754 and $1197 \mathrm{~cm}^{-1}$, while those of the physisorbed $\mathrm{CO}_{2}$ molecule were detected at 640 and $1372 \mathrm{~cm}^{-1}$, respectively [115]. The reactivity of alkali metals towards $\mathrm{CO}_{2}$ resulted in the peaks detected at $280,368,2055 \mathrm{~cm}^{-1}$, characteristics of liberation and frustrated translation, as well as stretching modes of carbon monoxide. Those at 1337 and 1424 $\mathrm{cm}^{-1}$ were assigned to $v_{3} \mathrm{~s}$ and $v_{3}$ as of monodentate carbonate. At higher temperatures, changes in the surface speciation took place with peaks associated with carbonates intensifying above 200K. The only species present were bent anionic $\mathrm{CO}_{2}$ and carbonates [115]. Photoelectron spectra confirmed the appearance of peaks at 287.4 and $290.4 \mathrm{eV}$ in C 1s spectra for K-doped $\mathrm{Cu}$ (110) surface, assigned to $\mathrm{CO}$ and bent $\mathrm{CO}_{2}{ }^{-}$, respectively [118]. From the $\mathrm{O} 1 \mathrm{~s}$ spectra, a binding state at $531 \mathrm{eV}$ was assigned to bent $\mathrm{CO}_{2}{ }^{-}$, while the presence of a peak at $536 \mathrm{eV}$ indicates $\mathrm{CO}_{2}$ in the physisorbed state, consistent with previous reports. Carbonate was also detected in some cases. C 1s spectra showed a peak at 290.8 and peaks at 531.9 and $531.0 \mathrm{eV}$ appeared in the $\mathrm{O} 1 \mathrm{~s}$ spectra for multilayer coverage and half-monolayer coverage, respectively. The presence of carbonates, $\mathrm{CO}$, and bent $\mathrm{CO}_{2}{ }^{-}$suggest the reaction $\mathrm{CO}_{2}{ }^{-}+\mathrm{CO}_{2} \rightarrow \mathrm{CO}_{3}{ }^{2-}+\mathrm{CO}_{\mathrm{a}}$ [118]. On the $\mathrm{Cu}(115)$ surface photoelectron spectra revealed the appearance of peaks at 287.4 , 290.3, and $291.2 \mathrm{eV}$, corresponding to carbon monoxide, surface carbonate, and $\mathrm{CO}_{2}$ [120]. The latter, however, only appeared at higher coverage of $\mathrm{CO}_{2}$, presumably due to the preferable chemisorption on the K-doped surface.

On a K-precovered $\mathrm{Cu}$ (110) surface, $\mathrm{CO}_{2}$ adsorption was monitored by photoelectron spectroscopy upon increasing gas exposure at $170 \mathrm{~K}$ [121]. Adsorption of $\mathrm{CO}_{2}$ caused a clear chemical shift of the K $3 p$ core line and a decrease in the asymmetry of the clean $\mathrm{K} 3 p$ with 
increasing $\mathrm{CO}_{2}$ exposure. Four new peaks also appeared at 8.5 and $11.7 \mathrm{eV}$ after the adsorption and were assigned to chemisorbed $\mathrm{CO}_{2}$ and at 8.5 and $12.6 \mathrm{eV}$ at higher saturation, indicating the presence of physisorbed $\mathrm{CO}_{2}$ with some peaks overlapping between the chemisorbed and physisorbed counterparts. Upon heating to $173 \mathrm{~K}$, the physisorbed species was desorbed, while at $233 \mathrm{~K} \mathrm{CO}$ was released from the surface, as observed from the intensity reduction of the complex peak structure between 6 and $9 \mathrm{eV}$. This result was also corroborated by HREELS, where peaks associated with physisorbed species at 631 and $2372 \mathrm{~cm}^{-1}$ disappeared at $173 \mathrm{~K}$. Peaks characterizing carbonate and $\mathrm{CO}$ appeared at 1512, 1045 and 1704, $2050 \mathrm{~cm}^{-1}$, respectively. Also shown was the effect of the amount of K-coverage on the $\mathrm{Cu}$ surface: more $\mathrm{CO}$ was adsorbed below monolayer K-coverage due to the free $\mathrm{Cu}$ sites [121]. Assignments of both photoelectron spectra and HREELS peaks are provided in Tables 11 and 12.

Table 11. HREELS spectra peaks assignment at different temperatures obtained from $\mathrm{CO}_{2}(10 \mathrm{~L})$ on a $\mathrm{K}(0.4 \mathrm{ML}) / \mathrm{Cu}(11 \mathrm{O})$ interface. Reproduce with permission from Elsevier [121].

\begin{tabular}{|c|c|c|c|c|c|}
\hline \multicolumn{5}{|c|}{$\mathrm{E}\left(\mathrm{cm}^{-1}\right)$} & \multirow{2}{*}{ Assignment } \\
\hline $107 \mathrm{~K}$ & $173 \mathrm{~K}$ & $233 \mathrm{~K}$ & $400 \mathrm{~K}$ & $500 \mathrm{~K}$ & \\
\hline & 362 & & & & $\mathrm{Cu}-\mathrm{C}$ stretching \\
\hline 627 & & & & & $\mathrm{CO}_{2}$ physisorbed \\
\hline & 1045 & 1045 & 1045 & 1045 & Carbonate $\left(\mathrm{CO}_{3}{ }^{2-}\right)$ \\
\hline 1375 & & & & & $\mathrm{CO}_{2}^{-}, \mathrm{CO}_{2}$ physisorbed \\
\hline 1440 & 1512 & 1512 & 1512 & 1512 & Carbonate $\left(\mathrm{CO}_{3}{ }^{2-}\right)$ \\
\hline 1704 & 1704 & & & & $\mathrm{CO}$ \\
\hline 2050 & 2050 & & & & $\mathrm{CO}$ \\
\hline 2356 & & & & & $\mathrm{CO}_{2}$ physisorbed \\
\hline
\end{tabular}

Table 12. Peak identifications, binding energies $(\mathrm{eV})$ and assignments of structures in the photoemission valence spectra. Reproduced with permission from Elsevier [121].

\begin{tabular}{|c|c|c|}
\hline \multicolumn{1}{|c|}{ Interface } & \multicolumn{1}{|c|}{$\begin{array}{c}\text { Binding energy } \\
(\mathrm{eV})\end{array}$} & \multicolumn{1}{c|}{ Assignment } \\
\hline $4 \mathrm{~L} \mathrm{CO}_{2}$ on $\mathrm{K}(0.5 \mathrm{ML}) / \mathrm{Cu}(110)$ & $8.5,12.6,14.2$ & Physisorbed $\mathrm{CO}_{2}: 1 \pi_{\mathrm{g}}, 3 \sigma_{\mathrm{u}}, 4 \sigma_{\mathrm{g}}$
\end{tabular}




\begin{tabular}{|l|l|l|} 
& $\begin{array}{l}11.6,14.3 \\
5.5,9.5,11.7\end{array}$ & $\begin{array}{l}\text { Cu 3d satellites: }{ }^{3} \mathrm{~F},{ }^{1} \mathrm{G} \\
\text { Chemisorbed } \mathrm{CO}_{2}\end{array}$ \\
& $\begin{array}{l}\text { CO: } 5 \sigma / 1 \pi, 4 \sigma \\
12 \mathrm{~L} \mathrm{CO}_{2} \text { on } \mathrm{K}(1.1 \mathrm{ML}) / \mathrm{Cu}(110) \\
8.9,13.0\end{array}$ & $\begin{array}{l}\text { Physisorbed } \mathrm{CO}_{2}: 1 \pi_{\mathrm{g}}, 3 \sigma_{\mathrm{u}} \\
\text { Chemisorbed } \mathrm{CO}_{2}\end{array}$ \\
\hline
\end{tabular}

The importance of alkali doping on a reaction towards adsorbing $\mathrm{CO}_{2}$ was illustrated on other surfaces. For example, $\mathrm{Pt}(111)$ is an inert surface towards $\mathrm{CO}_{2}$ that is activated by preadsorbing $\mathrm{K}$ on its surface [122][123]. The clean surface of the metal demonstrated an inability to adsorb $\mathrm{CO}_{2}$, as observed using both AES and HREELS. However, when the surface was covered with potassium, an oxygen signal was observed with AES and it increased with higher K-coverage. HREELS studies revealed the peaks associated with $\mathrm{CO}_{2}$ at $640,1205,1355,1560,2025$, and $2350 \mathrm{~cm}^{-1}$. While the first one is associated with the bending mode of weakly bound $\mathrm{CO}_{2}$, the last one is assigned to its asymmetric stretching mode. Peaks at 1205 and $1355 \mathrm{~cm}^{-1}$ were assigned to the $v_{3}(s)$ mode. For below monolayer K coverage, the lower spectrum exhibits three peaks indicative of the presence of anionic $\mathrm{CO}_{2}^{-}$at 780,1220 and $1520 \mathrm{~cm}^{-1}$ that shifted to 870 , 1340 and $1610 \mathrm{~cm}^{-1}$ at the other end of the spectrum. The dissociation of activated $\mathrm{CO}_{2}$ was confirmed, when the CO peak was spotted at 1670-1660 $\mathrm{cm}^{-1}$. At low K-coverage the anionic species dissociated to $\mathrm{CO}$ and $\mathrm{O}$ at temperatures above $300 \mathrm{~K}$, while at high $\mathrm{K}$-coverage carbonate was formed with the anion as the intermediate above $200 \mathrm{~K}$. It is also notable that authors tentatively assign some of the $\mathrm{CO}_{2}{ }^{-}$to be in the oxalate or a cluster $\left(\left(\mathrm{CO}_{2}\right)_{\mathrm{n}}{ }^{-}\right)$form, owing to the fact that split peaks are sometimes observed at 1286 and $1388 \mathrm{~cm}^{-1}$ due to a Fermi resonance or accidental degeneracy in the bending and symmetric stretching mode overtone [122]. Computational study using B3LYP functional also confirmed the inability of a Pt (111) surface to adsorb $\mathrm{CO}_{2}$ molecule. The optimized structure of $\mathrm{CO}_{2}$ adsorbed on clean $\mathrm{Pt}$ (111) 
demonstrated a weakly bonded physisorbed binding mode. However, co-adsorbing it with $\mathrm{K}$ had activated $\mathrm{CO}_{2}$ with a mandatory interaction between $\mathrm{CO}_{2}$ and $\mathrm{K}$ required to give anionic $\mathrm{CO}_{2}{ }^{-}$as the activated form [123]. Llorca et al., however, reported a dissociative adsorption of $\mathrm{CO}_{2}$ on $\mathrm{Pt}$ surfaces supported on silica, in addition to bimetallic phase $\mathrm{Sn}-\mathrm{Pt} / \mathrm{SiO}_{2}$ [124]. IR experiment showed that after $\mathrm{CO}_{2}$ was admitted to the system, a peak developed at $2344 \mathrm{~cm}^{-1}$ and was assigned to $\mathrm{CO}_{2}$. Gas phase $\mathrm{CO}$ was simultaneously detected. After 21 hours, a broad peak at $2061 \mathrm{~cm}^{-1}$ developed extensively. Flushing out the gas phase revealed the removal of the $\mathrm{CO}_{2}$ peak, while the peak associated with CO remained in the spectra. Deconvolution of the spectra demonstrated that there were actually two peaks at $\sim 2300 \mathrm{~cm}^{-1}$, one at $2339 \mathrm{~cm}^{-1}$ and the other at $2344 \mathrm{~cm}^{-1}$. The latter one, which was also the more prevalent, was associated with coordination of linear $\mathrm{CO}_{2}$ on a silica support, while the former was due to the interaction with the alloy itself [124].

Another support used as a $\mathrm{K}$ promoted $\mathrm{CO}_{2}$ adsorbing surface was $\mathrm{Ru}(001)$ [58]. $\mathrm{CO}_{2}$ appears to physisorb on $\mathrm{Ru}(001)$ surface, whereas $\mathrm{K}$-doped $\mathrm{Ru}(001)$ with $\mathrm{K}$ present in the form of both monolayer and multilayer chemisorbs $\mathrm{CO}_{2}$, yielding carbonate and $\mathrm{CO}$ in the process. This was confirmed by Fourier Transformed Infrared Reflection Adsorption Spectroscopy (FT-IRAS) and TDMS. Oxalate was also confirmed to appear as an intermediate with peaks at 1716, 1342, and $806 \mathrm{~cm}^{-1}$ for monolayer $\mathrm{K}$ coverage, as well as at $1708-1625,1345$, and $765 \mathrm{~cm}^{-1}$ for the multilayer K coverage case. Peaks at 1716, 1342, and $806 \mathrm{~cm}^{-1}$ were assigned to two stretching modes, $v_{3}\left(\right.$ as) and $v_{3}(\mathrm{~s})$ and the bending mode $\delta(\mathrm{OCO})$ of oxalate, respectively [58]. The formation of the carbonate species was also observed as characterized by peak sets for monolayer K $\left(1467\left(v_{3}\right), 787\left(v_{4}\right) \mathrm{cm}^{-1}\right)$ for — bayer" $\left(1490\left(v_{3}\right), 1040\left(v_{1}\right), 884\left(v_{2}\right)\right.$ and $764\left(v_{4}\right)$ $\mathrm{cm}^{-1}$ and for multilayer $\left(1447\left(v_{3}\right), 1071\left(v_{1}\right), 884\left(v_{2}\right)\right.$ and $\left.764 \mathrm{~cm}^{-1}\left(v_{4}\right)\right)$ coverage. 
Comprehensive analysis of the spectra can be found in reference [58]. However, from the temperature-programmed IR spectra it appears that the mechanism involves reaction between two $\mathrm{CO}_{2}$ molecules to give $\mathrm{C}_{2} \mathrm{O}_{4}$, after which it desorbs to give $\mathrm{CO}_{3}$ and $\mathrm{CO}$. Spectra of the adsorbates are shown in Figure 20.
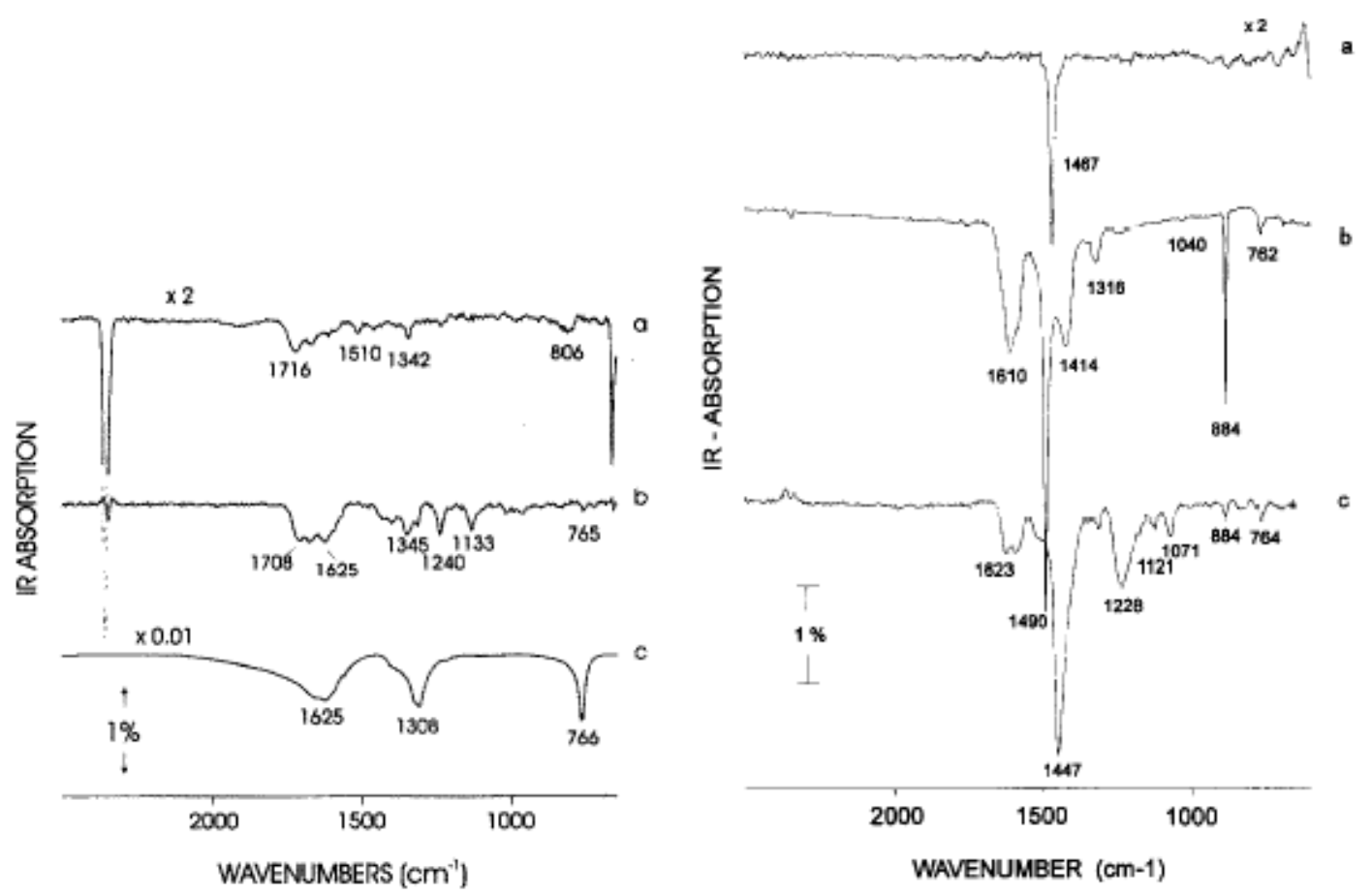

Figure 20. Left: vibrational spectra of oxalate species on: (a) monolayer $\mathrm{K}-\mathrm{Ru}(001)$, (b) $\mathrm{K}-$ multilayer, (c) bulk $\mathrm{K}_{2} \mathrm{C}_{2} \mathrm{O}_{4}$; Right: vibrational spectra of carbonate species on: (a) monolayer K$\mathrm{Ru}(001)$, (b) K-bilayer, (c) K-multilayer. Reprinted with permission from Elsevier [58].

Adsorption of $\mathrm{CO}_{2}$ on pristine and $\mathrm{Cu}$-covered $\mathrm{Re}(0001)$ surfaces was studied using XPS by Rodriguez et al. [125]. Chemisorption took place on both surfaces where $\mathrm{CO}_{2}$ dissociated to $\mathrm{CO}$ and $\mathrm{O}$. This experiment indicated the augmentation of the dissociative chemisorption due to the effect of Re support that makes the Cu dopant a better electron donor. Surface Re (0001) itself was already active for splitting $\mathrm{CO}_{2}$ into $\mathrm{CO}$ and $\mathrm{O}$ atoms as demonstrated via a broad $\mathrm{O}$ 1s peak shown in Figure 21 [125]. 


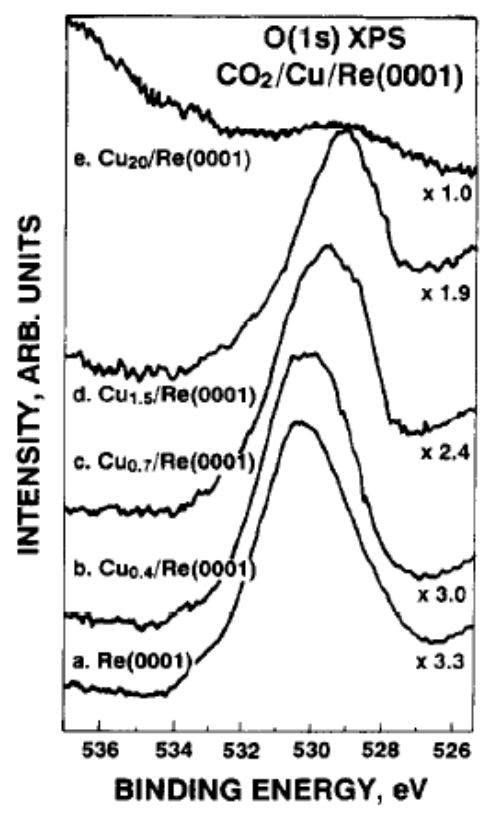

Figure 21. XPS spectra taken for clean and Cu-doped Re (0001) surfaces after dosing $50 \mathrm{~L}$ of $\mathrm{CO}_{2}$ at $\sim 350 \mathrm{~K}$. Reprinted with permission from Elsevier [125].

The dissociation is $\mathrm{CO}_{2}$ on rhodium surfaces, has been the object of debates in the literature. Several publications have pointed to the inability of the surface to induce chemisorption [126], a result that was supported further by thermodynamics and kinetics calculations on Rh (111) [127]. However, Dubois and Somorjai insisted that $\mathrm{CO}_{2}$ does dissociate on the Rh (111) surface [128], as HREELS C-O stretching modes at 1870 and $2070 \mathrm{~cm}^{-1}$ confirmed the presence of bridged CO and planar-bound $\mathrm{CO}$.

HREELS, coupled with an ELS study, has been conducted of Rh (111) as a potential $\mathrm{CO}_{2}$ adsorbing surface [129]. No chemisorption is observed (i.e. no peaks associated with CO formation) on clean surfaces. Physisorbed $\mathrm{CO}_{2}$ was observed only by ELS and not HREELS. On a K-doped Rh (111) surface the adsorption was enhanced, showing energy losses at 820, 1360, and $1620 \mathrm{~cm}^{-1}$, which are assigned to the $\mathrm{CO}_{2}^{-}$anion. The activated complex dissociated to give $\mathrm{CO}$ and $\mathrm{O}$ at low potassium coverage, while at higher coverage, $\mathrm{CO}_{3}{ }^{2-}$ and $\mathrm{CO}$ were produced 
[129]. However, later investigations using a combination of field emission microscopy (FEM) and temperature desorption spectroscopy (TDS) revealed the dissociation of $\mathrm{CO}_{2}$ on various $\mathrm{Rh}$ surface terminations [130]. The elucidation of the $\mathrm{O}_{2}$ molecule fate, which results from the recombination of oxygen radicals from $\mathrm{CO}_{2}$ dissociation, was also attained. Chemisorption occurred at temperatures above $165 \mathrm{~K}$, as observed by both FEM and TDS. For low exposure of $\mathrm{CO}_{2}$ the chemisorbed species recombined to yield $\mathrm{CO}_{2}$ as a product. Under high $\mathrm{CO}_{2}$ exposures there was a desorption maximum at $450 \mathrm{~K}$, which was similar to that found after the exposure of $\mathrm{Rh}$ surface to $\mathrm{CO}$. The remaining $\mathrm{O}$ atoms diffused to the surface of $\mathrm{Rh}$ at higher temperatures between $600 \mathrm{~K}$ and $1200 \mathrm{~K}$ as either $\mathrm{O}_{2}$ or form surface $\mathrm{RhO}_{\mathrm{x}}[130]$.

Recently, a comparative DFT study was conducted that analyzed $\mathrm{CO}_{2}$ interactions with rhodium nanoclusters $\left(\mathrm{Rh}_{13}\right)$ supported on unzipped graphene oxide $\left(\mathrm{Rh}_{13} / \mathrm{UGO}\right)$ surface, unsupported $\mathrm{Rh}_{13}$ nanocluster surfaces and $\mathrm{Rh}$ (111) surfaces [131]. The calculated $\mathrm{CO}_{2}$ adsorption energy on an $\mathrm{Rh}$ (111) surface was $+0.26 \mathrm{eV}$, supporting the argument that $\mathrm{CO}_{2}$ might not adsorb. For both $\mathrm{Rh}_{13}$ containing surfaces, dissociation of $\mathrm{CO}_{2}$ takes place with the UGO-supported, icosahedral $\mathrm{Rh}_{13}$ clustered surface exhibiting the lowest energy barrier. This finding is due to the greater charge transfer from $d$ electrons of the $\mathrm{Rh}$ atoms to $\mathrm{CO}_{2}$ adsorbate on the supported $\mathrm{Rh}$ cluster, compared to that of the free cluster [131].

The inability of platinum group metals to adsorb $\mathrm{CO}_{2}$ was also confirmed by in situ FTIR measurements of $\mathrm{CO}_{2}$ over $\mathrm{Pd} / \gamma-\mathrm{Al}_{2} \mathrm{O}_{3}$ [76]. At low coverages all peaks observed in the spectra were identical to those found on clean $\mathrm{Al}_{2} \mathrm{O}_{3}$ surfaces. These peaks were due to the adsorbed $\mathrm{CO}_{2}\left(2340-2370 \mathrm{~cm}^{-1}\right)$, bridging carbonates $\left(1060,1410,1700-1900 \mathrm{~cm}^{-1}\right)$ and bicarbonates $\left(1235,1485,1645,3610 \mathrm{~cm}^{-1}\right)$. However, at higher Pd coverage, peaks decreased in intensity, owing to the fact that Pd metal atoms blocked the adsorption of $\mathrm{CO}_{2}$ by occupying the defected 
sites [76]. HREELS of $\mathrm{CO}_{2}$ adsorption on $\mathrm{Pd}$ (110) metal surface with coadsorbed water confirmed the formation of $\mathrm{CO}_{2}{ }^{\delta-}$ [132]. At $110 \mathrm{~K}$ no chemisorption was observed on the clean $\operatorname{Pd}(110)$ surface and the coadsorption of water significantly changed the chemistry with the bent $\mathrm{CO}_{2}$ species, a precursor of $\mathrm{CO}$, observed. Adsorption of $\mathrm{CO}_{2}$ on water-covered surfaces lead to the appearance of two new peaks at 770 and $1200 \mathrm{~cm}^{-1}$, which were respectively assigned to $\mathrm{CO}_{2}{ }^{\delta-}$ bending and symmetric stretching modes. Physisorbed $\mathrm{CO}_{2}$ exhibited unperturbed modes at 667 (bending) and 1298 (stretching) $\mathrm{cm}^{-1}$. The other asymmetric mode of the chemisorbed species would be in the region of $\sim 1600 \mathrm{~cm}^{-1}$, which would overlap with the high intensity adsorbed water peaks. Further confirmation of the chemisorbed species formed upon coadsorption with water was attained using TPD, where $\mathrm{CO}_{2}$ and water are desorbed at the same time. However, TPD also confirmed that water exhibited competitive adsorption. This was also demonstrated by the decreasing concentration of chemisorbed species, when a higher dose of water was introduced [132].

$\mathrm{CO}_{2}$ undergoes no dissociative adsorption on an Fe (111) surface, as confirmed by time-resolved HREELS [133]. Three adsorbed states were present on the surface at low temperatures of $100 \mathrm{~K}$, two bent and one linear. Bent $\mathrm{CO}_{2}$ molecules are, however, more prominent than the linear ones, pointing to the saturation of bent states before occupying the linear state [133]. Fe (110) surface, when doped with $\mathrm{Cs}$, however, exhibits a lot of new surface chemistry upon $\mathrm{CO}_{2}$ adsorption [134]. Adsorption of $\mathrm{CO}_{2}$ at $85 \mathrm{~K}$ yields a variety of surface species resulting from $\mathrm{CO}_{2}$ chemisorption. Namely, CO, carbonates and oxalates, as confirmed by UPS and XPS, were detected. Temperature ramping demonstrated desorption of $\mathrm{CO}_{2}$, as well as reaction toward $\mathrm{CO}$, $\mathrm{CO}_{3}$, and carboxylate species $\left(\mathrm{C}_{2} \mathrm{O}_{4}{ }^{\mathrm{m}-}\right)$ at temperatures between $85 \mathrm{~K}$ to $160 \mathrm{~K}$. At higher temperatures oxalate decomposed to yield $\mathrm{CO}_{2}, \mathrm{CO}$, and surface carbonates. Decomposition of 
$\mathrm{CO}$ molecules into $\mathrm{C}$ and $\mathrm{O}$, and the corresponding recombination to $\mathrm{CO}$, take place at even higher temperature, above $320 \mathrm{~K}$ and between $500-700 \mathrm{~K}$, respectively. At low $\mathrm{CO}_{2}$ coverage linearly physisorbed $\mathrm{CO}_{2}$ was observed, as confirmed by peaks at $8.8,12.6,13.2$, and $14.8 \mathrm{eV}$ from UP spectra assigned to $1 \pi_{\mathrm{g}}, 1 \pi_{\mathrm{u}}, 3 \sigma_{\mathrm{u}}$ and $4 \sigma_{\mathrm{g}}$ molecular orbitals of $\mathrm{CO}_{2}$. $\mathrm{CO}$ was also observed with a peak at $7.1 \mathrm{eV}$ assigned to $1 \pi$ and $5 \sigma$, while the peak arising from the $4 \sigma$ orbital at $10.5 \mathrm{eV}$ was hidden under the Cs $5 \mathrm{p}_{3 / 2}$ core line. The carbonate was characterized by peaks at 4.4, 5.6, and $9.8 \mathrm{eV}$ and assigned to $1 \mathrm{a}_{2}{ }_{2}, 1 \mathrm{e}^{\prime \prime} / 4 \mathrm{e}^{\prime}$ and $1 \mathrm{a}_{2}{ }^{\prime \prime} / 3 \mathrm{e}$ ' carbonate orbitals, respectively. XPS binding energies of these molecules can be found elsewhere [134]. Temperature programmed X-ray and ultraviolet photoelectron spectra are shown in Figures 22 and 23, respectively.
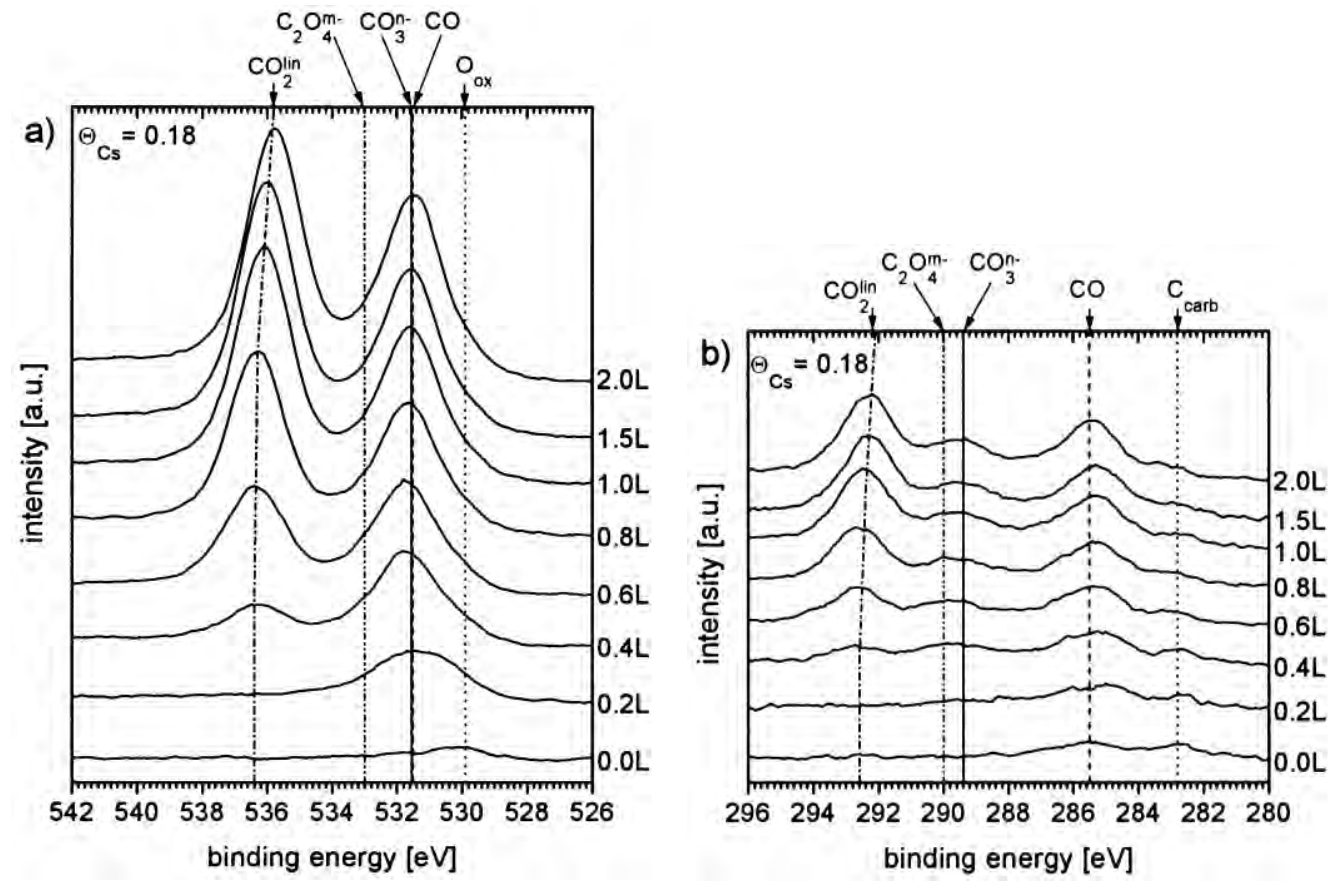

Figure 22. X-ray photoelectron spectra taken after subsequent exposure to $\mathrm{CO}_{2}$ at $\Theta_{\mathrm{Cs}}=0.18$ and $\mathrm{T}=85 \mathrm{~K}$. Reprinted with permission from Elsevier [134]. 


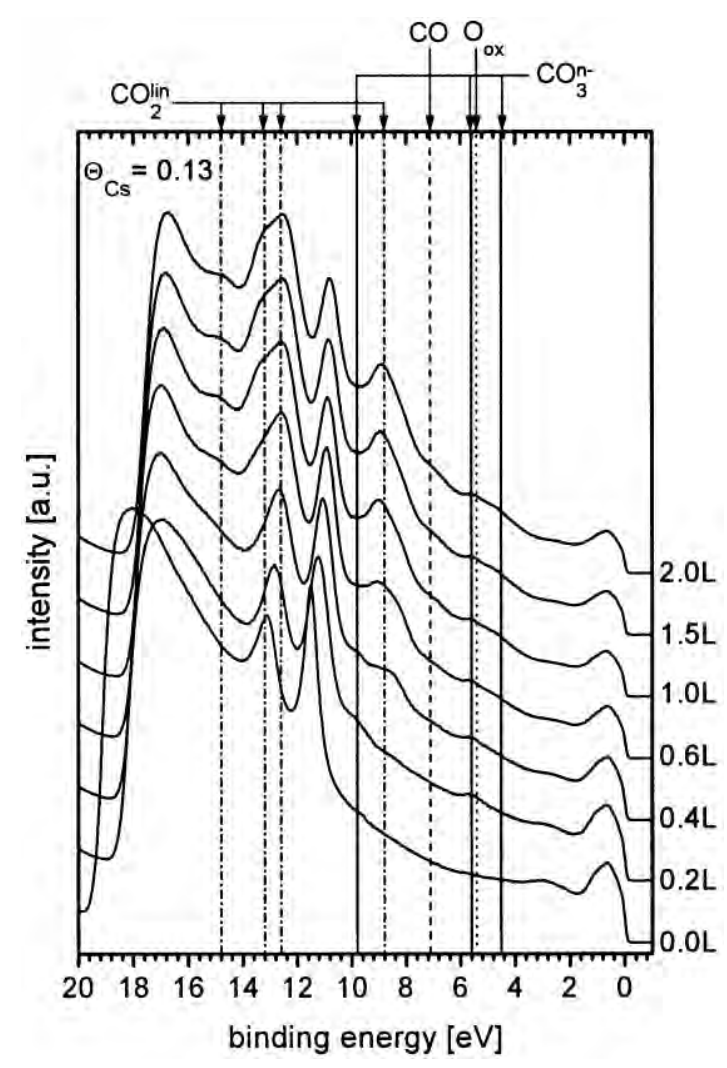

Figure 23. UP spectra of the Cs-covered surface at $\Theta_{\mathrm{Cs}}=0.13$ after subsequent $\mathrm{CO}_{2}$ exposure at 85 K. Reprinted with permission from Elsevier [134].

Another alkali metal proven to enhance the reactivity of $\mathrm{Fe}(110)$ towards $\mathrm{CO}_{2}$ is $\mathrm{K}[135,136]$. $\mathrm{CO}_{2}$ is adsorbed on K-precovered $\mathrm{Fe}$ (110) surface, even at low K-coverage with the small amount of $\mathrm{CO}_{2}$ undergoing dissociation to $\mathrm{CO}$. Upon prolonged adsorption, $\mathrm{CO}_{2}$ disproportionation takes place with carbonates and CO formation confirmed by UPS and XPS. Oxalate, however, can neither be confirmed nor ruled out. Typically, it is in the form of a C-O-C bridged iso-oxalate" species or a $\mathrm{CO}_{2}{ }^{\delta-} \cdot \mathrm{CO}_{2}$ complex [136]. TPD provides further insight into the chemical activity on the surface of $\mathrm{K} / \mathrm{Fe}(110)$ [135]. At low K-coverage $\left(0<\theta_{\mathrm{K}} \leq 0.20\right)$ in the temperature range 80 to $140 \mathrm{~K}$, desorption and reaction of linear $\mathrm{CO}_{2}$ to carbonates, $\mathrm{CO}$, and oxalates via $\mathrm{CO}_{2}{ }^{\delta-}$ occur, while carbonate decomposes within the temperature range of 140 to $330 \mathrm{~K}$. In the higher temperature range from 330 to $500 \mathrm{~K}$, $\mathrm{CO}$ dissociation and desorption 
occur. At high K-coverage $\left(0.26<\theta_{\mathrm{K}} \leq 0.30\right)$, the only differences are in the 140 to $330 \mathrm{~K}$ temperature region, where $\mathrm{C}_{2} \mathrm{O}_{4}{ }^{\mathrm{m}-}$ is decomposed, as well as at $500-600 \mathrm{~K}$, where surface carbonate undergoes decomposition. At higher coverage it is noticeable that carbonates have stronger bonds, presumably due to $\mathrm{K}$ atom abundance, which leads to a higher amount of coordinated carbonates [135].

Table 13. Binding energies (in eV) of $\mathrm{O}$ ls and $\mathrm{C}$ 1s peaks in $\mathrm{XP}$ spectra of $\mathrm{CO}_{2}$ adsorption on $\mathrm{K}$ precovered Fe (110) surface. Reproduced with permission from Elsevier [136].

\begin{tabular}{lllll} 
Species & $\boldsymbol{\theta}_{\mathbf{K}}$ & \multicolumn{3}{l}{ XPS binding energies } \\
\hline & & $\mathrm{O} 1 \mathrm{~s}$ & $\mathrm{C} 1 \mathrm{~s}$ & $\Delta \mathrm{E}_{\mathrm{b}}$ \\
$\mathrm{CO}_{2}$ & 0.08 & 535.6 & & \\
& 0.34 & 535.9 & & \\
$\mathrm{CO}$ & 0.34 & 531.6 & 285.5 & 246.1 \\
$\mathrm{CO}_{3}{ }^{\text {n- }}$ & 0.08 & 531.3 & 289 & 242 \\
& 0.34 & 531.6 & 289 & 242
\end{tabular}

Surface characterization of the adsorbent is done using XPS, and peak assignments can be seen above. With potassium coverage $\left(\theta_{\mathrm{K}}\right)$ of 0.34 , only with a $\mathrm{CO}_{2}$ exposure of more than $0.7 \mathrm{~L}$ can the peaks associated with $\mathrm{CO}$ and carbonates be seen in the spectra. The O1s peaks of both $\mathrm{CO}$ and carbonate coincide at $\sim 531.6 \mathrm{eV}$, while the corresponding $\mathrm{C} 1 \mathrm{~s}$ spectra shows peaks at 285.5 and $289 \mathrm{eV}$, respectively. Dissociation of $\mathrm{CO}_{2}$ on the surface is further corroborated by the presence of a shoulder at $529.5 \mathrm{eV}$, which can be assigned to oxide from the oxygen. Prolonged exposure to $\mathrm{CO}_{2}$ results in the appearance of another peak at $535.9 \mathrm{eV}$ in the $\mathrm{O} 1 \mathrm{~s}$ spectra, which is related to weakly adsorbed linear $\mathrm{CO}_{2}$ due to the fully occupied surface. The corresponding $\mathrm{C} 1 \mathrm{~s}$ spectra peak is at $292 \mathrm{eV}$, which coincides with the $\mathrm{K} 2 \mathrm{p}_{3 / 2}$ signal. At lower $\mathrm{K}$ coverage, i.e. $\theta_{\mathrm{K}}=0.08$, a shift is expected for O1s peaks of both carbonates and linear $\mathrm{CO}_{2}$, where the values are now $0.3 \mathrm{eV}$ lower than those at a higher $\theta_{\mathrm{K}}$. 
The corresponding UV photoelectron spectra for different $\theta_{\mathrm{K}}$ is presented in the table below. Linear $\mathrm{CO}_{2}$ presence is readily confirmed by intense peaks at $\sim 8-9$ and $\sim 13 \mathrm{eV}$. Increasing the $\mathrm{CO}_{2}$ exposure, i.e. $>0.2 \mathrm{~L}$, results in the formation of two other intense peaks at $\sim 6$ and $\sim 10.4$ $\mathrm{eV}$, accompanied by several weak peaks at $\sim 7.4$ and $\sim 11 \mathrm{eV}$, depending on the $\theta_{\mathrm{K}}$. The results from XPS and UPS led the authors to conclude that linearly adsorbed $\mathrm{CO}_{2}$ molecules react to give $\mathrm{CO}$ and carbonates.

Table 14. Binding energies (in eV) of characteristic emissions in UP spectra of $\mathrm{CO}_{2}$ adsorption on K-pre-covered Fe (110) surface; the values in brackets show the difference from the orbital marked by *. Reproduced with permission from Elsevier [136].

\begin{tabular}{lllllll} 
Species & $\boldsymbol{\theta}_{\mathbf{K}}$ & $\begin{array}{c}\text { hv } \\
(\mathbf{e V})\end{array}$ & \multicolumn{2}{c}{ UPS binding energies } \\
\hline & & & $1 \pi_{\mathrm{g}}$ & $1 \pi_{\mathrm{g}} / 3 \sigma_{\mathrm{u}}$ & $5 \sigma_{\mathrm{g}}$ & \\
$\mathrm{CO}_{2}$ & 0.05 & 21.2 & $8.4\left(^{*}\right)$ & $12.7(4.3)$ & & \\
& 0.31 & 21.2 & $9.2\left(^{*}\right)$ & $13.3(4.1)$ & & \\
& 0.06 & 40.8 & $8.8\left(^{*}\right)$ & $13.0(4.2)$ & $14.5(5.7)$ & \\
& 0.2 & 40.8 & $9.3\left(^{*}\right)$ & $13.5(4.2)$ & $15.0(5.7)$ & \\
& & & $1 \pi / 5 \sigma$ & $4 \sigma$ & & \\
$\mathrm{CO}$ & 0.18 & 21.2 & $7.4\left(^{*}\right)$ & $11.0(3.6)$ & & \\
& 0.17 & 40.8 & $8.1\left(^{*}\right)$ & $11.4(3.3)$ & & \\
& & & $1 \mathrm{a}^{\prime}{ }_{2}$ & $1 \mathrm{e}^{\prime \prime} / 4 \mathrm{e}^{\prime}$ & $1 \mathrm{a}^{\prime}{ }_{2} / 3 \mathrm{e}^{\prime}$ & $4 \mathrm{a}^{\prime}{ }_{1}$ \\
$\mathrm{CO}_{3}{ }^{\mathrm{n}-}$ & 0.31 & 21.2 & $4.4(-1.6)$ & $6.0(*)$ & $10.2(4.2)$ & $12.0(6.0)$ \\
& 0.2 & 40.8 & $4.4(-1.6)$ & $6.0(*)$ & $10.4(4.4)$ & $12.0(6.0)$
\end{tabular}

\subsection{2 $\mathrm{CO}_{2}$ interactions with co-adsorbing gas on metal surfaces}

While $\mathrm{CO}_{2}$ adsorption on clean metal surface sites yields either linear $\mathrm{CO}_{2}$ or bent anionic species, adsorption on precovered gas surfaces, typically hydrogen and oxygen, yields carbonate and even formate. The fate of the carbonate, however, depends on the surface itself; in some cases it gets stabilized [122], while in others it just reacts with $\mathrm{CO}$ resulting from $\mathrm{CO}_{2}$ dissociation to yield $\mathrm{CO}_{2}$, both bent and anionic [137]. Surface carbonate formed via co- 
adsorption of $\mathrm{CO}_{2} / \mathrm{O}_{2}$ on $\mathrm{Ni}$ (100) surface has been characterized using XPS, UPS, and TPR [112]. XPS showed the appearance of new peaks in the C 1s and O 1s spectra at $289.0 \mathrm{eV}$ and a doublet at 529.3 and $531.2 \mathrm{eV}$, respectively. The doublet indicates the presence of two different O-containing species. The peak from $\mathrm{C} 1$ s spectra, along with the first peak in the $\mathrm{O} 1 \mathrm{~s}$ doublet, were assigned to surface carbonate, while the peak at $531.2 \mathrm{eV}$ was attributed to either atomically adsorbed $\mathrm{O}$ or the atomic $\mathrm{O}$ that accompanies the formation of carbonate. It was also demonstrated that pretreating the surface with $\mathrm{O}_{2}$ is the only way to produce surface carbonate. Flowing $\mathrm{O}_{2}$ would yield basic surface $\mathrm{O}$ sites and resulting chemically adsorbed $\mathrm{CO}_{2}$ [112]. Polycrystalline $\mathrm{Cu}$ foil could potentially be a good candidate for $\mathrm{CH}_{3} \mathrm{OH}$ synthesis, because in the presence of 0.1 Torr $\mathrm{CO}_{2}$ and water, both formate and methoxy species were formed along with the other chemisorbed species. The assignment of the $\mathrm{C} 1 \mathrm{~s}$ peaks was reported as carbonate (289.3 eV), $\mathrm{CO}_{2}{ }^{\delta-}(288.4 \mathrm{eV})$, formate $(287.3 \mathrm{eV})$, methoxy $\left(-\mathrm{O}-\mathrm{CH}_{3}\right)(285.2 \mathrm{eV})$ and $\mathrm{C}^{0}(284.4$ $\mathrm{eV})$, respectively. On $\mathrm{Zn}$-pre-covered $\mathrm{Cu}$ foil surface, four species were observed: carbonate (289.3 eV), formate $(287.3 \mathrm{eV})$, methoxy $(285.2 \mathrm{eV})$ and $\mathrm{C} 0(284.4 \mathrm{eV})$. For the $\mathrm{O}$ 1s region, overlaps between the formate, carbonate, bent $\mathrm{CO}_{2}{ }^{-}$and methoxy were prominent, leading to the inability to accurately resolve the peaks [37]. $\mathrm{O}_{2}$-precovered $\mathrm{Cu}(311)$ was more reactive than $\mathrm{Cu}(110)$ and exhibited the capability to dissociate $\mathrm{CO}_{2}$, similar to when it is not pretreated with any gas. Similar to the adsorption without the presence of $\mathrm{O}_{2}$, water was produced due to the reaction with background $\mathrm{H}_{2}$ [113]. It is evident from the below $\mathrm{C}^{18} \mathrm{O}$ TDS spectra, which are taken by flowing $4 \mathrm{~L}$ of $\mathrm{C}^{18} \mathrm{O}_{2}$, that peaks were observed at $200 \mathrm{~K}$ and $\sim 480 \mathrm{~K}$, on any $\mathrm{Cu}(311)$ surface, but not on any $\mathrm{Cu}(110)$ surface. 


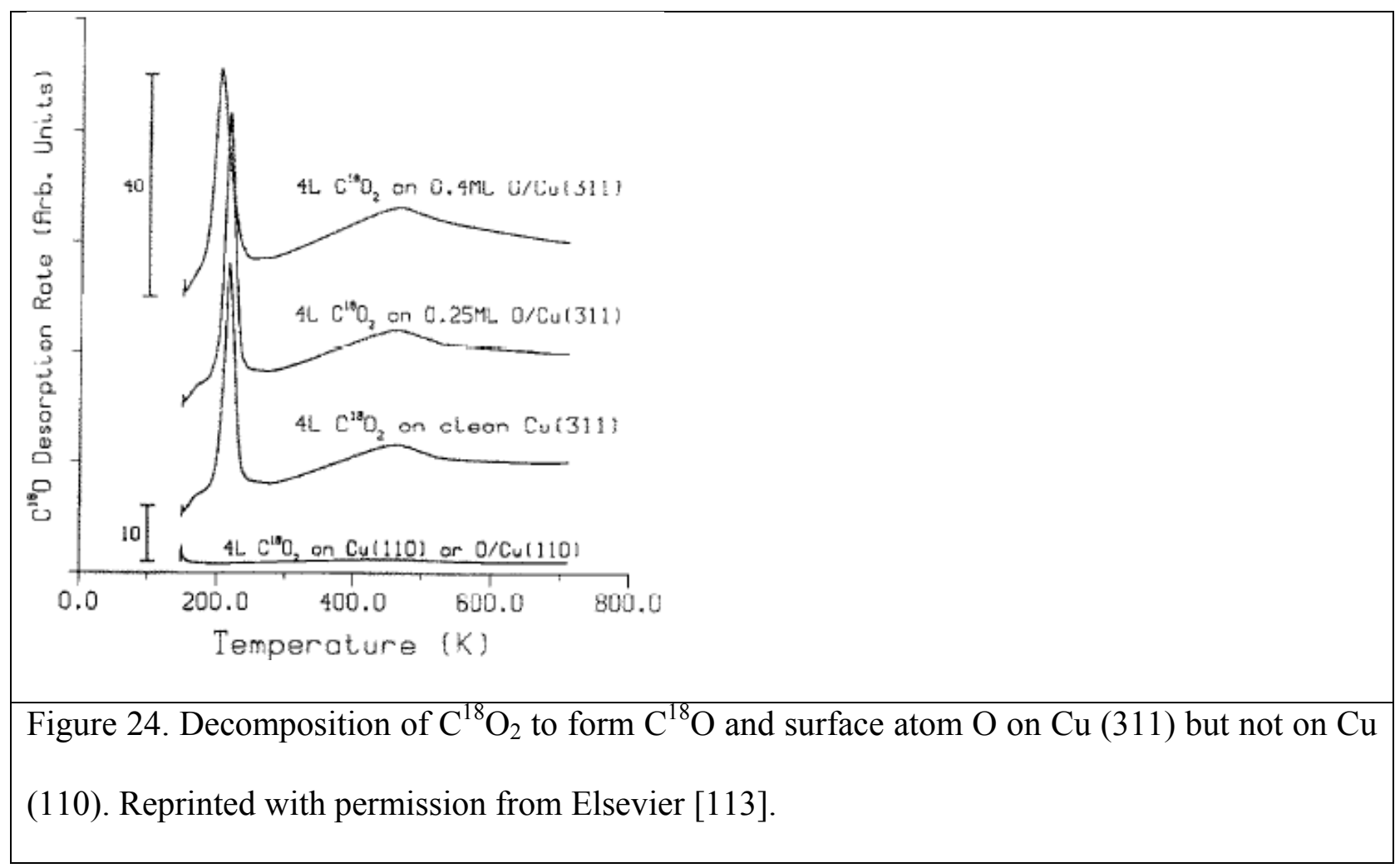

Pre-dosing Cs-doped $\mathrm{Cu}(110)$ with hydrogen before $\mathrm{CO}_{2}$ adsorption resulted in peak shifts on the UP spectra. For instance, carbonate peaks were apparent at 5.3, instead of $5.54 \mathrm{eV}$, and the peak due to the $4 \sigma_{\mathrm{g}}$ orbital of physisorbed $\mathrm{CO}_{2}$ shifted to 14.7 instead of $15 \mathrm{eV}$. The peak associated with one orbital molecule of a bent $\mathrm{CO}_{2}^{-}$molecule shifted from 6.9 to $6.6 \mathrm{eV}$, signifying interactions between the adsorbing $\mathrm{CO}_{2}$ and hydrogen. As expected, formation of surface formate was confirmed by the presence of peaks at 8.56, 10.3, 14.0, and $5.3 \mathrm{eV}$ (overlapping with that of carbonate) [117]. K-promoted $\mathrm{Cu}(115)$, when precovered with $\mathrm{H}$ gave a complex spectrum resulting from $\mathrm{CO}_{2}$ adsorption. Photoemission results indicated the presence of hydrogen-induced states, molecular $\mathrm{CO}_{2}, \mathrm{CO}$, surface formate and carbonates (Figure 25) [120]. 


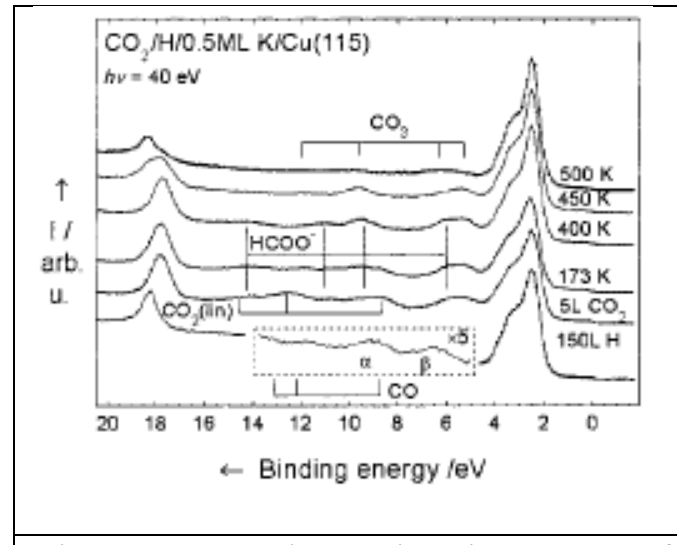

Figure 25. Valence band spectra of $\left(\mathrm{CO}_{2}+\mathrm{H}\right) / \mathrm{K} / \mathrm{Cu}(115) \quad$ interface obtained at $\mathrm{T}=125-500 \mathrm{~K}$. Reproduced with permission from Wiley [120].
Table 15. Peak assignments for valence band spectra of $\left(\mathrm{CO}_{2}+\mathrm{H}\right) / \mathrm{K} / \mathrm{Cu}(115)$ interface obtained at $\mathrm{T}=125-500$

K. Reproduced with permission from Wiley [120].

\begin{tabular}{l|l} 
BE position $[\mathrm{eV}]$ & \multicolumn{1}{|c}{ Identification } \\
\hline $6.5,9.0$ & hydrogen-induced states: $\beta, \alpha$ \\
$8.6,12.6,14.5$ & $\mathrm{CO}_{2}(\mathrm{lin}): 1 \pi_{\mathrm{g}}, 1 \pi_{\mathrm{u}} / 3 \sigma_{\mathrm{u}}, 4 \sigma_{\mathrm{g}}$ \\
$8.7,12.1,13.0$ & $\mathrm{CO}: 1 \pi / 5 \sigma, 4 \sigma, 4 \sigma_{\mathrm{sat}}$ \\
$6.0,9.2,11.1$, & $\mathrm{HCOO}^{-}: 4 \mathrm{~b}_{1} / 6 \mathrm{a}_{1}, 1 \mathrm{~b}_{2}, 3 \mathrm{~b}_{1} / 5 \mathrm{a}_{1}, 4 \mathrm{a}_{1}$ \\
14.2 & \\
$5.2,6.2,9.7,12.0$ & $\mathrm{CO}_{3}: 1 \mathrm{a}_{2}^{\prime}, 1 \mathrm{e}^{\prime \prime} / 4 \mathrm{e}^{\prime}, 3 \mathrm{e}^{\prime} / 1 \mathrm{a}_{2}{ }^{\prime \prime}, 4 \mathrm{a}_{1}{ }^{\prime}$
\end{tabular}

Pre-covering a K-deposited $\operatorname{Pt}(111)$ surface with oxygen atoms yields a similar result, as if the surface

was not pre-dosed with $\mathrm{O}_{2}$ upon $\mathrm{CO}_{2}$ adsorption [122]. Bent anionic $\mathrm{CO}_{2}{ }^{-}$species forms on the surface and readily reacts with a surface $\mathrm{O}$ atom to yield carbonate. Positive shifts in HREELS peak energies were observed for the O-pre-covered surface as compared to the clean K-Pt (111) with the peaks appearing at 955,1410 and $1710 \mathrm{~cm}^{-1}$ assigned to $\delta\left(\mathrm{CO}_{2}^{-}\right), v\left(\mathrm{CO}_{2}^{-}\right)$, and $v\left(\mathrm{CO}_{2}^{-}\right)$, respectively. The TDS spectra also showed surface $\mathrm{O}$ atoms playing a major role in stabilizing the carbonate formed on the surface [122].

An alloyed metal investigated as a $\mathrm{CO}_{2}$ adsorbing surface was Pd (100)-Mn-c(2x2) [138]. Adsorption on a pristine surface yielded no surface species due to the inactivity of the surface. However, co-adsorption with oxygen significantly altered the outcome. In particular, elemental carbon is detected in photemission spectra at $110 \mathrm{~K}$, as characterized by the peak at $283 \mathrm{eV}$, as well as $\mathrm{CO}$ on $\mathrm{Pd}$ and $\mathrm{CO}$ on $\mathrm{Mn}$ at $286.5 \mathrm{eV}$ and the corresponding shoulder, respectively. Upon heating, carbonates and $\mathrm{CO}_{2}$ were formed on the surface. The increased reactivity was suggested 
to arise from the appearance of different oxidation states of the alloy surface caused by pretreatment with oxygen. $\mathrm{O}_{2}$ pre-dosing destroyed the structure of the metal, creating clusters of Mn-oxides, which were highly reactive towards the formation of surface carbonate [138].

DFT calculations on the reverse reaction of $\mathrm{CO}_{2}$ dissociation on $\mathrm{Ru}(0001)$, i.e., catalytic oxidation of $\mathrm{CO}$, has been carried out [139]. Indirect correlation was inferred from this simulation with two mechanisms for the reaction available depending on the O-coverage. Covering the surface with oxygen reveals the first mechanism, which is a reaction of gas-phase $\mathrm{CO}$ with a surface oxygen atom, leading to $\mathrm{CO}_{2}$. The second one, which is more prominent, is the adsorption of $\mathrm{CO}$ on an O-vacancy site of the surface, followed by the reaction of the two adsorbed molecules. The reverse case of the reaction is the dissociation of $\mathrm{CO}_{2}$ on the surface [139].

Ag appears to be one of the most extensively studied metals [137,140-143] for $\mathrm{CO}_{2}$ adsorption along with other gases. On an oxygen pre-covered Ag (110) surface, Guo and Madix discovered the formation of carbonate which would react readily with background CO molecules [140]. These were formed when exposing the surface to $\mathrm{CO}_{2}$ using an ion pump, resulting in a chemisorbed $\mathrm{CO}_{2}$ state, as confirmed by the desorption temperature of $485 \mathrm{~K}$, remarkably higher than that of physisorbed $\mathrm{CO}_{2}$ desorbing at $130 \mathrm{~K}$ [140]. Dosing a clean $\mathrm{Ag}(110)$ surface with Cs results in reconstruction of the surface, as confirmed using STM and AES, and subsequently enhances the adsorption of $\mathrm{CO}_{2}$, whereas it does not adsorb on a pristine surface [137]. The adsorption leads to the formation of locally ordered (2x1) structures and linear (2x2) structures distributed inhomogeneously on the surface. Desorption of the surface intermediate revealed no oxygen was desorbed, leading to the notion that carbonate was not formed on the surface. Isotope-labeled $\mathrm{CO}_{2}$ adsorption revealed that even though $\mathrm{C}=\mathrm{O}$ bond scission could not be 
confirmed, extensive isotope exchange took place on the reconstructed surface. One possible surface intermediate was oxalate. However, the oxalate formed is stable on $\mathrm{Ag}$, while on Cs, the oxalate decomposes to give carbonate and CO [137]. The same group also performed STM analysis demonstrating that adsorbed carbonate surface structures are clearly different from those of chemisorbed $\mathrm{CO}_{2}$ [143]. Figure 26 depicts the difference in the STM images compared for the two distinct surface species (chemisorbed $\mathrm{CO}_{2}$ and carbonate), along with TPSR spectra to further confirm the gas-phase products.

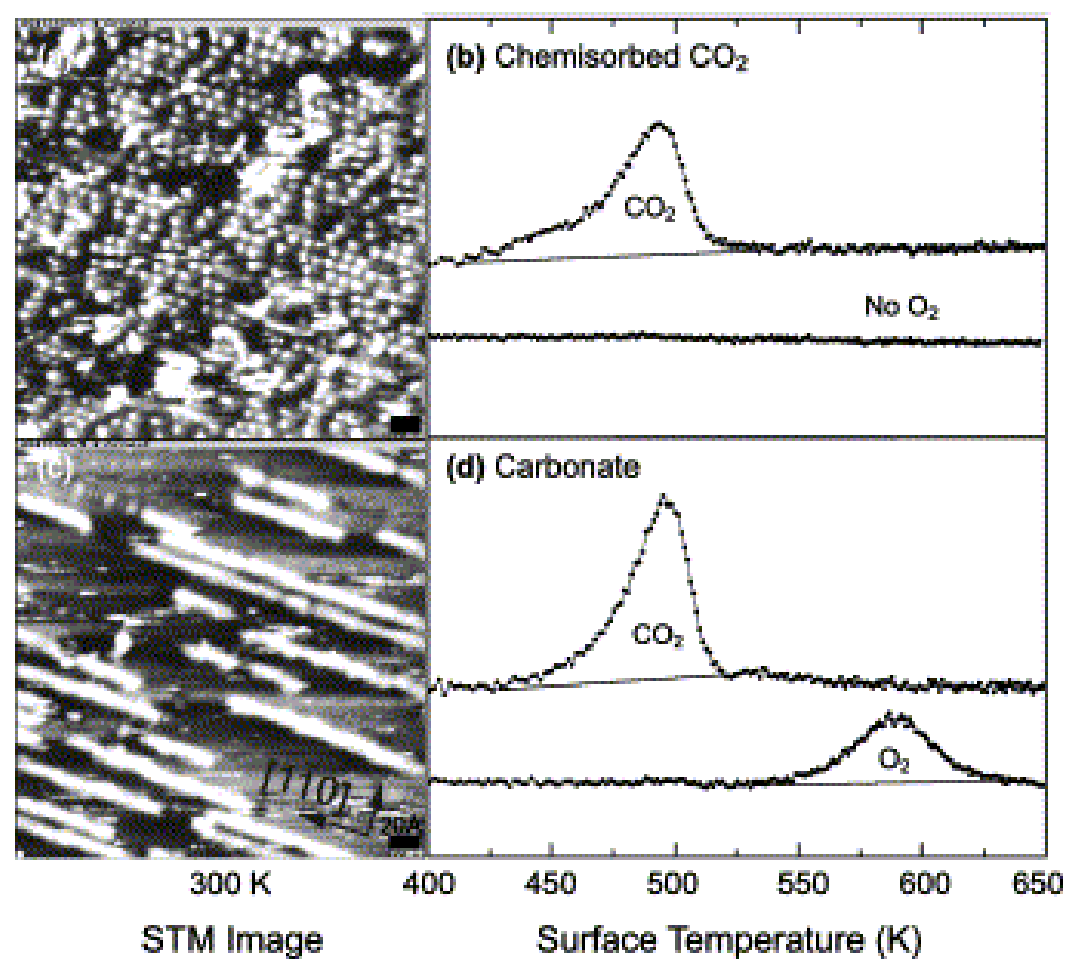

Figure 26. STM images and TPSR spectra for (top) chemisorbed $\mathrm{CO}_{2}$ and (bottom) carbonate. Reproduced with permission from Elsevier [143].

The striking difference in both species is that, upon desorbing, carbonate decomposes into $\mathrm{CO}_{2}$ and oxygen, as can be seen from the TPSR spectra. The images above clearly suggest different morphological forms of the two species. These are round protrusions for chemisorbed $\mathrm{CO}_{2}$ and rods parallel to $[1 \overline{1} 0]$ direction for chains of surface carbonates. This finding advocates the 
growth of carbonates taking place in the (110) direction, where the carbonate rods accumulate near the step edges, and the surface becomes more reactive due to its low coordination nature. The carbonate formation stages, as observed with STM, can be seen in the Figure 27.
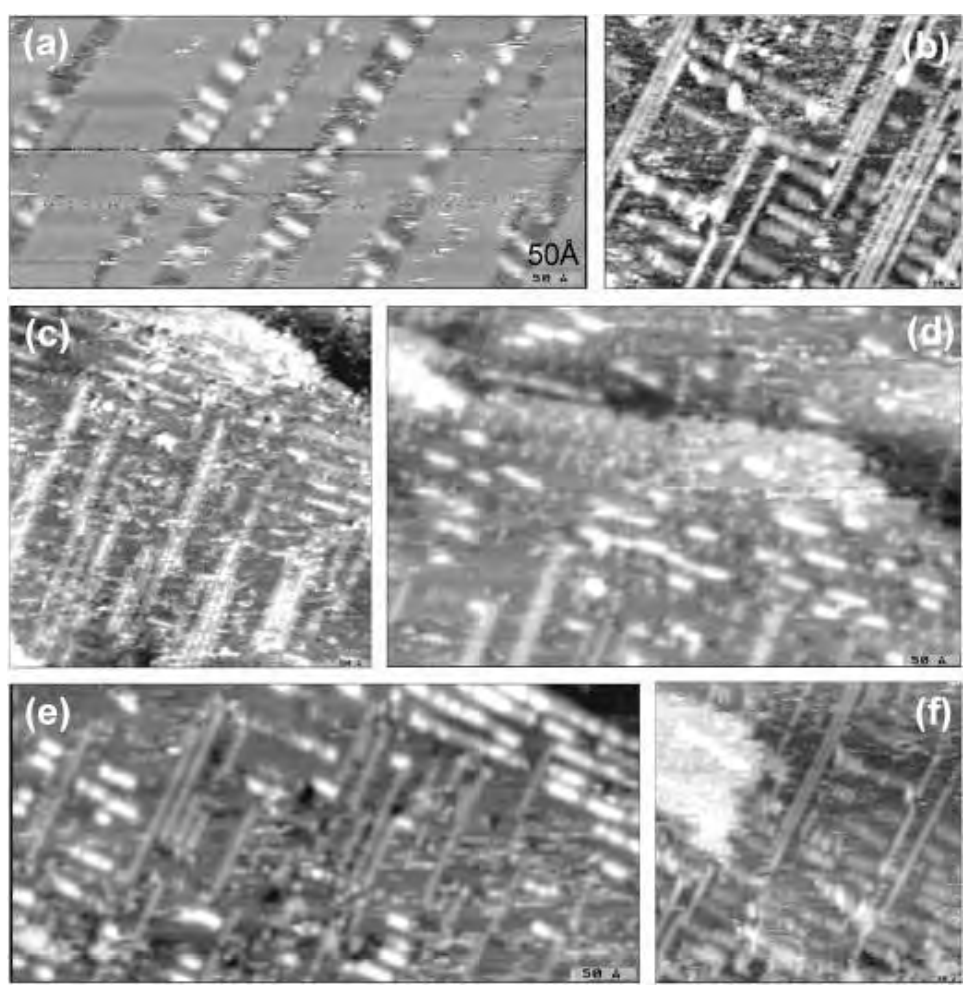

Figure 27. STM images of carbonates on Ag (110) at various carbonate formation stages; (a) $1.98 \mathrm{~V},+365 \mathrm{pA}$; (b) $+304 \mathrm{mV},+333 \mathrm{pA}$; (c) $+2.85 \mathrm{~V},+232 \mathrm{pA}$; (d) $+2.85 \mathrm{~V},+0.52 \mathrm{nA}$; (e) $+3.26 \mathrm{~V},+349 \mathrm{pA}$; (f) $+317 \mathrm{mV},+309 \mathrm{pA}$. Reproduced with permission from Elsevier [143]. In agreement with Guo and Madix,[143] Stensgaard et al., also confirmed that the reaction is preferentially initiated at steps, and defects, spreading anisotropically along the (001) direction, added Ag-O rows on the surface [141]. At higher oxygen coverage, however, the unreacted rows transform into $(2 \mathrm{X} 1)$ structure. In all cases observed by the authors, the reaction to carbonate leads to a new reconstruction of the surface, where the carbonate preferentially sets on top of the (110) triple structure. The transformation into $2 \times 1$ structure can be seen in the Figure 28. 

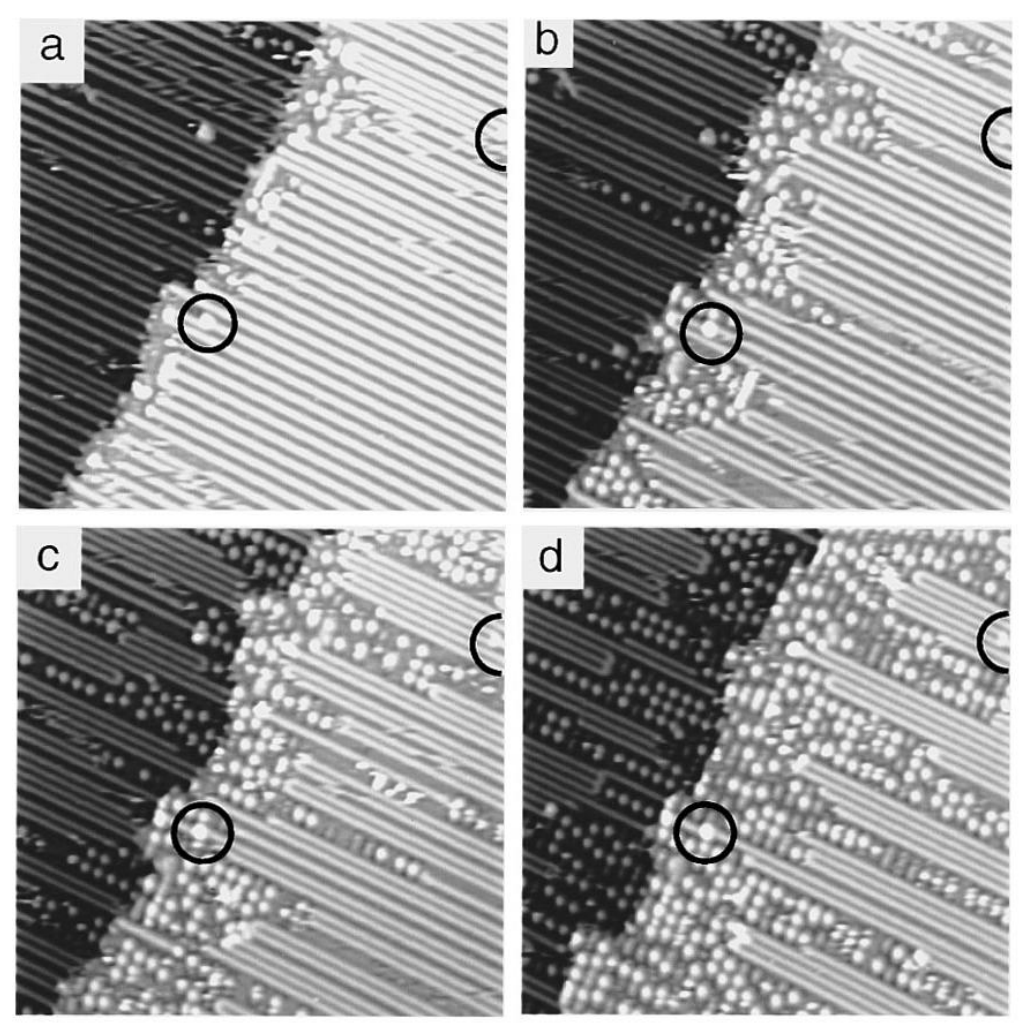

Figure 28. Carbonate formation on oxygen precovered Ag (110) surface, as observed using STM under different $\mathrm{CO}_{2}$ exposure (a-d). Notice that the initial 3x1 phase (a) has transformed into $2 \mathrm{x} 1$ phase along with higher exposure of $\mathrm{CO}_{2}$. Reprinted with permission from [141]. Copyright [2014], AIP Publishing LLC.

Formation of carbonate on $\mathrm{Ag}$ (110) with $\mathrm{O}_{2}$ pre-adsorption was also confirmed using SERS [142]. For the clean surface, a Raman shift of $\mathrm{CO}_{2}$ peaks was observed at $653,1276,1375$, and $2329 \mathrm{~cm}^{-1}$, which were assigned to the $v_{2}, 2 v_{2}, v_{1}$ and $v_{3}$ modes of $\mathrm{CO}_{2}$ deviating about 14-28 $\mathrm{cm}^{-1}$ from those in the $\mathrm{CO}_{2}$ gas spectra. SERS also confirmed the chemisorption via the appearance of peaks at $1046\left(v_{1}\right), 1289$ and $1420\left(v_{2}\right)$ and both 682 and $703 \mathrm{~cm}^{-1}\left(v_{4}\right)$, as well as peaks associated with the physisorbed $\mathrm{CO}_{2}$ when the clean surface was precovered with $\mathrm{O}_{2}$. Surface carbonate was formed perpendicularly to the surface, a conclusion drawn from the observed intensities of the peaks in the SERS spectra. On submonolayer alkali metal predosed 
silver of undefined surface termination, however, adsorption of $\mathrm{CO}_{2}$ lead to formation of three new peaks at 750,1200 , and $2130 \mathrm{~cm}^{-1}$. While the latter peak is easily assigned to $\mathrm{CO}$, data analysis by the authors linked the first two peaks to the formation of anionic $\mathrm{CO}_{2}{ }^{-}$caused by the presence of alkali metal ions [142]. Figure 29 shows the SERS spectra of $\mathrm{CO}_{2}$ adsorption on both oxygen precovered and alkali predosed silver metal surface. The main difference between them is that on the spectra of the left of Fig. 29 carbonate peaks are prominent, while those on the right exhibit two intense peaks from bent $\mathrm{CO}_{2}$ coordinated with the alkali, i.e. potassium.
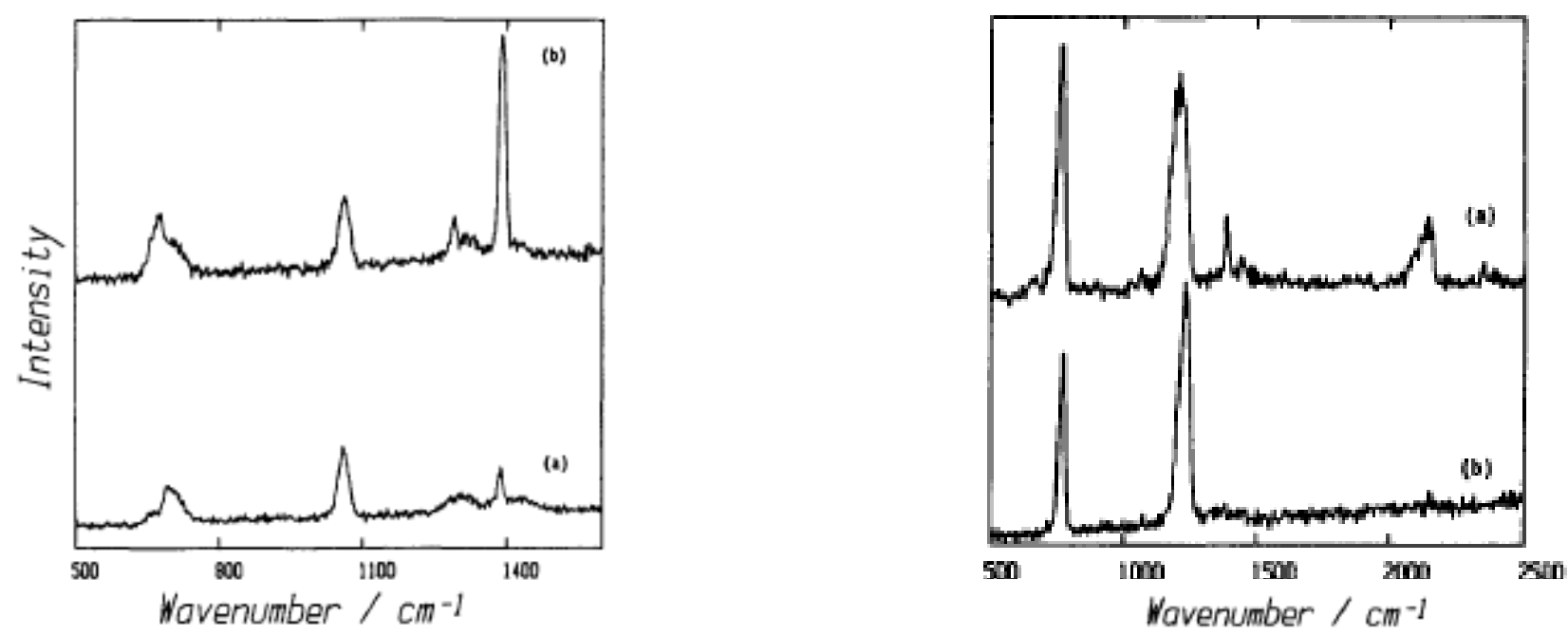

Figure 29. (Left) SERS spectra of $\mathrm{CO}_{2}$ on $\mathrm{O}_{2}$ pretreated silver surface. (a) After $0.5 \mathrm{~L} \mathrm{O}_{2}$ followed by $2.5 \mathrm{~L} \mathrm{CO}_{2}$, (b) same as (a) with a total of $8 \mathrm{~L} \mathrm{CO}_{2}$. (right) SERS spectra of $\mathrm{CO}_{2}$ on a $\mathrm{K}$ predosed surface at $50 \mathrm{~K}$ with (a) $\theta_{\mathrm{K}}=0.15$ and (b) $\theta_{\mathrm{K}}=0.40$. Reproduced with permission from [142]. Copyright (1989), AIP Publishing LLC.

A low reaction pathway to surface carbide or surface formate is available via coadsorption of $\mathrm{CO}_{2}$ with $\mathrm{H}_{2} \mathrm{O}$ vapor on $\mathrm{Al}$ (111) surface [144]. XPS showed three peaks in the C1s spectrum during the adsorption of $\mathrm{CO}_{2}$ on water-precovered surface at $295 \mathrm{~K}$ at 292,285 , and $282 \mathrm{eV}$ assigned to surface carbonate, carbon, and carbidic species, respectively. When coadsorbed with 
water, however, a peak at $286 \mathrm{eV}$ appeared at the expense of the carbidic peak at $282 \mathrm{eV}$. The former peak indicates the presence of a $\mathrm{C}-\mathrm{H}$ species suggesting hydrogenation of $\mathrm{CO}_{2}$ [144]. Alkali metal surfaces, such as $\mathrm{Li}$, are very reactive toward acids, such as $\mathrm{CO}_{2}$. When dosed with $\mathrm{O}_{2}$ at $120 \mathrm{~K}$, XPS showed a major peak at $530.3 \mathrm{eV}$ assigned to a bridged coordination of an oxygen atom with two Li atoms [145]. When the O-precovered Li surface was exposed to $\mathrm{CO}_{2}$, two other distinct peaks appeared along with two peaks in the C1s spectra at 534.0, 533.2, 290, and $292 \mathrm{eV}$, respectively. Supported with previous evidence on $\mathrm{K}$ and molecular orbital calculations, peaks at 530.3 and $292 \mathrm{eV}$ were assigned to carbonates. The peak at $290 \mathrm{eV}$ existed as a shoulder on the one at $292 \mathrm{eV}, \mathrm{C} 1 \mathrm{~s}$ peak of carbonate, along with the $533.2 \mathrm{eV}$ peak and were assigned to anionic bent $\mathrm{CO}_{2}$. Significant spectral changes occurred at temperatures above $370 \mathrm{~K}$, where all the carbonates decomposed into elemental $\mathrm{C}$ and $\mathrm{O}$ atoms. A different phenomenon was observed for $\mathrm{CO}_{2}$ adsorption on a clean Li surface, where adsorbed $\mathrm{CO}$ was also detected as evident from the appearance of peaks at $288.0 \mathrm{eV}$ in $\mathrm{C} 1 \mathrm{~s}$ and $534.3 \mathrm{eV}$ in $\mathrm{O} 1 \mathrm{~s}$, the latter overlapping with the peak due to the surface carbonate [145]. In this case, temperature ramping to $180 \mathrm{~K}$ resulted in decomposition of carbonate to yield $\mathrm{CO}_{2}$ and $\mathrm{CO}$, which further decomposed into elemental $\mathrm{C}$ and $\mathrm{O}$ atoms. Four main reactions were tentatively postulated for this system: activation of $\mathrm{CO}_{2}$, reaction between two anionic $\mathrm{CO}_{2}$ molecules to yield carbonate and $\mathrm{CO}$, decomposition of $\mathrm{CO}$ into elemental $\mathrm{C}$ and $\mathrm{O}$, and lastly, the formation of carbonate from $\mathrm{O}$ and $\mathrm{CO}_{2}[145]$

$$
\begin{gathered}
\mathrm{CO}_{2} \rightarrow \mathrm{CO}_{2}^{-*} \\
2 \mathrm{CO}_{2}^{-*} \rightarrow \mathrm{CO}_{3}^{2-}+\mathrm{CO}^{*} \text { (probably via an oxalate intermediate) } \\
\mathrm{CO} * \rightarrow \mathrm{C}+\mathrm{O}^{2-} \\
\mathrm{CO}_{2}+\mathrm{O}^{2-} \rightarrow \mathrm{CO}_{3}^{2-}
\end{gathered}
$$




\subsection{CO2 bonding on metal oxide surfaces}

4.2.1 Alkaline Earth Metal Oxides. Carbon dioxide is an acid gas which can readily interact with basic surface sites. Some metal oxides, such as $\mathrm{CaO}$ and $\mathrm{MgO}$, possess high basicity and therefore are expected to actively react with $\mathrm{CO} 2$. These two alkaline earth metal oxides are often regarded as model surfaces for the formation of adsorbed carbonates [77]. $\mathrm{CO} 2$ is also used as a surface site, probing molecules in case of $\mathrm{MgO}$, and these interactions have been studied extensively. Aramendia et al., for instance, characterized synthesized MgO particles using DRIFTS to understand the structure/reactivity relationships between the preparation method and the nature of the surface species formed [146]. Philipp and Fujimoto [59] studied $\mathrm{CO} 2$ adsorption using FTIR spectroscopy on $\mathrm{MgO}$ and $\mathrm{CaO}$, as well as mixed oxides of these two alkaline earth metal Busca and Lorenzelli [53] presented a comprehensive account on the IR peak assignments of the surface species observed on various metal oxides, including alkaline earth. Peaks assigned to surface unidentate (monodentate) carbonate as well as bicarbonate arising due to the interaction of $\mathrm{CO} 2$ with surface hydroxyl groups, were observed on the $\mathrm{MgO}$ surface upon exposure to $\mathrm{CO} 2$ at $950{ }^{\circ} \mathrm{C}$. On $\mathrm{CaO}$, similar peaks were observed. In particular, unidentate carbonate complexes were formed in addition to bicarbonate and bridging carbonate. Figure 30 represents the IR spectra of $\mathrm{CO} 2$ adsorbed on $\mathrm{MgO}$ and $\mathrm{CaO}$. Spectra of the adsorption on the mixed oxides has also been reported [59]. 

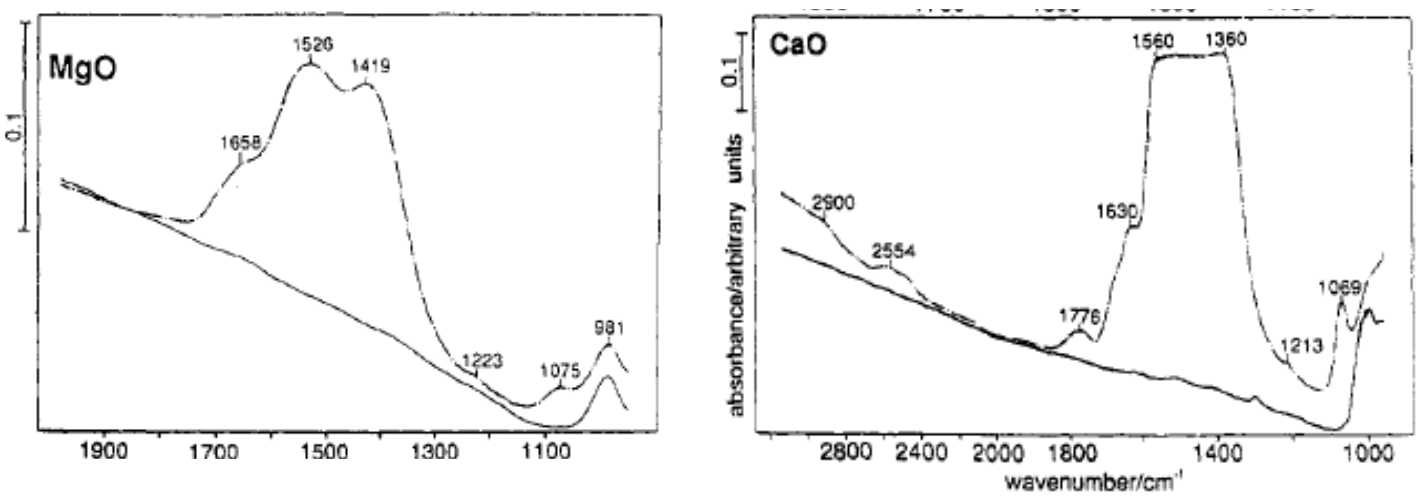

Figure 30. Spectra for $\mathrm{CO}_{2}$ Adsorption on (a) $\mathrm{MgO}$ and; (b) $\mathrm{CaO}$ at Room Temperature. Reproduced with permission from [59]. Copyright (1992) American Chemical Society.

Preparation methods for improving the lifetime of $\mathrm{CaO} / \mathrm{MgO}$ and $\mathrm{CaO} / \mathrm{Al}_{2} \mathrm{O}_{3}$ surfaces were studied by Luo et al. and Sun et al., respectively [147,148]. The methods used were combustion and wet mixing and they successfully increased the lifetime as well as the $\mathrm{CO}_{2}$ adsorption capacity. After several cycles of $\mathrm{CO}_{2}$ adsorption the surface morphology was imaged using SEM and compared with the corresponding metal carbonates. Figures 31 depicts the surface before and after $\mathrm{CO}_{2}$, as well as its comparison with the calcium carbonate. These SEM images suggest that after 20 cycles crystallite size increased from its original state (Figures 31a,b). It can be concluded that the sorbent maintained its $\mathrm{CO}_{2}$ capture capacity even after 20 cycles, where its bulk structure was still far from the morphology of calcium carbonate and the adsorption is surface limited. 


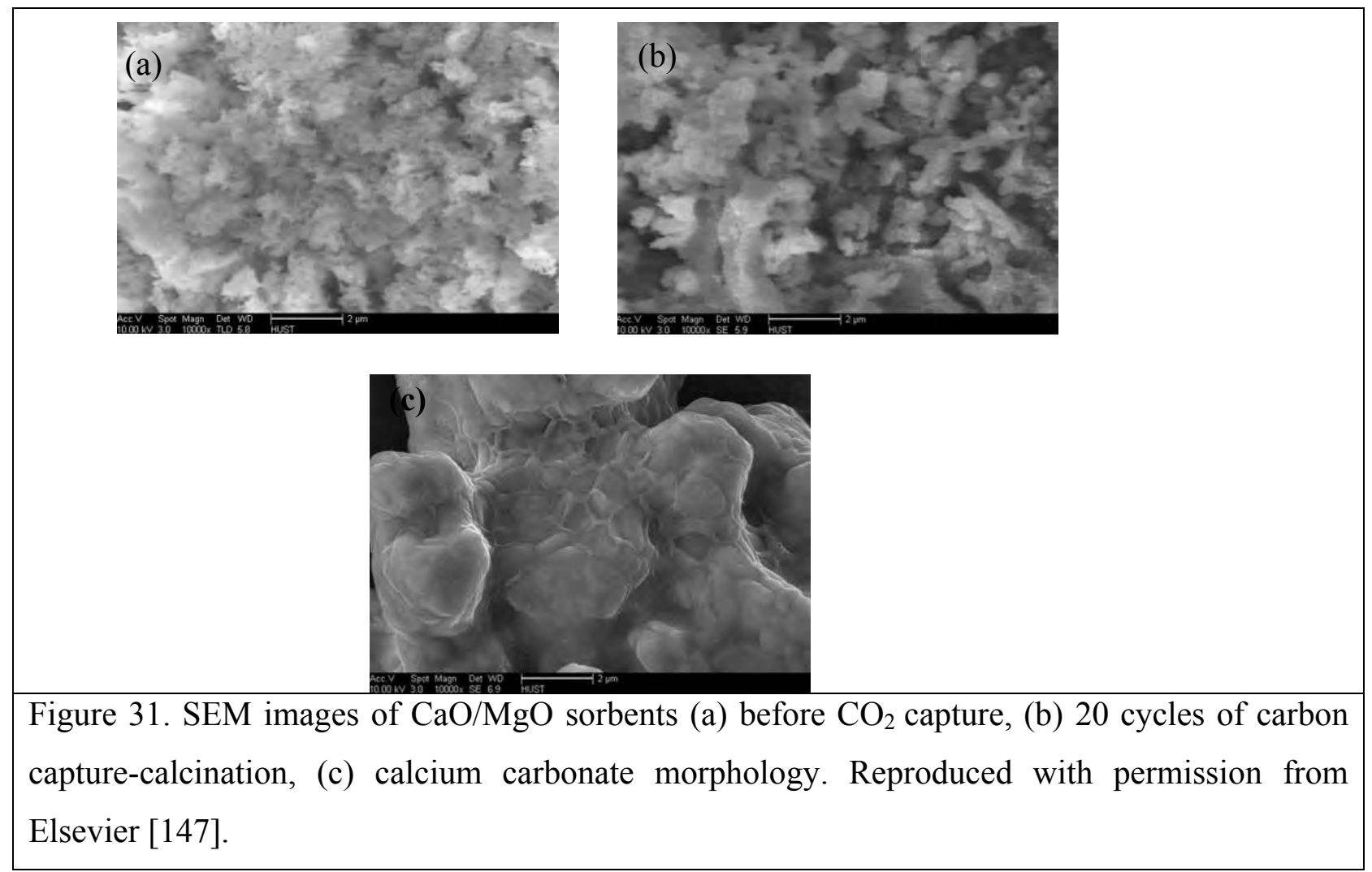

Another attempt at utilizing alkaline earth metal oxides for efficient $\mathrm{CO}_{2}$ adsorption was performed by Shao et al. [51] in which the authors synthesized mesoporous $\mathrm{MgO}$ nanoparticles applicable for $\mathrm{CO}_{2}$ capture. In situ IR spectroscopy was performed at a constant temperature to investigate the surface species formed during the adsorption process and shown in Figure 32 . In addition to an adsorbed complex surface carbonate structure, there was a notable observed peak at $2344 \mathrm{~cm}^{-1}$, due to the linearly adsorbed $\mathrm{CO}_{2}$. This observation complemented the spectra taken by Philipp and Fujimoto [59]. 


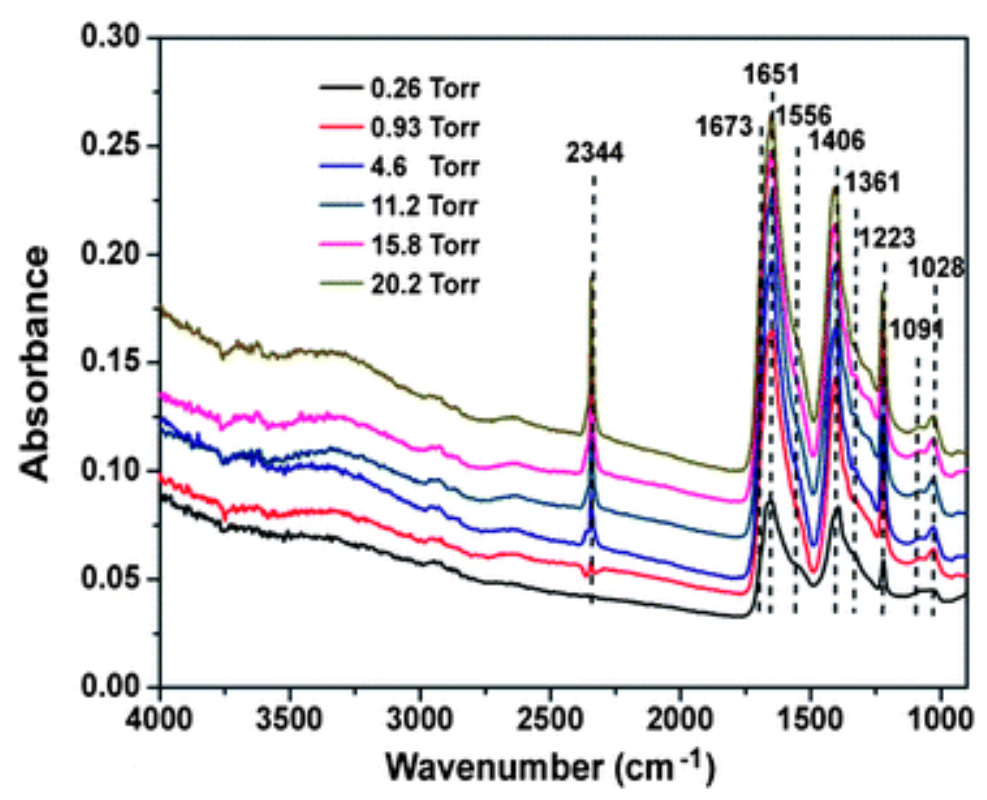

Figure 32. In situ IR Spectra of $\mathrm{CO}_{2}$ Adsorption on Mesoporous $\mathrm{MgO}$ taken at room temperature. Reproduced from [51] with permission from PCCP Owner Societies.

XPS analysis of $\mathrm{CO}_{2}$ adsorption on an $\mathrm{MgO}$ surface was conducted by Aswal et al. [149] and is shown in Figure 33. As received $\mathrm{MgO}$, which already contains $\mathrm{CO}_{2}$ adsorbed as carbonates due to the inherent $\mathrm{MgO}$ reactivity at atmospheric concentrations of $\mathrm{CO}_{2}$, was analyzed along with a thermally treated $\mathrm{MgO} . \mathrm{Mg} 2 \mathrm{p}$ spectra for the pristine crystal resolved peaks at $50.8 \mathrm{eV}$ and 51.6 $\mathrm{eV}$ are indicative of hydroxide and carbonate species, respectively. $\mathrm{O} 1 \mathrm{~s}$ spectra showed peaks at 531.5 and $533.8 \mathrm{eV}$ also due to the presence of $\mathrm{Mg}(\mathrm{OH})_{2}$ and $\mathrm{MgCO}_{3}$. The presence of adsorbed carbonate was further confirmed by the C 1s spectra where two peaks were also detected at 285 $\mathrm{eV}$ and $289 \mathrm{eV}$, with the latter from the carbonate and the former representing physically adsorbed $\mathrm{CO}_{2}$. At higher temperatures, all peaks assigned to the carbonates disappeared, while those assigned to hydroxide shifted to a lower energy value indicating the formation of pure $\mathrm{MgO}$ at higher temperatures. 

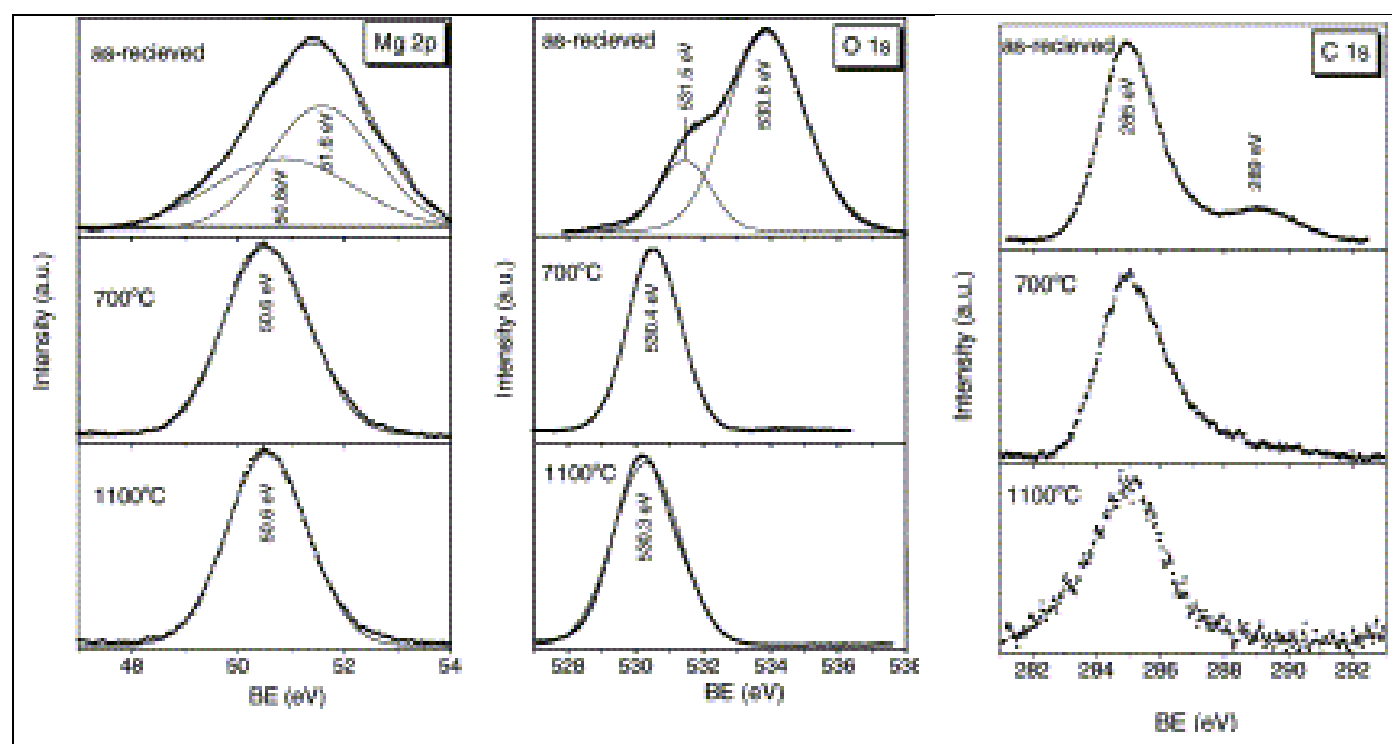

Figure 33. XPS spectra of $\mathrm{MgO}$ treated at different temperatures. Carbonates peaks can be observed on the as-received sample. Reproduced with permission from Elsevier [149].

A similar result on the XPS spectra for the $\mathrm{CO}_{2} / \mathrm{MgO}$ system was also presented by Chakradhar and Burghaus [150] where the spectra revealed a carbonate peak on the C 1s spectrum at 289.4 $\mathrm{eV}$, differing by $0.4 \mathrm{eV}$ from the observation from Aswal et al. [149], possibly due to the variability in the nature of the neighboring species.

Analysis of another $\mathrm{CO}_{2}$ interaction with $\mathrm{CaO}$ was carried out by Voigts et al. [151]. MIES (Metastable Induced Electron Spectroscopy) spectra revealed the ionization of O $2 p$ orbitals in the $\mathrm{CaO}$ via the presence of a peak at $5.1 \mathrm{eV}$, while the triplet carbonate peak appeared in the spectra at 7.4, 12.0 and $14.4 \mathrm{eV}$. Prolonged exposure to $\mathrm{CO}_{2}$ results in the disappearance of the $\mathrm{O}$ $2 p$ peak associated with $\mathrm{CaO}$, which is related to the consumption of the lattice oxygen to form carbonates when $\mathrm{CO}_{2}$ is introduced. Furthermore, dissociation of $\mathrm{CO}_{2}$ is not expected, since $\mathrm{CaO}$ has no density of states near the Fermi level. XPS spectra of the system were obtained in $\mathrm{O} 1 \mathrm{~s}$ and $\mathrm{C} 1 \mathrm{~s}$ regions with two peaks present in the former and only one peak in the latter. The $\mathrm{O}$ 1s region showed a peak at $530.8 \mathrm{eV}$ due to $\mathrm{CaO}$ and $533.5 \mathrm{eV}$ form adsorbed carbonate. The $\mathrm{C} 1 \mathrm{~s}$ 
region exhibited a contribution solely from the surface carbonate at $291.9 \mathrm{eV}$ [151]. Comparison among $\mathrm{BaO}, \mathrm{MgO}$ and $\mathrm{CaO}$ with $\mathrm{CO}_{2}$ adsorption capacity revealed the superiority of the latter [152]. While $\mathrm{BaO}$ and $\mathrm{MgO}$ demonstrated almost negligible adsorption at $600{ }^{\circ} \mathrm{C}, \mathrm{CaO}$ adsorbed nearly 12 wt. \% during a 1 -h equilibrium process. The effects of temperature and dopants on the $\mathrm{CaO}$ surface adsorption were further investigated revealing an increased amount of adsorbed $\mathrm{CO}_{2}$ with increase in temperature and a prominent effect of alkali metal dopants on the adsorption in the following order: $\mathrm{Cs}>\mathrm{Rb}>\mathrm{K}>\mathrm{Na}>$ none $>\mathrm{Li}$. Elucidation of this reactive surface behavior was provided by the XPS spectra of a $20 \% \mathrm{Cs} / \mathrm{CaO}$ surface before and after desorption of the previously $\mathrm{CO}_{2}$ adsorbed sample. The $\mathrm{O}$ 1s spectra show an overlap between the oxygen atom contributions from oxides and carbonates with the latter as a minor component in Figure 34 at $\sim 530.4 \mathrm{eV}$. The oxygen coordinated to either $\mathrm{Ca}$ or $\mathrm{Cs}$, represented by the peak at $532.5 \mathrm{eV}$, maintains its phase before and after adsorption. On the other hand, both $\mathrm{Ca} 2 \mathrm{p}$ and $\mathrm{Cs}$ 3d peaks at $\sim 347$ and $\sim 724 \mathrm{eV}$, respectively, exhibit shifts towards higher binding energy values. These shifts are attributed to the change of phase from the alkali carbonates to their respective oxides at $725{ }^{\circ} \mathrm{C}$. The peak at $530.4 \mathrm{eV}$ was attributed to $\mathrm{CaCO}_{3}$ and $\mathrm{Cs}_{2} \mathrm{CO}_{3}$ showing carbonate formation on the particle surface. 


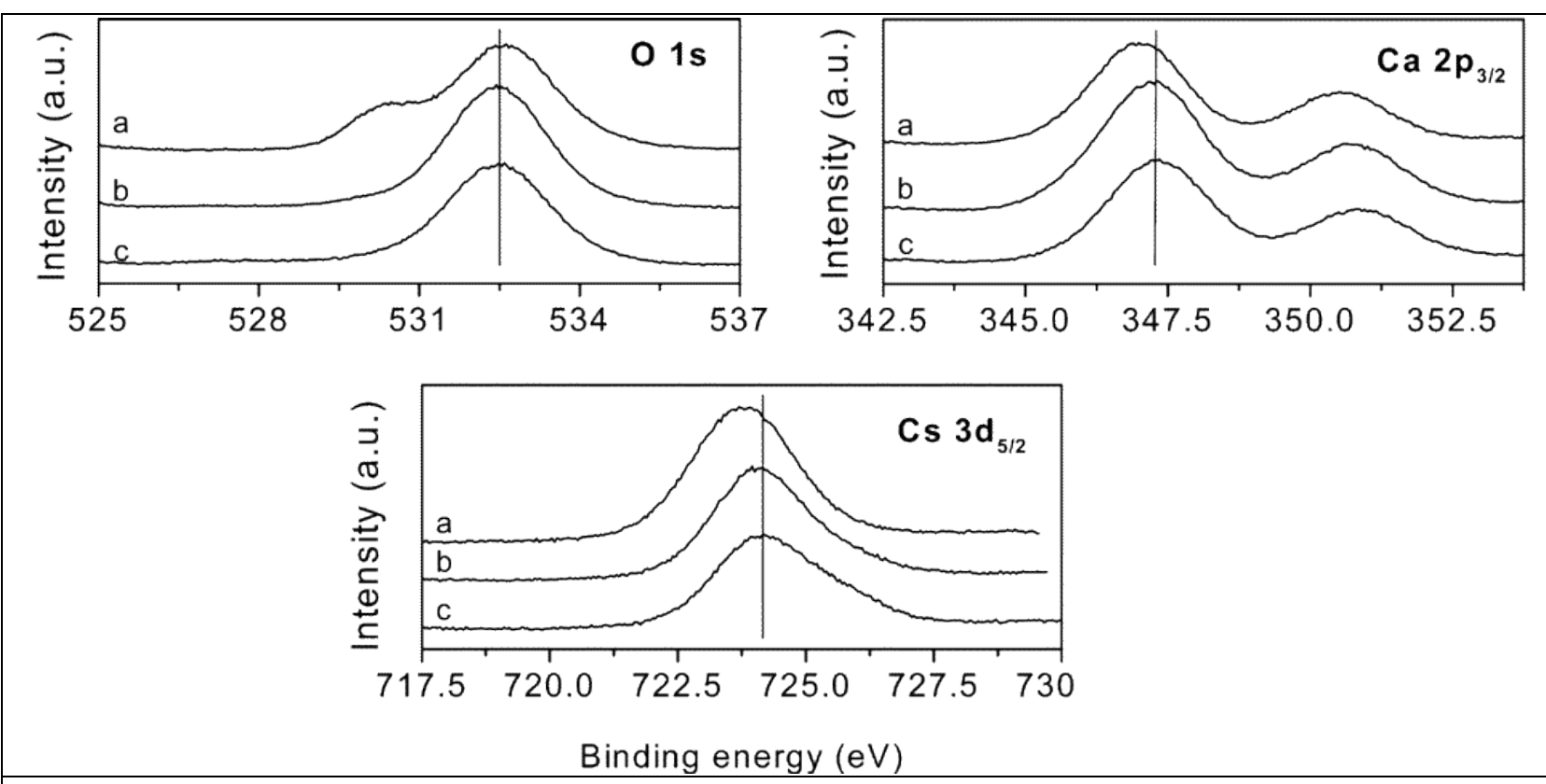

Figure 34. XPS Spectra of Cs 3d, Ca $2 \mathrm{p}$ and $\mathrm{O} 1 \mathrm{~s}$ core level peaks for $20 \mathrm{wt} \% \mathrm{Cs} / \mathrm{CaO}$ surface: (a) after adsorption at $600{ }^{\circ} \mathrm{C}$; (b) after desorption at $725^{\circ} \mathrm{C}$; (c) after temperature treatment at $750^{\circ} \mathrm{C}$. Reproduced with permission from [152]. Copyright (2004) American Chemical Society.

Theoretical modeling of $\mathrm{CO}_{2}$ adsorption using periodic boundary conditions and density functional theory on defect-free alkaline earth metal oxides has been performed previously using VASP computational code [90,153-156]. $\mathrm{MgO}, \mathrm{CaO}, \mathrm{SrO}$, and $\mathrm{BaO}$ were examined and $\mathrm{CO}_{2}$ was found to adsorb on the basic surface oxygen $\left(\mathrm{O}_{\mathrm{s}}{ }^{2-}\right)$. Adsorption was only physical in magnitude since surface oxygen is relatively less reactive than those of lower coordination, such as on steps, corners, and kinks, where adsorption would generate carbonates. Adsorption on $\mathrm{MgO}$, for instance, did not significantly elongate the $\mathrm{C}=\mathrm{O}$ bond and the adsorption energy was about $-3 \mathrm{kcal} / \mathrm{mol}$ [153]. However, $\mathrm{Ca}$ and $\mathrm{Fe}$ doping in the subsurface layer changed the strength of $\mathrm{MgO}(001)$ and $\mathrm{CO}_{2}$ interaction as shown in Figure 35. In particular, BSSE corrected adsorption energy utilizing periodic boundary conditions, Gaussian basis set and hybrid B3LYP

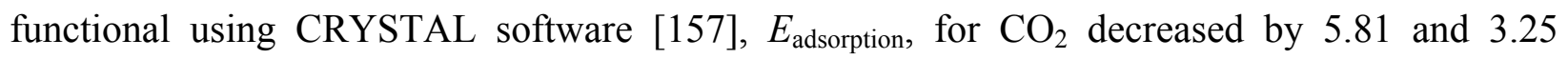
$\mathrm{kcal} / \mathrm{mol}$ from undoped to $\mathrm{Ca}$ - and Fe-doped $\mathrm{MgO}(001)$ with $-8.77,-14.58$, and -12.02 $\mathrm{kcal} / \mathrm{mol}$, respectively. Hence, showed a lower calculated adsorption energy (stronger 
adsorption) of $\mathrm{CO}_{2}$ on $\mathrm{Ca}-$ and Fe-doped $\mathrm{MgO}$ than in the undoped case [158]. This is of particular importance in atmospheric chemistry since $\mathrm{MgO}$ is an important compound in the environment and is found in the form of mineral periclase at $3.7 \%$ in the continental crust. As natural minerals are rarely pure in the environment, naturally occurring $\mathrm{MgO}$ can have varying concentrations of other elements substituted into its crystalline lattice with $\mathrm{Ca}$ and Fe reported as the main dopants and concentrations of Fe as high as 5-10 wt \% [159].

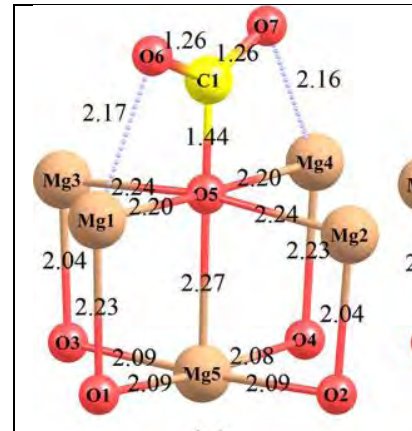

(a)

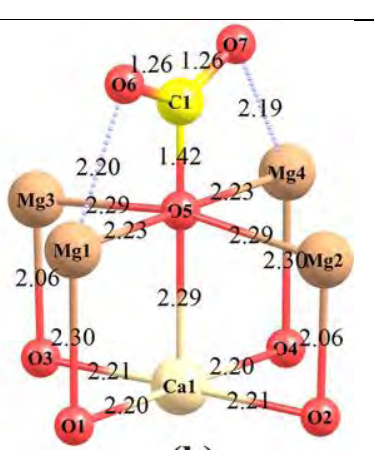

(b)

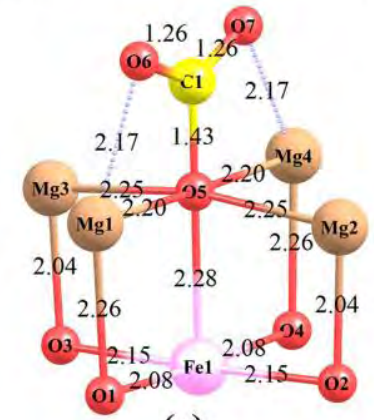

(c)

Figure 35. UB3LYP optimized geometries of $\mathrm{CO}_{2}$ adsorbed on (a) undoped and (b) Ca- or (c) Fe-doped $\mathrm{MgO}(001)$ surfaces. Only relevant atoms are shown. Reproduced with permission from [158]. Copyright (2012) American Chemical 
Society.

Adsorption of $\mathrm{CO}_{2}$ on defect sites, e.g. corners and steps, of $\mathrm{CaO}$ resulted in the formation of monodentate carbonate while on $\mathrm{MgO}$, monodentate was formed on the edge sites and bidentate on corner sites [90]. Figure 36 below shows the defect sites of a $\mathrm{CaO} / \mathrm{MgO}$ slab.

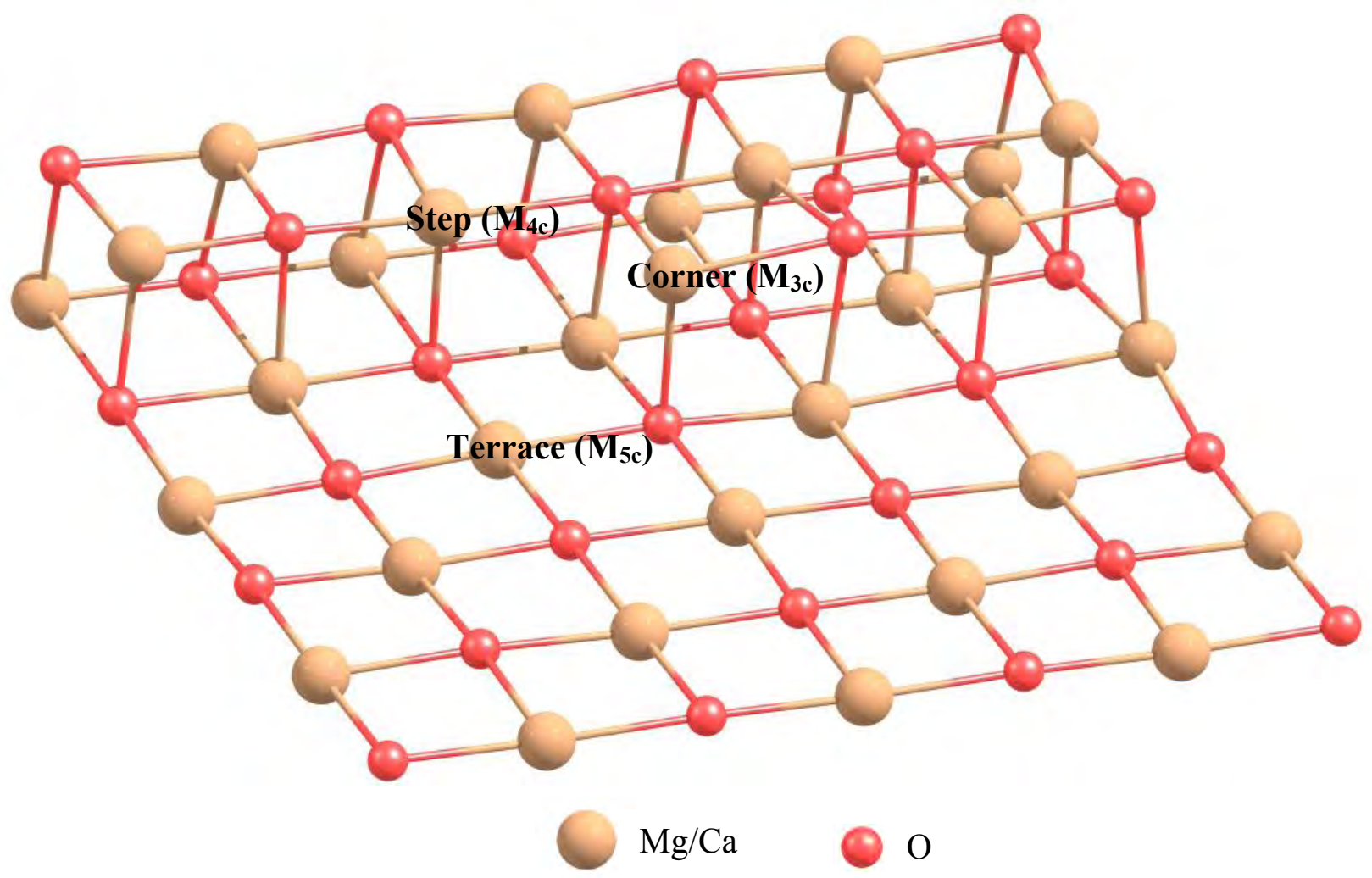

Figure 36. Low-coordination sites on $\mathrm{CaO}$ and $\mathrm{MgO}$ surface, including step $\left(\mathrm{M}_{4 \mathrm{c}}\right)$, corner $\left(\mathrm{M}_{3 \mathrm{c}}\right)$, and terrace $\left(\mathrm{M}_{5 \mathrm{c}}\right) ; \mathrm{M}=\mathrm{Ca} / \mathrm{Mg}$.

GGA (General Gradient Approximation) was also applied using CASTEP (Cambridge Sequential Total Energy Package) [160] for $\mathrm{CO}_{2}$ adsorption on $\mathrm{BaO}$ [154]. $\mathrm{CO}_{2}$ was found to chemisorb on the surface in a form of carbonate to a large extent. Calculated IR intensities, wavenumbers, and adsorption energies of $\mathrm{CO}_{2}$ on $\mathrm{MgO}$ and $\mathrm{CaO}$ are shown in Tables 16 and 17. 
Table 16. Calculated Wavenumbers, IR Intensities, and Adsorption Energies of $\mathrm{CO}_{2}$ at Various $\mathrm{MgO}$ Sites. Reproduced with permission from [90]. Copyright (2005) American Chemical Society.

\begin{tabular}{lllllr}
\hline Adsorption mode & $v_{3}$ as $\left(\mathrm{cm}^{-1}\right)$ & $v_{3} \mathrm{~s}\left(\mathrm{~cm}^{-1}\right)$ & $v_{1}\left(\mathrm{~cm}^{-1}\right)$ & $v_{2}\left(\mathrm{~cm}^{-1}\right)$ & $\mathrm{E}_{\text {ads }}(\mathrm{kJ} / \mathrm{mol})$ \\
\hline terrace, $\mathrm{O}_{5 \mathrm{c}}$, dih ang $0^{\circ}$ & 1784 & 1288 & 827 & 821 & 13 \\
step, $\mathrm{O}_{4 \mathrm{c}}$ & 1703 & 1327 & 1011 & 849 & -154 \\
corner, $\mathrm{O}_{3 \mathrm{c}}$, bidentate & 1778 & 1243 & 932 & 847 & -115 \\
corner, $\mathrm{O}_{3 \mathrm{c}}$, tridentate & 1451 & 1451 & 1084 & 906 & -152 \\
\hline
\end{tabular}

Table 17. Calculated Wavenumbers, IR Intensities, and Adsorption Energies of $\mathrm{CO}_{2}$ at Various $\mathrm{CaO}$ Sites. Reproduced with permission from [90]. Copyright (2005) American Chemical Society.

\begin{tabular}{lllllr}
\hline Adsorption mode & $v_{3}$ as $\left(\mathrm{cm}^{-1}\right)$ & $v_{3} \mathrm{~s}\left(\mathrm{~cm}^{-1}\right)$ & $v_{1}\left(\mathrm{~cm}^{-1}\right)$ & $v_{2}\left(\mathrm{~cm}^{-1}\right)$ & Eads $(\mathrm{kJ} / \mathrm{mol})$ \\
\hline terrace, $\mathrm{b}_{5 \mathrm{c}}$, dih ang $0^{\circ}$ & 1708 & 1298 & 876 & 847 & -100 \\
terrace, $\mathrm{b} \mathrm{O}_{5 \mathrm{c}}$, dih ang $45^{\circ}$ & 1692 & 1304 & 927 & 868 & -60 \\
step, $\mathrm{O}_{4 \mathrm{c}}$ & 1664 & 1316 & 968 & 845 & -219 \\
corner, $\mathrm{O}_{3 \mathrm{c}}$, monodentate & 1603 & 1314 & 1035 & 876 & -222 \\
corner, $\mathrm{O}_{3 \mathrm{c}}$, bidentate & 1703 & 1257 & 944 & 845 & -182 \\
corner, $\mathrm{O}_{3 \mathrm{c}}$, tridentate & 1461 & 1423 & 1080 & 881 & -164 \\
\hline
\end{tabular}

Cluster calculations, using the $a b$ initio Hartree-Fock approximation and assuming perfect ionicity of $\mathrm{MgO}$ and $\mathrm{CaO}$ crystals, were carried out. These calculations demonstrated formation of more strongly-bound carbonates on $\mathrm{CaO}$, because to the $\mathrm{CaO}$ is a better base. This was resolved from the decomposition of the interaction energy into electrostatic, polarization and charge transfer contributions [155]. The formation of $\mathrm{BaCO}_{3}$ on a pristine $\mathrm{BaO}$ surface after saturating it with $\mathrm{CO}_{2}$ was confirmed through XPS analysis [161]. Typical peaks that were associated with $\mathrm{BaCO}_{3}$ were observed, e.g. $289.5 \mathrm{eV}$ in $\mathrm{C} 1 \mathrm{~s}$ and $531.5 \mathrm{eV}$ in the $\mathrm{O} 1 \mathrm{~s}$ spectra. The assignments of these peaks was in agreement with those of $\mathrm{CaO}$ by Voights et al. [151].

4.2.2 Alkaline Metal Oxides. A recent review paper by Wang et al. in 2011 discusses the use of alkaline metal oxides, notably oxides and oxide composites of $\mathrm{Na}$ and $\mathrm{Li}$ [162], for $\mathrm{CO} 2$ 
adsorption. The group I oxides are the most basic oxides. Therefore, they should have the highest capability to adsorb carbon dioxide, an acid gas molecule. Duan and Sorescu performed a theoretical study of the structural, electronic and phonon properties of $\mathrm{Li} 2 \mathrm{O}$ and $\mathrm{Li} 2 \mathrm{CO} 3$ [163]. This VASP simulation led to the notion that Li2O would not be a good adsorbing surface for $\mathrm{CO} 2$ due to its very strong affinity for the acid gas, allowing desorption to take place only at very low $\mathrm{CO} 2$ pressure or very high temperature, where the carbonate is in a liquid phase. Calculations of all the vibration modes of both IR and Raman spectra of Li2CO3 are in a good agreement with earlier theoretical and experimental studies [164]. A comprehensive analysis of $\mathrm{CO} 2$ adsorption on Li2O, including TGA, SEM and $\mathrm{XRD}$, before and after the adsorption, together with the adsorption isotherms at various temperatures, was carried out by Mosqueda et al. [165]. In agreement with the work of Duan, $\mathrm{Li} 2 \mathrm{O}$ was found to be extremely reactive with the formation of carbonate, but not for the reverse reaction. XRD experiments with the sample during adsorption at high temperatures and post-desorption showed the formation of carbonate without significant desorption taking place even after 22 days. Two models were inferred from the adsorption isotherm curves, including a first-order surface reaction and a diffusional mechanism, controlled by the movement of an interface moving from the surface inward [165]. Other alkaline metal oxide composites, such as lithium silicate, were also studied as $\mathrm{CO} 2$ adsorbing surfaces at room temperature. Research from the Toshiba R\&D laboratory revealed that humidity played an important role in promoting $\mathrm{CO} 2$ adsorption [166]. Lithium silicate was confirmed to be superior to another commercially available adsorbent (soda lime) under conditions of controlled humidity. Nakagawa's group performed a body of work in oxide composites of lithium [167]. Lithium zirconate (Li2ZrO3) and orthosilicate (Li4SiO4) were explored, with the latter being the more promising of the two composite oxides. The use of 
composites, as opposed to the bare $\mathrm{Li} 2 \mathrm{O}$, provided reversible $\mathrm{CO} 2$ adsorption mechanisms that cannot be realized via the use of $\mathrm{Li} 2 \mathrm{O}$ directly. Of the two composites, $\mathrm{Li} 4 \mathrm{SiO} 4$ generated multiple sites for the lithium ion to hop, which therefore created faster hopping and the stronger $\mathrm{CO} 2$ adsorbing surface, even at room temperature. SEM images of Li4SiO4 were recently obtained [168]. The kinetic modeling of the associated surface was also performed, where carbonation, i.e. $\mathrm{CO} 2$ adsorption, and decarbonation, i.e., $\mathrm{CO} 2$ desorption, took place between $500-715{ }^{\circ} \mathrm{C}$ and above, respectively. Carbonation of the initially smooth surface resulted in the formation of single particles on the surface, as shown in Figure 37. After decarbonation, however, the surface particles disappear and its roughness changes.

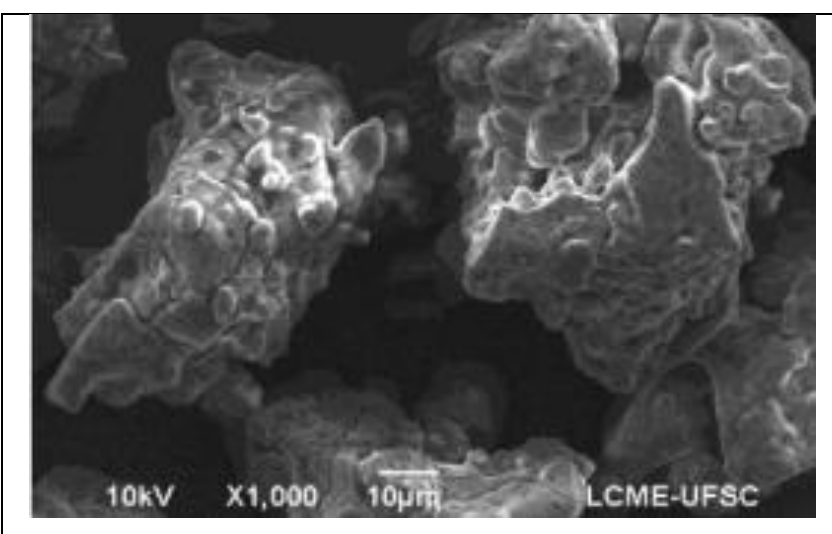

(a)

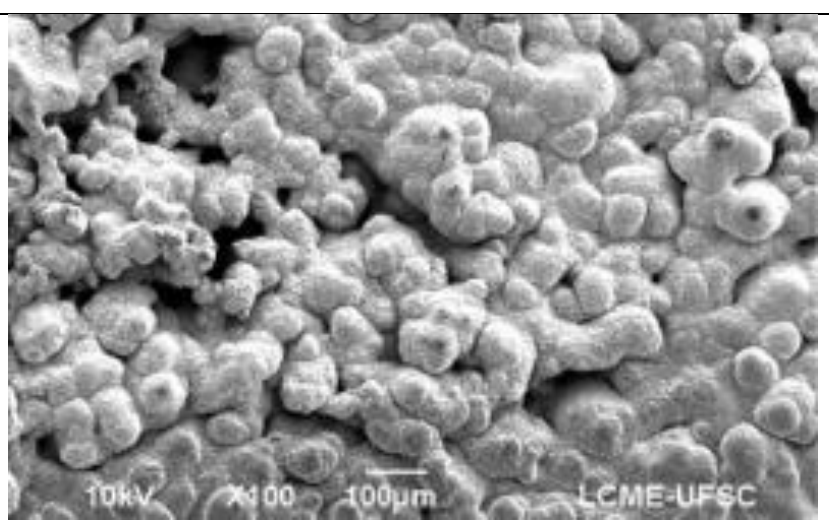

(b)

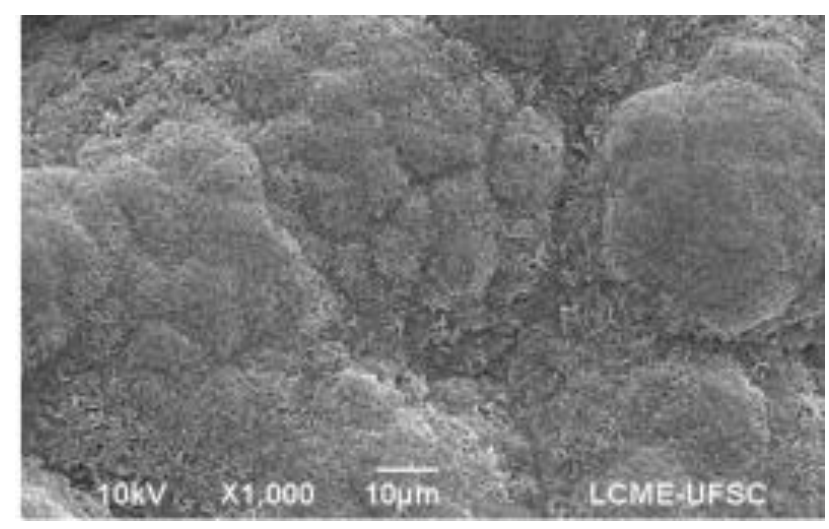

(c)

Figure 37. SEM images of $\mathrm{Li}_{4} \mathrm{SiO}_{4}$ sorbents; (a) pretreated, (b) after carbonation, and (c) after regeneration. Reproduced with permission from Elsevier. [168] 
Calculations on alkali carbonates and Raman experiments had been done before and can be found elsewhere [164]. However, not much work has been done to attempt to use these single alkali metal oxides as a $\mathrm{CO}_{2}$ adsorbing surface, mostly likely due to their high reactivity and stability of the resulting structures with $\mathrm{CO}_{2}$ desorption being very thermodynamically limited. 


\subsubsection{Other Metal Oxides (Pure and Doped Al2O3, ZrO2, Cr2O3, TiO2, ZnO, Ga2O3)}

4.2.3.1 $\mathrm{Al}_{2} \mathrm{O}_{3}$ Doped $\mathrm{Al}_{2} \mathrm{O}_{3}$ was also studied for the $\mathrm{CO}_{2}$ sequestration purpose as an adsorbent. $\mathrm{Al}_{2} \mathrm{O}_{3}$ is a feasible $\mathrm{CO}_{2}$ adsorbent because it is inexpensive, has high surface area and possesses good mechanical and thermal stability $[5,169]$. The adsorption capacities of a typical basic $\mathrm{Al}_{2} \mathrm{O}_{3}$ surface (98AA1149) at three temperatures were measured in the order of $Q(293 \mathrm{~K})>Q(573 \mathrm{~K})>$ $Q(473 \mathrm{~K})$, at $1,0.62$, and $0.35 \mathrm{mmol} / \mathrm{g}$ at $1 \mathrm{bar}$, respectively. To improve $\mathrm{CO}_{2}$ adsorption capacity of $\mathrm{Al}_{2} \mathrm{O}_{3}$, other basic metal oxides have been added via surface impregnation before high temperature calcination. Caram's group at Lehigh University studied chemisorption of $\mathrm{CO}_{2}$ on $\mathrm{Na}_{2} \mathrm{O}$ promoted $\mathrm{Al}_{2} \mathrm{O}_{3}$ and developed a relevant model, where the adsorption isotherm follows the Langmuirian model, but deviating at higher temperatures. The column breakthrough curves for the reversible adsorption-desorption can also be described by the linear driving force (LDF) model in conjunction with the adsorption isotherm [170]. At lower $\mathrm{CO}_{2}$ pressures of up to $2.0 \mathrm{kPa}$ the adsorption isotherms followed Langmuir behavior, while deviation was observed at higher $\mathrm{CO}_{2}$ pressures. The column breakthrough curves for both $\mathrm{CO}_{2}$ sorption from inert $\mathrm{N}_{2}$ and desorption by $\mathrm{N}_{2}$ purge fit the linear driving force model in conjunction. This is with the new sorption isotherm, where the mass transfer coefficients were independent of $\mathrm{CO}_{2}$ feed gas concentration and were a weak function of temperature. IR spectroscopy analysis of $\mathrm{CO}_{2}$ adsorption on $\mathrm{Al}_{2} \mathrm{O}_{3}$ was investigated at pressures of 51, 97, 185, 280, 498, and 915 mTorr [5]. Peaks associated with $\delta_{4}, v_{3} \mathrm{~s}, v_{3}$ as and $v_{5}$ were observed at $1228,1435,1650$ and $3620 \mathrm{~cm}^{-1}$, respectively, for adsorbed bidentate bicarbonate. Also present on $\gamma-\mathrm{Al}_{2} \mathrm{O}_{3}$ surface were other peaks and they were located at 1383 and $1040 \mathrm{~cm}^{-1}$, for monodentate carbonate $\left(v_{3} \mathrm{~s}, v_{1}\right)$ and $1644,1355,1010 \mathrm{~cm}^{-1}$ for bidentate carbonate $\left(v_{3}\right.$ as, $\left.v_{3} \mathrm{~s}, v_{1}\right)$ [5].

Horiuchi et al. impregnated rare earth, alkaline earth and alkaline metal oxides onto $\mathrm{Al}_{2} \mathrm{O}_{3}$, producing dispersed metal oxide particles on the surface in an effort to increase the $\mathrm{CO}_{2}$ retention time [72]. As expected, alkaline metal oxides, particularly $\mathrm{Cs}_{2} \mathrm{O}$, gave the highest $\mathrm{CO}_{2}$ retention time, while rare earth metal oxides were the worst performers. This observation demonstrated the efficacy of metal oxides with low electronegativity in stabilizing the adsorption 
of $\mathrm{CO}_{2}$, thus resulting in a satisfactory $\mathrm{CO}_{2}$ separation from the feed stream. IR spectra of the adsorbed $\mathrm{CO}_{2}$ indicated the formation of a monodentate bicarbonate species, which disappeared upon evacuation at $373 \mathrm{~K}$. That formation was observed at 1230,1450 , and $1650 \mathrm{~cm}^{-1}$. Impregnation with $\mathrm{MgO}$ gave rise to a more strongly bound bicarbonate species, which was persistent even after evacuation at $473 \mathrm{~K}$ and a weak peak at $1330 \mathrm{~cm}^{-1}$ assigned to bidentate carbonate. $\mathrm{CaO}, \mathrm{BaO}$, and $\mathrm{SrO}$-modified $\mathrm{Al}_{2} \mathrm{O}_{3}$ gave similar spectra to those of $\mathrm{MgO}$-doped $\mathrm{Al}_{2} \mathrm{O}_{3}$, with the only difference appearing in the peaks at $1350 \mathrm{~cm}^{-1}$ and $1600 \mathrm{~cm}^{-1}$ which still remained after evacuation at $573 \mathrm{~K}$ and indicated the presence of adsorbed carbonate, as shown in Figure 38. 

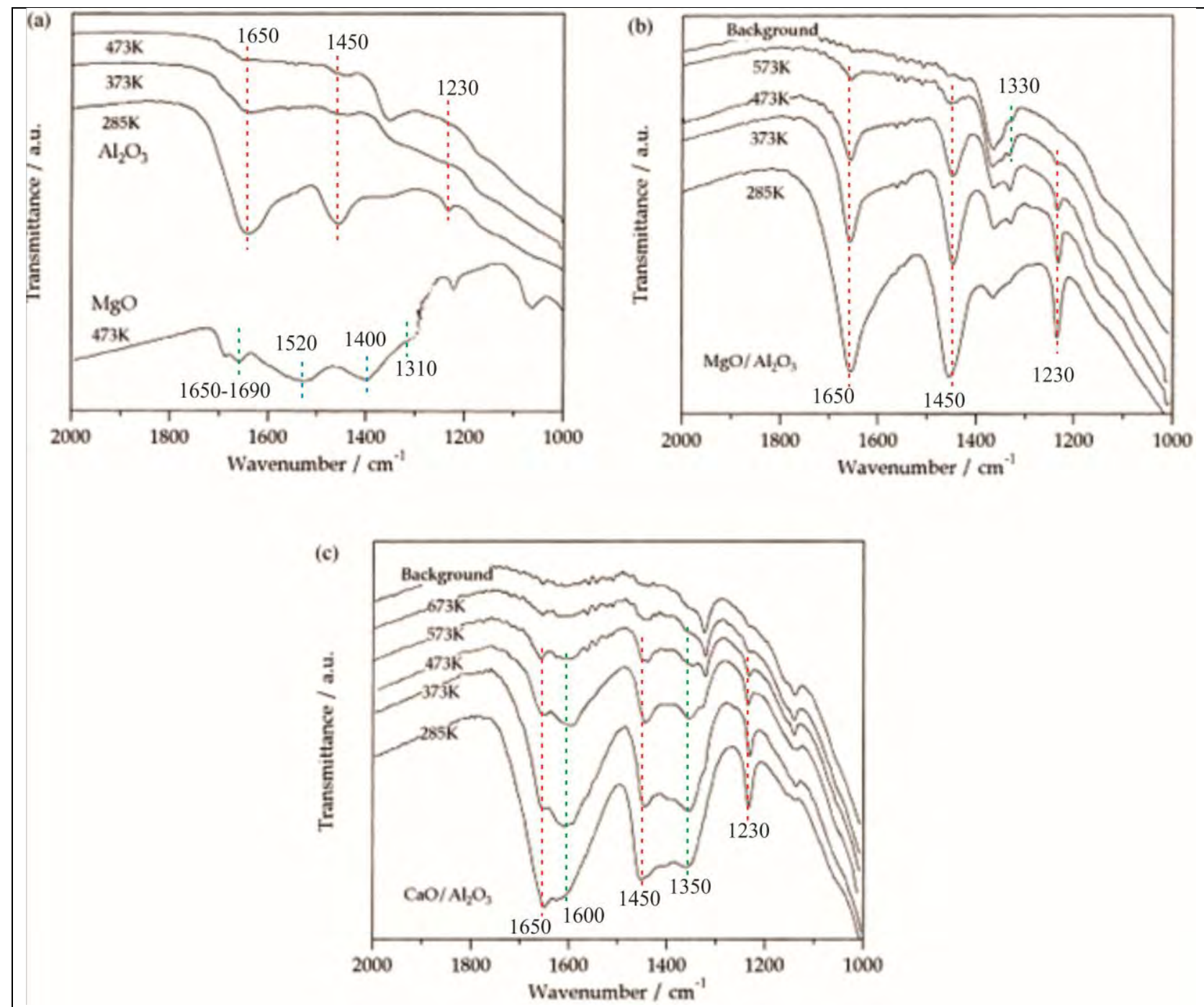

Figure 38. IR spectra of $\mathrm{CO}_{2}$ adsorbed on (a) $\gamma-\mathrm{Al}_{2} \mathrm{O}_{3}$ and $\mathrm{MgO}$ (b) $\mathrm{MgO}$-impregnated $\mathrm{Al}_{2} \mathrm{O}_{3}$ at various temperatures and (c) IR spectra of $\mathrm{CO}_{2}$ adsorbed on $\mathrm{CaO}$ - impregnated $\mathrm{Al}_{2} \mathrm{O}_{3}$ at various temperatures. Red, blue, and green dashed lines represent monodentate bicarbonate, monodentate carbonate, and bidentate carbonate, respectively. Reproduced with permission from [72]. Copyright (1998) American Chemical Society.

Keturakis et al. investigated the surface chemistry of $\mathrm{CO}_{2}$ adsorption on $\gamma-\mathrm{Al}_{2} \mathrm{O}_{3}$ with and without Na modification [75]. The IR spectroscopy data they obtained on bare $\mathrm{Al}_{2} \mathrm{O}_{3}$ surface is in accordance with that by Horiuchi et al. , indicating the formation of bicarbonate as the only 
surface species present. However, the addition of $\mathrm{Na}$ to the surface would unselectively bind to the surface hydroxyl groups, replacing the proton as well as activating inert hydroxyl sites, hence, forming bidentate and polydentate carbonates [75]. Prinetto et al. studied the use of Pt$\mathrm{K} / \mathrm{Al}_{2} \mathrm{O}_{3}$ as a $\mathrm{NO}_{\mathrm{x}}$ Storage Reduction (NSR) catalyst [171]. In their study, the use of $\mathrm{CO}_{2}$ as a probe molecule was employed on the substrates allowing further understanding of the interaction between $\mathrm{CO}_{2}$ and doped $\mathrm{Al}_{2} \mathrm{O}_{3}$ surface. For a Pt-doped sample few surface species were formed. The peaks at 2345 and $2358 \mathrm{~cm}^{-1}$, in the range of $1780-1860 \mathrm{~cm}^{-1}$ correlated with peaks at 1200 $1180 \mathrm{~cm}^{-1}$, and were reversible when outgassing at room temperature. The first doublet is associated with linearly physisorbed $\mathrm{CO}_{2}$, with the second group of peaks corresponding to strongly bent $\mathrm{CO}_{2}$ molecules. Other species observed were two surface bicarbonates, indicated by the stable peaks at $1646,1480,1440$, and $1230 \mathrm{~cm}^{-1}$, and assigned to the $v_{3}$ as, $v_{3} \mathrm{~s}$, and $\delta_{4}$ modes, respectively. Impregnating $\mathrm{K}$ on Pt-impregnated $\mathrm{Al}_{2} \mathrm{O}_{3}$ resulted in an envelope of five strongly overlapping peaks at 1710, 1685, 1660, 1645, and $1610 \mathrm{~cm}^{-1}$, a second envelope centered around $1320 \mathrm{~cm}^{-1}$, and a third one at 1100,1070, $1010 \mathrm{~cm}^{-1}$. Those three envelopes were assigned to either bridged or bidentate carbonates. The formation of the bridged carbonates was thought to result from the addition of the K phase [171].

The fact that $\mathrm{MgO}$ and $\mathrm{CaO}$ are strong adsorbents of $\mathrm{CO}_{2}$ motivated researchers to impregnate them onto pristine $\gamma-\mathrm{Al}_{2} \mathrm{O}_{3}$ surfaces $[73,74,81]$. But conflicting findings were reported on the $\mathrm{MgO}$ doped surfaces, where Li et al. observed monodentate bicarbonate formed due to the bending vibration at $1220 \mathrm{~cm}^{-1}$ and $1650 \mathrm{~cm}^{-1}$. In addition, there were unidentate and bidentate carbonates, characterized by the peaks at $1420,1506,1574,1591 \mathrm{~cm}^{-1}$, and $1380,1708 \mathrm{~cm}^{-1}$, respectively [73]. Hu et al., however, only spotted bridged carbonate, free carbonate ions, and bidentate carbonate. These were indicated by the peaks at 1675 and $1403 \mathrm{~cm}^{-1}$ assigned to 
surface bridged carbonate species and free carbonate ion, and 1610 and $1340 \mathrm{~cm}^{-1}$ due to $v_{3}$ as and $v_{3} s$ of surface bidentate carbonate species, respectively [74]. TPD confirmed the disappearance of bicarbonate at $150{ }^{\circ} \mathrm{C}$, while above $450{ }^{\circ} \mathrm{C}$ only monodentate carbonate was observed [73].

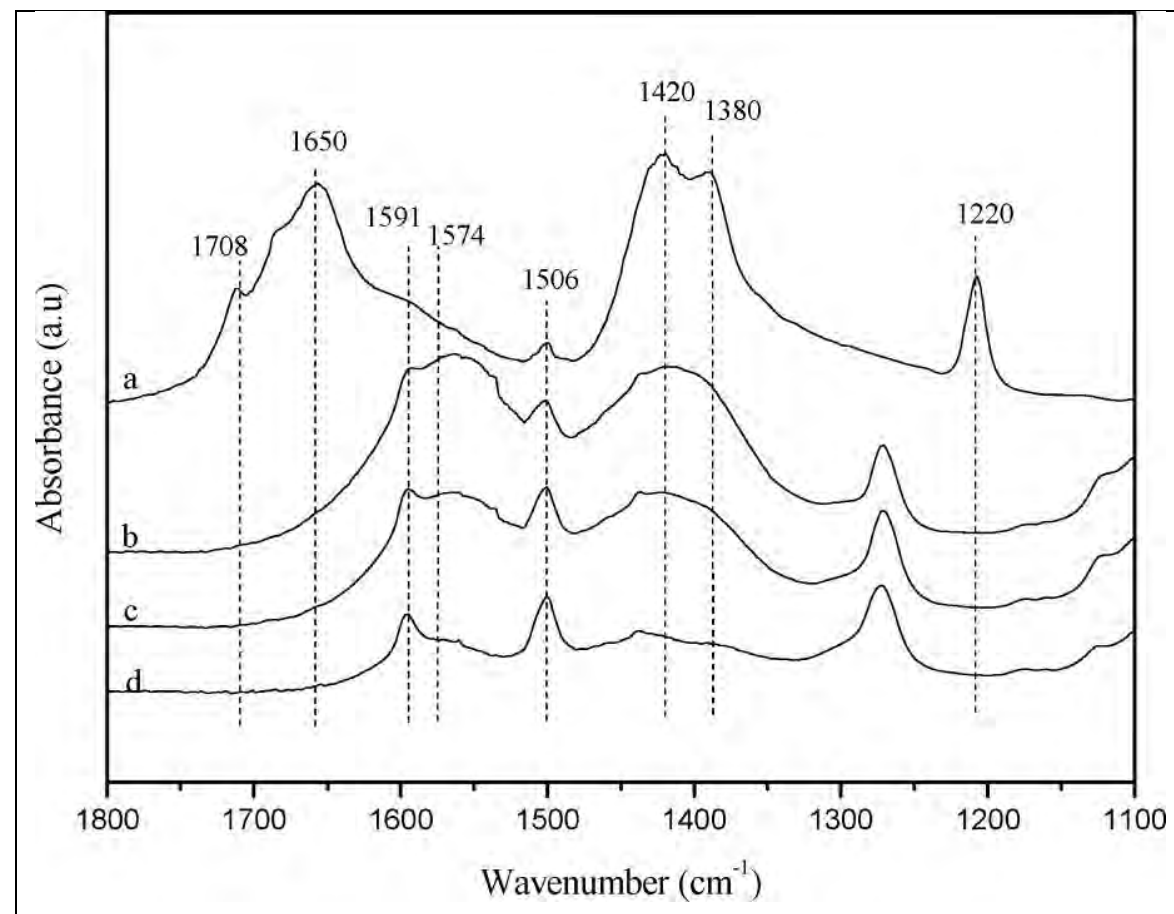

Figure 39. IR spectra of $\mathrm{CO}_{2}$ adsorbed over $\mathrm{MgO} / \mathrm{Al}_{2} \mathrm{O}_{3}$ surface upon increasing evacuation temperatures: (a) $30{ }^{\circ} \mathrm{C}$, (b) $150{ }^{\circ} \mathrm{C}$, (c) $300{ }^{\circ} \mathrm{C}$, and (d) $450{ }^{\circ} \mathrm{C}$. Reproduced with permission from [73]. Copyright (2010) American Chemical Society.

DRIFTS confirmed very different surface interactions between $\mathrm{CO}_{2}$ and the surface, when $\mathrm{CaO} /$ $\gamma-\mathrm{Al}_{2} \mathrm{O}_{3}$ was used instead of pristine $\mathrm{CaO}$. On a clean $\mathrm{Al}_{2} \mathrm{O}_{3}$ surface at $300{ }^{\circ} \mathrm{C}$, weakly-bound bidentate bicarbonate $\left(1649,1440,1230 \mathrm{~cm}^{-1}\right)$ and carbonate $\left(1518,1300 \mathrm{~cm}^{-1}\right)$ species. The associated peaks readily vanished upon degassing. On pure $\mathrm{CaO}$ the surface species formed was strongly-bound carbonate, differing significantly from those found on $\mathrm{CaO} / \gamma-\mathrm{Al}_{2} \mathrm{O}_{3}$, as shown in Figure 40. Only two peaks were observed at 1630 and $1340 \mathrm{~cm}^{-1}$. They were assigned to the $v_{3}$ 
doublet vibration of a carbonate species, most likely bidentate. The splitting $\Delta v_{3}$ is $135 \mathrm{~cm}^{-1}$ and larger, as compared to $\mathrm{CO}_{2}$ on bulk $\mathrm{CaO}$. The carbonate is loosely-bound and desorbs with time, indicating surface inability to retain the adsorbed $\mathrm{CO}_{2}[81]$.

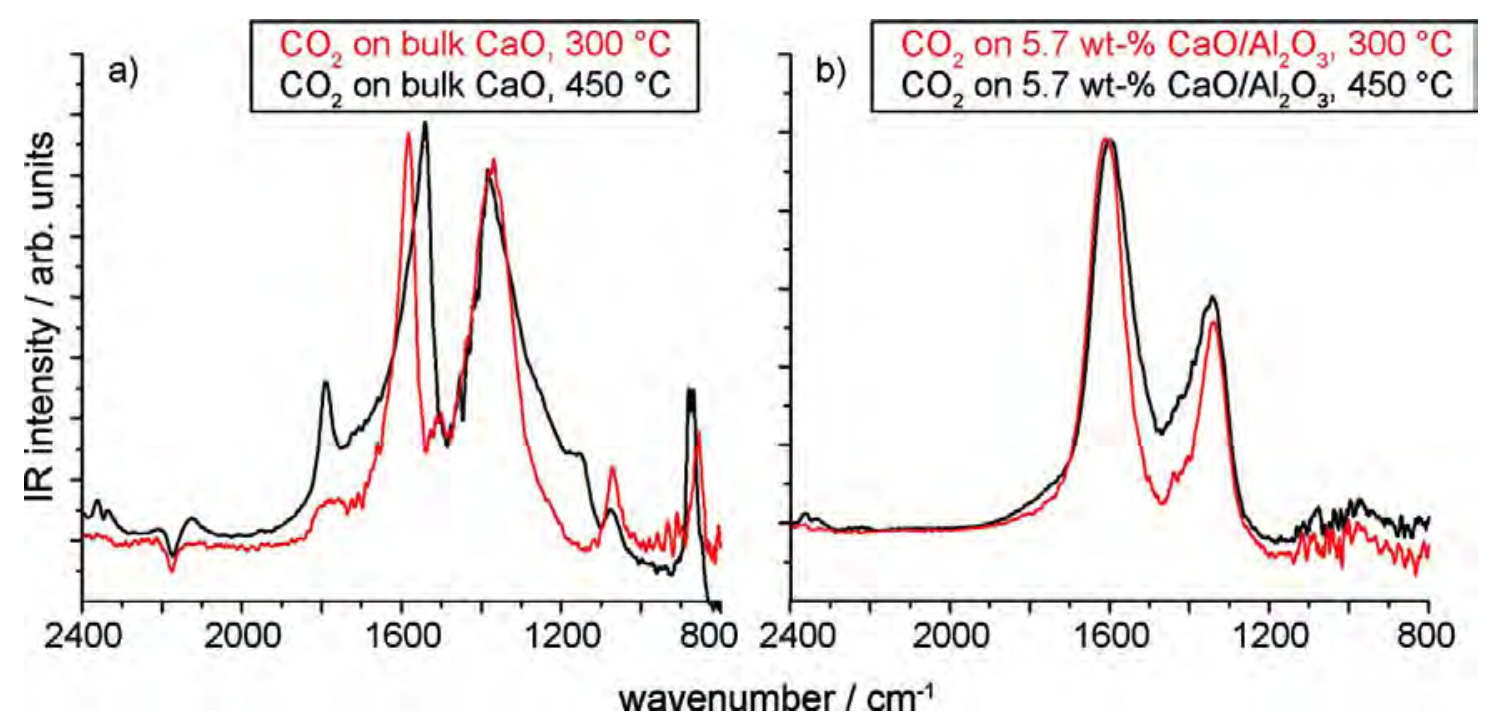

Figure 40. DRIFT spectrum of $\mathrm{CO}_{2}$ on (a) bulk $\mathrm{CaO}$ powder and (b) $\mathrm{CaO} / \gamma-\mathrm{Al}_{2} \mathrm{O}_{3}$ at 300 and 450 ${ }^{\circ} \mathrm{C}$. Reproduced with permission from [81]. Copyright (2011) American Chemical Society.

The proposed molecular structures of the adsorbed bicarbonate structures were verified using cluster model calculations at the DFT/B3LYP/6-31+G(d) level of theory [50]. The comparison between the experimental and calculated vibrational frequencies of adsorbed $\mathrm{HC}^{16} \mathrm{O}_{3}^{-}, \mathrm{DC}^{16} \mathrm{O}_{3}^{-}$, $\mathrm{HC}^{18} \mathrm{O}_{3}^{-}, \mathrm{HC}^{16} \mathrm{O}^{18} \mathrm{O}_{2}^{-}$, and $\mathrm{HC}^{18} \mathrm{O}^{16} \mathrm{O}_{2}^{-}$indicated that bicarbonate bonds to the surface in a bridged structure. Also, detailed analysis of the mixed isotope bicarbonate data suggested a proton transfer from the surface hydroxyl groups to the adsorbed bicarbonate ion. This was followed by the intramolecular transfer with the MP2/6-311+G(d,p) calculated barrier of 25.78 $\mathrm{kcal} / \mathrm{mol}$, a rather high energy. An alternate intermolecular pathway involves neighboring hydroxyl or bicarbonate groups. A similar mechanism involving surface bicarbonate was later believed to take place during carbonic acid $\left(\mathrm{H}_{2} \mathrm{CO}_{3}\right)$ formation on $\mathrm{Al}(\mathrm{OH})_{3}$ clusters using RI- 
SCS-MP2/aug-cc-pVTZ//B3LYP/6-311++G(d,p) level of theory [172]. A main point regarding the potential energy surface (PES) enabling a low energy barrier transition state was the stabilization of bicarbonate on the $\mathrm{Al}(\mathrm{OH})_{3}$ cluster (step III in Figure 41). This is followed by either intra- or intermolecular proton transfer involving bound $\mathrm{H}_{2} \mathrm{O}$ molecules (step IV) to yield a stable $\mathrm{H}_{2} \mathrm{CO}_{3}$ molecule.

\begin{tabular}{|c|c|c|c|c|c|}
\hline$\frac{\text { I }}{}$ & II & III & IV & V & VI \\
\hline (1.70 & (174.6 & 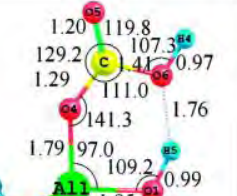 & 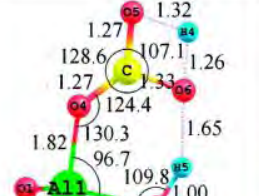 & 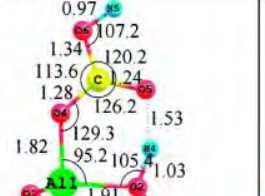 & 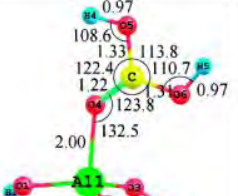 \\
\hline 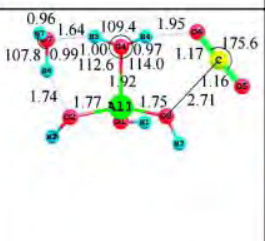 & 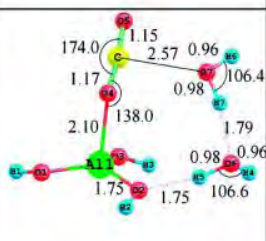 & 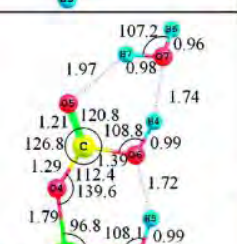 & 每 & 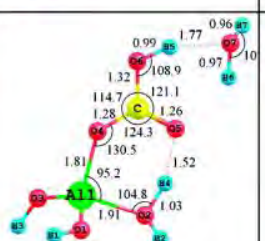 & 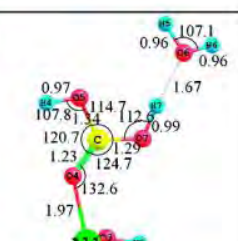 \\
\hline 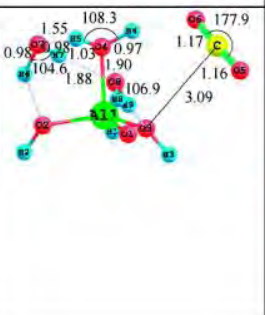 & 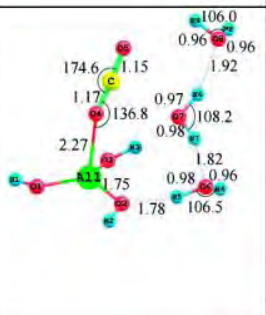 & 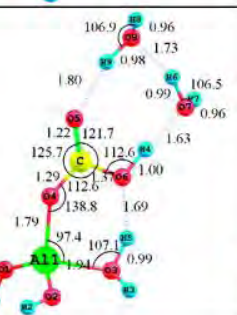 & 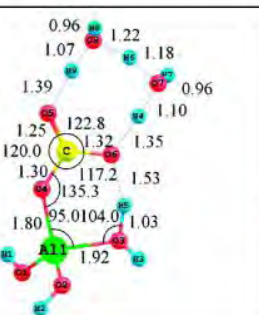 & 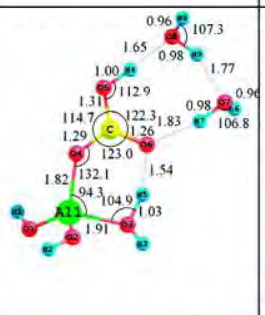 & 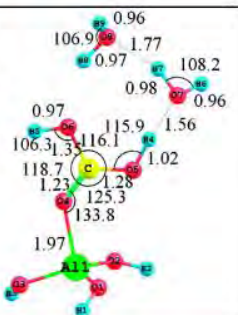 \\
\hline
\end{tabular}

Figure 41. $\mathrm{H}_{2} \mathrm{CO}_{3}$ formation from $\mathrm{CO}_{2}$ and $\mathrm{H}_{2} \mathrm{O}$ on $\mathrm{Al}(\mathrm{OH})_{3}$ via bicarbonate intermediate. Bicarbonate intermediate (III) is followed by the proton transfer on $\mathrm{Al}(\mathrm{OH})_{3}$ to yield adsorbed $\mathrm{H}_{2} \mathrm{CO}_{3}$ from $\mathrm{CO}_{2}$ and $\mathrm{H}_{2} \mathrm{O}$. Adopted from Baltrusaitis and Grassian. Reproduced with permission from [172]. Copyright (2010) American Cemical Society.

4.2.3.2 $\mathrm{TiO}_{2} \cdot \mathrm{TiO}_{2}$ was also investigated as an adsorbent for $\mathrm{CO}_{2}$ capture $[5,60-62,82,173,174]$. Rasko et al. carried out an investigation on the surface facilitated $\mathrm{CO}_{2}$ adsorption on reduced, oxidized and evacuated rutile $\mathrm{TiO}_{2}$, as well as its rhenium-impregnated counterpart using FTIR [82]. From these spectra there was only a slight difference in the region of $2500-2200 \mathrm{~cm}^{-1}$. Notable differences were observed for some peaks, namely 3704, 3597, 2364, 2352, 1676 and $1376 \mathrm{~cm}^{-1}$, where these peaks appeared in the presence of $\mathrm{CO}_{2}$ at $190 \mathrm{~K}$ and attenuated when the 
system was evacuated. Bent $\mathrm{CO}_{2}$ was proposed to show peaks at $1630-1640$ and $1218 \mathrm{~cm}^{-1}$. The electronic and defect structure of the $\mathrm{TiO}_{2}$ sample also played an important role on the formation of the bent $\mathrm{CO}_{2}$ surface species [82]. The absence of $\mathrm{CO}$ vibrations at 2180, 2127 and $2206 \mathrm{~cm}^{-1}$ indicated no dissociative adsorption taking place at all times on the pristine surface. The opposite was true for the case where $\mathrm{Rh}$ was deposited on the $\mathrm{TiO}_{2}$ surface, for which the $\mathrm{CO}_{2}$ dissociation was further enhanced significantly by the presence of $\mathrm{H}_{2}$. The proposed mechanism of the dissociative adsorption was provided as shown in Figure 42, along with the spectra taken for $\mathrm{CO}_{2}$ adsorption on clean $\mathrm{TiO}_{2}$ surface.

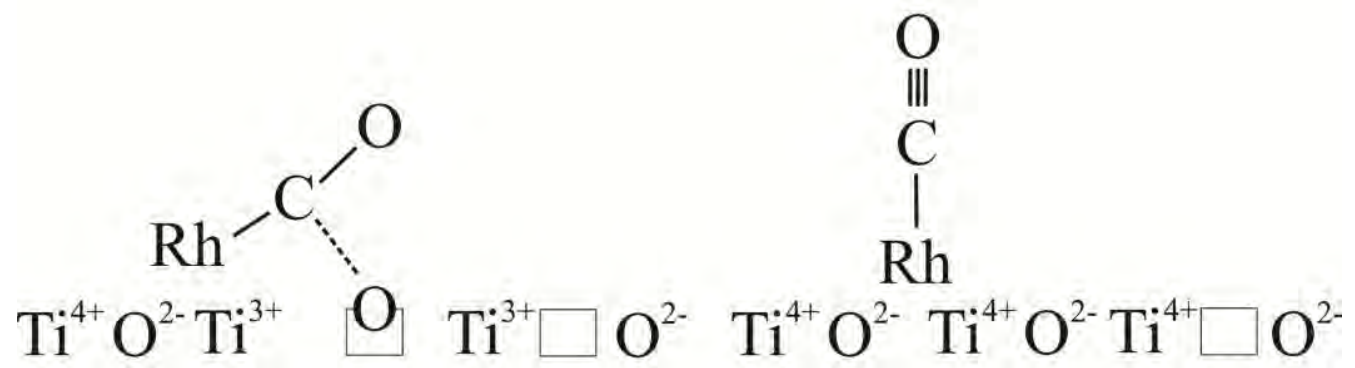

Figure 42. Dissociative Adsorption of $\mathrm{CO}_{2}$ on $\mathrm{Rh}$-doped $\mathrm{TiO}_{2}$. Notice that the chemistry occurred due to O vacancy. Reproduced with permission from [82]. Copyright (1994) American Chemical Society. 

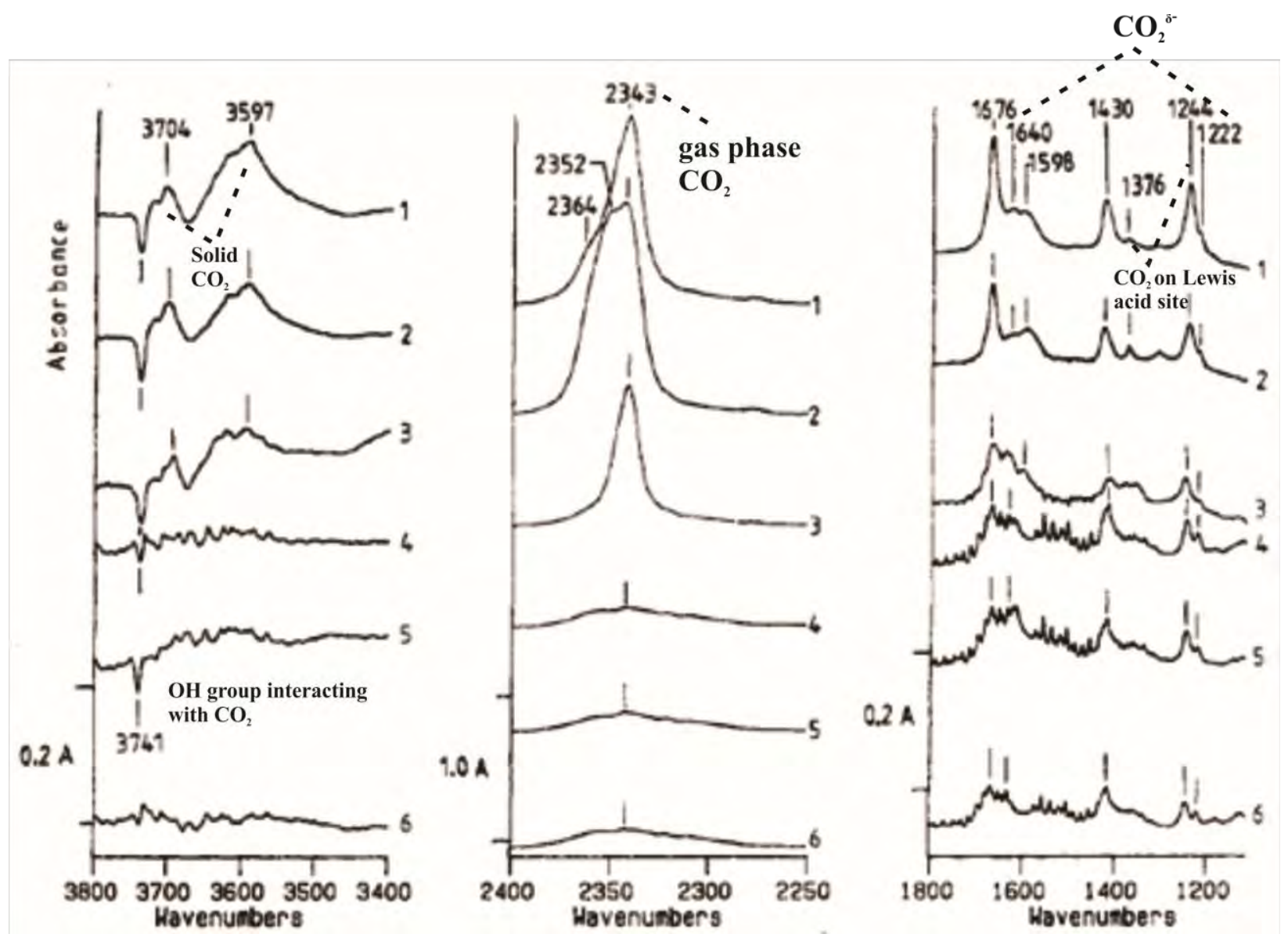

Figure 43. Spectra of Adsorbed $\mathrm{CO}_{2}$ on Various Pretreated $\mathrm{TiO}_{2}$ Surfaces at $673 \mathrm{~K}$ with $\mathrm{CO}_{2}$ Flux at $190 \mathrm{~K}$ and $300 \mathrm{~K}$. (1)-(3) represent spectra taken at $190 \mathrm{~K}$, for oxidized, evacuated, and reduced samples, respectively; (4)-(6) represent spectra taken at $300 \mathrm{~K}$. Reproduced with permission from [82]. Copyright (1994) American Chemical Society.

To complement the spectra assignment provided previously by Rasko et al. , Figure 44 portrays another IR experiment carried out by Liao et al. [60] albeit using different experimental set-ups. 


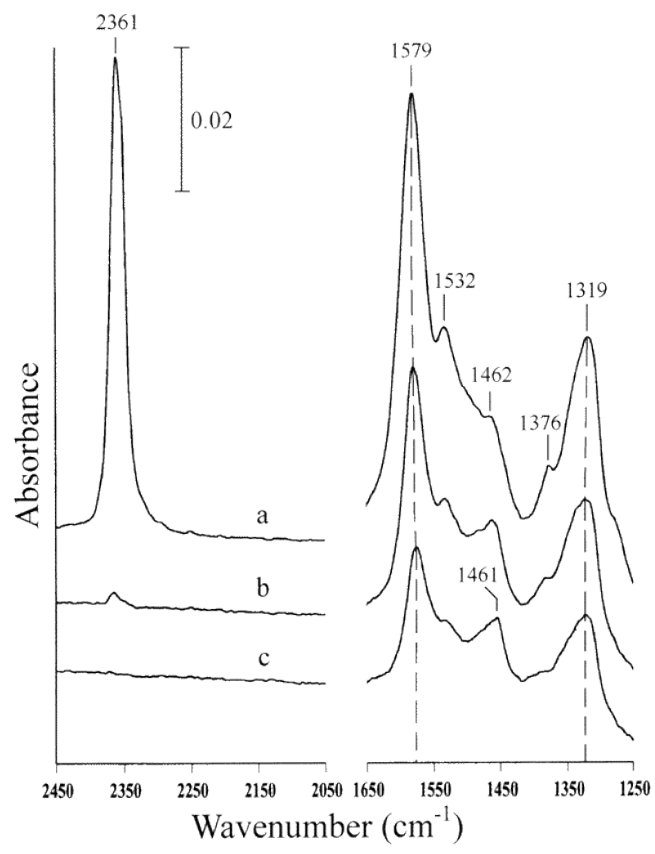

Figure 44. Spectra of adsorbed $\mathrm{CO}_{2}$ on $\mathrm{TiO}_{2}$ surface (a) in contact with $\sim 0.1$ Torr $\mathrm{CO}_{2}$ at $35{ }^{\circ} \mathrm{C}$, (b) followed by evacuation, (c) and heated up to $70{ }^{\circ} \mathrm{C}$ in vacuum. Reproduced with permission from [60]. Copyright (2002) American Chemical Society.

As shown in Figure 44, peaks associated with carbonate appeared at 1319 and $1579 \mathrm{~cm}^{-1}$ for bidentate species and $1461 \mathrm{~cm}^{-1}$ for monodentate carbonate. The peak at $2361 \mathrm{~cm}^{-1}$ was assigned to linearly adsorbed $\mathrm{CO}_{2}$ with a Ti-O-C-O configuration. Similar to Rasko et al. [60], the authors did not observe any peaks associated with the formation of $\mathrm{CO}$. Bicarbonate peaks were also not detected in the spectra. Different phenomena were observed by researchers from Pacific Northwest National Laboratory [173]. IRAS revealed that no chemisorption takes place on the model surface rutile $\mathrm{TiO}_{2}(110)-1 \times 1$, which contradicts the findings from Rasko et al. and Liao et al. $[60,82]$. Instead, the adsorbate was weakly-bound and of linear geometry. This suggests that any presence of surface defects might contribute to the increased reactivity of the surface. Functionalization of $\mathrm{TiO}_{2}$ with aminopropylsilane was investigated and shown to yield a strongly $\mathrm{CO}_{2}$ adsorbing surface [61]. ATR-FTIR spectroscopy revealed through the appearance of 
characteristic peaks at 1691 and $1265 \mathrm{~cm}^{-1}$ that the functionalization yielded bidentate carbonate when $\mathrm{CO}_{2}$ was adsorbed on the surface, Adsorption of $\mathrm{CO}_{2}$ on both rutile and anatase $\mathrm{TiO}_{2}$ surface was reported in [62]. For the former, the formation of bidentate carbonate, bicarbonate and bridged carbonate was observed, as demonstrated by the peaks measured at 1606; 1416 and 1220; and $1706 \mathrm{~cm}^{-1}$, respectively. The anatase phase, on the other hand, yielded the formation of bidentate carbonate, bicarbonate, monodentate carbonate and carboxylate, as evident from the peaks at $1589,1315,1055 \mathrm{~cm}^{-1}$ for bidentate, 1434 and $1222 \mathrm{~cm}^{-1}$ for bicarbonate, $1377 \mathrm{~cm}^{-1}$ for monodentate, and 1670 and $1245 \mathrm{~cm}^{-1}$ for carboxylate [62]. Adsorption at low pressure was carried out by Baltrusaitis et al. [5]. In their work, the surface species adsorbed was mainly carbonate with some bicarbonate observed. Specifically, the peaks at 1392, 1076 and $1510 \mathrm{~cm}^{-1}$ as well as 1355 and $1566 \mathrm{~cm}^{-1}$ were assigned to the $\mathrm{O}-\mathrm{C}-\mathrm{O}$ stretching vibrations of adsorbed monodentate and bidentate carbonate, respectively. Bicarbonate and bent $\mathrm{CO}_{2}{ }^{-}$were observed by peaks at 1623,1423 , and $1222 \mathrm{~cm}^{-1}$, as well as 1670 and $1251 \mathrm{~cm}^{-1}$, respectively [5].

An in situ STM study of $\mathrm{CO}_{2}$ adsorption on $\mathrm{TiO}_{2}(110)-1 \times 1$ was recently performed [174]. Two adsorption sites were identified, including bridge-bonded oxygen vacancy sites and $\mathrm{Ti}^{4+}$ rows. Adsorption on the former immobilized $\mathrm{CO}_{2}$, while on the latter $\mathrm{CO}_{2}$ was still diffusive even at lower temperatures. DFT calculations showed that $\mathrm{CO}_{2}$ LUMO was situated above the conduction band onset of $\mathrm{TiO}_{2}$ by $2.3 \mathrm{eV}$ or $2.7 \mathrm{eV}$ above the Fermi level for both vertical and inclined, yet still linear, adsorption configurations. This LUMO hybridizes with the $3 \mathrm{~d}$ orbital of Ti making it difficult to excite electrons from the valence band to $\mathrm{CO}_{2} \mathrm{LUMO}$ and for the excited electron to transfer from the $\mathrm{TiO}_{2}$ conduction band to $\mathrm{CO}_{2}$. Figure 45 depicts the STM images taken on the bare $\mathrm{TiO}_{2}(110)-1 \times 1$ surface, after exposure to $\mathrm{CO}_{2}$, as well as after the tipinduced adsorbate dissociation. 

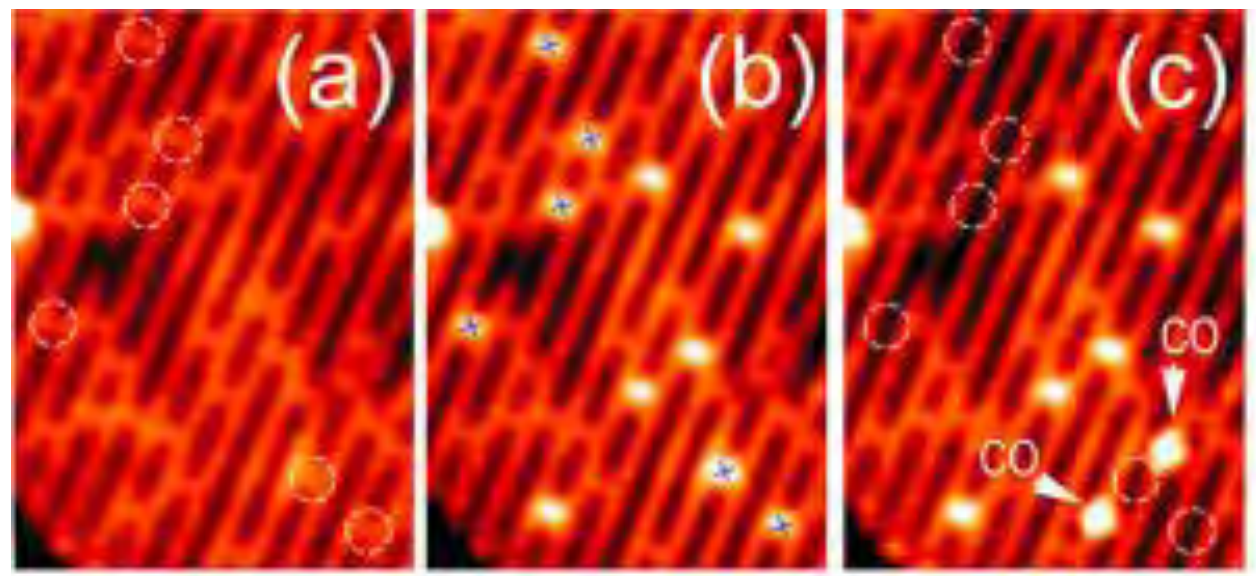

Figure 45. STM images of (a) bare $\mathrm{TiO}_{2}(110)-1 \times 1$ surface, (b) after $\mathrm{CO}_{2}$ exposure at $80 \mathrm{~K}$, and (c) tip-induced dissociation of $\mathrm{CO}_{2}$ into $\mathrm{CO}$ and $\mathrm{O}$. Reproduced with permission from [174]. Copyright (2011) American Physical Society. 
4.2.3.3 $\mathrm{ZrO}_{2}$. The surface chemistry of $\mathrm{CO}_{2}$ on zirconia has been investigated both by probing a specific catalyst with $\mathrm{CO}_{2}$ and by directly characterizing a given material for $\mathrm{CO}_{2}$ capture [6366]. $\mathrm{ZrO}_{2}$ surfaces prepared using different synthesis methods have different surface hydroxyl groups and result in different adsorbed $\mathrm{CO}_{2}$ surface species. IR spectra obtained for monoclinic zirconia with surface terminal hydroxyls revealed the formation of bicarbonate early during the adsorption of $\mathrm{CO}_{2}$ at room temperature exhibiting peaks at $1625,1430\left(v_{3}\right.$ as and $\left.v_{3} \mathrm{~s}\right)$ and 1220 $\mathrm{cm}^{-1}\left(\delta_{\mathrm{OH}}\right)$ [63]. The bicarbonate species was relatively unstable. It was eliminated upon evacuation at $373 \mathrm{~K}$. However, other peaks related to adsorbed bidentate and monodentate carbonates showed superior stability on the surface, persisting even under evacuation at $573 \mathrm{~K}$. The former was characterized by the peaks at 1575 and $1325 \mathrm{~cm}^{-1}$, while the latter was identified from the peaks at 1490 and $1395 \mathrm{~cm}^{-1}$. For tetragonal/cubic zirconia with no surface terminal hydroxyls, there was no bicarbonate species detected, indicating the necessity of surface terminal hydroxyls for the relevant chemistry to take place. Monodentate and bidentate carbonates were detected as characterized by the peaks at $1450,1425 \mathrm{~cm}^{-1}$ and $1550,1355 \mathrm{~cm}^{-1}$, respectively. Figure 46 shows these spectra taken for the two different zirconia samples by Bachiller-Baeza et al. [63]. 

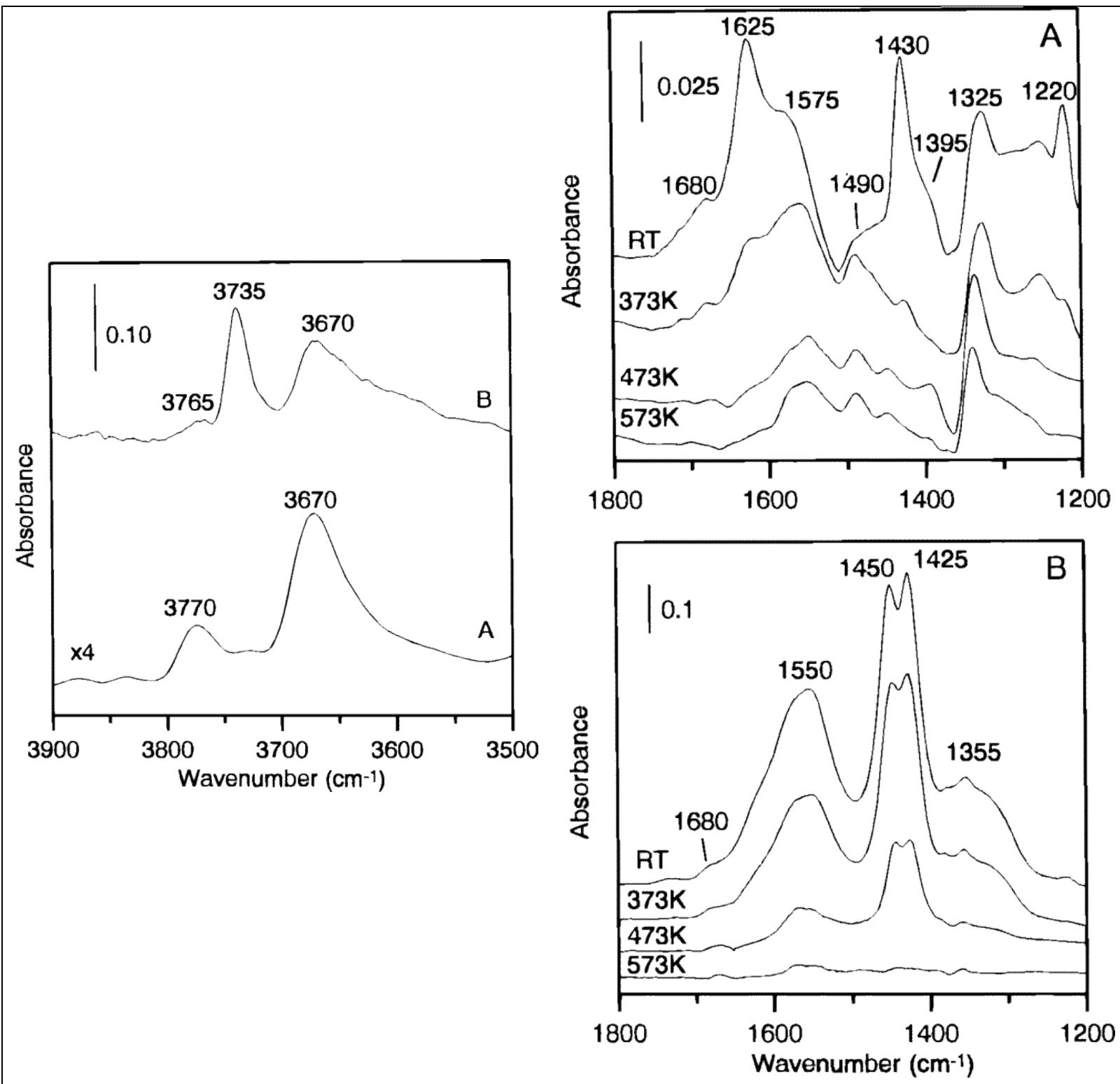

Figure 46. (Left) Spectra taken of clean surface, (a) monoclinic zirconia and (b) tetragonal/cubic zirconia showing the presence of isolated hydroxyl groups; (Right) Evolution of surface species during adsorption and TPD observed by IR Spectroscopy for (a) monoclinic zirconia and (b) tetragonal/cubic zirconia. Reproduced with permission from [63]. Copyright (1998) American Chemical Society.

Similar mechanistic considerations were proposed by Pokrovski et al. [64]. Formation of bicarbonate, monodentate and bidentate carbonate was observed during the adsorption and desorption of $\mathrm{CO}_{2}$ on a monoclinic zirconia surface. However, different conclusions were obtained for the tetragonal zirconia surface. Their IR spectra indicated the formation of bidentate 
at 1595 and $1315 \mathrm{~cm}^{-1}$ and polydentate carbonate, instead of bidentate and monodentate carbonate, which were observed by Bachiller-Baeza et al. [63]. The peaks at 1450 and $1430 \mathrm{~cm}^{-1}$ assigned to polydentate carbonate species were essentially the same as Bachiller-Baeza et al. assigned to monodentate species. Figure 47 shows the spectra taken by Pokrovski et al. [64].

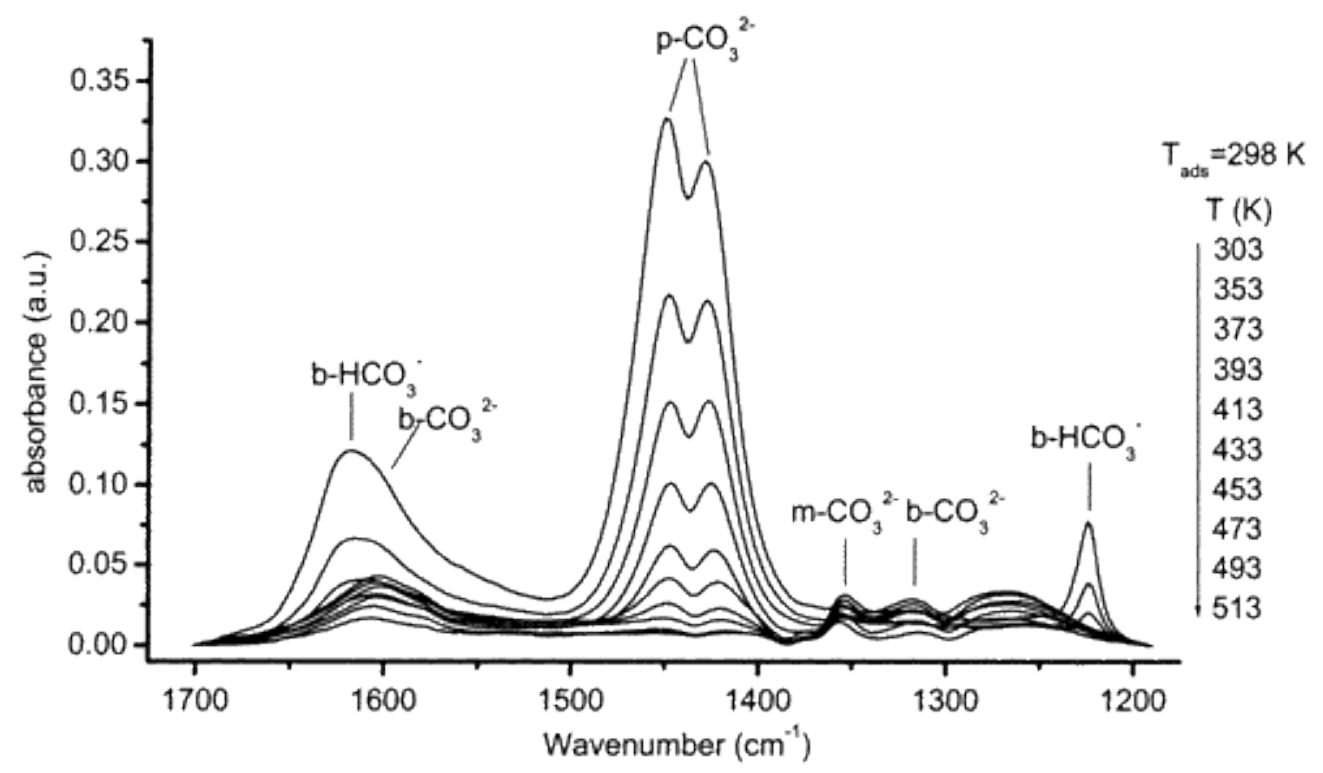

Figure 47. Spectra taken for $\mathrm{CO}_{2}$ adsorbed on tetragonal zirconia. Reproduced with permission from [64]. Copyright (2001) American Chemical Society.

The formation of bidentate carbonate and bicarbonate on zirconia was also observed by Dobson and McQuillan [65] and Ouyang et al. [66]. The former reported peaks at 1573 and $1354 \mathrm{~cm}^{-1}$ assigned to bidentate carbonate and 1613,1443 , and $1243 \mathrm{~cm}^{-1}$ assigned to adsorbed bidentate bicarbonate. Ouyang et al. used $\mathrm{CO}_{2}$ as a probing molecule, observing the appearance of bidentate carbonate and monodentate bicarbonate, which were characterized by the peaks at 1559, 1310 and $1065 \mathrm{~cm}^{-1}$ and 3607, 1610, 1453, $1224 \mathrm{~cm}^{-1}$, respectively. However, unlike Bachiller-Baeza et al. [63] and Pokrovski et al. [64], Ouyang et al. [66]did not observe the formation of either polydentate/monodentate carbonate. 
4.2.3.4 ZnO. Noei et al. conducted UHV-FTIR analysis of $\mathrm{CO}_{2}$ adsorption on various $\mathrm{ZnO}$ surfaces [175]. Different coordinations of $\mathrm{CO}_{2}$ were observed on different sites of $\mathrm{ZnO}$. The mixed-termination $\mathrm{ZnO}(10 \overline{\mathbf{1}} 0)$ facet yields tridentate carbonate. The polar O-terminated $(000 \overline{\mathbf{1}})$ facet yields bidentate carbonate on O-vacancy sites and both monodentate and polydentate species on defect sites, such as kinks and steps. A similar work was also done by Buchholz et al., where UHV-IRAS was done on a $\mathrm{ZnO}(10 \overline{\mathbf{1}} 0)$ surface facet [176]. Tridentate carbonate was detected on the surface, confirmed by peaks at $1584 / 1591$ and $1340 / 1344 \mathrm{~cm}^{-1}$, corresponding to $v_{3}$ as and $v_{3} \mathrm{~s}$, respectively. The orientation of the carbonate species, which is aligned along the [0001] direction, was determined using reflectivity and absorbance relations, taking into account the particular optical properties of the dielectric surface [176]. Cu-doped $\mathrm{ZnO}$ was used as a catalyst for methanol synthesis from either $\mathrm{CO}_{2}$ or $\mathrm{CO}$. IR spectra acquired during the reaction can shed some light on how $\mathrm{CO}_{2}$ adsorbs and reacts on the surface $[177,178]$. While $\mathrm{ZnO}$ itself contributed to the adsorption of $\mathrm{CO}_{2}$ and formation of carbonate, $\mathrm{Cu}$ as a dopant had increased the adsorption capacity of the carbonate and even catalyzed transformation of carbonates into formate [177], which is an important intermediate in methanol synthesis.

Comprehensive experimental and theoretical work has been done in the past on $\mathrm{CO}_{2}$ adsorption, particularly on the $(000 \overline{1}),(0001)$, and $(10 \overline{1} 0)$ facets. However, no agreement on the adsorption geometries exists, because some studies showed carbonate or bent $\mathrm{CO}_{2}^{-}$formation, while others argued that the adsorption is mostly physical [176,179-184]. The structure-activity relationship (SAR) of $\mathrm{CO}_{2}$ adsorption on $\mathrm{ZnO}$ surface was studied. most of the time using TDS by Wang and Burghaus [184]. Perfect surface and defective sites were investigated in a study that rejected carbonate formation on the surface. Hydrogen was preadsorbed on the surface to block any defect sites, causing the adsorption to take place only on perfect sites. The resulting binding energies for both cases, i.e., perfect and defective sites, are consistent with physisorption or weak chemisorption. The authors' view is somehow shared by Dutta et al., where, in their DFT study, based on a hybrid, quantum chemical/molecular mechanical (QM/MM) embedded cluster approach, $\mathrm{CO}_{2}$ is expected to adsorb as bent anionic $\mathrm{CO}_{2}^{-}$[185]. During adsorption, the $\mathrm{CO}_{2}$ 
molecule anchors itself to the surface by orienting one of its oxygen atoms into a vacant site and accepting the localized, trapped electron there. Further bending towards one of the neighboring ions would result in the formation of a carboxylate ion, rather than carbonate [185].

Koßmann et al. applied ab initio DFT study with an embedded cluster approach to calculate vibrational spectra for various molecules, as intermediates for $\mathrm{CO}_{2}$ to methanol conversion over a $\mathrm{ZnO}(0001)$ surface [183]. Polydentate and monodentate carbonate were expected, along with formate species, as the calculations were carried out using a Turbomole program package with PBE functional $[186,187]$. Monodentate structures are readily formed on defect free surfaces and $\mathrm{F}$ vacancy, while bidentate and tridentate carbonates are observed on $\mathrm{F}^{2+}$ vacancies and a $\mathrm{V}_{2 \mathrm{H} 2 \mathrm{O}}$ vacancy, respectively. A stable physisorbed $\mathrm{CO}_{2}$ molecule, however, is also observed on O-vacancy sites. Figure 48 depicts the formation of all carbonate species along with the IR peak assignments.

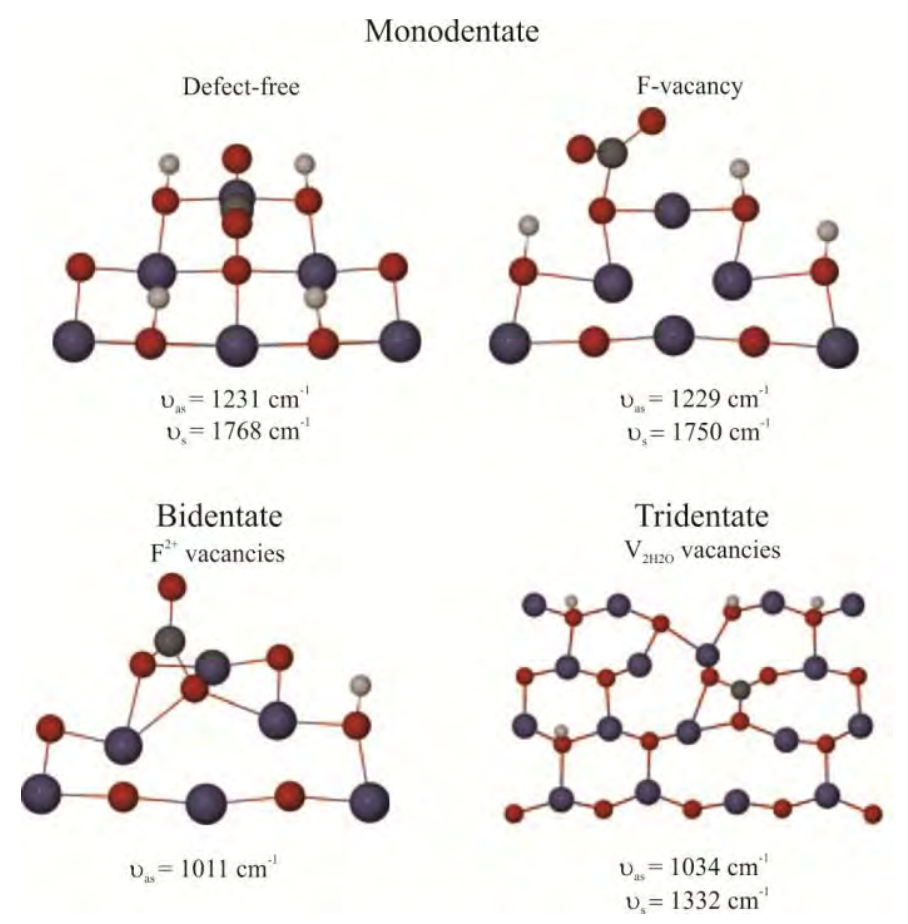

Figure 48. Carbonate configurations on various $\mathrm{ZnO}$ adsorption sites. Reproduced with permission from [183]. Copyright (2002), AIP Publishing LCC. 
The formation of carbonates on various facets of a $\mathrm{ZnO}$ surface is also confirmed by another computational work quite recently $[180,182]$. The first-principles calculation was performed at the DFT + U level of theory using VASP with GGA-PW91 functional. The calculation shows that the adsorption binding strength is ranked in the following order: $\mathrm{ZnO}(0001) \quad \mathrm{ZnO}(0001)<$ $\mathrm{ZnO}(112 \mathrm{l})<\mathrm{ZnO}(1129) \mathrm{ZnO}(1010)$. Interestingly, $\mathrm{CO}_{2}$, which is supposedly an electronegative adsorbate, may be positively charged on some $\mathrm{ZnO}$ surfaces, such as the stepped (112 1) facet. The calculation clearly demonstrated that physisorption takes place on singly terminated surfaces, while chemisorption is prevalent on mixed terminated surfaces. Similar to Koßmann et al., all monodentate, bidentate, and tridentate carbonates were observed on different facets of a $\mathrm{ZnO}$ surface [182].

Experimental work on this sorbent remains scarce, and theoretical chemists have not yet arrived to a unanimous view on binding mechanisms. This area is challenged further by the strong dependence in mechanisms with the nature of adsorption sites, which could yield bent anionic $\mathrm{CO}_{2}{ }^{-}$, or carbonate species. [180,182-184,186,187] 
4.2.3.5 $\mathrm{Cr}_{2} \mathrm{O}_{3} \cdot \mathrm{Cr}_{2} \mathrm{O}_{3}$ has also been considered as an active surface for $\mathrm{CO}_{2}$ adsorption. Seiferth et al. discussed the structure/reactivity differences of $\mathrm{Cr}_{2} \mathrm{O}_{3}(0001) / \mathrm{Cr}(110)$ and polycrystalline $\mathrm{Cr}_{2} \mathrm{O}_{3}$ [67]. On the former, physisorbed $\mathrm{CO}_{2}$ was observed as characterized by the presence of peaks at 2353 and $2375 \mathrm{~cm}^{-1}$. Bent $\mathrm{CO}_{2}{ }^{\delta-}$, however, was also formed, according to the peaks at $1277 \mathrm{~cm}^{-1}$ that shifted to $1289 \mathrm{~cm}^{-1}$ when $\mathrm{CO}_{2}$ flux was increased. This surface species was assigned to be a bent species due to the absence of the $v_{3}$ at around $1600 \mathrm{~cm}^{-1}$. Peak assignments for bent $\mathrm{CO}_{2}{ }^{\delta-}$ to different vibrational modes on different surfaces is adequately provided elsewhere [67]. IR spectra resulting from $\mathrm{CO}_{2}$ adsorption products on polycrystalline $\mathrm{Cr}_{2} \mathrm{O}_{3}$, on the other hand, revealed the formation of surface bidentate carbonates evident from the broadening of peaks at 1240, 1650 and $850 \mathrm{~cm}^{-1}$. Figure 49 show the spectra of $\mathrm{CO}_{2}$ adsorbed on both surfaces.

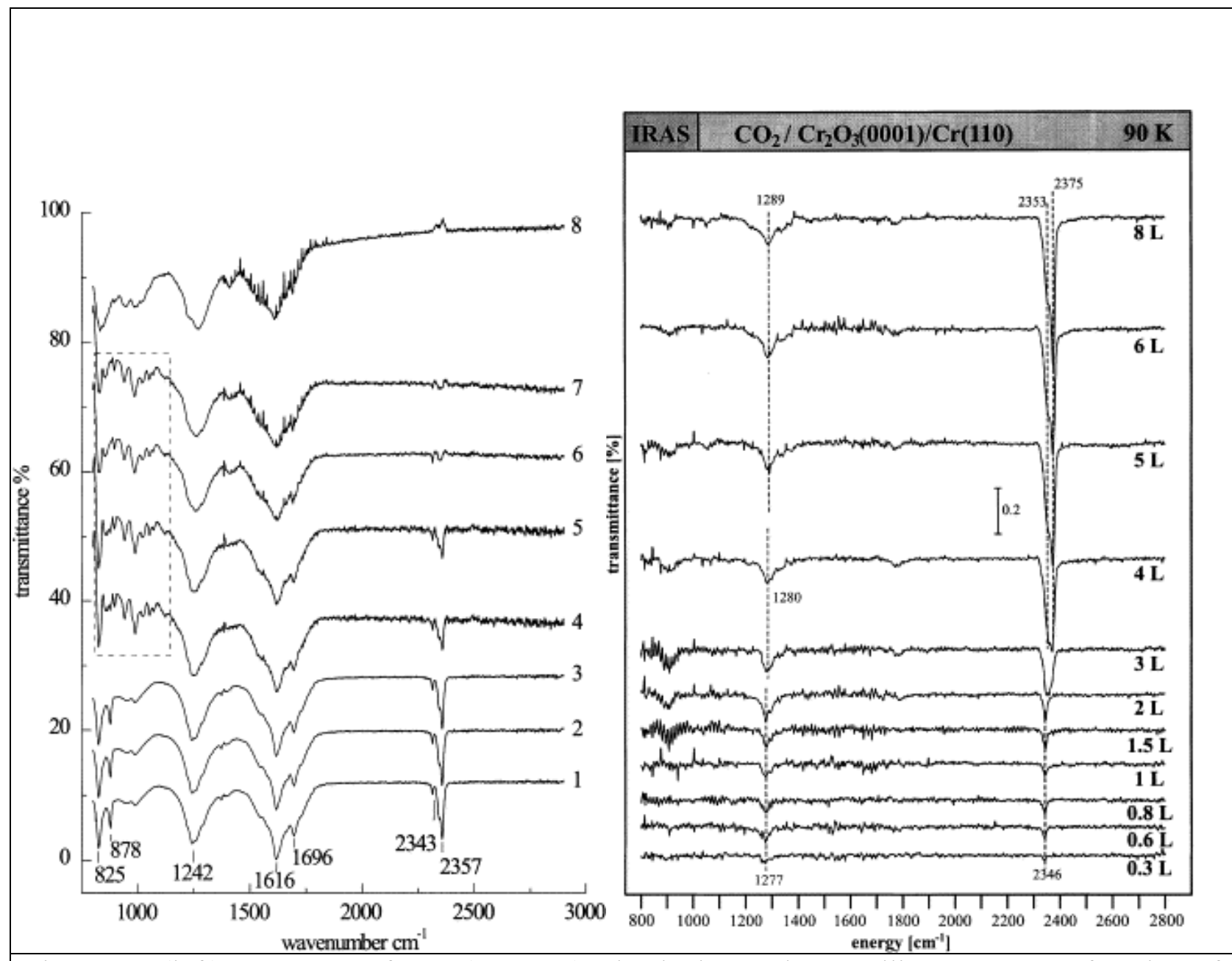

Figure 49. (left) IR spectra of $\mathrm{CO}_{2}$ (0.1 Torr) adsorbed on polycrystalline $\mathrm{Cr}_{2} \mathrm{O}_{3}$ as a function of 
temperature, (1) at $100 \mathrm{~K},(8)$ at $300 \mathrm{~K}$. (right) IRAS of $\mathrm{CO}_{2}$ adsorbed on $\mathrm{Cr}_{2} \mathrm{O}_{3}(0001) / \mathrm{Cr}(110)$ as a function of $\mathrm{CO}_{2}$ dosage. Reproduced with permission from Elsevier [67].

On stoichiometric $\mathrm{Cr}_{2} \mathrm{O}_{3}(101 \overline{2}) \mathrm{CO}_{2}$ was found to form bidentate carbonates stable at room temperature [188]. This was due to the five-coordinated $\mathrm{Cr}^{3+}$ cations and the three-coordinated $\mathrm{O}^{2-}$ anions, leading to an $\mathrm{O}$ vacancy on the $\mathrm{Cr}$ site on the stoichiometric, nonpolar surface. The chemistry between $\mathrm{CO}_{2}$ and Na-doped $\mathrm{Cr}_{2} \mathrm{O}_{3}$ was also investigated [189]. Similar to $\mathrm{Cr}_{2} \mathrm{O}_{3}$ (0001), formation of bent $\mathrm{CO}_{2}^{-}$was observed at low $\mathrm{Na}$ coverage evident from the peak at 1289 $\mathrm{cm}^{-1}$ in the IRAS spectra. Also, the addition of $\mathrm{Na}$ significantly changed the chemistry on the surface with the presence of an $\mathrm{Na}^{+} \mathrm{CO}_{2}{ }^{-}$complex formed at low temperatures and regarded as the intermediate for the formation of carbonate on the surface [189].

4.2.3.6 $\mathrm{Ga}_{2} \mathrm{O}_{3}$. Gallium oxide is a potential catalyst for methanol synthesis from $\mathrm{CO} 2$, just like $\mathrm{ZnO}$, and has been already studied using spectroscopy to analyze CO2 adsorption/transformations [70,83]. Direct comparison between $\gamma-\mathrm{Ga}_{2} \mathrm{O}_{3}$ and its isostructural counterpart, $\gamma-\mathrm{Al}_{2} \mathrm{O}_{3}$, is reviewed spectroscopically using $\mathrm{CO} 2$ as a probe molecule [83]. On $\square$ $\mathrm{Ga}_{2} \mathrm{O}_{3}, \mathrm{CO}_{2}$ adsorption gives rise to the peaks at $3607,1619,1456$ and $1231 \mathrm{~cm}^{-1}$ associated with monodentate bicarbonate species, compared to the same species on $\gamma-\mathrm{Al}_{2} \mathrm{O}_{3}$, with the corresponding peaks at 3608, 1648, 1485 , and $1234 \mathrm{~cm}-1$ [83]. Three crystal phases, $\alpha-, \beta-$, and $\gamma-\mathrm{Ga}_{2} \mathrm{O}_{3}$, were studied elsewhere [70]. Adsorption of $\mathrm{CO}_{2}$, as shown by the in situ IR spectroscopy experiment, resulted in the formation of various surface species, including carboxylate, bridged carbonate, bidentate carbonate, polydentate carbonate, monodentate bicarbonate, and bidentate bicarbonate. More peaks were observed in the spectra where $\gamma-\mathrm{Ga} 2 \mathrm{O} 3$ is used as the reactive surface. For instance, peaks at 1750 and $1170 \mathrm{~cm}^{-1}$ were assigned to carboxylate. This assignment was supported by the fact that the splitting of carbonate v3 vibration should not exceed $400 \mathrm{~cm}^{-1}$. The most prevalent surface species was found to be bidentate bicarbonate on all of the surfaces. The associated peaks observed were at 1630, 1431 and $1225 \mathrm{~cm}^{-1}$. The peaks are there due to the $v 3(\mathrm{as}), v 3(\mathrm{~s})$ and $\delta 4$, respectively. The IR spectra 
of the adsorbed $\mathrm{CO}_{2}$ products from all three crystalline phases of $\mathrm{Ga}_{2} \mathrm{O}_{3}$ can be found in Figure 50.
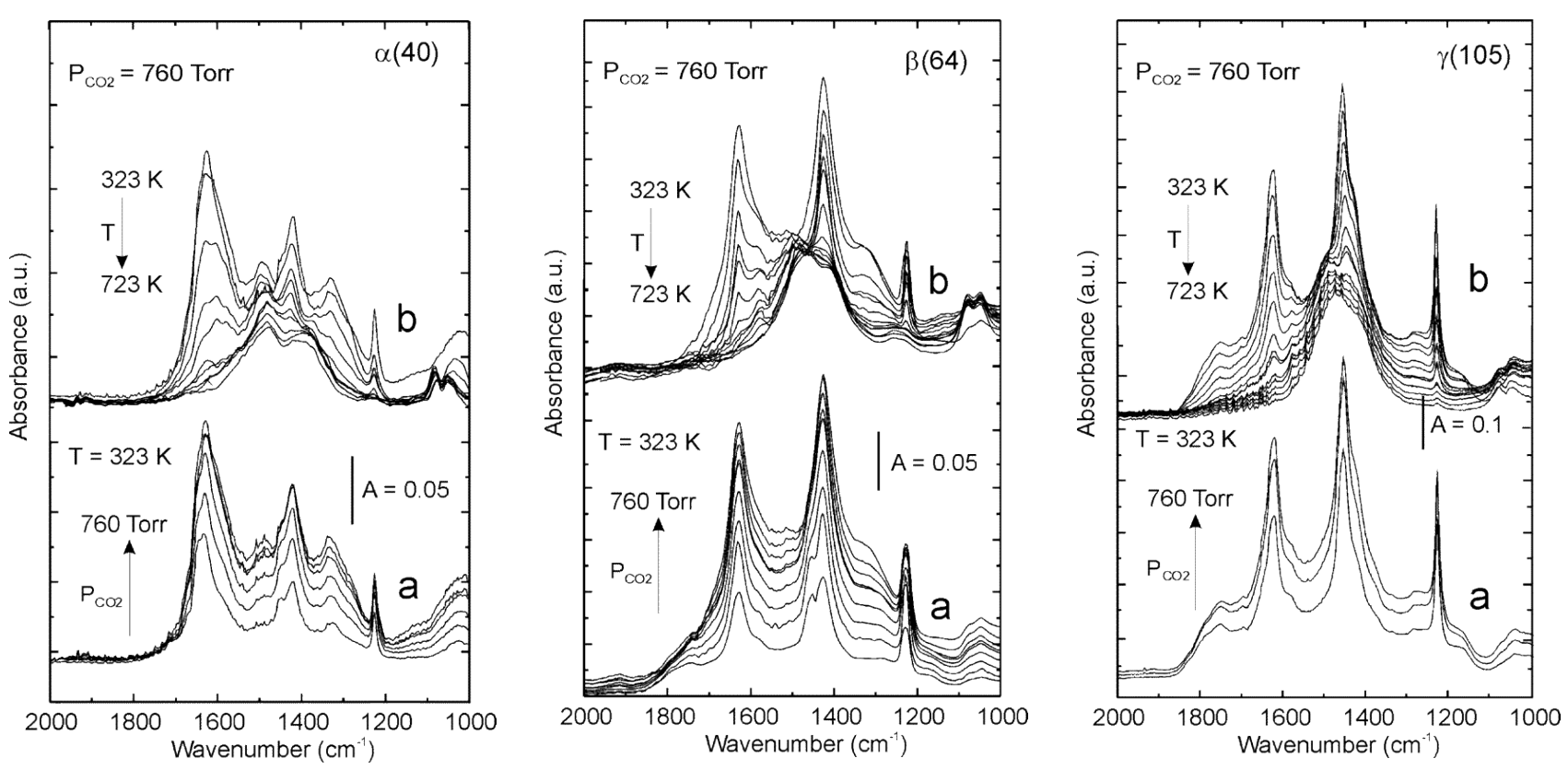

Figure 50. In situ IR spectra of $\mathrm{CO}_{2}$ adsorption on $\alpha-, \beta$ - and $\gamma-\mathrm{Ga}_{2} \mathrm{O}_{3}$. (a) isothermal adsorption at $323 \mathrm{~K}$ with increasing $\mathrm{CO}_{2}$ pressure; (b) temperature programmed desorption of $\mathrm{CO}_{2}$ from the surface up to $723 \mathrm{~K}$. Reproduced with permission from [70]. Copyright (2006) American Chemical Society.

A later observation by Tsuneoka et al. [190] confirmed the peak assignments on $\beta-\mathrm{Ga}_{2} \mathrm{O}_{3}$. The formation of monodentate bicarbonate and bidentate bicarbonate was observed on the $\beta-\mathrm{Ga}_{2} \mathrm{O}_{3}$ surface and confirmed by the presence of the peaks at 1432, 1463 for $v_{3}(\mathrm{~s})$ mode of bidentate and monodentate species, respectively, while the ones at 1634 , and $1229 \mathrm{~cm}^{-1}$ were not resolved due to overlaps between the respective $v_{3}$ as and $\delta_{4}$ of both species.

4.2.3.7 Iron oxides and oxyhydroxides. Baltrusaitis et al. discuss the use of amorphous nanoparticulate $\mathrm{Fe}_{2} \mathrm{O}_{3}$ as a $\mathrm{CO}_{2}$ adsorbing surface [5,50,52,191]. Bicarbonate was formed on the $\mathrm{Fe}_{2} \mathrm{O}_{3}$ surface upon adsorbtion of $\mathrm{CO}_{2}$ as characterized by peaks at 1010, 1222, 1410, 1629 and $3619 \mathrm{~cm}^{-1}$, assigned to the $v_{1}, \delta_{4}, v_{3} \mathrm{~s}, v_{3}$ as, and $v_{5}$ vibrational modes, respectively [5]. The 
formation of bidentate and monodentate carbonate was also observed, signified by the peaks at $1316,1553,1590 \mathrm{~cm}^{-1}$ for bidentate species, and $1040 \mathrm{~cm}^{-1}$ for monodentate carbonate [5]. Surface hydroxyl groups as a proxy of adsorbed bicarbonate formation, as well as the corresponding reactive mechanisms, were investigated in detail using a combination of FTIR spectroscopy, quantum chemical calculations and isotope labelling. Data for $\mathrm{Fe}_{2} \mathrm{O}_{3}$ nanoparticles following evacuation of the IR cell to $\sim 1 \times 10^{-5}$ Torr overnight are illustrated in Figure 51. These data show a high density of isolated (3687 and $3655 \mathrm{~cm}^{-1}$ ) and hydrogen-bonded $\mathrm{O}-\mathrm{H}$ groups on the surface along with a small amount of adsorbed water at $3365 \mathrm{~cm}^{-1}$, as also confirmed by $\mathrm{D}_{2} \mathrm{O}$ and $\mathrm{H}_{2} \mathrm{O}(18)$ experiments [52].

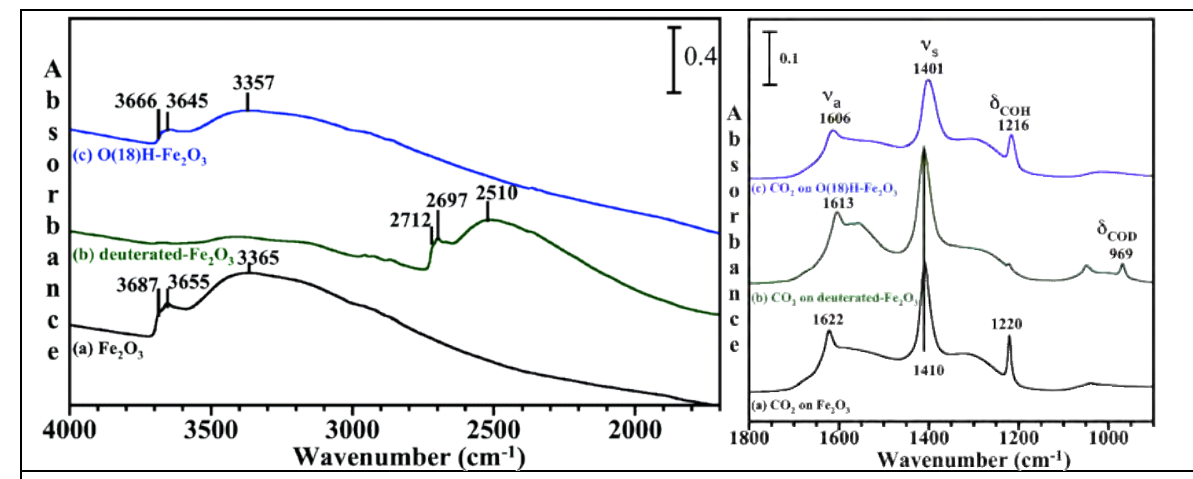

Figure 51. $\mathrm{O}-\mathrm{H}$ stretching and carbonate/bicarbonate regions for (a) unlabeled hydroxylated $\mathrm{Fe}_{2} \mathrm{O}_{3}$. (b) Shift in peaks following isotope exchange with $\mathrm{D}_{2} \mathrm{O}$ to give a predominantly $\mathrm{O}-\mathrm{D}$ terminated surface denoted as deuterated- $\mathrm{Fe}_{2} \mathrm{O}_{3}$. (c) Shift in peaks following isotope exchange with $\mathrm{H}_{2} \mathrm{O}$ (18) to give a predominantly $\mathrm{O}(18)-\mathrm{H}$ terminated surface denoted as $\mathrm{O}(18) \mathrm{H}-\mathrm{Fe}_{2} \mathrm{O}_{3}$.

Reproduced with permission from [52]. Copyright (2005)

American Chemical Society.

Small shifts in the $v_{3}$ as and $v_{3} \mathrm{~s}$ vibrations of the adsorbed bicarbonate formed of the isotope labeled surfaces and a large shift for the bending mode in the case of deuterated $\mathrm{Fe}_{2} \mathrm{O}_{3}$ were observed in the 1800 to $900 \mathrm{~cm}^{-1}$ region as $\delta_{\mathrm{COD}}$ peak shifts to 969 from $1220 \mathrm{~cm}^{-1}$.

Ferrihydrite, a naturally occurring nanoscale iron oxyhydroxide mineral, is a precursor to other iron minerals, such as goethite $(\alpha-\mathrm{FeO}(\mathrm{OH}))$ and hematite $\left(\alpha-\mathrm{Fe}_{2} \mathrm{O}_{3}\right)$ [192]. A combined experimental ATR-FTIR and B3LYP/6-31G(d) DFT study was performed and a bent bicarbonate like - adsorbed $\mathrm{CO}_{2}$ complex was believed to have formed, while hydrated ferrihydrite resulted in no bicarbonate formation, only carbonate due to the hydrogen bound 
water competing for surface sites [192]. Further molecular level details of the impact of FeOOH mineral surface structure on adsorbed $\mathrm{CO}_{2}$ product carbonate speciation were explored by Song and Boily by identifying adsorption sites and geometries of (bi)carbonate species at surfaces of nanosized goethite $(\alpha-\mathrm{FeOOH})$ and lepidocrocite $(\gamma-\mathrm{FeOOH})$ particles [193]. Monodentate (mononuclear and binuclear) bicarbonate were proposed to coexist. Adsorbed bicarbonate was the dominant species on $\alpha-\mathrm{FeOOH}$, while a mixture of adsorbed bicarbonate and carbonate was present on $\gamma-\mathrm{FeOOH}$ due to the various hydrogen bonding patterns on these mineral surfaces. $\mathrm{Fe}_{3} \mathrm{O}_{4}$ decorated-graphene nanoplatelets were found to coordinate $\mathrm{CO}_{2}[194,195]$. FTIR analysis showed a complex peak pattern due to the $\mathrm{C}-\mathrm{O}, \mathrm{C}=\mathrm{C}$ and $\mathrm{C}-\mathrm{H}$ vibrations inherently present on graphene. However, an increase in 1402 and $1033 \mathrm{~cm}^{-1}$ peaks was attributed to the vibrational modes of adsorbed bicarbonate and carbonate, respectively. A large shift in the vibrational spectrum was observed for the Fe-O-Fe vibrational mode from 598 to $578 \mathrm{~cm}^{-1}$, suggesting a high degree of interaction between adsorbing $\mathrm{CO}_{2}$ and the $\mathrm{Fe}_{3} \mathrm{O}_{4}$ in the composite material.

4.2.3.8 PdO. $\mathrm{PdO}$ is one of the least studied surfaces for $\mathrm{CO}_{2}$ adsorption. A both experimental and theoretical single study was conducted by Hinojosa et al. [196]. TPD and quantum chemical calculations using DFT-D3 were performed to analyze the adsorption products of $\mathrm{CO}_{2}$ on the surface. These calculations revealed no formation of carbonates and bicarbonates. The adsorption was considered physisorption in agreement with some of the work regarding $\mathrm{TiO}_{2}$, because the structure of the crystal resembled rutile $\mathrm{TiO}_{2}(110)$. DFT calculations predicted that the initial adsorption of $\mathrm{CO}_{2}$ is in linear configuration, which will form bent-linear pairs and further, linear-bent-linear trimers on cus-Pd rows. At coverage above $0.26 \mathrm{ML}, \mathrm{CO}_{2}$ begins to physically adsorb on the 4f-Pd sites, and further saturates the sites until total coverage reaches 0.52 ML.

4.2.3.9 NiO. The interaction between $\mathrm{CO}_{2}$ and a single-crystal $\mathrm{NiO}$ (111) surface, as well as hydroxylated $\mathrm{NiO}$ (111), were investigated by Matsumoto and coworkers [68]. Adsorption structures of the adsorbed $\mathrm{CO}_{2}$ species and the effect of hydroxylating the surface were studied 
using IRAS under UHV conditions. Two peaks associated with monodentate carbonate were observed during the temperature programmed desorption. These peaks appeared at 1263 (1267) and $910 \mathrm{~cm}^{-1}$ and were assigned to $v_{3} \mathrm{~s}$ and $v_{2}$ and disappeared when the temperature was ramped up to $248 \mathrm{~K}$. The hydroxylated surface exhibited a much less intense deformation peak, which, according to the authors, is indicative of the perpendicular orientation of the molecule to the surface.

\subsection{4 $\mathrm{CO}_{2}$ adsorption on metal oxide surfaces in the presence of coadsorbing molecules}

Under $\mathrm{O}_{2}$-rich and atmospherically relevant conditions, most metal oxides are coordinated by (hydr)oxo groups. These groups can be coordinated to one (-O), two $(\mu-\mathrm{O})$ or three $\left(\mu_{3}-\mathrm{O}\right)$ metal ions, and consequently have considerably different abilities to bind or exchange with $\mathrm{CO}_{2}$. Coordination of oxygen moieties of the surface (hydr)oxo groups with incoming $\mathrm{CO}_{2}(\mathrm{~g})$ will therefore result in the stabilization of (bi)carbonate species. Gas-phase FTIR spectroscopic studies of $\mathrm{CO}_{2}(\mathrm{~g})$ binding to metal oxide and mineral surfaces have thus taken these interactions within, and several have tentatively supported peak assignments with theoretical frequency calculations of (bi)carbonate species bound to (hydr)oxo-bearing clusters (Table 18) [45,105,193,197]. Mixed isotope experiments [50] have also provided insight into the initial nucleophilic attack of surface hydroxo groups, providing evidence that proton transfer is involved in the formation of bicarbonate species at $\alpha-\mathrm{Fe}_{2} \mathrm{O}_{3}$ and $\gamma-\mathrm{Al}_{2} \mathrm{O}_{3}$ surfaces.

Table 18. Theoretical frequency calculations of (bi)carbonate-bound metal (oxy)hydroxide $\mathrm{Fe}$ and $\mathrm{Al}$ clusters

\begin{tabular}{lcccc}
\hline & $v_{3}$ as & $v_{3} \mathrm{~s}$ & $\delta_{\mathrm{COH}}$ & $v_{3}$ as $-v_{3} \mathrm{~s}$ \\
\hline MBC & $1701-1708$ & $1162-1166$ & & $539-546$ \\
MBC (hydrated) & $1517-1523$ & $1323-1329$ & & 194 \\
MBB & $1590-1620$ & $1414-1435$ & 1193 & $185-199$ \\
MMC & 1452 & 1271 & & 181 \\
MMB & $1716-1779$ & $1182-1293$ & & $486-534$ \\
MMB & 1627 & 1390 & 1193 & 237 \\
\hline
\end{tabular}




\begin{tabular}{lllll}
\hline MMB-a & 1589 & 1204 & 1038 & 385 \\
MMB-b0 & 1575 & 1372 & 1177 & 203 \\
MMB-b1 & 1701 & 1325 & 1173 & 376 \\
\hline
\end{tabular}

MMC=monodentate mononuclear carbonate; $\mathrm{MMB}=$ monodentate mononuclear bicarbonate; $\mathrm{MBC}=$ monodentate binuclear carbonate; $\mathrm{MBB}=$ monodentate binuclear bicarbonate. Adopted from $[45,105,192,193]$.

Studies on mixed Al/Fe oxohydroxides [197] using ATR-FTIR with DFT provide evidence for binding at three distinct sites. $\mathrm{Al}$ also played an important role in the form of bound $\mathrm{CO}_{2}$. Thus, while low $\mathrm{Al}$ content led to $\mathrm{Al}-$ and $\mathrm{Fe}-$ bound $\mathrm{CO}_{2}$ species, larger $\mathrm{Al}$ content ( $>20$ mol\%) promoted bicarbonate binding to discrete phases of $\mathrm{AlOOH}$, a result that could possibly be affected by morphological differences controlling site availability in the different mixtures.

The behavior of mixed $\mathrm{CO}_{2}-\mathrm{H}_{2} \mathrm{O}$ gases is of particular relevance to environmental studies focused on atmospheric and geochemical processes [198,199]. Work along this front includes vibration spectroscopy and theoretical calculations efforts $[45,52,172])$ describing the formation of (bi)carbonate species within thin water films at aluminum and ferric iron oxide surfaces. Other work [5], comparing binding at $\mathrm{Fe}_{2} \mathrm{O}_{3}, \gamma-\mathrm{Al}_{2} \mathrm{O}_{3}$ and $\mathrm{TiO}_{2}$ nanoparticle surfaces, also showed that thin water films effectively decreased $\mathrm{CO}_{2}$ adsorption rates, as water competed for the same $\mathrm{CO}_{2}$ binding sites. Allen et al. [200] also report an ab initio-derived phase diagram for the (100), (110), (111) and (310) surfaces of $\mathrm{CaO}$ and $\mathrm{MgO}$ contacted with mixtures of these gases. Their results underscored the role of water in catalyzing carbonate formation, as well as face-specific products. For instance, carbonate phases preferably form on the (100) face of $\mathrm{CaO}$, while hydration is favored on $\mathrm{MgO}$. The (111) faces of $\mathrm{CaO}$ and $\mathrm{MgO}$ are, on the other hand, preferentially hydroxylated, while steps of the (310) face promote interactions with carbonate species. DFT investigations also detected considerably stronger $\mathrm{CO}_{2}$ binding over $\mathrm{H}_{2} \mathrm{O}$ on the $\mathrm{BaO}(100)$ face [201]. 
A recent review contrasting the $\mathrm{CO}_{2}$ binding attributes of different minerals includes the one of Baltrusaitis et al. [5] on $\mathrm{Fe}_{2} \mathrm{O}_{3}, \gamma-\mathrm{Al}_{2} \mathrm{O}_{3}$ and $\mathrm{TiO}_{2}$. This work highlighted the roles that sites of contrasting basicity play in $\mathrm{CO}_{2}$ binding under low levels of humidity. The comparative study showed that $\mathrm{Fe}_{2} \mathrm{O}_{3}$ and $\gamma-\mathrm{Al}_{2} \mathrm{O}_{3}$ favor bicarbonate species, while $\mathrm{TiO}_{2}$ favors bidentate carbonate species. In another study [193], FTIR measurements of iron oxyhydroxide nanoparticles showed that the actual dispositions of surface $\mathrm{OH}$ groups, and their resulting hydrogen bond strengths and populations, impact the speciation of the resulting carbonate/bicarbonate species. This was demonstrated for the case of rows of singly-coordinated (-OH) groups on the (110) face of goethite in contrast to the (100) face of lepidocrocite (Figure 52).
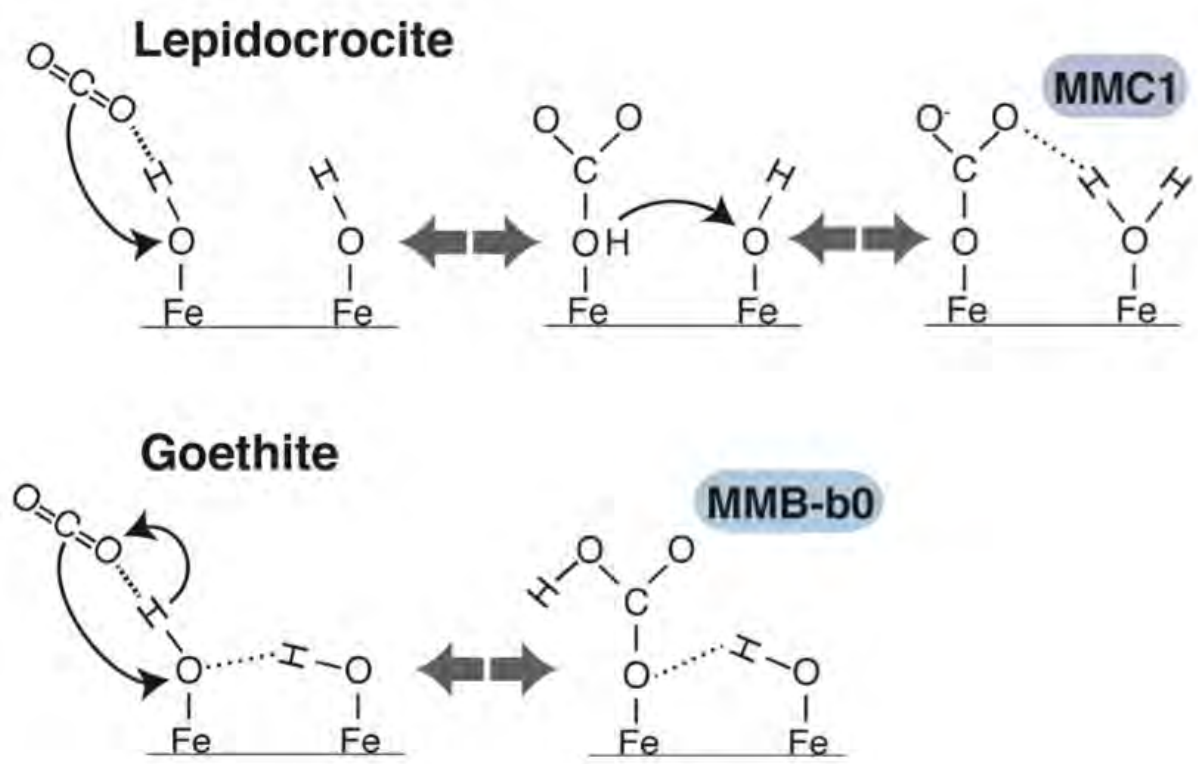

Figure 52. Schematic representation of $\mathrm{CO}_{2}(\mathrm{~g})$ adsorption mechanisms and (bi)carbonate formation at lepidocrocite and goethite surfaces. Reproduced with permission from [193]. Copyright (2013) American Chemical Society.

While both faces exhibit highly comparable $-\mathrm{OH}$ site densities and are separated by $\sim 3.0 \AA$, only $25 \%$ of those on lepidocrocite donate H-bonds, in contrast to $50 \%$ on goethite. The stronger $\mathrm{OH} . .-\mathrm{OH}$ interactions in the latter prevent $\mathrm{H}$-bonds from forming with neighboring 
(bi)carbonate species, and thus favor the stabilization of bicarbonate species of the type -O$\mathrm{CO}_{2} \mathrm{H}$. The weaker H-bond in lepidocrocite favor, on the other hand, a co-existence of both -O$\mathrm{CO}_{2} \mathrm{H}$ and $-\mathrm{O}-\mathrm{CO}_{2}$ species. Other binding sites to consider include oxygen defects, such as in the proposed case for the (101) face of anatase [202], where $\mathrm{CO}_{2}$ binding to a $\mathrm{V}_{\mathrm{O}}$ defect site leads to a carbonate-like species. Mechanisms of this type have strong implications for interfacial isotopic exchange, as noted in a vibration spectroscopic study [203] building upon these calculations.

A particularly curious case of $\mathrm{CO}_{2}$ interactions with a nanoparticulate $\mathrm{Fe}_{2} \mathrm{O}_{3}$ surface in the presence of $\mathrm{H}_{2} \mathrm{O}$ as relative humidity, was presented by Baltrusaitis and coworkers as shown in Figure 53 [191]. At the lower relative humidity, there was a decrease in the intensity of the adsorbed bicarbonate peaks at 1622,1410 , and $1220 \mathrm{~cm}^{-1}$ for the nanoparticulate $\mathrm{Fe}_{2} \mathrm{O}_{3}$ as the relative humidity increased (Figure 53, left). The decrease in intensity of the bicarbonate peaks was concomitant with an increase and the apparent shift of the intensity of the absorption peaks near 1511 and $1333 \mathrm{~cm}^{-1}$ for nanoparticulate $\mathrm{Fe}_{2} \mathrm{O}_{3}$. In addition, in the low relative humidity spectra, the growth of a peak due to the bending mode of adsorbed water, $\delta\left(\mathrm{H}_{2} \mathrm{O}\right)$, near $1640 \mathrm{~cm}^{-}$ ${ }^{1}$ can be seen. This peak is observed starting at 1 to $2 \% \mathrm{RH}$, indicating the presence of molecularly adsorbed water on the surface. These peaks can be attributed to the adsorbed solvated surface carbonate, as apparent from the right side of Figure 53. Here, in (a) the ATRFTIR spectrum of $1 \mathrm{M} \mathrm{NaHCO}_{3}$ solution at $\mathrm{pH}=8$ is shown, which remarkably resembles and is almost analogous to the vibrations observed in (b) for $\mathrm{CO}_{2}+40 \% \mathrm{RH} \mathrm{H} \mathrm{H}_{2} \mathrm{O}$. This was confirmed by the $\mathrm{D}_{2} \mathrm{O}$ experiments in (c) and $\mathrm{H}_{2} \mathrm{O}(18)$ experiments in (d) and (e) [52]. 


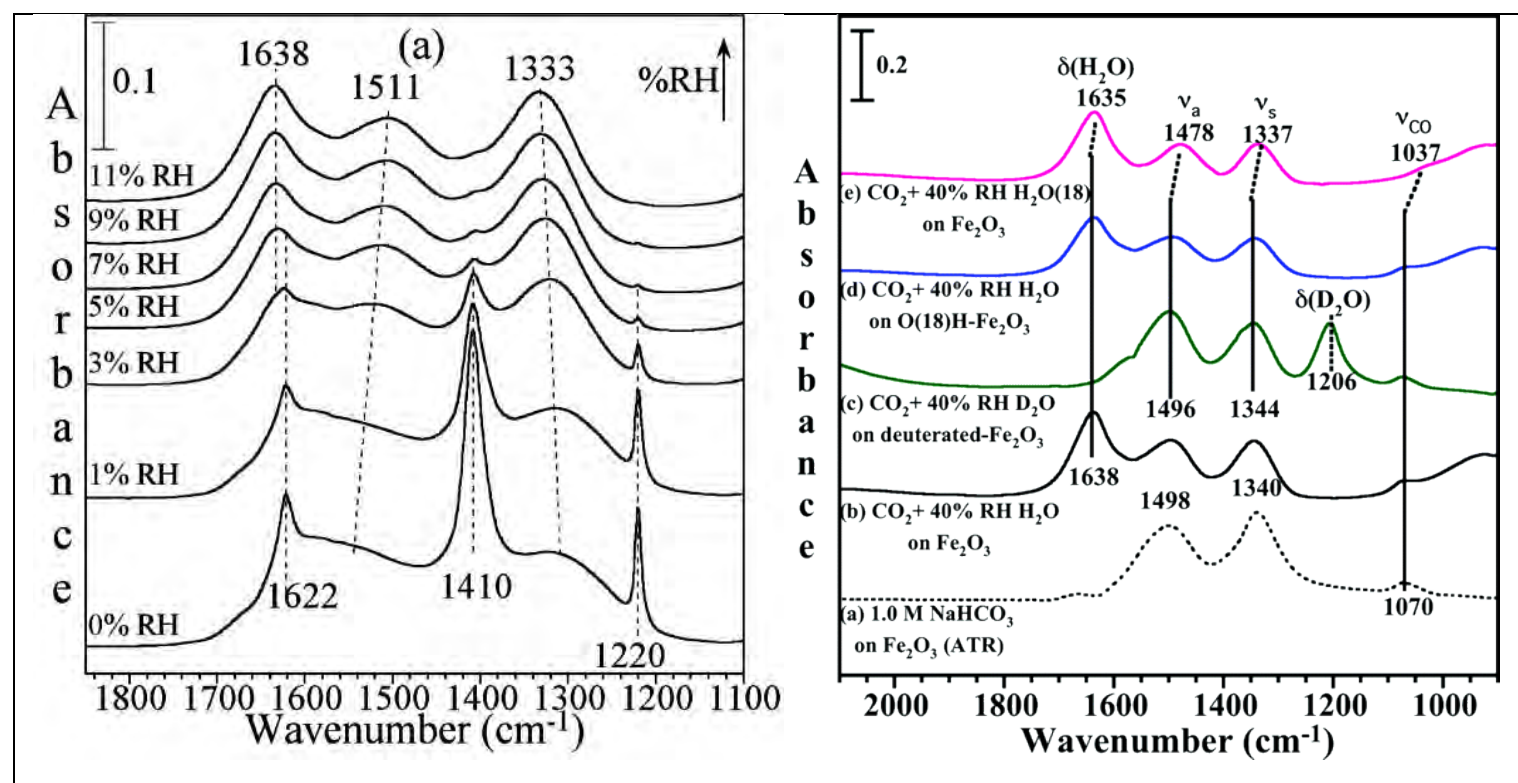

Figure 53. (left) FTIR spectra of nanoparticulate $\mathrm{Fe}_{2} \mathrm{O}_{3}$ following exposure to mixtures of 0.274 Torr $\mathrm{CO}_{2}$ with increasing relative humidity from 0 to $11 \% \mathrm{RH}(0,1,3,5,7,9,11)$ in the 1100 to $1850 \mathrm{~cm}^{-1}$ region. Reproduced with permission from [191]. Copyright (2007) American Chemical Society. (right) FTIR spectra are shown for $\mathrm{Fe}_{2} \mathrm{O}_{3}$ in the presence of (a) $1 \mathrm{M} \mathrm{NaHCO}_{3}$ solution at $\mathrm{pH}=8$; solution-phase absorptions have been subtracted from the ATR spectrum. The other spectra (b)-(e) are in the presence of gas-phase $\mathrm{CO}_{2}(16)$ at a pressure of $275 \mathrm{mT}$ Trr and $40 \% \mathrm{RH}$, (b) $\mathrm{H}_{2} \mathrm{O}$ (16) on $\mathrm{Fe}_{2} \mathrm{O}_{3}$, (c) $\mathrm{D}_{2} \mathrm{O}$ on deuterated $\mathrm{Fe}_{2} \mathrm{O}_{3}$, (d) $\mathrm{H}_{2} \mathrm{O}$ (16) on $\mathrm{O}$ (18) labeled $\mathrm{Fe}_{2} \mathrm{O}_{3}$, and (e) $\mathrm{H}_{2} \mathrm{O}(18)$ on $\mathrm{O}(16)$ labeled $\mathrm{Fe}_{2} \mathrm{O}_{3}$. Gas-phase absorptions have been subtracted from the transmission spectra shown in (b)-(e). Reproduced with permission from [52]. Copyright (2005) American Chemical Society.

The remarkable resemblance between the spectra again suggests solvated carbonate species on the surface of nanoparticulate $\mathrm{Fe}_{2} \mathrm{O}_{3}$ with similar behavior observed for $\gamma-\mathrm{Al}_{2} \mathrm{O}_{3}$ [191]. The estimated thickness of the $\mathrm{H}_{2} \mathrm{O}$ layer on metal oxides, however, is only about 2 monolayers at 40 $\% \mathrm{RH}$ without presenting the same bulk solvent properties, such as those for $1.0 \mathrm{M} \mathrm{NaHCO}_{3}$ [204]. This resulted in a series of works explaining the structure of this partially solvated carbonate ion and how its potential vibrational frequencies can be affected [191]. In particular, vibrational frequency calculations were performed for uncoordinated "free" carbonate ions and compared with those adsorbed on $\mathrm{Al}(\mathrm{OH})_{3}$, as shown in Figure 54, top left. Cluster models $\left[\mathrm{M}(\mathrm{OH})_{3}\left(\mathrm{H}_{2} \mathrm{O}\right)_{x}\left(\mathrm{CO}_{3}\right)\right]^{2-}$ (where $\mathrm{M}=\mathrm{Al}$ and $x=0,1,2,3$, or 4$)$ were used and calculations were carried out using B3LYP/6-31G(d) level of theory. The $\mathrm{O}-\mathrm{C}$ bond in the $\mathrm{Al}-\mathrm{O}-\mathrm{C}$ linkage 
decreased from 1.39 to $1.32 \AA$, because water molecules solvated the coordinated carbonate ion and elongated the $\mathrm{C}-\mathrm{O}$ bond length of the carbonate ion, showing profound structural (and resulting vibrational) changes of the solvated carbonate ion. The fundamental $v_{3}$ vibrational frequency split also systematically decreased showing that local coordination of $\mathrm{H}_{2} \mathrm{O}$ molecules around the carbonate ion can perturb its vibrational properties and need to be accounted for during the vibrational frequency analysis.

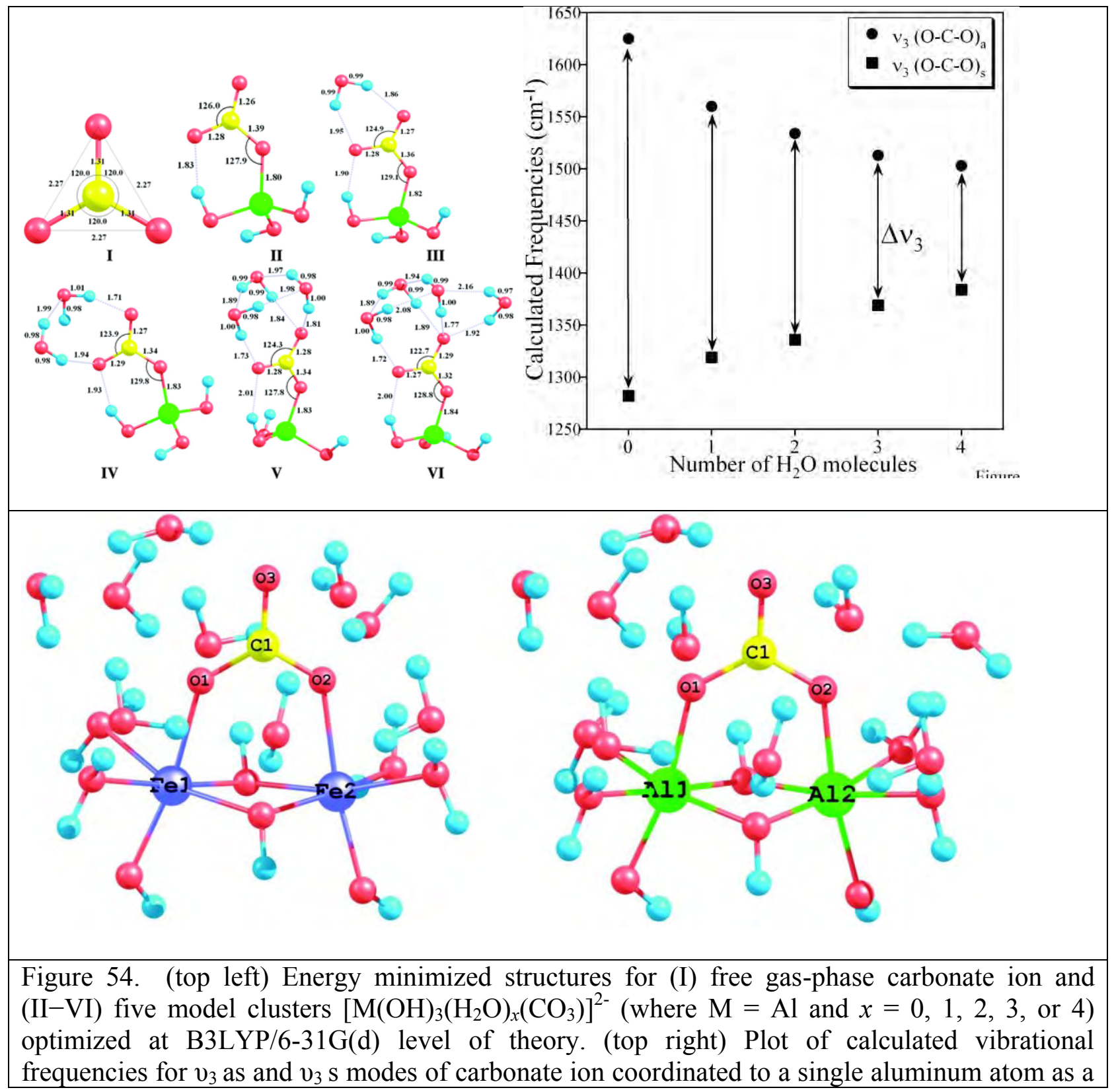


function of the amount of outer sphere coordinated water molecules. (bottom) Energy minimized structures for $\left[\mathrm{M}_{2}(\mathrm{OH})_{2}(\mu-\mathrm{OH})_{2}\left(\mathrm{H}_{2} \mathrm{O}\right)_{11}\left(\mathrm{CO}_{3}\right)\right]$ (where $\mathrm{M}=\mathrm{Fe}$ and $\mathrm{Al}$ ) optimized at B3LYP/6-31G(d) level of theory. Atoms of different elements are highlighted with different colors; iron, purple; aluminum, green; oxygen, red; hydrogen, blue; and carbon, yellow. Reproduced with permission from [191]. Copyright (2007) American Chemical Society.

Another calculation attempted to replicate this complex surface coordination/hydrogen bonded

$\mathrm{H}_{2} \mathrm{O}$ molecule effect on adsorbed carbonate vibrational frequencies using binuclear $\left[\mathrm{M}_{2}(\mathrm{OH})_{2}(\mu-\right.$

$\left.\mathrm{OH})_{2}\left(\mathrm{H}_{2} \mathrm{O}\right)_{11}\left(\mathrm{CO}_{3}\right)\right]$ clusters, where $\mathrm{M}=\mathrm{Fe}$ and $\mathrm{Al}$ optimized at B3LYP/6-31G(d) level of theory

(Figure 53 bottom). Comparison for both Fe and Al unlabeled calculated frequencies, $\omega$, was determined to be in close agreement with experimental values [191]. The proposed structure was that of bridged carbonate, also confirmed by both DFT and experimental $\mathrm{C}(18) \mathrm{O}_{2}$ and $\mathrm{H}_{2} \mathrm{O}(18)$ isotope measurements.

The proposed reactive mechanism of $\mathrm{CO}_{2}$ adsorption and chemical transformation on the nanoparticulate $\mathrm{Fe}_{2} \mathrm{O}_{3}$ surface in the presence of $\mathrm{H}_{2} \mathrm{O}$ as relative humidity was presented by Baltrusaitis and Grassian as shown in Figure 55 [52]. In particular, a direct reaction to yield a carbonic acid intermediate was discussed, which would deprotonate to yield bicarbonate. Bicarbonate then displaces the hydroxyl group on an $\mathrm{Fe}_{2} \mathrm{O}_{3}$ surface followed by the deprotonation, analogous to the solution phase mechanism proposed by $\mathrm{Su}$ and Suarez [205], as well as work by Henderson showing the reaction between $\mathrm{CO}_{2}$ and $\mathrm{H}_{2} \mathrm{O}$ occurring on a single crystal of $\mathrm{TiO}_{2}(110)$ at $110 \mathrm{~K}$ in the presence of oxygen vacancies [206]. This work was also later substantiated by the DFT calculations of $\mathrm{H}_{2} \mathrm{CO}_{3}$ formation on $\mathrm{Al}(\mathrm{OH})_{3}[172]$. 


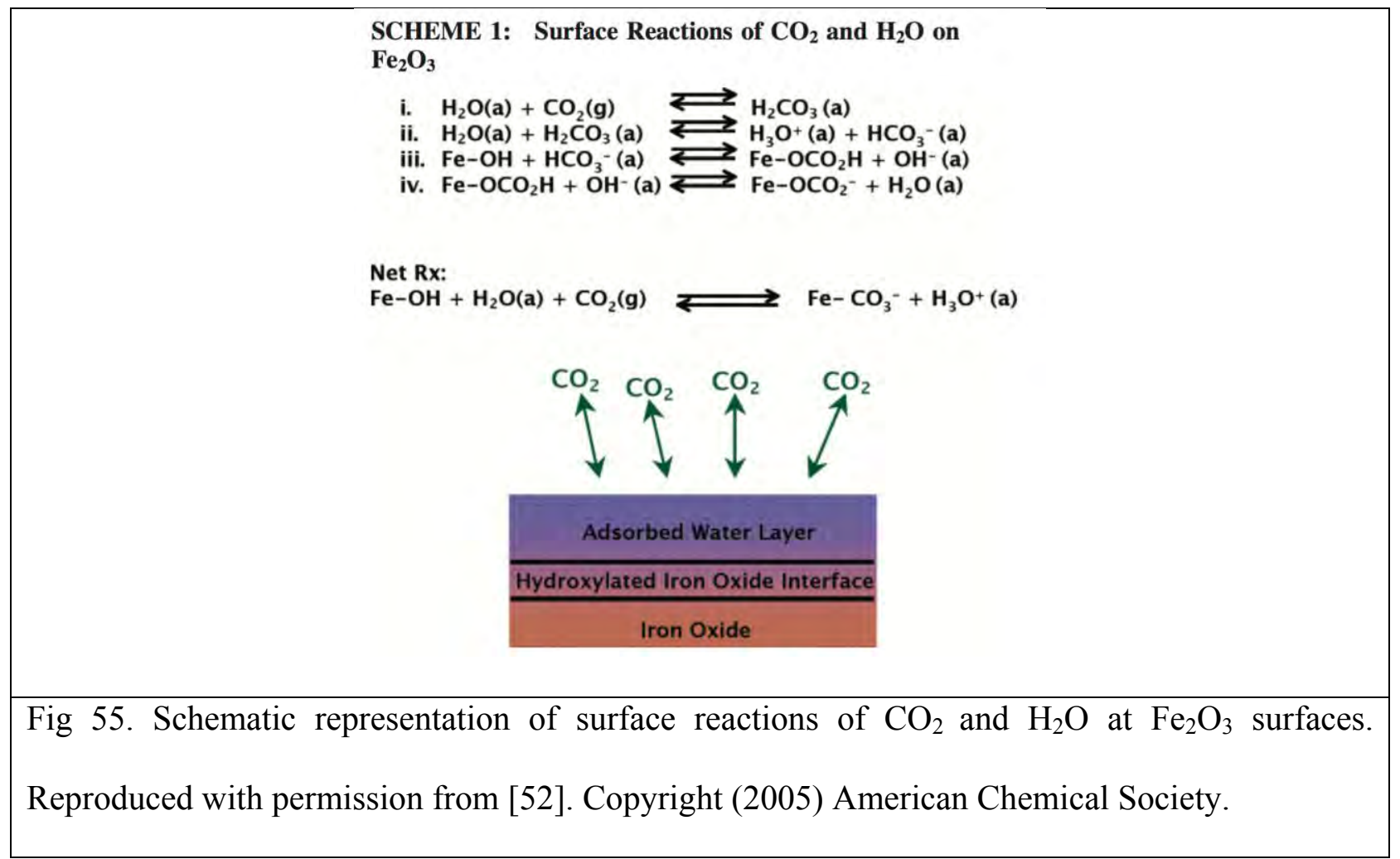

Similar hydrated carbonate structures on $\alpha-\mathrm{Fe}_{2} \mathrm{O}_{3}$ were modelled to agree with their ATR-FTIR air-equilibrated aqueous carbonate data via modelling hydrated monodentate binuclear carbonate surface complexes $\mathrm{Fe}_{2}(\mathrm{OH})_{4}\left(\mathrm{OH}_{2}\right)_{4} \mathrm{CO}_{3} \cdot 2\left(\mathrm{H}_{2} \mathrm{O}\right)$ and outer-sphere/hydrogen bonded complex $\mathrm{Fe}_{2} \mathrm{O}(\mathrm{OH})_{3}\left(\mathrm{OH}_{2}\right)_{5-} \mathrm{CO}_{3}{ }^{2-} \cdot 10\left(\mathrm{H}_{2} \mathrm{O}\right)$. While the former was bridged, the latter was perpendicular to the iron site containing cluster and dipole aligned within the interfacial layer [105]. A remarkable similarity between the vibration properties of the bulk solvated carbonate and $\mathrm{CO}_{2}$ adsorbed in the presence of two monolayers of $\mathrm{H}_{2} \mathrm{O}$ condensed from the vapor phase suggests a complex coordination environment governed by the first coordination layer of $\mathrm{H}_{2} \mathrm{O}$ and surface atoms and almost inevitably results in a bridge molecule on the surface or similarly distorted one by the first $\mathrm{H}_{2} \mathrm{O}$ coordinating sphere. 


\section{3 $\mathrm{CO}_{2}$ bonding at other surfaces}

\subsubsection{Surface/gas interface}

\subsubsection{Zeolites}

Study of the interaction of $\mathrm{CO}_{2}$ with various zeolites was carried out by Stevens et al. [207] with five zeolite materials, i.e. 13X, WEG, AGP, 4A, and 5A, investigated. Researchers found that zeolite pretreatment and adsorption temperature affected the adsorbed $\mathrm{CO}_{2}$ surface species present with carbonates, physisorbed $\mathrm{CO}_{2}$ and carboxylate ions identified using IR spectroscopy. On $13 \mathrm{X}$ surface, pretreatment at $350{ }^{\circ} \mathrm{C}$ lead to the formation of bridged carbonate. In addition to bidentate carbonate, physisorbed $\mathrm{CO}_{2}$ was found on zeolite surface pretreated at $120{ }^{\circ} \mathrm{C}$. Species were characterized by the peaks at 1710 and $1364 \mathrm{~cm}^{-1}$ (bridged bidentate carbonate), $2356 \mathrm{~cm}^{-1}$ (physisorbed $\mathrm{CO}_{2}$ ) and 1486 and $1427 \mathrm{~cm}^{-1}$ (bidentate carbonate) with a shift observed for the bridged species to 1688 and $1361 \mathrm{~cm}^{-1}$, when the surface was pretreated at lower temperature. Notable was the loss of $\mathrm{OH}$ group intensity on the lower temperature-treated surface, which was not encountered on the higher temperature-treated surface, indicating that the $\mathrm{CO}_{2}$ interactions with the $\mathrm{OH}$ group was not present on the surface treated at the higher temperature. The adsorption behavior on WEG and AGP zeolites, which are also X-type zeolites, was similar to that of $13 X[207]$.

On zeolite 4A a significant difference in adsorbed $\mathrm{CO}_{2}$ products was observed, when pretreatment was carried out at $350^{\circ} \mathrm{C}$, as evident from the formation of additional peaks in the spectra. When pretreated at a lower temperature only bridged carbonate and physisorbed $\mathrm{CO}_{2}$ were observed, as characterized by the peaks at $1682,1377 \mathrm{~cm}^{-1}$ and $2351 \mathrm{~cm}^{-1}$, respectively. Sorbents pretreated at $350^{\circ} \mathrm{C}$ produce bidentate carbonate $\left(1506\right.$ and $\left.1457 \mathrm{~cm}^{-1}\right)$ and two different types of bridged carbonate species. The first one was chemisorbed on a Ca site (1735 
and $\left.1245 \mathrm{~cm}^{-1}\right)$ and the second adsorbed on an Na site $\left(1675\right.$ and $\left.1373 \mathrm{~cm}^{-1}\right)$. There was also a notable shift in the physisorbed $\mathrm{CO}_{2}$ peak from 2361 and $2294 \mathrm{~cm}^{-1}$ to 2351 and $2285 \mathrm{~cm}^{-1}$, suggesting that there is a dipole-dipole interaction between adsorbed $\mathrm{CO}_{2}$ molecules. Montanari and Busca studied the same system and observed a peak at $2422 \mathrm{~cm}^{-1}$ assigned to a combination of $v_{3}$ with a hindered rotation (libration) mode $\left(v_{3}+v_{\text {lib }}\right)$ [208]. Upon desorbing, the OCO asymmetric stretching split into 2361 and $2351 \mathrm{~cm}^{-1}$. In the lower frequency region various peaks were observed. The peak at $1382 \mathrm{~cm}^{-1}$ was assigned to $v_{1}$ of linearly adsorbed $\mathrm{CO}_{2}$ due to the activation during the change of symmetry upon adsorption. The other peaks in this region were due to the formation of carbonates or bent $\mathrm{CO}_{2}$ species. So called eovalent" carbonate was observed because there were peaks at 1725 and $1248 \mathrm{~cm}^{-1}$, while strong peaks at 1456 and 1390 $\mathrm{cm}^{-1}$ appeared after outgassing the system and were attributed to monodentate carbonates. Several other peaks were also present in the spectra at $1693,1660,1640$, and $1580 \mathrm{~cm}^{-1}$ with the corresponding peaks in the range of $1400-1250 \mathrm{~cm}^{-1}$. These peaks were assigned to either bidentate or bridging carbonates.

On zeolite $5 \mathrm{~A}$, bridged carbonate and physisorbed $\mathrm{CO}_{2}$ were confirmed using IR spectroscopy by Stevens et al., as characterized by peaks at 1667 and $1384 \mathrm{~cm}^{-1}$ (bridged carbonate), and 2353 $\mathrm{cm}^{-1}$ (physisorbed $\mathrm{CO}_{2}$ ) [207]. An additional insight concerning the system was offered by Montanari and Busca, where a negative peak in the carbonate region was observed [208]. This phenomenon was tentatively attributed to a linear $\mathrm{CO}_{2}$ molecule adsorbing on the occupied cation site that had originally adsorbed a symmetrical carbonate species. Additionally, several peaks in the same region were also found and were similar to outgassing at room temperature, even though these peaks had lower intensity [208]. The same group also investigated the 3A zeolite system, where they found a peak at $2351 \mathrm{~cm}^{-1}$ and assigned it to a linear $\mathrm{CO}_{2}$ molecule 
shifted upward due to the Lewis acidity of the adsorbing center. Sharp peaks were formed at 1653 and $1359 \mathrm{~cm}^{-1}$, while weaker peaks were also present at 1715 and $1246 \mathrm{~cm}^{-1}$. These last twopeaks are characteristic of carbonate species and/or bent $\mathrm{CO}_{2}{ }^{-}$molecules.

Pillai et al. investigated the interaction between $\mathrm{CO}_{2}$ and an Na-ETS zeolite sample using DRIFTS [209]. Two degassing temperatures prior to $\mathrm{CO}_{2}$ adsorption were used and compared at $373 \mathrm{~K}$ and $423 \mathrm{~K}$. In both, peaks at 2340,1586 and $1371 \mathrm{~cm}^{-1}$ were observed and attributed to physisorbed $\mathrm{CO}_{2}$ and a $v_{3}$ split of adsorbed carbonates, respectively. For the lower temperature treatment, these peaks disappeared completely upon outgassing the sample, while the higher temperature treated sample retained the peak at $1371 \mathrm{~cm}^{-1}$, even after prolonged evacuation. The author attributed the persistent nature of this peak to the carbonate's coordination to an extra $\mathrm{Na}^{+}$ ion framework. Also notable in the experiment was the peak at $2340 \mathrm{~cm}^{-1}$ that did not completely disappear during the sample treatment at higher temperatures, even after prolonged outgassing [209].

A combined DFT and IR spectroscopy investigation was used to elucidate the interaction between $\mathrm{CO}_{2}$ and zeolite Na-A [210]. IR spectroscopy revealed no carbonation taking place on the surface since the only peak associated with the $\mathrm{CO}_{2}$ surface species was present at 2349 and $2360 \mathrm{~cm}^{-1}$, characteristic of physisorbed species. The two peaks were, as confirmed by DFT simulation, associated with two different physisorbed $\mathrm{CO}_{2}$ species. While the former was present only at very low coverage with the $\mathrm{CO}_{2}$ molecule preferentially adsorbing on either the S2-S1 or S2-S3 site, interacting with three $\mathrm{Na}^{+}$cations in the supercage, the latter was found to take place at a higher coverage range, where the molecule sets on a dual cation site formed by $\mathrm{Na}^{+}$cations in S2 and S1 sites. Figure 56 depicts the supercage model used in the calculation along with adsorption configurations at low and higher coverage [210]. 

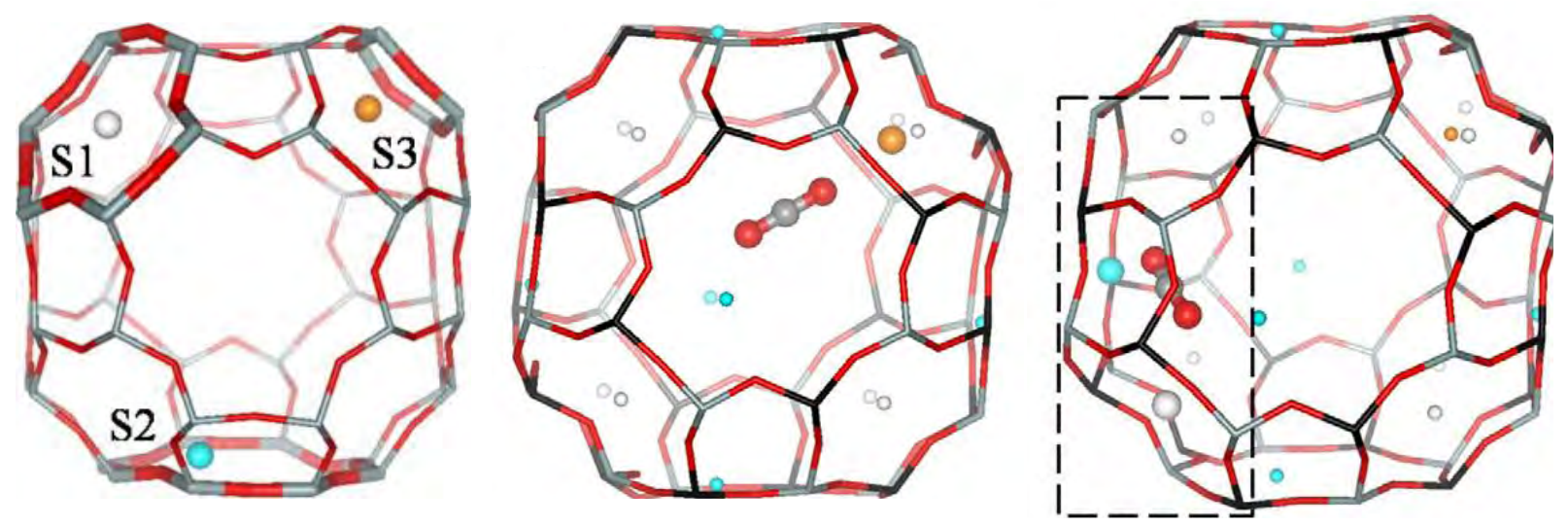

Figure 56. (Left) S1-S3 sites with three $\mathrm{Na}^{+}$cations (white, blue, and yellow colored) within the supercage used for the calculation. (Mid) $\mathrm{CO}_{2}$ adsorption sites at low coverage. (Right) adsorption configuration for higher $\mathrm{CO}_{2}$ coverage, where the molecule is situated on a dual cation site formed by $\mathrm{Na}^{+}$cations on S2 and S1 sites. Reproduced with permission from Elsevier. [210].

Adsorption of $\mathrm{CO}_{2}$ on acidic zeolites, such as $\mathrm{H}-\beta$ and H-FER, was studied by Delgado et al. [211,212] using variable temperature IR (VTIR) spectroscopy. Both surfaces possess a high acidity due to the protonic zeolite. Due to this, no carbonate peaks were observed in the 1350$1700 \mathrm{~cm}^{-1}$ region. These carbonate species formed most of the time on basic oxygen atoms of zeolite. A physisorbed molecule, however, was observed, as confirmed by peaks at 2348 and $2346 \mathrm{~cm}^{-1}$ for $\mathrm{H}-\beta$ and H-FER, respectively, which intensified when the temperature was decreased [211]. Other authors analyzed alkali ion-exchanged H-FER zeolites, too, and also did not detect any formation of carbonates, when $\mathrm{CO}_{2}$ molecules were adsorbed [213]. $\mathrm{For}^{+}{ }^{+}$and $\mathrm{K}^{+}$, exchanged surface peaks at 2370 and $2357 \mathrm{~cm}^{-1}$ were observed due to the physisorbed $\mathrm{CO}_{2}$ species. On Li-exchanged FER a peak was observed at $2353 \mathrm{~cm}^{-1}$. The $\mathrm{CO}_{2}$ surface species was proposed to be bridged between two cations in all cases. Additionally, the same group also 
conducted VTIR of $\mathrm{CO}_{2}$ adsorption using the alkaline zeolite $\mathrm{K}-\mathrm{L}$ with only one peak detected at $2346 \mathrm{~cm}^{-1}$ and assigned to a physisorbed $\mathrm{CO}_{2}$ molecule [214].

$\mathrm{Li}^{+}$modified zeolite SSZ-13 was also investigated and $\mathrm{CO}_{2}$ adsorption studied using FTIR under near vacuum conditions [215]. The interaction between $\mathrm{CO}_{2}$ and the surface resulted in the appearance of a peak near $2350 \mathrm{~cm}^{-1}$, which was assigned to linear $\mathrm{CO}_{2}$. The upward shift due to the ion-dipole interaction between $\mathrm{Li}^{+}$and $\mathrm{CO}_{2}$ was more pronounced at low pressures where $\mathrm{CO}_{2}$ had a greater probability of interacting with cations. At higher pressures more peaks between 3598 and $3725 \mathrm{~cm}^{-1}$ were observed due to the combination peaks $\left(v_{3}+v_{1}\right)$ and $\left(v_{3}+2\right.$ $v_{2}$ ). A chemisorbed species was also detected at 1700 and $1360 \mathrm{~cm}^{-1}$ and considered a carbonate-like species, although with lower intensities, indicating the significance of physical adsorption on the surface. Furthermore, while the peaks associated with the physisorbed molecule increased with pressure, the peaks attributed to chemisorbed species did not increase, suggesting that chemisorption only takes place at lower $\mathrm{CO}_{2}$ loading [215].

Temperature-programmed desorption on alkali-treated zeolite-Y was conducted during $\mathrm{CO}_{2}$ adsorption in an attempt to elucidate the interaction between the alkali-modified surface and $\mathrm{CO}_{2}$ [216]. The alkali investigated were $\mathrm{Na}$ and $\mathrm{Cs}$, and TPD results clearly showed two desorption peaks taking place during the temperature ramp with the first one, between 200 and $400{ }^{\circ} \mathrm{C}$, related to physisorbed $\mathrm{CO}_{2}$. The other one took place at significantly higher temperatures of $500-600^{\circ} \mathrm{C}$. This second peak was assigned to $\mathrm{CO}_{2}$ resulting from alkali carbonate decomposition. Between the two dopants Cs was shown to have improved adsorption capacity towards $\mathrm{CO}_{2}$. On an $\mathrm{H}-\mathrm{Y}$ zeolite, IR spectroscopy showed the interaction between $\mathrm{CO}_{2}$ and the surface silanol groups [217]. The native silanol peak at $3747 \mathrm{~cm}^{-1}$ subsequently diminished upon exposure to $\mathrm{CO}_{2}$, while another peak in the same region ca. $3540 \mathrm{~cm}^{-1}$ simultaneously increased 
in intensity. This phenomenon was explained as a native $\mathrm{OH}$ group being consumed when $\mathrm{CO}_{2}$ is introduced, resulting in a different $\mathrm{OH}$ group. Physisorbed $\mathrm{CO}_{2}$ was also observed as characterized by the peak at $2353 \mathrm{~cm}^{-1}$. The carbonate region, i.e., $1300-1700 \mathrm{~cm}^{-1}$, however, was not discussed in that publication [217].

Doping zeolites using alkali metals results in a highly basic surface, which would retain $\mathrm{CO}_{2}$ at high temperatures [218]. TPD experiments of $\mathrm{CO}_{2}$ adsorption on zeolite surfaces demonstrated the superiority of alkali-added surfaces to the ion-exchange surfaces, where $\mathrm{CO}_{2}$ desorption was observed even at $673 \mathrm{~K}$ [218]. The alkali-added zeolites were synthesized by soaking Linde13X in an aqueous alkali nitrate solution and then filtered. Ion-exchanged surfaces are essentially alkali-added zeolites that are further washed with deionized water. On the $\mathrm{K}$ - and $\mathrm{Rb}$-added surfaces, IR experiments showed the development of several peaks assigned to carbonates at 1670,1338 and $1570,1380 \mathrm{~cm}^{-1}$. They were all attributed to bidentate carbonate, with the first two peaks disappearing when the surface was heated up to $500 \mathrm{~K}$. The peaks at 1570 and 1380 $\mathrm{cm}^{-1}$ were stable at the higher temperature possibly due to their bonding to a more basic site of the surface [218].

Modification of zeolites with organic aminosilane has also been studied [219]. IR spectroscopy revealed that adsorption of $\mathrm{CO}_{2}$ on these functionalized zeolites involved the formation of alkyl ammonium carbamate as characterized by peaks at $1488,1492,1484$, and $1479 \mathrm{~cm}^{-1}$ on the spectra of zeolites modified with 3-aminopropyltriethoxysilane (APS), Nmethylaminopropyltrimethoxysilane MAPS, N-(2-aminoethyl)-3-aminopropyltrimethoxysilane (AEAPS), and 3-trimethoxysilylpropyl)diethylenetriamine (TA), respectively. The $\mathrm{C}=\mathrm{O}$ stretch was also observed in the spectra at $1563,1529,1566$, and $1566 \mathrm{~cm}^{-1}$ for each of the organic modifiers, respectively. Upon $\mathrm{CO}_{2}$ adsorption, negative peaks appeared at 3365 and $3301 \mathrm{~cm}^{-1}$, 
characteristic of the $\mathrm{NH}_{2}$ asymmetrical and symmetrical stretch, respectively. This phenomenon implied that $\mathrm{CO}_{2}$ interacted with $\mathrm{N}-\mathrm{H}$ bonds leading to the formation of carbamate. For this particular adsorption system, the presence of water did not affect the binding configuration, as identical spectra were obtained for each surface [219].

\subsubsection{Carbides}

Transition metal carbides have recently attracted a lot of interest in $\mathrm{CO}_{2}$ adsorption for sequestration and activation purposes [220-228]. The $\mathrm{Mo}_{2} \mathrm{C}$ surface shows great promise in replacing noble metals for $\mathrm{CO}_{2}$ activation [222]. On the $\mathrm{Mo}_{2} \mathrm{C}$ surface $\mathrm{CO}_{2}$ dissociates and adsorbs with better activity than that of its oxide counterpart. AP-XPS investigations of the $\mathrm{Mo}_{2} \mathrm{C} / \mathrm{Mo}$ (110) surface under $\mathrm{CO}_{2}$ and $\mathrm{H}_{2}$ flow showed the formation of oxy-carbide and are shown in Figure 56. In the $\mathrm{C} 1 \mathrm{~s}$ region the carbide was shown by a peak at $282.9 \mathrm{eV}$, while small amounts of $\mathrm{MoO}_{\mathrm{x}}$ were also present, as evidenced by the peak at $530.4 \mathrm{eV}$ in the $\mathrm{O} 1 \mathrm{~s}$ region. Another peak in the $\mathrm{O} 1 \mathrm{~s}$ region at $531.7 \mathrm{eV}$ was attributed to oxycarbide, which appeared after exposing the surface to 150 mTorr of $\mathrm{CO}_{2}$. The accompanying peak in the $\mathrm{C} 1 \mathrm{~s}$ region was present at $283.6 \mathrm{eV}$. Formates and carbonates, previously reported in metal/MO $\mathrm{MU}_{\mathrm{x}}$ surfaces upon $\mathrm{CO}_{2}$ adsorption, were not detected and a different mechanism of adsorption was proposed. On a carbide surface $\mathrm{CO}_{2}$ was predicted to dissociate and adsorb to form $\mathrm{CO}$ and $\mathrm{O}$, with the latter yielding oxycarbide via a reaction with the $\mathrm{Mo}_{2} \mathrm{C}$ lattice. The $\mathrm{Mo}_{2} \mathrm{C}$ site was determined to be the active site on the catalyst, and for the catalyst to retain its activity, it needs to be in its carburized state, i.e. carbide. Confirmed by in-situ XANES experiments, the catalyst maintains its carburized state, as the linear fit with $\mathrm{Mo}_{2} \mathrm{C}$ and $\mathrm{MoO}_{3}$ standard shows good approximation. However, when the surface is impregnated with Co, the linear fit with the standards no longer holds, suggesting the presence of another phase, likely $\mathrm{CoMoC}_{\mathrm{y}} \mathrm{O}_{\mathrm{z}}$ [222]. 

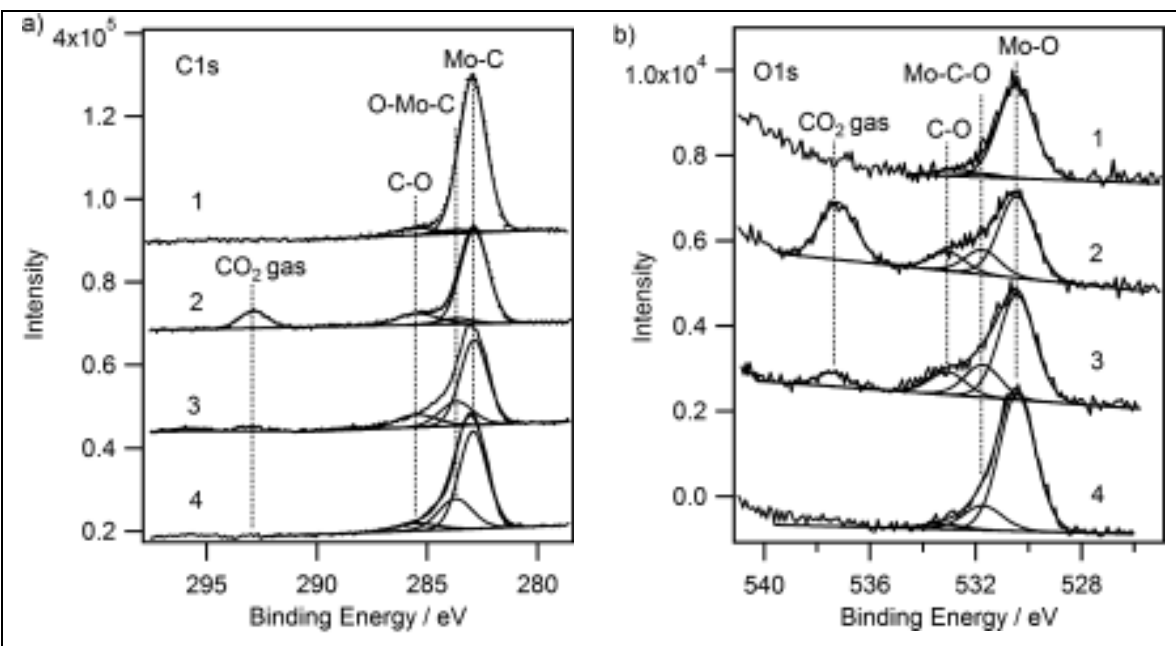

Figure 57. High resolution $\mathrm{C} 1 \mathrm{~s}$ and $\mathrm{O} 1 \mathrm{~s}$ XANES spectra of the $\mathrm{Mo}_{2} \mathrm{C} / \mathrm{Mo}(110)$ surface before and after $\mathrm{CO}_{2}$ adsorption: (1) Clean $\mathrm{Mo} 2 \mathrm{C}$, (2) 150 mTorr $\mathrm{CO}_{2}$ at room temperature, (3) 150 mTorr $\mathrm{CO}_{2}+550 \mathrm{mT}$ Torr $\mathrm{H}_{2}$ with annealing to $523 \mathrm{~K}$, then cooling to room temperature, 4) 150 mTorr $\mathrm{CO}_{2}+550 \mathrm{mTorr} \mathrm{H}_{2}$ at $523 \mathrm{~K}$. Reproduced with permission from Wiley [222].

DFT calculations were performed on $\alpha-\mathrm{Mo}_{2} \mathrm{C}(0001), \beta-\mathrm{Mo}_{2} \mathrm{C}(001)$ and $\delta-\mathrm{Mo}_{2} \mathrm{C}(001)$ using the GGA-PBE level of theory augmented with the van der Waals correction [224,225]. Separate calculations carried out by these two authors predict that either dissociation of $\mathrm{CO}_{2}$ to $\mathrm{CO}$ and $\mathrm{O}$ or $\mathrm{CO}_{2}$ activation to bent anionic $\mathrm{CO}_{2}^{-}$to be the most stable adsorption configuration. In this case, the dissociated oxygen atom is bonded to two Mo atoms on the top layer, averaging a 2.051 $\AA$ bond length. The surface $\mathrm{CO}$ species bridges two Mo atoms with its bond length elongated from $1.179 \AA$ to $1.233 \AA$. In other bonding configurations of adsorbed $\mathrm{CO}_{2}$, charge transfer is expected to take place from the surface to the molecule's anti-bonding orbital, resulting in the bent structure of the surface species [225]. Figure 58 shows various bonding configurations of $\mathrm{CO}_{2}$ on the $\alpha-\mathrm{Mo}_{2} \mathrm{C}(0001)$ surface. 

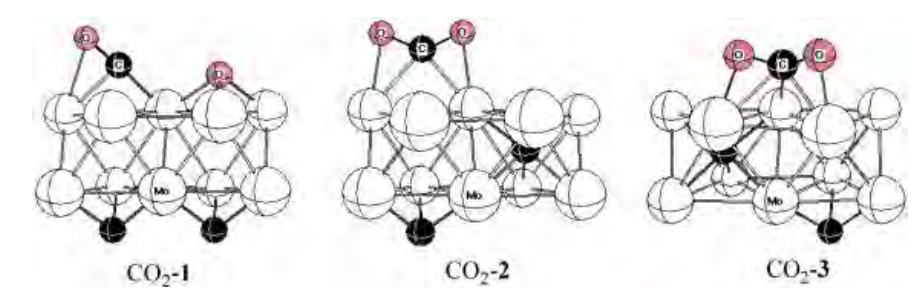

8

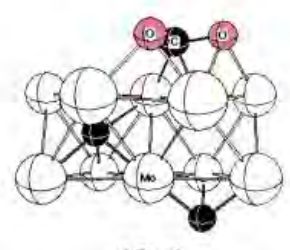

$\mathrm{CO}_{2}-4$

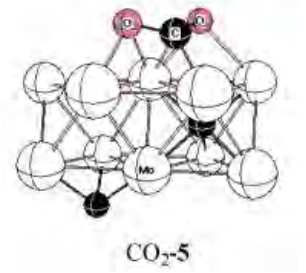

Figure 58. $\mathrm{CO}_{2}$ bonding configurations on terminated $\alpha-\mathrm{Mo}_{2} \mathrm{C}(0001)$ surface. Reproduced with permission from Elsevier [225].

On $\beta-\mathrm{Mo}_{2} \mathrm{C}(001)$ and $\delta-\mathrm{Mo}_{2} \mathrm{C}(001) \mathrm{CO}_{2}$ adsorbs and reacts differently [224]. Adsorption on the Mo-terminated structure of the former leads to dissociation of $\mathrm{CO}_{2}$. However, on both $\mathrm{C}$ terminated of the former and the latter, $\mathrm{CO}_{2}$ is present as a bent structure. As a note of interest, the initial position of the $\mathrm{CO}_{2}$ determines whether or not the molecule is dissociated. On the Moterminated $\beta-\mathrm{Mo}_{2} \mathrm{C}(001)$, when the initial position of $\mathrm{CO}_{2}$ is not on top of the Mo site, the molecule is solely activated, as opposed to when it is dissociated on top of the Mo site. Another carbide, e.g. tungsten carbide (WC), has been a subject of a theoretical calculation based on the PAW method with the GGA-PW91 exchange-correlation approximation [228]. On the bare WC surface dissociation is not readily observed. However, on a Co-promoted surface, dissociation of $\mathrm{CO}_{2}$ takes place when cobalt atoms are layered on the top of the surface. The adsorption energy is actually lowered in the case of Co-doping, where the surface contains $\mathrm{CoW}_{\mathrm{x}} \mathrm{C}_{\mathrm{y}}$ species decreasing from $-0.99 \mathrm{eV}$ for bare surface to $-1.61 \mathrm{eV}$. The activation energy for the dissociation, however, ranges from 0.57 to $1.18 \mathrm{eV}$ for several permutations of the doped surface [228]. 
The adsorption site for the $\mathrm{CO}_{2}$ - $\mathrm{TiC}$ system was identified to be a carbon atom on the carbide surface [226,227]. Using DFT calculations, a C-C bond was established upon adsorbing $\mathrm{CO}_{2}$ on the surface, with a regular bond length of $1.48 \AA$. Oxygen atoms preferentially adsorb on top of the nearest Ti sites, establishing a bent geometry, due to charge transfer taking place from the surface to $\mathrm{CO}_{2}$. Adsorption of $\mathrm{CO}_{2}$ molecules on $\mathrm{Cu}$ and Au-promoted TiC substrates was calculated to have lowered the adsorption energy of $\mathrm{CO}_{2}$, from $-0.62 \mathrm{eV}$ to $-0.68 \mathrm{eV}$ and $-1.12 \mathrm{eV}$ for the Au-promoted and Cu-promoted substrates, respectively. Both $\mathrm{Au}$ and $\mathrm{Cu}$-promoted substrates afford an endothermic dissociation process with the bare surface possessing relatively higher C-O cleaving energy compared to the doped surface. In both cases elongation of the C-O bond takes place upon adsorption with the bond length increasing from $1.17 \AA$ to $1.29 \AA, 1.36 \AA$, and $1.31 \AA$ for bare surface, $\mathrm{Cu}$-doped surface and Au-doped surface, respectively [227].

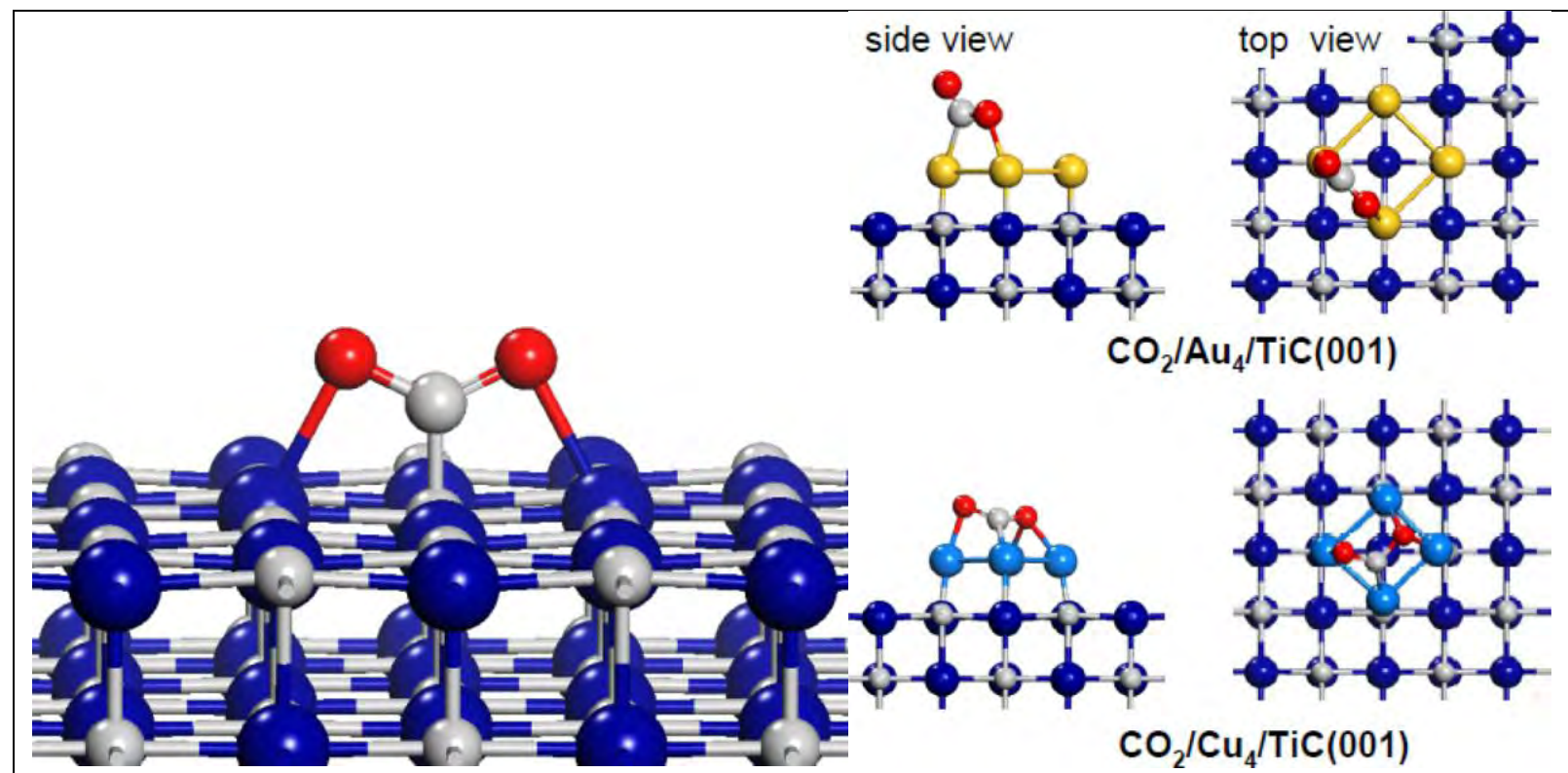

Figure 59. Bent $\mathrm{CO}_{2}$ molecule adsorbed on (left) bare TiC surface and (right) $\mathrm{Au}$ and $\mathrm{Cu}$-doped TiC surface. Reproduced with permission from [227]. Copyright (2012) American Chemical Society. 


\subsubsection{Nitrides}

Nitrides [229-232] and sulfides [233-236] are two classes of compounds rarely used for $\mathrm{CO}_{2}$ surface facilitated reactions. Boron nitride is a novel nitride for $\mathrm{CO}_{2}$ adsorption. A DFT calculation using PAW-PBE indicated two adsorption states on boron-rich boron nitride nanotube [229]. The $\mathrm{CO}_{2}$ molecule initially adsorbs physically on the surface, demonstrating charge transfer from the gas to the surface, before electron backdonation takes place from boron antisite $\left(\mathrm{B}_{\mathrm{N}}\right)$, distorting the structure and breaking the $\pi$-bond, resulting in a carboxylate-like structure, depicted in Figure 60.

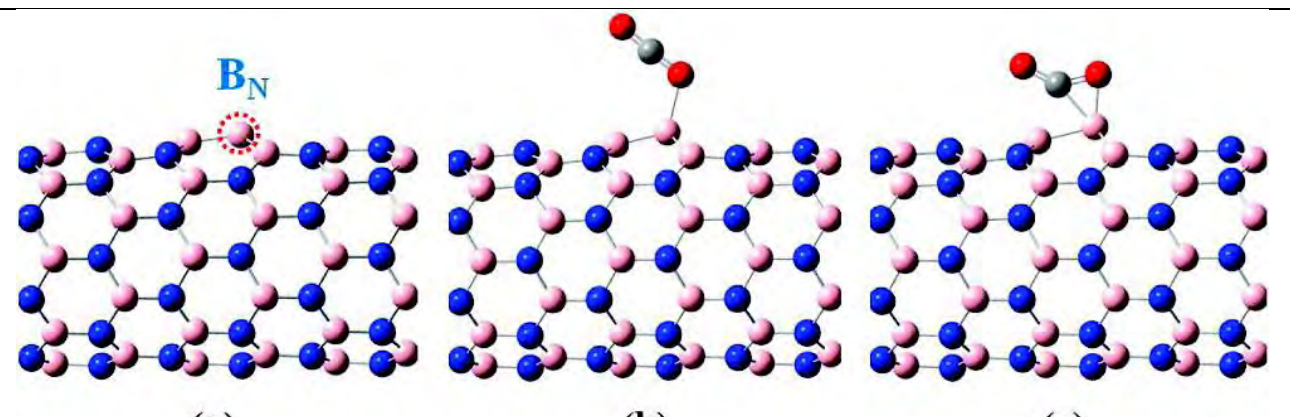

(a)

(b)

(c)

Figure 60. Adsorption states of $\mathrm{CO}_{2}$ on a boron-rich boron nitride nanotube: (a) active site, (b) physisorbed $\mathrm{CO}_{2}$ and (c) carboxylate-like coordination of the surface species. The $\mathrm{C}-\mathrm{O}$ bond is elongated from $1.17 \AA$ to $1.28 \AA$ for the chemisorbed state. Reproduced with permission from [229]. Copyright (2011) American Chemical Society.

Theoretical calculations also demonstrated the existence of two energy barriers between the physisorbed molecule and the dissociated structure on a graphene-like boron nitride with Bvacancy [230]. The first energy barrier connects the physisorbed state and bent $\mathrm{CO}_{2}$ with a 0.82 eV energy barrier, where the right-hand minimum state refers to the bent $\mathrm{CO}_{2}$ molecule, in which the carbon is displaced toward the boron vacancy. A lattice-embedded carbon is then obtained 
after the second energy barrier is overcome, leading to a dissociated $\mathrm{CO}_{2}$ product. This atypical dissociation scheme, depicted in the Figure 61, subsequently produces an $\mathrm{O}_{2}$ molecule [230].

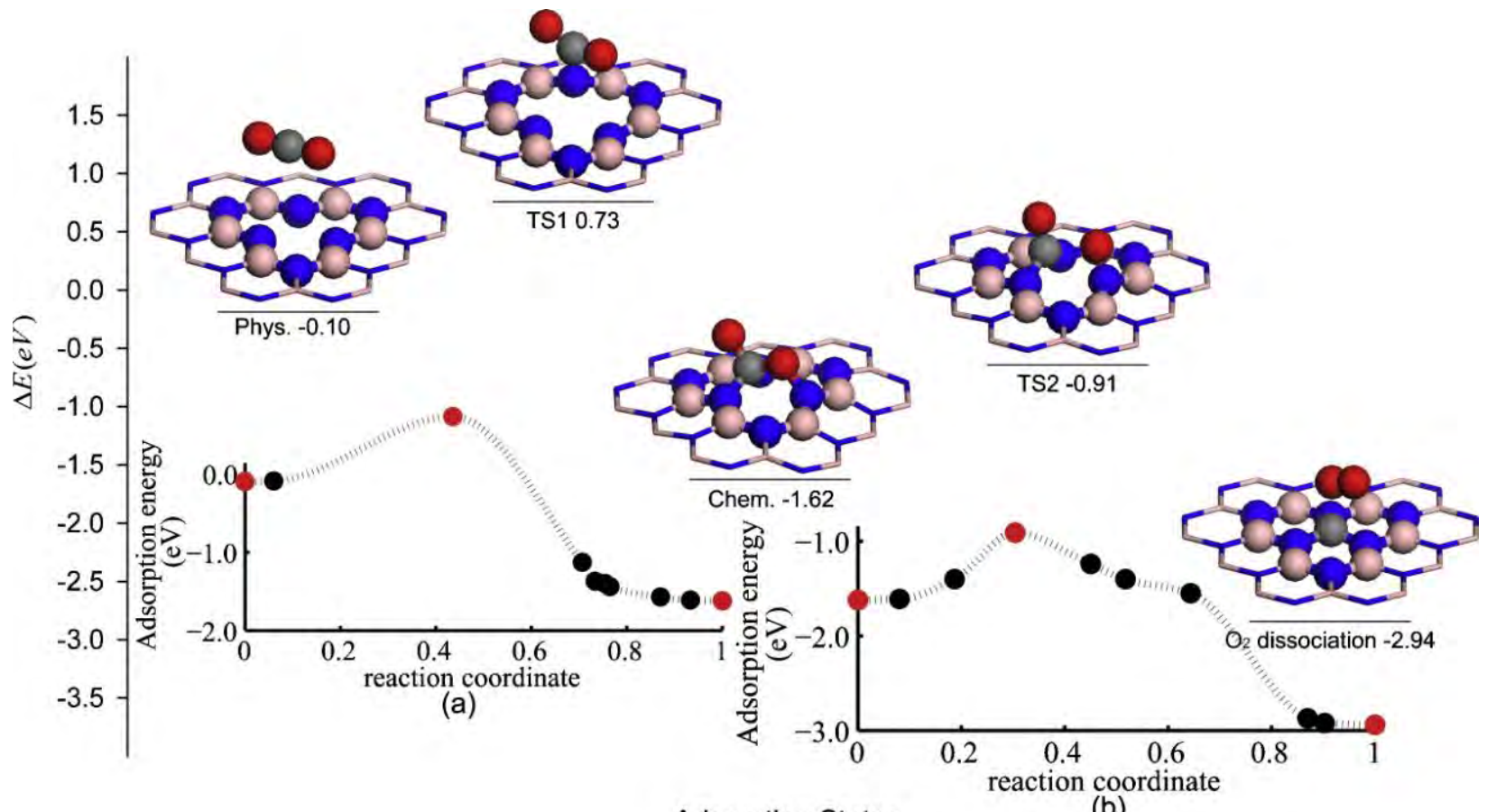

Adsorption States

(b)

Figure 61. DFT calculation on the catalytic reaction scheme for $\mathrm{CO}_{2}$ dissociation on B-vacancy sites of boron nitride. Reproduced with permission from Elsevier [230].

To overcome the energy barrier presented by boron nitride, surface dopants such as $\mathrm{Al}$ [231] and Ti [232] were tried. DFT calculations show that on a single, Al atom-doped boron nitride surface, the $\mathrm{CO}_{2}$ molecule dissociates on the surface. This is also true for the Ti case, where the $\mathrm{C}-\mathrm{O}$ bond is broken and $\mathrm{CO}$ and $\mathrm{O}$ molecules are produced. To date, surface studies on nitride materials for $\mathrm{CO}_{2}$ capture are mostly limited to the theoretical calculations reviewed here.

\subsubsection{Sulfides.}

$\mathrm{CO}_{2}$ adsorption on Cs-promoted $\mathrm{MoS}_{2}$ has been studied using SIMS [236]. In the SIMS spectra analysis an increase of $\mathrm{O}^{-}, \mathrm{m} / \mathrm{z} 60\left(\mathrm{CO}_{3}^{-}\right.$or $\left.\mathrm{SCO}^{-}\right)$was observed. The level of $\mathrm{MoO}_{3}{ }^{-}$and $\mathrm{MoSO}^{-}$, which would increase if $\mathrm{CO}_{2}$ were to dissociate into $\mathrm{CO}$ and $\mathrm{O}$, was barely detected, suggesting 
that $\mathrm{CO}_{2}$ does not dissociate on the surface. Increases in $\mathrm{CO}_{2}^{-}(\mathrm{m} / \mathrm{z} 44)$ and $\mathrm{CO}$ signals were not observed, leading to the conclusion that the molecule did not dissociate, although physisorption and carbonate formation cannot be ruled out [236]. Undoped $\mathrm{MoS}_{2}$ was also tested for $\mathrm{CO}_{2}$ reduction, along with $\mathrm{WS}_{2}[234,235]$. Both pristine sulfide sorbents exhibit good activity for $\mathrm{CO}_{2}$ dissociation. The gas phase product, recorded using GC-MS, demonstrates the effectiveness of both sorbents to dissociate $\mathrm{CO}_{2}$ into $\mathrm{CO}$, with selectivity over $99.9 \%$ for the case of $\mathrm{WS}_{2}$ [234]. Another sulfide that might have the capability to reduce $\mathrm{CO}_{2}$ is $\mathrm{Cu}_{2} \mathrm{~S}$ [233]. With the help of light, the surface effectively dissociates $\mathrm{CO}_{2}$ into $\mathrm{CO}$ with subsequent desorption. However, scarcity of publications on sulfides suggests that additional work is necessary before a complete understanding of this compound class' efficacy in $\mathrm{CO}_{2}$ adsorption and transformation is attained.

\subsubsection{Other solid surface/fluid $\mathrm{CO}_{2}$ interface interactions.}

Entrapment of $\mathrm{CO}_{2}$ by cap rocks is of high impact for environmental sciences, as well as for developing $\mathrm{CO}_{2}$ capture and storage technologies to mitigate industrial emissions. Results from Wdowin et al. [237] showed that carbonate rocks have poor adsorptive capabilities for $\mathrm{CO}_{2}$, on the order of $0.1 \mathrm{mmol} / \mathrm{g}$, while zeolites, with their porous networks, proved to be far superior capture agents and therefore were of further consideration. Other studies have revealed trapping of $\mathrm{CO}_{2}$ into the intercalation of expandable phyllosilicates with a special emphasis on montmorillonites. Studies have notably pointed to important expansion of the layer-to-layer spacing (XRD-derived $\mathrm{d}_{001}$-spacing) of $9 \%$ upon exposure of up to 50 bars $\mathrm{CO}_{2}$ in the presence of small amounts of water [238]. However, no further expansion occurs at greater pressures, tested up to 640 bars. Giester et al. [239] and other studies (e.g. [240]) have also identified at least a partial irreversibility in these reactions. Giester et al. [239] also noted considerably faster 
swelling kinetics in Na- (tens of min or less) than Ca- montmorillonite (up to $42 \mathrm{~h}$ ). The presence of interlayer hydroxo groups, intercalated cations and water are driving intercalation of $\mathrm{CO}_{2}$ in the form of bicarbonate species. Plausible interactions, probed both experimentally and theoretically, include hydrogen bonding with adjacent basal oxygen planes and hydration by the intercalated water molecules. Calculations, in fact, suggest these reactions are responsible for the greater concentrations of intercalated $\mathrm{CO}_{2}$ in these systems than in liquid water [241]. Moreover, complexation with intercalated cations also tends to correlate with expected cation- $\mathrm{CO}_{2}$ bond strength (e.g. $\mathrm{Na}^{+}, \mathrm{Li}^{+}$, and even $\left.\mathrm{Ni}^{2+}\right)$ as highlighted by Michels et al. [242]. This appears to be consistent with the difference in size between the smaller $\mathrm{Li}^{+}$cation versus the larger $\mathrm{Na}^{+}$cation. $\mathrm{Li}^{+}$has a more concentrated charge distribution than $\mathrm{Na}^{+}$and can thus polarize the $\mathrm{CO}_{2}$ molecule, thereby forming a stronger bond to it. We also note that interactions with surface groups are highly responsible for the formation of these species and that probing clay edge site chemistry is a growing challenge in the community given the importance of these interactions.

The prospect of geological storage of $\mathrm{CO}_{2}$ for climate warming mitigation has triggered a number of research programs dedicated to the study of mineral- $\mathrm{CO}_{2}$ interactions and concomitant mineralogical transformations in supercritical $\mathrm{CO}_{2}\left(\mathrm{scCO}_{2}\right)[101,243-250]$. The interest for $\mathrm{scCO}_{2}$ lies in the lower density and viscosity of this phase, compared to the fluids that it would displace during injection in deep geologic formations. Experimental and theoretical studies have consequently focused on the surface chemistry of minerals under elevated temperatures (e.g. 35$100{ }^{\circ} \mathrm{C}$ ) and pressures (e.g. 90-200 bars) and thus represent a considerable departure from other studies, which focus on environmentally-relevant conditions of atmospheric partial pressures of $\mathrm{CO}_{2}$, which is where this work is typically carried out. A focus on the reactive basalt-building minerals was motivated by their common occurrence in (e.g. continental flood) basalts, which 
were targeted host rocks for geological storage [251-256]. The interest in phyllosilicates $[101,248,257,258]$, especially expandable clays, was also motivated by their ability to intercalate and thus lock $\mathrm{CO}_{2}$ species into their bulk structure. Also, there is a potential means for extracting methane from clay-rich formations, such as nearly depleted shale gas reservoirs [259]. Both experimentation and theory have helped resolve the issue of reactivity of silicates, including olivines (e.g. forsterite $=\mathrm{Mg}_{2} \mathrm{SiO}_{4}$; fayalite $=\mathrm{Fe}_{2} \mathrm{SiO}_{4}$ ), pyroxenes (e.g. enstatite $=$ $\left.\mathrm{MgSiO}_{3}\right)$, wollastonite $\left(\mathrm{CaSiO}_{3}\right)$, and serpentine (e.g. antigorite $\left.=\mathrm{Mg}_{3} \mathrm{Si}_{2} \mathrm{O}_{4}(\mathrm{OH})_{4}\right)$ towards $\operatorname{scCO}_{2}[200,201,203,205]$. These efforts demonstrate the importance of thin water film thickness in driving the overall reactivity. The films are formed under $\mathrm{scCO}_{2}$ by hydrogen bonding of water molecules to mineral surface (hydr)oxo groups and/or outcropping cationic centers. Those of several monolayers in thickness (e.g. 3.7-7.7 monolayers of 7-15 $\AA$ ) facilitated carbonation, both as mineral surface complexes (e.g. as bidentate Mg-carbonate surface complexes) and also through the formation of hydrated magnesium carbonates (e.g. nesquehonite, magnesite) by forsterite $\left(\mathrm{Mg}_{2} \mathrm{SiO}_{4}\right)$ and antigorite $\left(\mathrm{Mg}_{3} \mathrm{Si}_{2} \mathrm{O}_{5}(\mathrm{OH})_{4}\right)$ dissolution [251-253]. Thinner layers were, on the other hand, considerably less reactive, possibly due to the restricted mobility of ions under these conditions. These studies thus opened the door for the investigation of new mechanisms involving ion mobility driven by mineral dissolution, nucleation and growth, all within the confines of a thin water film. DFT calculations of a suite of olivine minerals also suggested that water can readily displace carbon dioxide at olivine surfaces and that the ionic character of alkaline earth metal cations outcropping the olivine surfaces facilitates the $\mathrm{H}_{2} \mathrm{O}$ and $\mathrm{CO}_{2}$ adsorption reaction in an exothermic fashion [260].

Important efforts involving clay minerals focus on the impact of $\mathrm{H}_{2} \mathrm{O}$ loadings on swelling (i.e. XRD-derived $\mathrm{d}_{001}$-spacing values) and $\mathrm{CO}_{2}$ intercalation. Efforts along these lines include $\mathrm{CO}_{2}$ 
and $\mathrm{H}_{2} \mathrm{O}$ partition studies involving Na-, Ca- and Mg-exchanges montmorillonite, a 2:1 layer phyllosilicate with swelling capabilities, under systematically varied conditions of hydration under $\mathrm{scCO}_{2}[101,248,257,258]$.

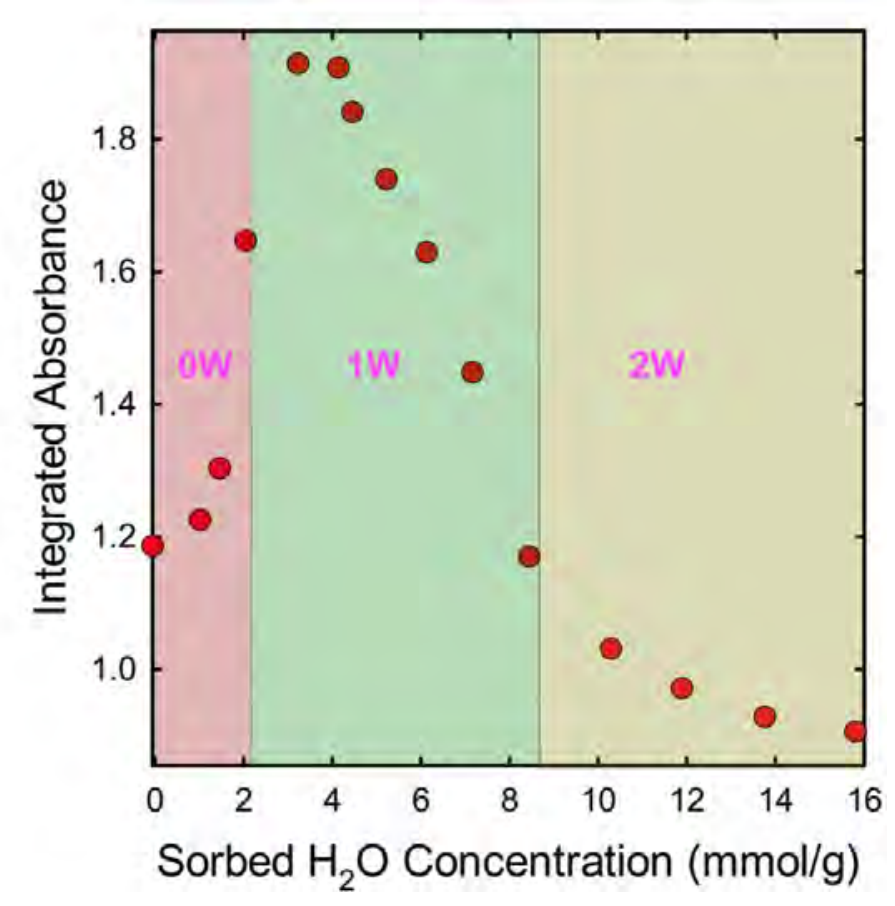

Figure 62. Integrated absorbance of the asymmetric $\mathrm{CO}$ stretching peak of the $\mathrm{CO}_{2}$ molecules that are associated with the Na-SWy-2 as a function of sorbed $\mathrm{H}_{2} \mathrm{O}$ concentration from a titration of $0.0441 \mathrm{~g}$ of Na-SWy-2 with water at $5{ }^{\circ} \mathrm{C}$ and 90 bar. Reproduced with permission from [248]. Copyright (2014) American Chemical Society.

Experimental (X-ray diffraction, vibration spectroscopy and ${ }^{13} \mathrm{C}$ nuclear magnetic resonance) and theoretical (DFT) studies point to upper limits in $\mathrm{CO}_{2}$ incorporation capacities of clays below one monolayer of intercalated water (1W in Figure 62;12.3-12.6 $\AA$ thick). Larger $\mathrm{CO}_{2}$ loadings are favored at low water content, given the ability for $\mathrm{CO}_{2}$ to solvate interlayer cations (e.g. $\left.\mathrm{Na}^{+}, \mathrm{Ca}^{2+}, \mathrm{Mg}^{2+}\right)$. This reaction is outcompeted by the more energetically favorable hydration reactions at larger water loadings, thus favoring a larger portioning of $\mathrm{CO}_{2}$ back to the adjacent $\mathrm{scCO}_{2}$ phase (e.g. [261]) and potentially compromising cap rock integrity for geological storage of $\mathrm{CO}_{2}$. Other molecular modeling studies (Monte Carlo and molecular dynamics) of related systems point to the thermodynamic stability of expanded montmorillonite spacing, when 
exposed to $\mathrm{scCO}_{2}$ with conformation involving single and double layers of interlayer $\mathrm{CO}_{2}$ [262]. Those in the center of interlayers containing $1 \mathrm{~W}$ lie parallel to the clay surface, while those containing the $2 \mathrm{~W}$ system consist of linear $\mathrm{CO}_{2}$ molecules close to the surface $[262,263]$. These authors also point to important decreases in ion diffusion at large intercalated $\mathrm{CO}_{2}$ loadings. Efforts have also been made to account for vibration spectroscopic observations of intercalated $\mathrm{CO}_{2}$ in clays. One notable development includes extension of the widely used ClayFF potentials to $\mathrm{scCO}_{2}$ and to the generation of a theoretical power spectra that can be used to relate simulated molecular structures and molecular flexibility to vibration spectral attributes, as well as diffusion rates $[264,265]$. Mechanisms through which $\mathrm{CO}_{2}$ migrates through nano- and micro-porous environments of clays have also called for an understanding of their physical properties in relation to diffusion properties. One small-angle neutral scattering (SANS) and molecular dynamics study, for instance, suggests that $15 \AA$ wide slit pores in muscovite can be filled with a layered structure of low diffusivity/high-density $\mathrm{CO}_{2}$. Larger pores contain, on the other hand, $\mathrm{scCO}_{2}$ that cannot be efficiently mobilized. These authors conclude that mobilization of $\mathrm{CO}_{2}$ in the crystal structure of muscovite requires entrapment as a single layer or through carbonation reactions (surface complexes, mineralization) [266].

Unlike other surfaces, interactions between zeolite $13 \mathrm{X}$ and $\mathrm{CO}_{2} / \mathrm{H}_{2} \mathrm{O}$ do not result in new adsorbates [207]. While the same interaction on metal/metal oxide surfaces would yield formation of bicarbonates, or some sort of hydroxylated surface species, water and $\mathrm{CO}_{2}$ compete for the same adsorption site. In the case of $13 \mathrm{X}$, water tends to displace adsorbed $\mathrm{CO}_{2}$ molecules, as observed using IR spectroscopy. Adsorption of both molecules initially produces several peaks related to hydroxyl groups at 3690 (stretching) and $1652 \mathrm{~cm}^{-1}$ (bending), as well as physisorbed $\mathrm{CO}_{2}$, bridged carbonate, and bidentate carbonate at $2354 \mathrm{~cm}^{-1}, 1710$ and $1363 \mathrm{~cm}^{-1}$, 
1484 and $1429 \mathrm{~cm}^{-1}$, respectively. However, extended exposure leads to the disappearance of all peaks mentioned above, except for the bending mode of the hydroxyl group [207].

\subsection{Carbonate $/ \mathrm{H}_{2} \mathrm{O}$ vapor or fluid interfaces}

\subsubsection{Solid metal carbonate/gas interface}

4.4.1.1 Metal carbonate surfaces in the presence of significant humidity. Metal carbonates are the inevitable products of metal oxide surface interactions with $\mathrm{CO}_{2}$. They are stable and naturally present in the environment. Solid metal carbonate surfaces exposed to gases are reactive substrates for chemical exchanges. Calcite $\left(\mathrm{CaCO}_{3}\right)$ exposed to a humid environment will exhibit a very different surface chemistry from that in bulk aqueous solutions [267-273], as discussed in section 4.4.2. Here $\mathrm{H}_{2} \mathrm{O}$ is introduced in a form of a vapor expressed in the water activity range of $0.1<a<1$

$a=\frac{p\left(\mathrm{H}_{2} \mathrm{O}\right)}{p^{*}\left(\mathrm{H}_{2} \mathrm{O}\right)}$

where $p\left(\mathrm{H}_{2} \mathrm{O}\right)$ is water vapor pressure and $p^{*}\left(\mathrm{H}_{2} \mathrm{O}\right)$ is the saturation water vapor pressure. FTIR data can be used to quantify the amount of adsorbed water on the surface with 1 ML of water formed at $\sim 20 \% \mathrm{RH}$ [268]. The methods of choice in this case are both surface sensitive imaging techniques that can operate under gaseous conditions on non-conducting samples (Atomic Force Microscopy) as well as XPS. This combination provides critical information on structure, morphology and chemical changes induced on a sample surface. One such design is shown in Figure 63 with an Asylum Research MFP-3D AFM instrument, which was coupled with a custom built environmental cell consisting of (i) a gas handling system to control relative humidity; (ii) an environmental cell connected to the scanner head and coupled to a sample heater/cooler; and (iii) an environmental monitor and control system [268,274]. Low force 
constant Si cantilevers, with a typical force constant of $1.2 \mathrm{~N} / \mathrm{m}$ to minimize any tip effects on the surface, are typically used, while relative humidity can be easily adjusted, where $70 \% \mathrm{RH}$ is routinely used.

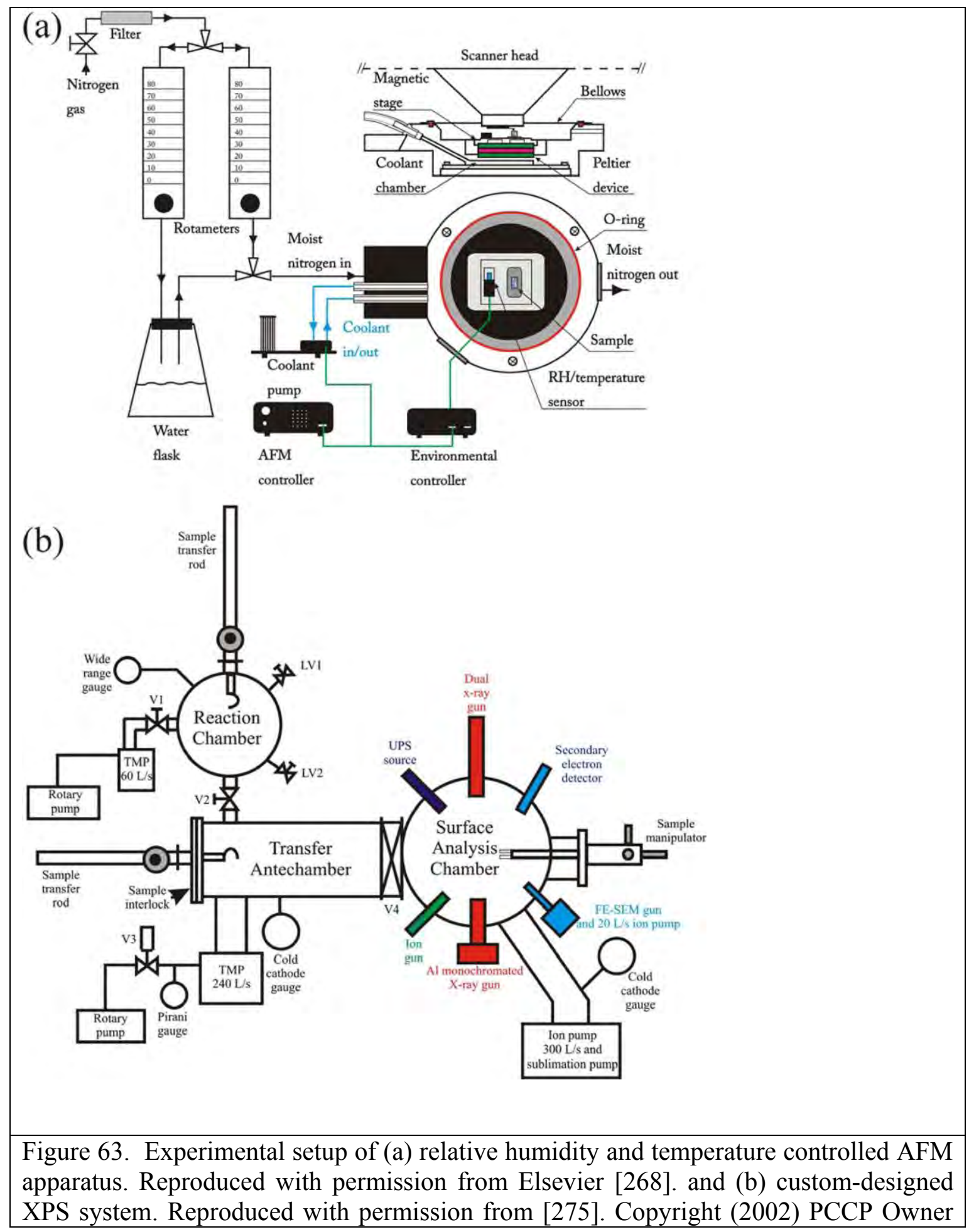


Societies. The AFM consists of (i) relative humidity preparation system, (ii) closed environmental cell connected to the scanner head and a sample heater/cooler and, (iii) environmental monitor and control system. The XPS system consists of (i) surface analysis chamber equipped with monochromated X-ray source, (ii) transfer antechamber, and (iii) reaction chamber.

XPS, on the other hand, due to the problems arising from relative humidity with the high voltage electronics, can be performed using a custom-designed reaction chamber after reacting/pumping out the water vapor. A regular monochromatic radiation of $1486.6 \mathrm{eV}$ can be used, so that the sample is transferred under vacuum conditions without exposing it to the environment.

A complex picture (literally speaking) emerges when $\mathrm{CaCO}_{3}(10 \overline{1} 4)$ is exposed to $70 \%$ RH at 296 K. Surface reconstruction takes place over a period of $180 \mathrm{~min}$, roughening up from $0.32 \pm 0.2 \mathrm{~nm}$ to micron scale, as shown in Figure 64. Fast nucleation of islands occurs primarily in the vicinity of monoatomic steps, together with the simultaneous growth of etch pits, with the fast growth direction occurring nearly perpendicular to that of the islands [268]. Rates of material
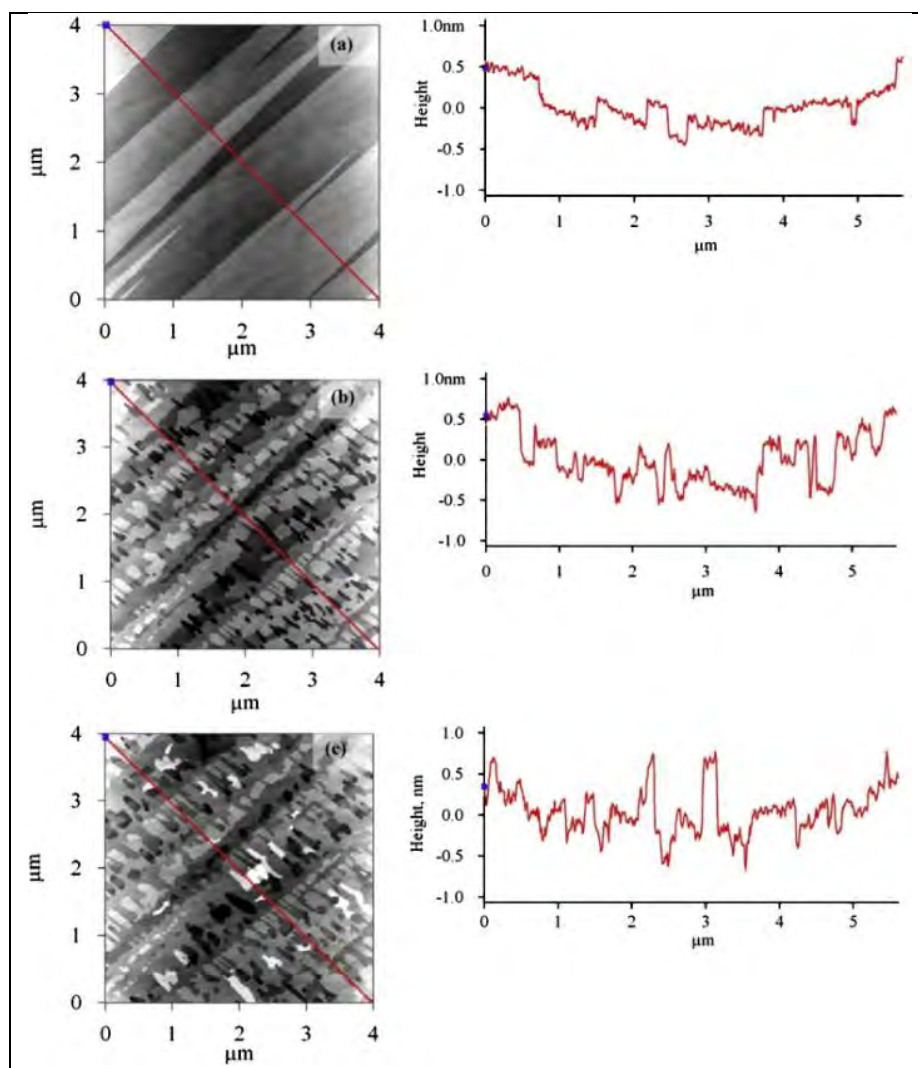

Figure 64. Time sequence topography images of $\mathrm{CaCO}_{3}(10 \overline{1} 4)$ surface at $70 \% \mathrm{RH}$ and $296 \mathrm{~K}$. Images were collected at (a) before, (b) after $71 \mathrm{~min}$, (c) 194 min of RH introduction. Corresponding line scans are shown on the right. Full data scale is set to $1.2 \mathrm{~nm}$. Reproduced with permission from Elsevier [268].

transport in $\mathrm{nm} / \mathrm{min}$ can then be calculated from the image sequence. A two-layer mechanism 
was proposed, since the second hydration layer exhibited very different viscoelastic properties from the first one, as shown utilizing force spectroscopy combined with the AFM phase imaging. In particular, exposure to water vapor induces phase changes to hydrated layers composed of amorphous calcium carbonate hydrates and vaterite [268,276,277], as shown in Figure 65. This mobility of the $\mathrm{CaCO}_{3}$ surface layers (as well as other metal carbonates, including $\mathrm{FeCO}_{3}$, $\mathrm{ZnCO}_{3}, \mathrm{MgCO}_{3}$ and $\left.\mathrm{MnCO}_{3}\right)[269,276]$ has a major effect on the reactivity of these carbonate surfaces, beyond those of non-mobile metal oxide surface, as shown in 4.4.1.2.

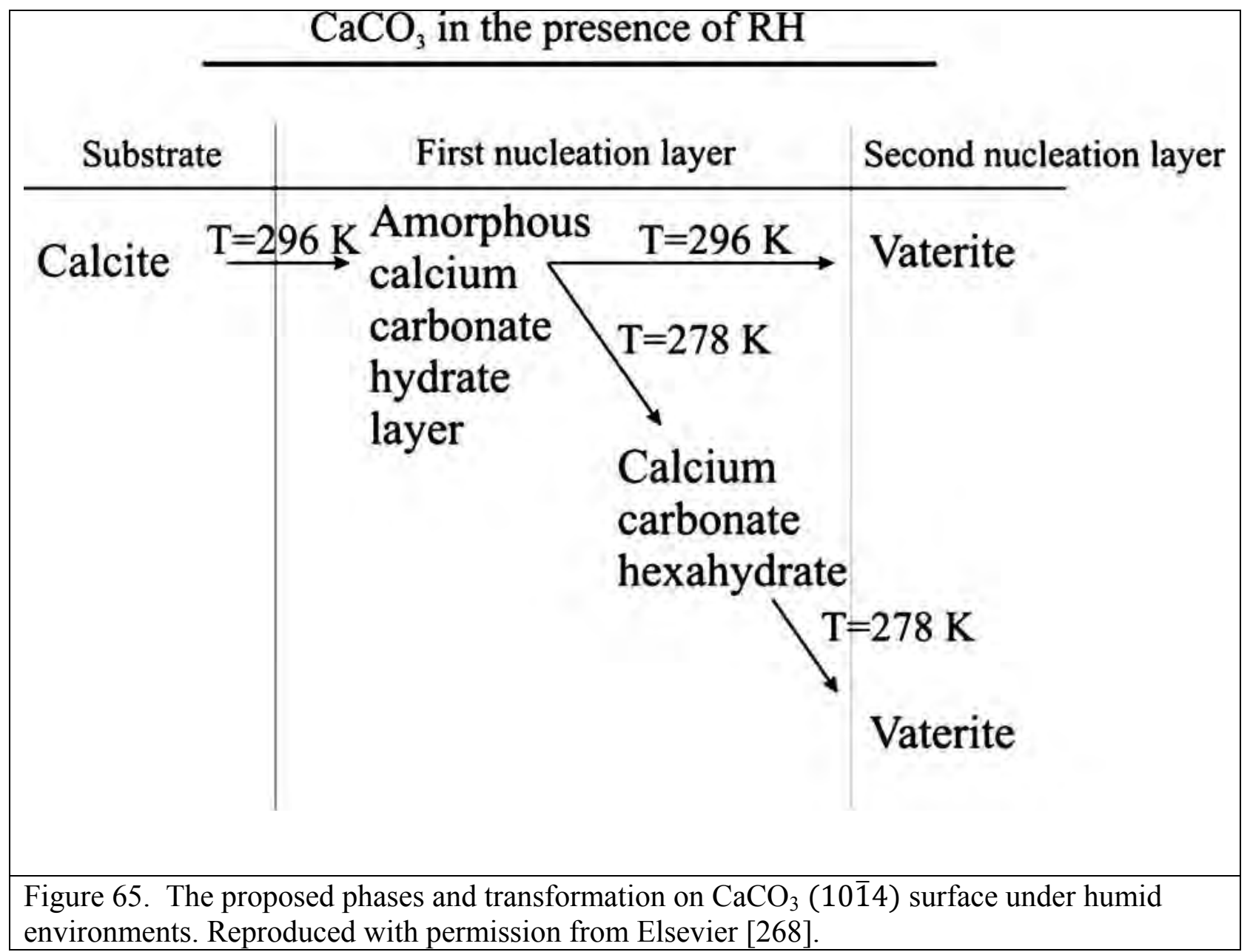

At the same time, surface contaminants, such as $\mathrm{Cd}$, can inhibit such phase changes [278]. In this case, $\mathrm{Cd}$ surface complexes, especially at step edges, inhibit ion mobility and therefore phase change at calcite surfaces. Exposure of humid air to metal carbonates containing redox-active 
metals can, on the other hand, lead to the growth of secondary oxides, such as in the case of rhodocrocite $\left(\mathrm{MnCO}_{3}\right)$ [279,280]. In this case [268] surface oxidation of $\mathrm{Mn}(\mathrm{II})$ was proposed to proceed by surface dissolution followed by oxidation. A solid-state diffusion of $\mathrm{Mn}(\mathrm{II})$ then follows, producing an autocatalytic pathway, as illustrated in Figure 66.

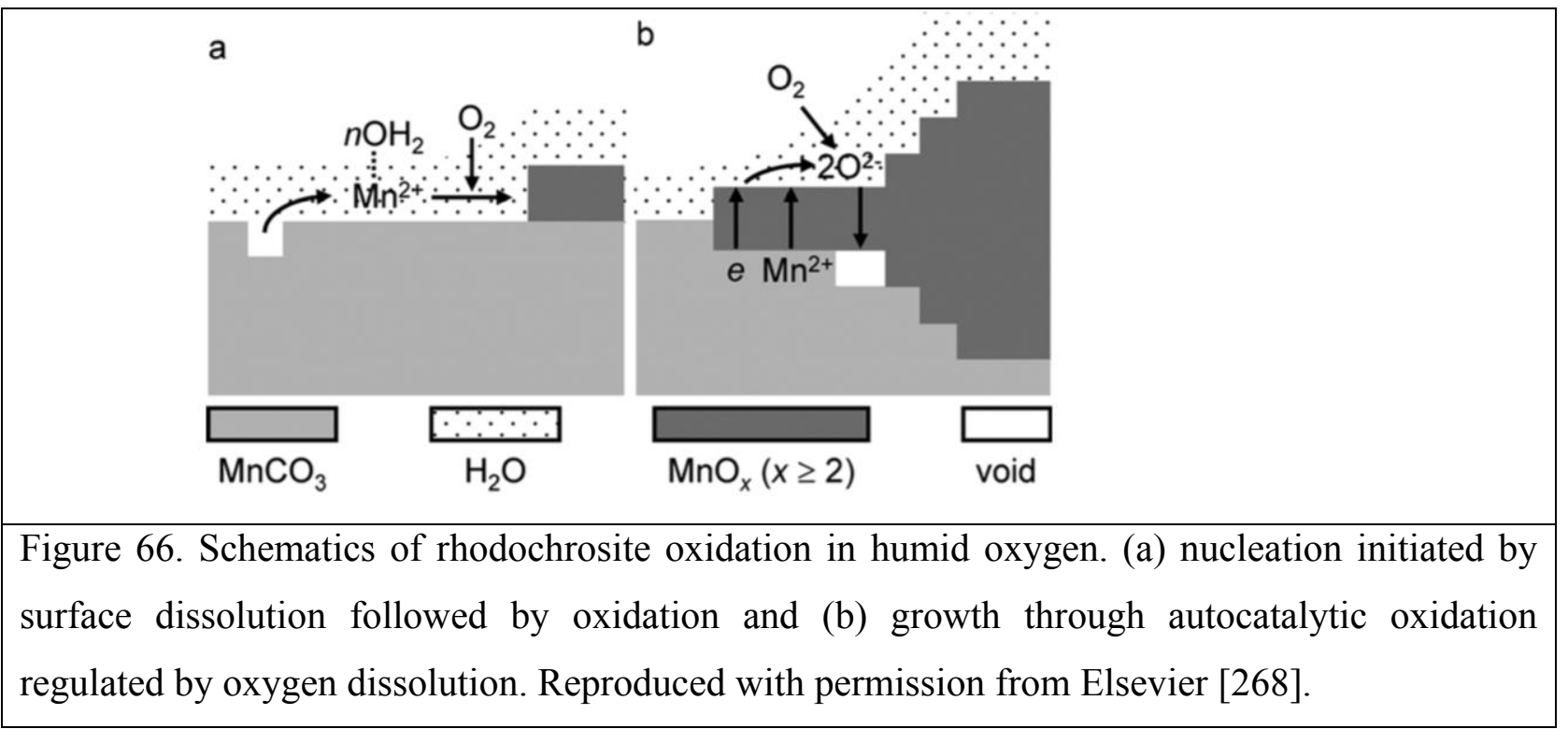

4.4.1.2. Metal carbonate surface in the presence of acidic gases. Of particular interest are the reactions with acidic gases, such as $\mathrm{HNO}_{3}, \mathrm{NO}_{\mathrm{x}}, \mathrm{SO}_{2}$, during or after the metal carbonate's exposure to $\mathrm{H}_{2} \mathrm{O}$ as a relative humidity [281]. Exposure to atmospherically relevant gases, such as $\mathrm{SO}_{\mathrm{x}}$ and $\mathrm{NO}_{\mathrm{x}}$, can also induce important phase changes [282-285]. For instance, reactions with $\mathrm{SO}_{\mathrm{x}}$ lead to

$$
\begin{aligned}
& \mathrm{CaCO}_{3}(\mathrm{~s})+\mathrm{SO}_{2}(\mathrm{~g}) \rightarrow \mathrm{CaSO}_{3}(\mathrm{~s})+\mathrm{CO}_{2}(\mathrm{~g}) \\
& \mathrm{CaCO}_{3}(\mathrm{~s})+\mathrm{SO}_{2}(\mathrm{~g})+1 / 2 \mathrm{O}_{2}(\mathrm{~g}) \rightarrow \mathrm{CaSO}_{4}(\mathrm{~s})+\mathrm{CO}_{2}(\mathrm{~g})
\end{aligned}
$$

Rather than leaving homogeneous surface coatings, these reactants produce crystallites, as evidenced by AFM imaging [275]. In the presence of water vapor, exposure to $\mathrm{SO}_{2}$ or $\mathrm{NO}_{2}$ also produces surface-bound sulfate and nitrate species, alongside crystalline hydrates of $\mathrm{CaSO}_{3}$ and $\mathrm{Ca}\left(\mathrm{NO}_{3}\right)_{2}$ [267]. The S2p:Ca2p ratio monotonically increased with $\mathrm{RH}$ in the presence of 100 
mTorr $\mathrm{SO}_{2}$, as evidenced by XPS analysis of $\mathrm{CaCO}_{3}$ surfaces [275]. When exposed to $10 \mathrm{mTorr}$ $\mathrm{NO}_{2}$ at $70 \% \mathrm{RH}$ for $210 \mathrm{~min}$, XPS analysis showed the presence of a single peak in the N1s region at $407.5 \mathrm{eV}$, indicative of nitrate, $\mathrm{NO}_{3}{ }^{-}$and analogous with that scanned for a nitrocalcite $\left(\mathrm{Ca}\left(\mathrm{NO}_{3}\right)_{2} \cdot 4 \mathrm{H}_{2} \mathrm{O}\right)$ surface. A proposed surface reaction sequence entailed an adsorbed $\sim 15 \AA$ $\mathrm{H}_{2} \mathrm{O}$ layer yielding surface hydroxyl/bicarbonate groups, via $\mathrm{H}_{2} \mathrm{O}$ dissociation, followed by $\mathrm{NO}_{2}$ reaction with surface oxygen or hydroxyl sites via

$\mathrm{H}_{2} \mathrm{O}(\mathrm{g}) \rightarrow \mathrm{H}_{2} \mathrm{O}(\mathrm{a})$

$\mathrm{CaCO}_{3}(\mathrm{~s})+\mathrm{H}_{2} \mathrm{O}(\mathrm{g}) \rightarrow \mathrm{Ca}(\mathrm{OH})\left(\mathrm{HCO}_{3}\right)(\mathrm{s})$

$\mathrm{NO}_{2}(\mathrm{~g})+\mathrm{O}^{-}(\mathrm{s}) \rightarrow \mathrm{NO}_{3}^{-}(\mathrm{s})$

Evidence for related reactions in the field was also noted in a study by Laskin et al. [286]. This noteworthy study demonstrated complete conversion of calcite particles to calcium dinitrate by exposure to humid atmospheres of nitric acid. Such reactions, which incidentally result from the industrial production of $\mathrm{NO}_{\mathrm{x}}$ gases, can have important implications on atmospheric cloud chemistry and physics. A comparison has to be made between the hygroscopic metal carbonates, such as $\mathrm{CaCO}_{3}$ and metal oxides, such as $\alpha-\mathrm{Fe}_{2} \mathrm{O}_{3}$ and $\alpha-\mathrm{FeOOH}$ [287]. It has been shown and discussed in 4.4.1.1 that the former undergoes dramatic reconstruction in the presence of $\mathrm{RH}$ and surface adsorbed $\mathrm{SO}_{2}$ has been measured to increase five- to ten-fold [275]. The latter, on the other hand, exhibits negligible changes in the amount of adsorbed $\mathrm{SO}_{2}$ product, providing a detailed background on the underlying reactivity of adsorbed $\mathrm{H}_{2} \mathrm{O}$ modified metal oxide and carbonate surfaces. In particular, increased ion mobility on $\mathrm{CaCO}_{3}$ opens up new surface regions for further adsorption and uptake of $\mathrm{SO}_{2}$, while on $\alpha-\mathrm{Fe}_{2} \mathrm{O}_{3}$ and $\alpha-\mathrm{FeOOH}$, the reaction is limited to the very top surface layer due to the low ionic mobility. Another observation emerging from Figure 65 is the surface area effect. In particular, $\mathrm{CaCO}_{3}$ exhibited greater 
reactivity towards $\mathrm{SO}_{2}$ at all relative humidities. Since the $\mathrm{S} 2 \mathrm{p}: \mathrm{Ca} 2 \mathrm{p}$ ratio accounts for the number of available $\mathrm{Ca}$ sites, enhanced particulate $\mathrm{CaCO}_{3}$ reactivity can be attributed to the intrinsic reactivity and inhomogeneity greater than in the cleaved single crystal $\mathrm{CaCO}_{3}(10 \overline{1} 4)$, which also shows greater reactivity towards adsorbing $\mathrm{SO}_{2}$.
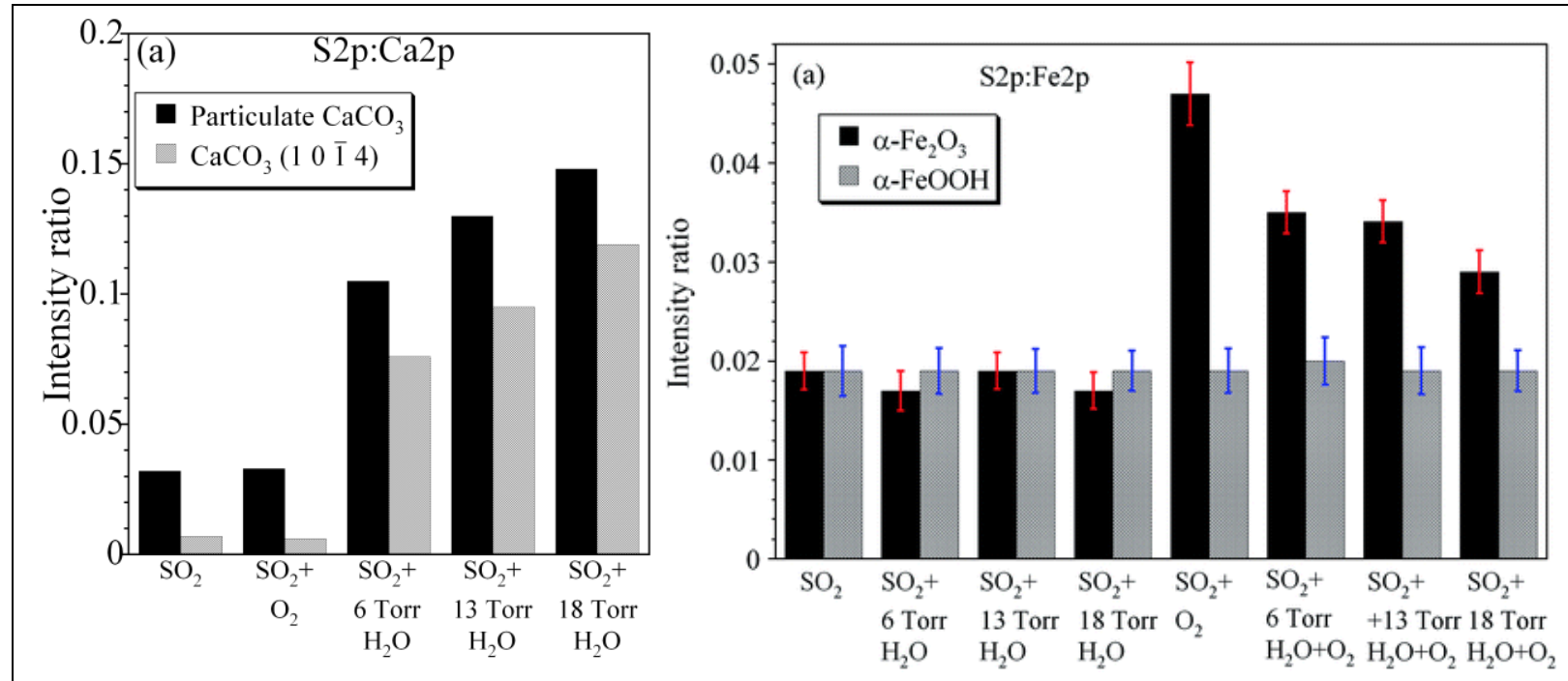

Figure 67. (left) S2p:Ca2p. Reproduced with permission from [275]. Copyright (2002) PCCP Owner Societies; and (right) S2p:Fe2p. Reproduced with permission from [287]. Copyright (2007) PCCP Owner Societies; ratio from the peak areas determined from XPS spectra. The dramatic effect of $\mathrm{RH}$ is seen on $\mathrm{SO}_{2}$ uptake on $\mathrm{CaCO}_{3}$, whereas no effect is apparent on $\alpha-\mathrm{Fe}_{2} \mathrm{O}_{3}$ and $\alpha-\mathrm{FeOOH}$.

\subsubsection{Aqueous carbonate ion/solution interface}

The dissolution of carbon dioxide in water via

$\mathrm{CO}_{2}(\mathrm{~g})+3 \mathrm{H}_{2} \mathrm{O} \rightarrow \mathrm{CO}_{2}(\mathrm{aq})+3 \mathrm{H}_{2} \mathrm{O}$

is a process of paramount importance in environmental, biological and technological systems [288-294]. Examples include the key roles that soluble carbonate species play in ocean geochemistry [291,292], buffering of blood $\mathrm{pH}$ and $\mathrm{CO}_{2}$ transport as a key physiological process in organisms [295] and the (geo)engineered sequestration of $\mathrm{CO}_{2}$ in geological fluids. Henry's law $\left(p=k_{\mathrm{H}} c\right)$ is a very well-known formulation, which predicts the amount of dissolved gas $(c)$ 
in a fluid at a given temperature based on its partial pressure $(p)$ in the gas-phase. As an example, incorporation of the current-day $\mathrm{CO}_{2}(\mathrm{~g})$ level of $\sim 397 \mathrm{ppm}$ to water at ambient conditions leads to about $13.4 \mu \mathrm{M}$ total $\mathrm{CO}_{2}(\mathrm{aq})$. Prediction of the pressure and temperature dependence of $\mathrm{CO}_{2}(\mathrm{~g})$ solubility and for the $\mathrm{CO} 2-\mathrm{H}_{2} \mathrm{O}-\mathrm{NaCl}$ system [296-299].are performed with Equations of State, which have been under development for several decades [296,300-305], Diamond and Akinfiev [306] proposed a general formulation of Henry's law based on a critical review of 520 data points from 25 literature studies and it is valid from -1.5 to $100{ }^{\circ} \mathrm{C}$ and from 0.1 to $100 \mathrm{MPa}$ $\mathrm{CO}_{2}$ (Fig. 68). This formulation was later extended to $\mathrm{NaCl}$ solutions [307]. Another formulation also predicts densities and volumes in $\mathrm{CO}_{2}-\mathrm{H}_{2} \mathrm{O}-\mathrm{NaCl}$ systems up to 374 and $100 \mathrm{MPa}$ [308].
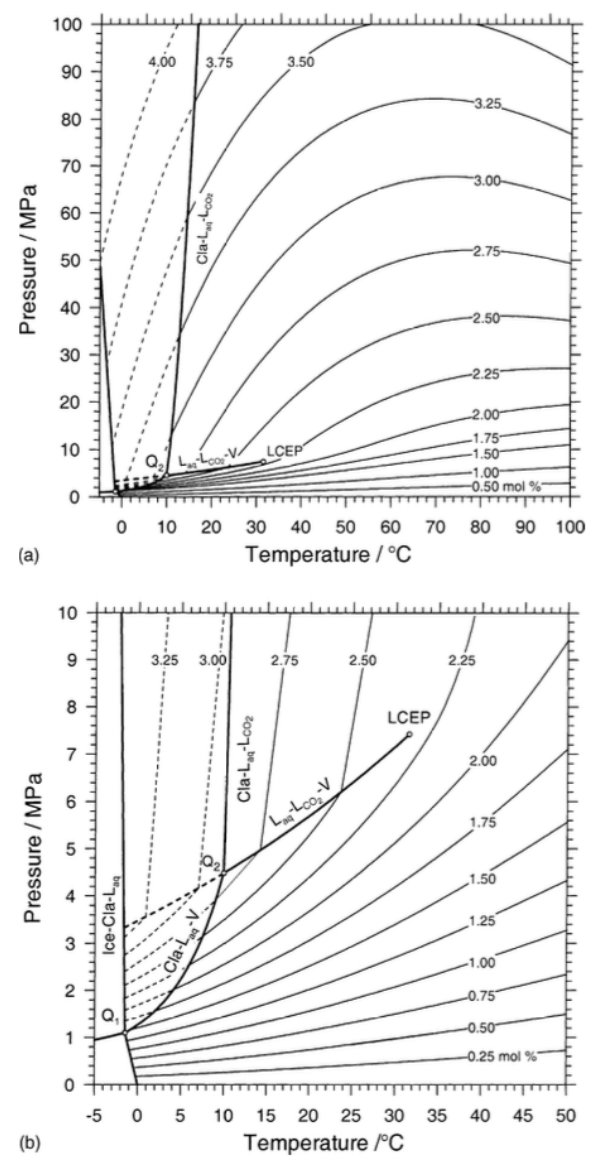

Figure 68. P-T diagram of solubility isopleths of $\mathrm{CO}_{2}$. Reproduced with permission from Elsevier [306]. 
Models predicting the temperature and pressure dependence of the first and second dissociation constants of carbonic acid have also been the object of development throughout several decades [309-322]. The more recent model of $\mathrm{Li}$ and Duan [322] predicts the speciation of $\mathrm{H}^{+}, \mathrm{HCO}_{3}{ }^{-}$, $\mathrm{CO}_{3}{ }^{2-}$ and $\mathrm{CO}_{2}$ (aq) in aqueous solutions of $0-5.0 \mathrm{~mol} / \mathrm{kg} \mathrm{NaCl}$ at temperatures in the $0-225^{\circ} \mathrm{C}$ range and pressures in the $0-1000$ bar range. We note that these models have built a secured foundation upon which multicomponent systems, such as interfacial systems to be described in this review article, can be studied in a detailed manner.

While thermodynamics offers a reliable means for predicting air/water partitioning of $\mathrm{CO}_{2}$, the actual mechanisms of the incorporation of $\mathrm{CO}_{2}$ into the fluid phase continue to be elusive. Most particularly, the air/water interface plays a primordial role in this process. Surface tension and surface potential studies have looked into the interfacial distribution of (bi)carbonate ions. A theoretical study [323], for example, classifies the carbonate ions as a strongly hydrated kosmotrophic ion that ought to be depleted at the air/water interface. This was corroborated further experimentally by heterodyne detected phase-sensitive sum-frequency [324] in sodium carbonate and by X-ray photoelectron spectroscopy [325] in potassium carbonate. Both studies also show that sodium and potassium ions are located near the air/water interface. It also suggests that bicarbonate is more closely involved in the hydrogen bonding network of the interface and at the same level of sodium atoms. Thus, while these studies do not directly address the mechanisms of $\mathrm{CO}_{2}(\mathrm{~g})$ adsorption at the air/water interface, this interfacial distribution of ions could possibly suggest that it proceed first via an interfacial transformation to bicarbonate. Current-day knowledge on the mechanisms of bicarbonate formation [326-328], to be detailed in the latter part of this section, could in fact fall in line with this concept, although the potential involvement of cations ought to be addressed. Along these lines, recent molecular modeling 
work by Galib and Hanna [329] suggests faster dissociation rates for carbonic acid at the air/water interface. This may be caused by a greater structured solvation of water at the interface facilitating the solvation of the transition state species involved in the dissociation reaction (Fig. 69). This remains, however, an area that is in dire need of development.

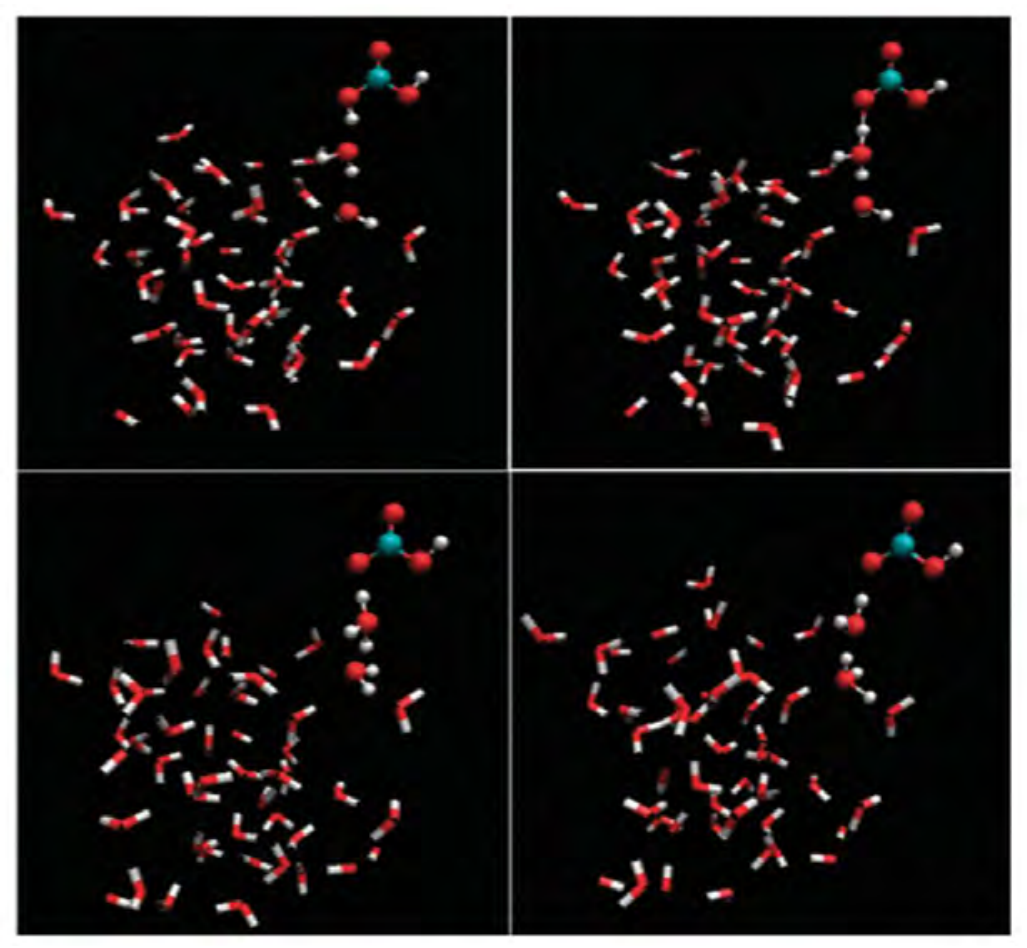

Figure 69. Simulation of $\mathrm{H}_{2} \mathrm{CO}_{3}$ dissociation along a representative metadynamics trajectory. Clockwise from top left: hydrogen bond formation between $\mathrm{H}_{2} \mathrm{CO}_{3}$ and water molecule; formation of Zundel-like structure; formation of a metastable contact ion pair; complete dissociation. Reproduced with permission from [329]. Copyright (2014) PCCP Owner Societies. The hydration assimilation of $\mathrm{CO}_{2}$ into the matrix of aqueous solutions has also been studied. Recent notable developments in this area show that aqueous $\mathrm{CO}_{2}$ can be regarded as hydrophobic: namely, with a small hydrogen bond number $\left(0.56\right.$ bond/ $\left.\mathrm{CO}_{2}\right)[330,331]$ as shown in Figure 70. 


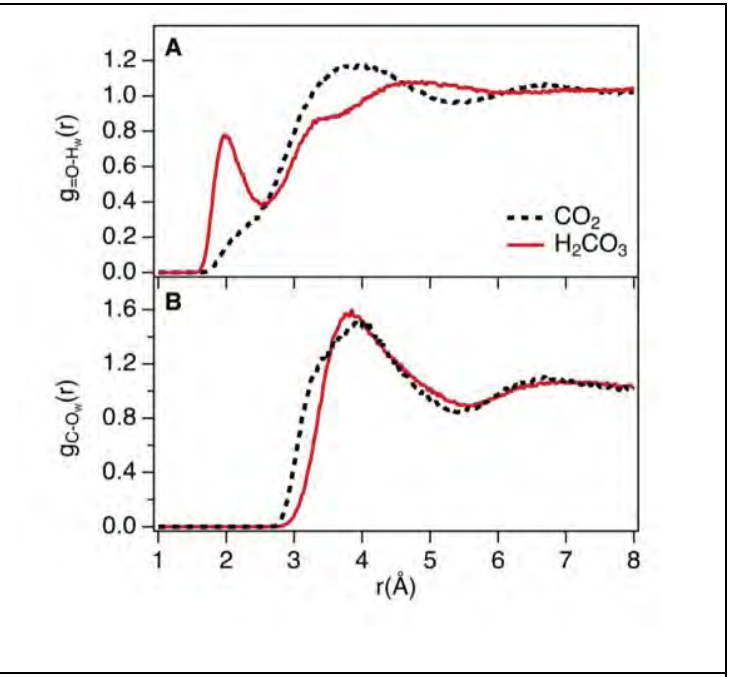

Figure 70. Theoretical RDF of aqueous carbonic acid and dissolved carbon dioxide. Reproduced with permission from Elsevier [330].

The $\mathrm{CO}_{2}$ (aq) molecule is embedded in a cylindrical void which forces a slightly larger local ordering of water. Carbonic acid, formed via

$\mathrm{CO}_{2}(\mathrm{aq})+\mathrm{H}_{2} \mathrm{O} \rightarrow \mathrm{H}_{2} \mathrm{CO}_{3}$

, is an instable species [332-334] representing $\sim 1 \%$ of the total $\mathrm{CO}_{2}$ (aq) under ambient and acidic conditions. It has consequently long eluded unambiguous experimental detection of the first dissociation constant, as has been described through

$\mathrm{CO}_{2}(\mathrm{aq})+2 \mathrm{H}_{2} \mathrm{O} \rightarrow \mathrm{HCO}_{3}^{-}+\mathrm{H}_{3} \mathrm{O}^{+}$

with a well-known $\mathrm{pK}_{\mathrm{a}}=6.35$ in pure water at $25{ }^{\circ} \mathrm{C}$. This overall reaction thus accounts for energetic contributions from (de)hydration and (de)solvation reactions of $\mathrm{CO}_{2}(\mathrm{aq})$. Theoretical studies [330,331,335] suggest that the hydroxyl, and not the carbonyl, group of carbonic acid is strongly hydrated in aqueous solutions. Building upon multiple efforts attempting to isolate carbonic acid [336-341], the study of Adamczyk et al. [340] measured the proton transfer rate to the bicarbonate anion upon electronic excitation of photoacid. They proposed a more realistic $\mathrm{pK}_{\mathrm{a}}$ value of 3.45 for the reaction 
$\mathrm{H}_{2} \mathrm{CO}_{3}+\mathrm{H}_{2} \mathrm{O} \rightarrow \mathrm{HCO}_{3}^{-}+\mathrm{H}_{3} \mathrm{O}^{+}$

corroborating earlier suggestions for values in the 3.4-3.8 range [326,334,342,343]. An ab initio molecular dynamics study [344] shortly after predicted comparable pKa values for (anti-anti, anti-syn) conformers of carbonic acid. The femto-second infrared spectroscopy measurements of Adamczyk et al. [340] also pointed to a lifetime of the order of $\sim 300 \mathrm{~ns}$ for carbonic acid. They also suggested deprotonation and not dissociation to $\mathrm{CO}_{2}$ and $\mathrm{H}_{2} \mathrm{O}$, as often stated in textbooks, is responsible for the instability of carbonic acid in solutions. Concomitantly, the Saykally group [330,345] added further insight into the aqueous chemistry of carbonic acid via near absorption fine structure (NEXAFS) spectroscopy of aqueous $\mathrm{H}_{2} \mathrm{CO}_{3}$ using a high velocity liquid microjet mixing system combining a bicarbonate and a hydrochloric solution. This approach took advantage of the slow dehydration rate of carbonic acid $\left(k=26.3 \mathrm{~s}^{-1} ; t_{1 / 2}=26 \mathrm{~ms}\right)$ and the fast protonation rate of bicarbonate $\left(k=4.7 \times 10^{10} \mathrm{M}^{-1} \mathrm{~s}^{-1} ; t_{1 / 2}=21.3 \mathrm{ps}\right)$ to produce carbonic acid. These measurements produced the first NEXAFS data of the $\mathrm{C}(1 \mathrm{~s}) \rightarrow \pi^{*}$ transitions for $\mathrm{CO}_{2}$, $\mathrm{HCO}_{3}{ }^{-}$and $\mathrm{H}_{2} \mathrm{CO}_{3}$, whose spectral assignments were substantiated by DFT calculations. MD simulations from the same group suggested, at the same time, hydration numbers of 3.17 for $\mathrm{H}_{2} \mathrm{CO}_{3}, 4.26$ for $\mathrm{HCO}_{3}{ }^{-}$and 0.56 for $\mathrm{CO}_{2}$ in the presence of sodium as a counterion.

Other studies focused on the mechanisms of carbonic acid decomposition. These include the theoretical studies $[326,327]$ showing that hydration of $\mathrm{CO}_{2}(\mathrm{aq})$ involves a (1) hydroxylation of $\mathrm{CO}_{2}$ to form $\mathrm{HCO}_{3}^{-}$, followed by (2) protonation. Recent ab initio metadynamics simulations of the converse reaction [328] suggest that the deprotonation involves a metastable solventseparated $\mathrm{HCO}_{3}{ }^{-} / \mathrm{H}_{3} \mathrm{O}^{+}$pair part of a Zundel-type structure $\left(\mathrm{H}_{5} \mathrm{O}_{2}{ }^{+}\right)$. A similar concept was pursued in gas-phase cluster calculations [346]. The rupture of the remaining $\mathrm{C}-\mathrm{OH}$ bond then proceeds via hydrogen bonding to a hydrogen-bonded $\mathrm{H}_{3} \mathrm{O}^{+}$, such that 
$\mathrm{HCO}_{3}{ }^{-}+\mathrm{H}_{3} \mathrm{O}^{+} \rightarrow \mathrm{CO}_{2}+2 \mathrm{H}_{2} \mathrm{O}$.

Finally, we note that the second dissociation reaction

$\mathrm{HCO}_{3}{ }^{-}+\mathrm{H}_{2} \mathrm{O} \rightarrow \mathrm{CO}_{3}{ }^{2-}+\mathrm{H}_{3} \mathrm{O}^{+}$

has also been studied along such lines. For instance, ab initio molecular dynamics resolved a plausible Grotthus-type (proton shuttling) protonation of the carbonate ion that involved a cooperative network of water responding in the time scale of picoseconds (Fig. 71). [347]).

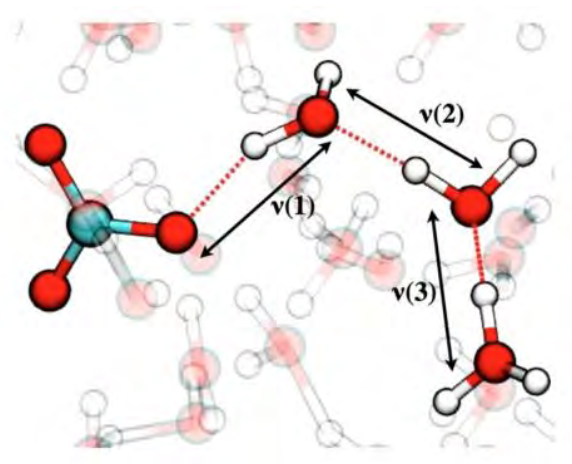

Figure 71. Recombination of carbonate via a Grotthus-type transfer of protons in a cooperative network of waters. Reproduced with permission from [347]. Copyright (2014) American Chemical Society.

A classical molecular dynamics study by Bruneval et al. [348] also suggests that in aqueous calcium carbonate solutions, the ion forms 12 long-lived (36 ps relaxation time under ambient conditions) hydrogen bonds with a highly organized first water shell. The second hydration shell adopts a three-dimensional structure creating a hydrophobic-like hydration exclusion area on top of the carbon atom. The ab initio molecular dynamics study of Kumar et al. [331] (Fig. 72) also adds further insight into the hydration environment of carbonate in pure aqueous solutions. In particular, their study points to an average of 2.85 hydrogen bonds per $\mathrm{O}$ site in carbonate, and to 
a slight fall in the number of water-water interactions. Their study also points to slow rates of structural relaxation of water and rates of hydrogen-bond reorganization.

Collectively, these recent sets of studies pave the way for a new understanding of $\mathrm{CO}_{2}$ hydration and hydrolysis reactions in confined aqueous systems, such as thin water films bound to solid surfaces.
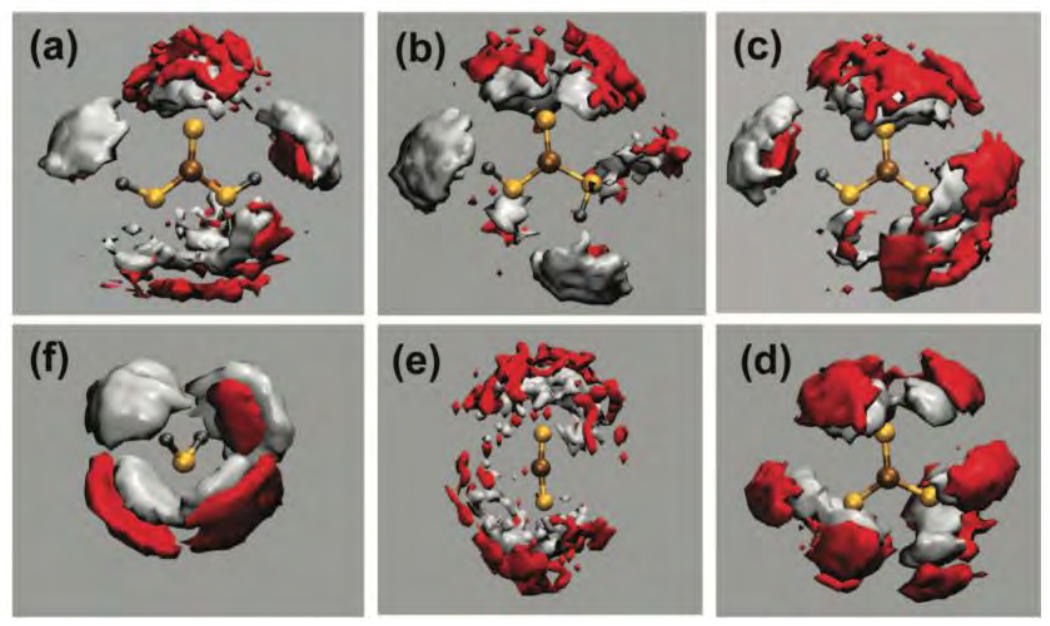

Figure 72. Atomic density distribution of hydrogens (gray) and oxygens (red) of water near (a-b) carbonic acid, (c) bicarbonate, (d) carbonate, (e) $\mathrm{CO}_{2}$ and (d) pure water. Reproduced with permission from [331]. Copyright (2009) American Chemical Society.

\subsubsection{Carbonate/Water Interfaces}

While this review does cover the extremely vast literature on carbonate crystal growth, we note that interfacial carbonate species are key players in crystallization reactions. These species are binding sites for crystal growth and also for foreign ions, which may ultimately alter or poison growth, or give rise to solid-solutions. Surface carbonate species have, for instance, been identified through various chemical [349,350] and/or isotopic exchange methods [351] and vibration spectroscopy [352]. Carbonate surface structures have been mapped by AFM 
[353,354], probed by crystal truncation rod [355], modeled by $a b$ initio/DFT [356], and their hydration layers mapped by amplitude-modulation AFM [293]. Carbonate surface species (e.g. $\equiv \mathrm{CO}_{3} \mathrm{H}, \equiv \mathrm{CO}_{3}^{-}, \equiv \mathrm{CO}_{3} \mathrm{Mg}^{+}, \equiv \mathrm{MgHCO}_{3}$ ) have also been explicitly accounted for in thermodynamic models as potential-determining species accounting for the complex reactivity of carbonate phases $[350,357,358]$.

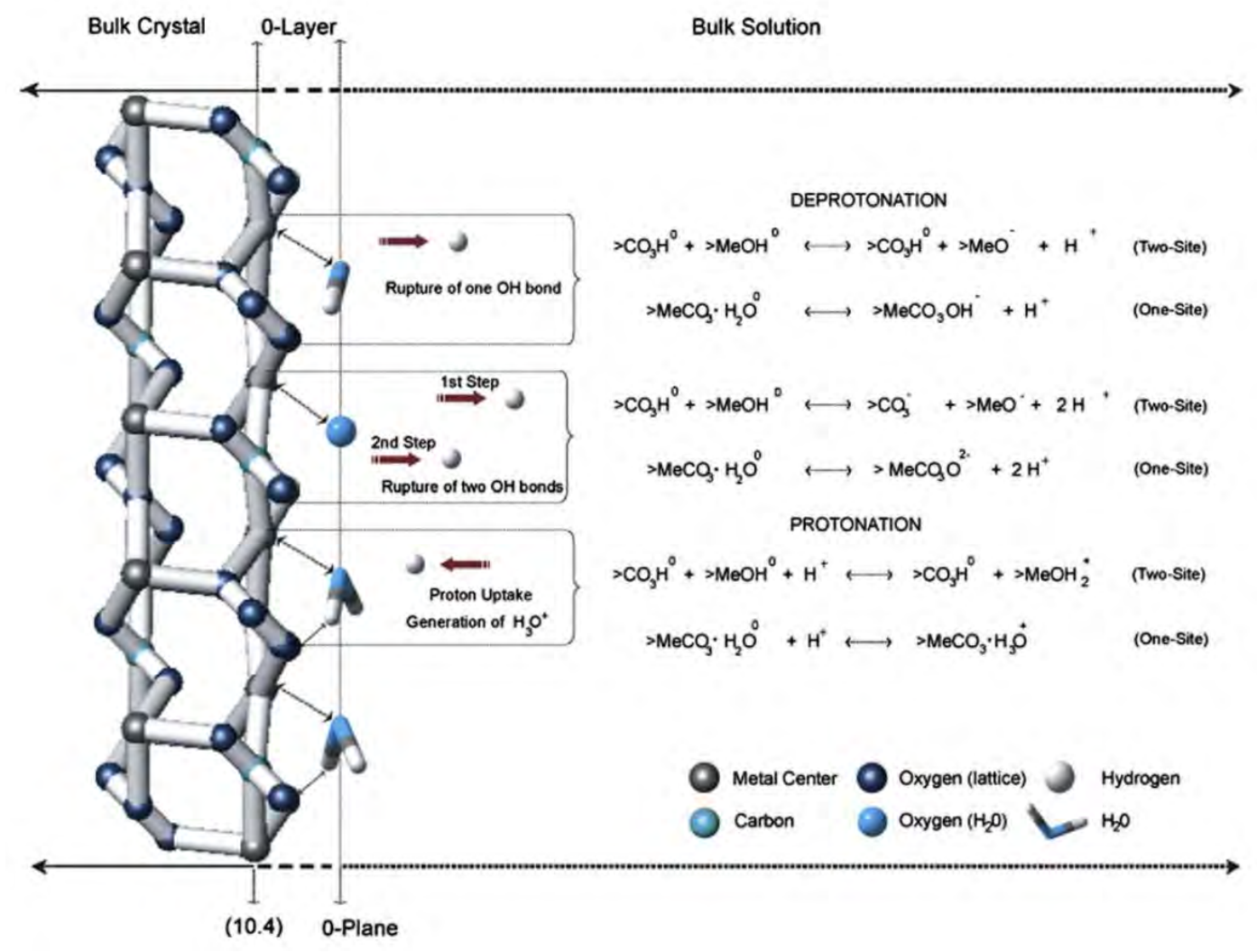

Figure 73. Conceptual molecular representation of possible protonation/deprotonation reactions at the $(10 \overline{1} 4)$ rhombohedral carbonate mineral surface. Reproduced with permission from Elsevier [350].

Metal-carbonate ternary complexes can also have considerable effects on carbonate surface chemistry. This was, for instance, denoted in the case of calcite dissolution contacted with 
soluble $\mathrm{Mn}(\mathrm{II})$, where manganese-carbonate complexes stabilized reactive sites and consequently worked against surface step movement and defect nucleation [359].

The flotation properties of trona $\left(\mathrm{Na}_{2} \mathrm{CO}_{3} \cdot \mathrm{NaHCO}_{3} \cdot 2 \mathrm{H}_{2} \mathrm{O}\right)$, a mineral mined for sodium carbonate production, investigated by contact angle and bubble attachment studies, suggested that $\mathrm{Na}_{2} \mathrm{CO}_{3}$ surfaces are considerably more hydrated and structured than their $\mathrm{NaHCO}_{3}$ counterparts, a finding tentatively ascribed to the greater water-making structure of the interfacial carbonate ion species [360]. Carbonate mineral surfaces are hydrophilic, with small (e.g. $<10^{\circ}$ ) contact angles in distilled water [361]. Commonly occurring alkaline earth ions, such as $\mathrm{Ca}^{2+}$ and $\mathrm{Mg}^{2+}$, surface bindings contribute to positive charges on carbonates and could be a cause in the preferential separation of huntite $\left(\mathrm{Mg}_{3} \mathrm{Ca}\left(\mathrm{CO}_{3}\right)_{4}\right)$ from magnesite $\left(\mathrm{MgCO}_{3}\right)$.

While this review shall neither cover the extremely vast literature on carbonate crystal growth, dissolution [362] and solubility [312] in aqueous solutions, nor its broad geochemical and atmospheric implications $[198,199,363]$, it cannot ignore the rich interfacial chemistry of carbonate minerals. Thus, in this section, we will limit our review to interfacial species of carbonate. Carbonate species outcropping metal carbonate surfaces are not only binding sites for crystal growth and dissolution [364,365], but also for binding foreign ions, which may ultimately alter or poison growth, or produce solid-solutions [366-371]. Surface carbonate species (e.g. $\equiv \mathrm{CO}_{3} \mathrm{H}, \equiv \mathrm{CO}_{3}^{-}, \equiv \mathrm{CO}_{3} \mathrm{Ca}^{+}, \equiv \mathrm{MeHCO}_{3}, \equiv \mathrm{MeOH}$; where $\left.\mathrm{Me}=\mathrm{Ca}^{2+}, \mathrm{Mg}^{2+}\right)$ have been inferred through various chemical $[349,350]$ and/or isotopic exchange methods [351], as well as through vibration spectroscopy [352,372] At the same time, X-ray reflectivity [373] results favored the concept that metal-bound hydroxo groups $($ e.g. $\equiv \mathrm{CaOH})$ are the protonation sites of the calcite/water interface, and that interfacial exchange of calcium and carbonate ions should predominantly occur at step-edge kink sites. Surface carbonate and metal-bound hydroxo species 
have also been explicitly accounted for in thermodynamic models as potential-determining species that may account for the complex reactivity of carbonate phases [350,357,358,374,375]. More recently, amplitude modulation atomic force microscopy (AM-AFM) has provided direct visualization of single ions coordinated to interfacial carbonate species, such as in the case of the (1014) face of calcite [353], as shown in Figure 74.
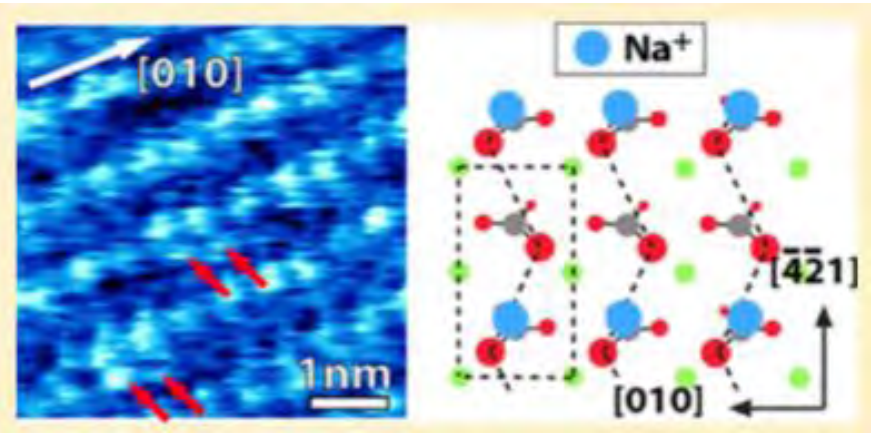

Figure 74. Amplitude modulation atomic force microscopy imaging of the (1014) face of calcite in (left) $10 \mathrm{mM} \mathrm{NaCl}$. Schematic representation of sodium species is shown at the right. Reproduced with permission from [353]. Copyright (2013) American Chemical Society.

A surface diffraction study by Heberling et al. [376] also provided evidence for a layering of electrolyte ions at the (1014) face of calcite, as shown in Figure 75, a finding that contrasts with classical views of the electric double layer and that potentially highlights the direct involvement of electrolyte ions in the charging process. 


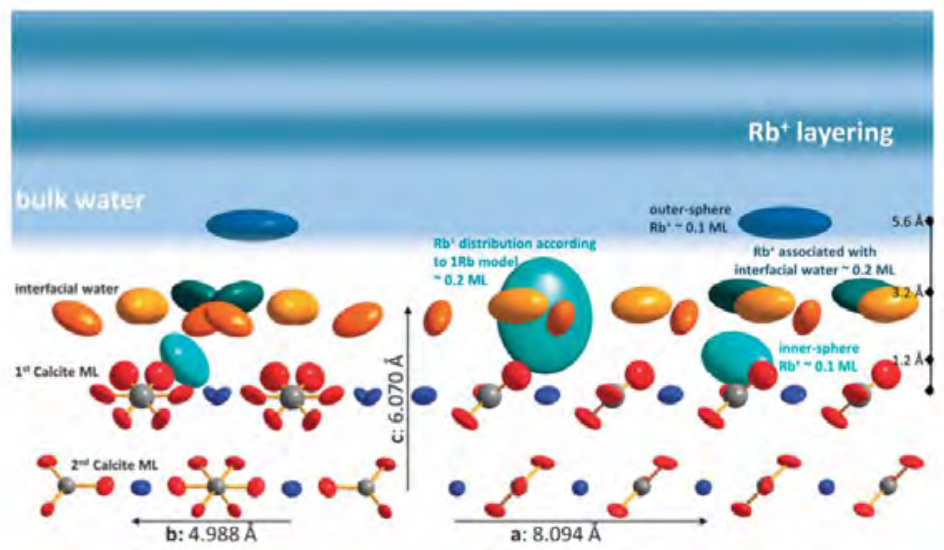

Figure 75. Schematic representation of calcite $(10 \overline{1} 4)-\mathrm{H}_{2} \mathrm{O}$ interface in the presence of $\mathrm{Rb}^{+}$. Reproduced with permission from [376]. Copyright (2014) PCCP Owner Societies.

Still, a recent X-ray reflectivity study [377] underscored continuing uncertainties with respect to key structural and dynamic properties of the calcite-water interface, and offered a means to benchmark molecular dynamics parameters to improve modeling of this important system. In a very recent study on dynamics of a propagating dissolution front at the calcite/water interface, Laanait et al. [362] also reported the prevalence of anisotropic front velocities, and therefore of no preferential control from defects or pits. These latest efforts consequently highlight further the complexity of the surface chemistry of carbonate minerals.

\subsubsection{Metal Oxide/Aqueous Carbonate Ion Interface}

Carbonate species are ubiquitous in many aqueous solutions exposed to the atmosphere. A great deal of studies focused on fundamental surface chemical aspects of metal oxides and minerals (e.g. hydroxyapatite [378] or iron oxides [379]) go, in fact, to great lengths to avoid carbonate contamination. Interfacial carbonate species, which are stabilized by electrostatic, hydrogen or covalent bonds, can not only block adsorption sites, but also alter the proton budgets of solid/solution suspensions [380], inhibit mineral (e.g. forsterite [381]) dissolution, depress mineral flotation [382] in alkaline solutions, and lower the point of zero charge (pzc) and 
isoelectric (ise) points. Thermodynamics calculations, moreover, suggest that carbonate surface complexes do not considerably affect the inner-Helmholtz potentials of mineral surfaces, but rather impact those of the diffuse layer, which are manifested in the ise [379].

Studies directly addressing carbonate binding at metal oxide and mineral surfaces are of particular relevance for atmospheric, groundwater and even industrial water (e.g. mine flotation waters or Bayer liquors) studies, where this ion is of great abundance. Adsorption experiments are carried out in both open and closed atmospheres. Work by Villalobos and Leckie [107] on goethite provided one of the few available experimental constraints of carbonate loadings achieved at mineral/water interfaces (Fig. 76).

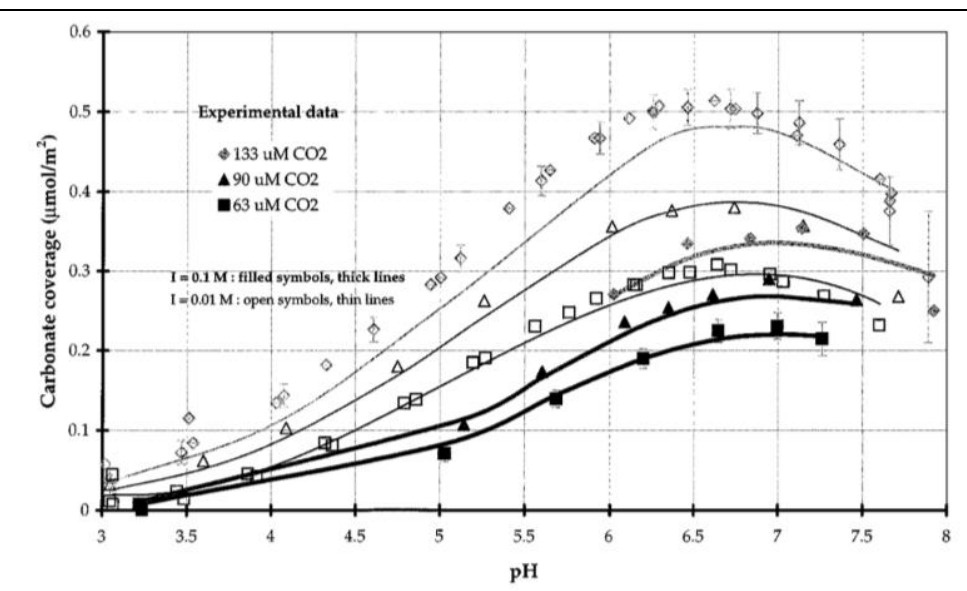

Figure 76. Carbonate loadings at the goethite/water interface. Reproduced with permission from [383]. Copyright (2001) American Chemical Society.

Focusing on submicron-sized synthetic goethite $(\alpha-\mathrm{FeOOH})$ surfaces, these authors report carbonate loadings of up to 0.3 sites $/ \mathrm{nm}^{2}\left(0.5 \mu \mathrm{mol} / \mathrm{m}^{2}\right)$ at circumneutral $\mathrm{pH}$ under close conditions $\left(133 \mu \mathrm{M} \mathrm{CO}_{2}\right)$. Under open conditions (0.24-0.41 atm $\left.\mathrm{CO}_{2}\right)$, loadings are up to 0.70.8 sites $/ \mathrm{nm}^{2}\left(1.2-1.4 \mu \mathrm{mol} / \mathrm{m}^{2}\right)$; namely, about one-fourth of the reactive site densities on these surfaces. The authors also detected an ionic strength dependence on the surface loadings below pH 7 only, suggesting that outer-sphere complexes predominate under these conditions. The 
same authors also characterized surface complexes by FTIR spectroscopy [106] and interpreted a split of $155 \mathrm{~cm}^{-1}$ between $v_{3} \mathrm{~s}$ and $v_{3}$ as evidence for monodentate inner-sphere complexation reactions. Other ATR-FTIR studies of carbonate binding at hematite [105], magnetite [384], aluminum and iron oxide surfaces [205] have identified key (bi)carbonate species. The study of Bargar et al. [105], comparing ATR-FTIR spectra and DFT frequency calculations, notably revealed coexisting carbonates at the hematite surface. These complexes include a monodentate binuclear inner-sphere and a symmetry-broken hydrogen-bonded complex alongside an additional one located in the diffuse layer. In a more recent study of $\mathrm{CO}_{2}$ binding at the hematite/water interface, Chernyshova et al. [385] constrained plausible binding mechanisms by use of rhombohedral nanoparticles predominantly terminated by the $\{014\}$ facet. Vibration spectroscopic measurements notably suggest a Langmuir-Hinselwood type of binding for $\mathrm{CO}_{2}$, involving nucleophilic attack from neighboring $\mu_{3}-\mathrm{OH}$ sites.

Thermodynamic adsorption models accounting for a molecular-level representation of carbonate interfacial species have been developed using the surface complexation modeling approach, one that accounts for complexation and ligand exchange reactions involving surface (hydr)oxo/aquo groups [106,386,387]. The model developed by Villalobos and Leckie [106] predicts experimental carbonate loadings achieved on goethite in both closed and open conditions involving a monodendate inner-sphere proposed from concurrent ATR-FTIR spectra. A sodiumcarbonate ternary complex accounts for ionic strength effects. Their model was also used to suggest carbonate loadings that can be achieved in groundwater under circumneutral conditions up to 1.8 site/ $\mathrm{nm}^{2}$; namely, about half of the $-\mathrm{OH}$ site densities at typically iron oxyhydroxide surfaces. Hiemstra et al. [386] later developed an alternative complexation model from the same 
data set, arguing that the FTIR absorption band splitting of the $\mathrm{C}-\mathrm{O}$ stretching region may be more representative of bidentate complexes as shown in Figure 77.

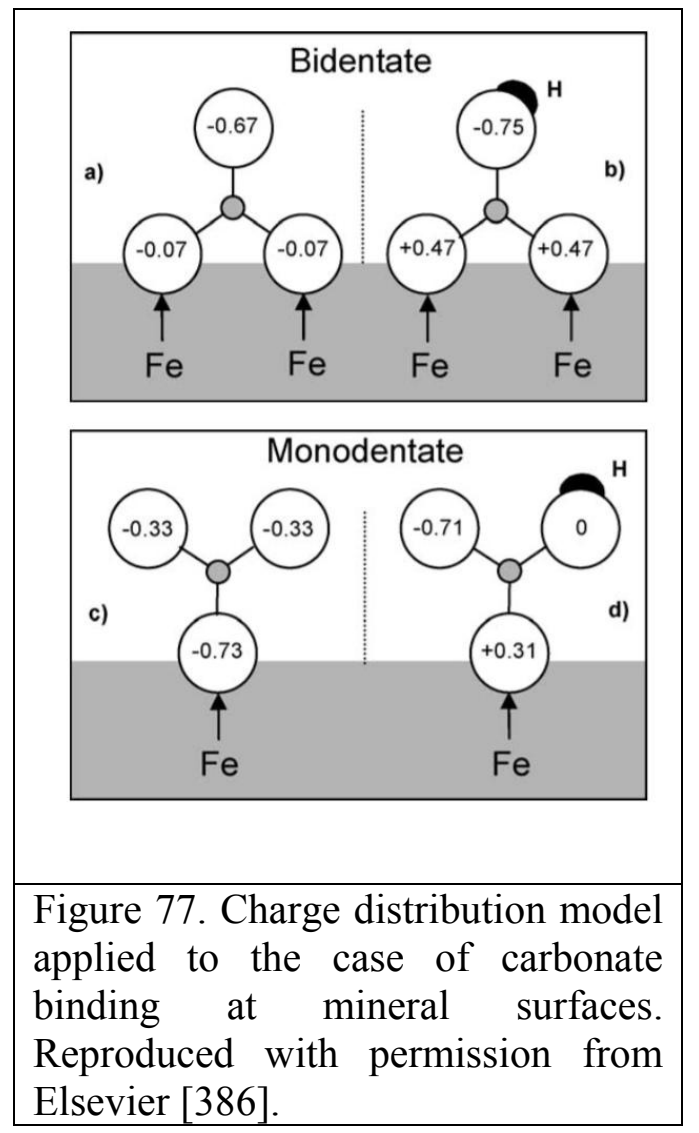

Using a charge-distribution modeling strategy [388] these authors assigned $2 / 3$ of the charges of innerspherically bound carbonate species to an innerHelmholtz plane and the remaining to an outerHemlholtz plane and proposed that the proton coadsorption response to carbonate, and by extension oxyanion, binding is strongly correlated to these distributions. Both models were used to describe sorption in competitive systems. The one of Villalobos et al. [383] was used to describe how interfacial carbonate species enhanced $\mathrm{Pb}(\mathrm{II})$ uptake by mineral surfaces through the formation of -tpe A" ternary surface complexes, $(\equiv \mathrm{FeO})_{2} \mathrm{H}-\mathrm{Pb}-\mathrm{OCO}_{2}{ }^{-}$(where $\equiv \mathrm{FeO}$ is a surface oxo site). The formation of a comparable complex for uranyl, $(\equiv \mathrm{FeO})_{2}{ }^{2-}-\mathrm{UO}_{2}-\left(\mathrm{CO}_{3}\right)^{2-}$, was, in turn, used to explain the greater loadings achieved under alkaline systems contacted with atmospheres of $\mathrm{CO}_{2}(\mathrm{~g})$. The study also accounts for competitive adsorption effects in mixed carbonate-chromate systems, effectively decreasing chromate loadings at goethite surfaces. Hiemstra, on the other hand, developed a model accounting for the competitive sorption of carbonate and phosphate [387]. Other competitive systems of noteworthy interest include the cases of sulfate and selenite [389] on aluminum oxide surface. These authors demonstrated the protonation of additional surface hydroxo groups that would be otherwise proton silent under these conditions. In other studies, 
carbonate ions were shown to competitively displace $\mathrm{Sb}(\mathrm{V})$ at surfaces [390] of boehmite and corundum, yet they could be readily displaced by the formation of five-member chelates of the Al-oxalate surface species [391].

Interfacial species of carbonate also play key roles in actinides (geo)chemistry. These affect actinide binding modes and strengths [392-400]. EXAFS studies of uranyl-carbonate species [401] [402] revealed the presence of uranyl-carbonato ternary surface complexes on minerals. These have also been the focus of theoretical studies, for example, on quartz [403], underscoring the co-existence of inner- and outer-sphere species involving carbonate in the equatorial shell of uranyl. Such complexes can enhance U(VI) uptake in some situations, such as has been shown in the case of iron oxide coated quartz surfaces [378], but decrease adsorption on negatively charged surfaces, such as on kaolinite [400] or low-charged clays like montmorillonite [404]. The impact of carbonate in contaminated soils is more complex, as mineral (e.g. U(VI) phosphate) dissolution, i.e. $\mathrm{U}(\mathrm{IV})$ oxidation, $\mathrm{U}(\mathrm{VI})$ complexation and desorption of $\mathrm{U}(\mathrm{VI})$ organic matter complexes under alkaline conditions, can act independently or concurrently. One study suggested that these effects may be responsible for the enhanced leaching and mobilization of uranyl by carbonate in soils [405], as well as diffusivity at interfaces and within (e.g. clay) pores [406] and fractures [407]. Neptunyl(V) biscarbonato inner-sphere complexes have also been shown to inhibit calcite growth rates [408].

Carbonate species can also play key roles in solid synthesis/growth and transformation mechanisms in aqueous solutions. A study by Zhang et al. [409], for instance, demonstrated carbonate ions effectively alter the coordination environment in fresh short-range ordered Al hydroxides precipitates. Carbonate interactions with incipient metal (oxy)hydroxide clusters/nuclei during synthesis can even alter solid formation pathways. In goethite, for 
example, carbonate ions favor the formation of nano-sized particles ( $c f$. nanogoethite), and incipient interactions are also responsible for the formation of carbonate-goethite solid solutions [410,411], which can contain up to $4 \% \mathrm{C}$ [412]. The stability of such goethite and even gibbsite

[413] solid solutions of carbonate has also lead to the use of the ${ }^{13} \mathrm{C}$ isotopic composition of goethite in paleosols, when determining atmospheric $\mathrm{CO}_{2}$ levels in the context of paleoclimatological studies $[412,414,415]$.

Finally, we note that interfacial species of carbonate have even broader implications for environmental processes involving more complex systems. For instance, analogous forms of interactions can also occur in the cases of organic adsorption on mineral surfaces. Demonstrated cases include those of thiram disulfate pesticide adsorption on corundum and montmorillonite surfaces where a thiram- $\mathrm{HCO}_{3}$ complex shows enhanced adsorption abilities, and even alters the electronic structure and UV-Vis spectrum of the molecule [416]. Another example is a study demonstrating that carbonate binding at goethite surfaces promoted virus attachment, while inactivating their infectivity from neighboring protonate groups [417].

\section{Outlook}

Two decades after the review of H.-J. Freund and M.W. Roberts in Surface Science Reports [13] the scientific literature on the interfacial chemistry of $\mathrm{CO}_{2}$ continues to grow at a rapid pace. This field becomes even more relevant now that the Earth's atmospheric $\mathrm{CO}_{2}$ levels have exceeded $400 \mathrm{ppm}$ and that 185 nations and the European Union have engaged in a common goal to mitigate emissions of carbon dioxide and other greenhouse gases in the recent 2015 Paris Climate Change Conference. A Chemical \& Engineering News article [418] even foresees that the Success of Climate Deal Will Hinge on Chemistry. When it comes to $\mathrm{CO}_{2}$ chemistry, this will call for a new generation of studies that will not only push forward current boundaries in our 
fundamental understanding of the electronic and molecular structures of $\mathrm{CO}_{2}$-related species, but also in their (photo)chemistry atmosphere and linkages with terrestrial processes, as well as in new technologies aimed at capturing, sequestering $\mathrm{CO}_{2}$ and even converting it to useful forms of carbon. Advancing this knowledge will rely on a concerted effort in the chemical, geochemical, and atmospheric communities to develop new experimental and theoretical approaches that will probe the interfacial chemistry of $\mathrm{CO}_{2}$ in unforeseen ways in the days the original H.-J. Freund and M.W. Roberts [13] was printed and even hopefully as this review is written.

The vast literature of the in vacuo interfacial chemistry of $\mathrm{CO}_{2}$ is serving as a sound steppingstone to a new generations of studies focused on environmentally relevant systems at ambient and even to industrially relevant systems at elevated pressures. As such, as classical UHV methods are adapted to emulate such conditions, as for example seen in the increasing usage of Ambient Pressure XPS, Time Resolved Sum-Frequency Generation Spectroscopy, Cavity RingDown Spectroscopy, Environmental Molecular Beam Spectroscopy and Environmental Electron Microscopy, new knowledge on the interfacial reactivity of $\mathrm{CO}_{2}$ should be gained. On the modeling front, we anticipate that new advances allowing bond formation and breaking (e.g. new reactive force fields for $\mathrm{MD}$, $a b$ initio and hybrid $a b$ initio $\mathrm{MD}$ methods) will allow the community to resolve more precisely conversion mechanisms in settings as varied as solid/air, solid/water and even solid/water/air interfaces.

\section{Acknowledgements}

This work by J.B. and W.T. was supported as part of UNCAGE-ME, an Energy Frontier Research Center funded by the U.S. Department of Energy, Office of Science, Basic Energy Sciences under Award No. DE-SC0012577. This work was also supported by funds from the Swedish Research Council (2012-2976) to J.-F.B. Dr. Neal Fairley, Prof. Eric V. Patterson and Ms. Courtney Lenzo are acknowledged for proofreading the manuscript. 


\section{References}

[1] D. Luthi, M. Le Floch, B. Bereiter, T. Blunier, J.-M. Barnola, U. Siegenthaler, et al., High-resolution carbon dioxide concentration record 650,000-800,000 years before present, Nature. 453 (2008) 379-382.

[2] D.C. Harris, Charles David Keeling and the Story of Atmospheric CO2 Measurements, Anal. Chem. 82 (2010) 7865-7870.

[3] P. Goodwin, R.G. Williams, M.J. Follows, S. Dutkiewicz, Ocean-atmosphere partitioning of anthropogenic carbon dioxide on centennial timescales, Global Biogeochem. Cycles. 21 (2007) GB1014.

[4] M. Schulz, J.M. Prospero, A.R. Baker, F. Dentener, L. Ickes, P.S. Liss, et al., Atmospheric Transport and Deposition of Mineral Dust to the Ocean: Implications for Research Needs, Environ. Sci. Technol. 46 (2012) 10390-10404.

[5] J. Baltrusaitis, J. Schuttlefield, E. Zeitler, V.H. Grassian, Carbon dioxide adsorption on oxide nanoparticle surfaces, Chem. Eng. J. 170 (2011) 471-481.

[6] E. V Kondratenko, G. Mul, J. Baltrusaitis, G.O. Larrazábal, J. Pérez-Ramírez, Status and perspectives of $\mathrm{CO} 2$ conversion into fuels and chemicals by catalytic, photocatalytic and electrocatalytic processes, Energy Environ. Sci. 6 (2013) 3112.

[7] J. Ma, N. Sun, X. Zhang, N. Zhao, F. Xiao, W. Wei, et al., A short review of catalysis for CO2 conversion, Catal. Today. 148 (2009) 221-231.

[8] G. Centi, S. Perathoner, Opportunities and prospects in the chemical recycling of carbon dioxide to fuels, Catal. Today. 148 (2009) 191-205.

[9] C. Song, Global challenges and strategies for control, conversion and utilization of CO2 for sustainable development involving energy, catalysis, adsorption and chemical processing, Catal. Today. 115 (2006) 2-32.

[10] I. Omae, Aspects of carbon dioxide utilization, Catal. Today. 115 (2006) 33-52.

[11] D. Cheng, F.R. Negreiros, E. Aprà, A. Fortunelli, Computational approaches to the chemical conversion of carbon dioxide., ChemSusChem. 6 (2013) 944-65.

[12] A.L. Stottlemyer, T.G. Kelly, Q. Meng, J.G. Chen, Reactions of oxygen-containing molecules on transition metal carbides: Surface science insight into potential applications in catalysis and electrocatalysis, Surf. Sci. Rep. 67 (2012) 201-232.

[13] H.-J. Freund, M.W. Roberts, Surface chemistry of carbon dioxide, Surf. Sci. Rep. 25 (1996) 225-273.

[14] A.D. Walsh, The Electronic Orbitals, Shapes, and Spectra of Polyatomic Molecules. Part II. * Non-hydride AB2, and BAC Molecules., J. Chem. Soc. (1953) 2266-2288.

[15] M.J. Frisch, G.W. Trucks, H.B. Schlegel, G.E. Scuseria, M.A. Robb, J.R. Cheeseman, et al., Gaussian09 Revision D.01, (2009).

[16] S. Noury, X. Krokidis, F. Fuster, B. Silvi, TopMoD package, Univ. Pierre Marie Curie. (1997). 
[17] B. Silvi, A. Savin, Classification of chemical bonds based on topological analysis of electron localization functions, Nature. 371 (1994) 683-686.

[18] U. Burghaus, Surface chemistry of $\mathrm{CO} 2$ - Adsorption of carbon dioxide on clean surfaces at ultrahigh vacuum, Prog. Surf. Sci. 89 (2014) 161-217.

[19] U. Burghaus, Surface science perspective of carbon dioxide chemistry-Adsorption kinetics and dynamics of $\mathrm{CO} 2$ on selected model surfaces, Catal. Today. 148 (2009) 212220.

[20] J.C. Vickerman, I.S. Gilmore, Surface Analysis - The Principal Techniques, John Wiley \& Sons, Ltd, 2009.

[21] N. Stojilovic, N. Farkas, R.D. Ramsier, Auger electron spectroscopic study of CO2 adsorption on Zircaloy-4 surfaces, Appl. Surf. Sci. 254 (2008) 2866-2870.

[22] Y. Wang, A. Lafosse, K. Jacobi, Adsorption and Reaction of CO2 on the RuO2(110) Surface, J. Phys. Chem. B. 106 (2002) 5476-5482.

[23] S. Hufner, Editor., Very High Resolution Photoelectron Spectroscopy (Lect. Notes Phys. 715), Springer GmbH, 2007.

[24] A. V. Naumkin, A. Kraut-Vass, S.W. Gaarenstroom, C.J. Powell, NIST Standard Reference Database 20, Version 4.1, (2012).

[25] W. Olovsson, C. Goransson, T. Marten, I.A. Abrikosov, Core-level shifts in complex metallic systems from first principle., Phys. Status Solidi B Basic Solid State Phys. 243 (2006) 2447-2464.

[26] M. den Bossche, N.M. Martin, J. Gustafson, C. Hakanoglu, J.F. Weaver, E. Lundgren, et al., Effects of non-local exchange on core level shifts for gas-phase and adsorbed molecules, J. Chem. Phys. 141 (2014) 034706.

[27] H. Siegbahn, S. Svensson, M. Lundholm, A new method for ESCA studies of liquid-phase samples, J. Electron Spectros. Relat. Phenomena. 24 (1981) 205-213.

[28] H. Siegbahn, K. Siegbahn, ESCA applied to liquids, J. Electron Spectros. Relat. Phenomena. 2 (1973) 319-325.

[29] M. Salmeron, R. Schlögl, Ambient pressure photoelectron spectroscopy: A new tool for surface science and nanotechnology, Surf. Sci. Rep. 63 (2008) 169-199.

[30] S. Andersson, M. Frank, A. Sandell, J. Libuda, B. Brena, A. Giertz, et al., Temperature dependent XPS study of CO dissociation on small Rh particles, Vacuum. 49 (1998) $167-$ 170 .

[31] K. Mudiyanselage, S.D. Senanayake, L. Feria, S. Kundu, A.E. Baber, J. Graciani, et al., Importance of the Metal-Oxide Interface in Catalysis: In Situ Studies of the Water-Gas Shift Reaction by Ambient-Pressure X-ray Photoelectron Spectroscopy., Angew. Chemie, Int. Ed. 52 (2013) 5101-5105.

[32] J.K. Heuer, J.F. Stubbins, An XPS characterization of $\mathrm{FeCO} 3$ films from $\mathrm{CO} 2$ corrosion, Corros. Sci. 41 (1999) 1231-1243. 
[33] Y. Yu, B. Mao, A. Geller, R. Chang, K. Gaskell, Z. Liu, et al., CO2 activation and carbonate intermediates: an operando AP-XPS study of $\mathrm{CO} 2$ electrolysis reactions on solid oxide electrochemical cells, Phys. Chem. Chem. Phys. 16 (2014) 11633-11639.

[34] J.-T. Li, J. Swiatowska, A. Seyeux, L. Huang, V. Maurice, S.-G. Sun, et al., XPS and ToFSIMS study of Sn-Co alloy thin films as anode for lithium ion battery, J. Power Sources. 195 (2010) 8251-8257.

[35] Y. Lykhach, T. Staudt, R. Streber, M.P.A. Lorenz, A. Bayer, H.-P. Steinrueck, et al., CO2 activation on single crystal based ceria and magnesia/ceria model catalysts., Eur. Phys. J. B Condens. Matter Complex Syst. 75 (2010) 89-100.

[36] T. Staudt, Y. Lykhach, N. Tsud, T. Skala, K.C. Prince, V. Matolin, et al., Electronic Structure of Magnesia-Ceria Model Catalysts, CO2 Adsorption, and CO2 Activation: A Synchrotron Radiation Photoelectron Spectroscopy Study., J. Phys. Chem. C. 115 (2011) 8716-8724.

[37] X. Deng, A. Verdaguer, T. Herranz, C. Weis, H. Bluhm, M. Salmeron, Surface Chemistry of $\mathrm{Cu}$ in the Presence of CO2 and H2O, Langmuir. 24 (2008) 9474-9478.

[38] S. Blomberg, M.J. Hoffmann, J. Gustafson, N.M. Martin, V.R. Fernandes, A. Borg, et al., In situ X-ray photoelectron spectroscopy of model catalysts: at the edge of the gap., Phys. Rev. Lett. 110 (2013) 117601/1-117601/5.

[39] J.C. Riviere, S. Myhra, Editors., Handbook Of Surface And Interface Analysis: Methods For Problem-Solving, Second Edition., CRC Press, 2009.

[40] D.A. Shirley, High-Resolution X-Ray Photoemission Spectrum of the Valence Bands of Gold, Phys. Rev. B. 5 (1972) 4709-4714.

[41] S. Tougaard, Quantitative analysis of the inelastic background in surface electron spectroscopy, Surf. Interface Anal. 11 (1988) 453-472.

[42] C.D. Wagner, L.E. Davis, M. V Zeller, J.A. Taylor, R.H. Raymond, L.H. Gale, Empirical atomic sensitivity factors for quantitative analysis by electron spectroscopy for chemical analysis, Surf. Interface Anal. 3 (1981) 211-225.

[43] J.H. Scofield, Hartree-Slater subshell photoionization cross-sections at 1254 and $1487 \mathrm{eV}$, J. Electron Spectros. Relat. Phenomena. 8 (1976) 129-137.

[44] C. Weilach, C. Spiel, K. Föttinger, G. Rupprechter, Carbonate formation on A12O3 thin film model catalyst supports, Surf. Sci. 605 (2011) 1503-1509.

[45] J. Baltrusaitis, J. Schuttlefield, J.H. Jensen, V.H. Grassian, FTIR spectroscopy combined with quantum chemical calculations to investigate adsorbed nitrate on aluminium oxide surfaces in the presence and absence of co-adsorbed water, Phys. Chem. Chem. Phys. 9 (2007) 4970-4980.

[46] X. Song, J.-F. Boily, Water vapor interactions with FeOOH particle surfaces, Chem. Phys. Lett. 560 (2013) 1-9.

[47] X. Song, Surface and Bulk Reactivity of Iron Oxyhydroxides : A Molecular Perspective, Umeå Universitet, 2013. 
[48] P. Galhotra, J.G. Navea, S.C. Larsen, V.H. Grassian, Carbon dioxide (C16O2 and C18O2) adsorption in zeolite Y materials: effect of cation, adsorbed water and particle size, Energy Environ. Sci. 2 (2009) 401-409.

[49] C.E. Nanayakkara, W.A. Larish, V.H. Grassian, Titanium Dioxide Nanoparticle Surface Reactivity with Atmospheric Gases, CO2, SO2, and NO2: Roles of Surface Hydroxyl Groups and Adsorbed Water in the Formation and Stability of Adsorbed Products, J. Phys. Chem. C. 118 (2014) 23011-23021.

[50] J. Baltrusaitis, J.H. Jensen, V.H. Grassian, FTIR Spectroscopy combined with isotope labeling and quantum chemical calculations to investigate adsorbed bicarbonate formation following reaction of carbon dioxide with surface hydroxyl groups on $\mathrm{Fe}(2) \mathrm{O} 3$ and Al2O3, J. Phys. Chem. B. 110 (2006) 12005-12016.

[51] S.-W. Bian, J. Baltrusaitis, P. Galhotra, V.H. Grassian, A template-free, thermal decomposition method to synthesize mesoporous $\mathrm{MgO}$ with a nanocrystalline framework and its application in carbon dioxide adsorption, J. Mater. Chem. 20 (2010) 8705.

[52] J. Baltrusaitis, V.H. Grassian, Surface reactions of carbon dioxide at the adsorbed wateriron oxide interface, J. Phys. Chem. B. 109 (2005) 12227-12230.

[53] G. Busca, V. Lorenzelli, Infrared spectroscopic identification of species arising from reactive adsorption of carbon oxides on metal oxide surfaces, Mater. Chem. 7 (1982) 89126.

[54] K. Sumida, D.L. Rogow, J. a Mason, T.M. Mcdonald, E.D. Bloch, Z.R. Herm, et al., Carbon Dioxide Capture in Metal - Organic Frameworks, Chem. Rev. 112 (2012) 724781.

[55] W. Leitner, The coordination chemistry of carbon dioxide and its relevance for catalysis: A critical survey, Coord. Chem. Rev. 153 (1996) 257-284.

[56] M. Aresta, A. Dibenedetto, Utilisation of $\mathrm{CO} 2$ as a chemical feedstock: opportunities and challenges., Dalton Trans. (2007) 2975-2992.

[57] D.H. Gibson, The Organometallic Chemistry of Carbon Dioxide., Chem. Rev. 96 (1996) 2063-2096.

[58] F.M. Hoffmann, M.D. Weisel, J. Paul, The activation of CO2, by potassium-promoted $\mathrm{Ru}($ 001) I. FT-IRAS and TDMS study of oxalate and carbonate intermediates, Surf. Sci. 316 (1994) 277-293.

[59] R. Philipp, K. Fujimoto, FTIR Spectroscopic Study of CO2 Adsorption/Desorption on $\mathrm{MgO} / \mathrm{CaO}$ Catalysts, J. Phys. Chem. 9038 (1992) 9035-9038.

[60] L. Liao, C. Lien, D. Shieh, M. Chen, J. Lin, FTIR Study of Adsorption and Photoassisted Oxygen Isotopic Exchange of Carbon Monoxide, Carbon Dioxide, Carbonate, and Formate on TiO2, J. Phys. Chem. B. (2002) 11240-11245.

[61] C. Knöfel, C. Martin, V. Hornebecq, P.L. Llewellyn, Study of carbon dioxide adsorption on mesoporous aminopropylsilane- functionalized silica and titania combining microcalorimetry and in situ infrared spectroscopy, J. Phys. Chem. C. 113 (2009) 2172621734. 
[62] W. Su, J. Zhang, Z. Feng, T. Chen, P. Ying, C. Li, Surface phases of TiO2 nanoparticles studied by UV raman spectroscopy and FT-IR spectroscopy, J. Phys. Chem. C. 112 (2008) 7710-7716.

[63] B. Bachiller-Baeza, I. Rodriguez-Ramos, A. Guerrero-Ruiz, Interaction of Carbon Dioxide with the Surface of Zirconia, Langmuir. 14 (1998) 3556-3564.

[64] K. Pokrovski, K.T. Jung, A.T. Bell, Investigation of $\mathrm{CO}$ and $\mathrm{CO} 2$ adsorption on tetragonal and monoclinic zirconia, Langmuir. 17 (2001) 4297-4303.

[65] K.D. Dobson, a J. McQuillan, An Infrared Spectroscopic Study of Carbonate Adsorption to Zirconium Dioxide Sol-Gel Films from Aqueous Solutions, Langmuir. 7463 (1997) 3392-3396.

[66] F. Ouyang, A. Nakayama, K. Tabada, E. Suzuki, Infrared Study of a Novel Acid-Base Site on $\mathrm{ZrO} 2$ by Adsorbed Probe Molecules. I. Pyridine, Carbon Dioxide, and Formic Acid Adsorption, J. Phys. Chem. B. 104 (2000) 2012-2018.

[67] O. Seiferth, K. Wolter, B. Dillmann, G. Klivenyi, H.-J. Freund, D. Scarano, et al., IR investigations of $\mathrm{CO} 2$ adsorption on chromia surfaces: $\mathrm{Cr} 2 \mathrm{O} 3(0001) / \mathrm{Cr}(110)$ versus polycrystalline $\alpha$-Cr2O3, Surf. Sci. 421 (1999) 176-190.

[68] T. Matsumoto, J. Kubota, J.N. Kondo, C. Hirose, K. Domen, Adsorption structures of carbon dioxide on $\mathrm{NiO}(111)$ and hydroxylated $\mathrm{NiO}(111)$ studied by infrared reflection adsorption spectroscopy, Langmuir. 15 (1999) 2158-2161.

[69] H. Noei, L. Jin, H. Qiu, M. Xu, Y. Gao, J. Zhao, et al., Vibrational spectroscopic studies on pure and metal-covered metal oxide surfaces, Phys. Status Solidi. 250 (2013) 12041221.

[70] S.E. Collins, M. a Baltanás, A.L. Bonivardi, Infrared spectroscopic study of the carbon dioxide adsorption on the surface of Ga2O3 polymorphs., J. Phys. Chem. B. 110 (2006) 5498-5507.

[71] E. K ck, M. Kogler, T. Bielz, B. Kl tz er, S. Penner, In Situ FT-IR Spectroscopic Study of CO2 and CO Adsorption on Y2O3 , J. Phys. Chem. C. 117 (2013) 17666-17673.

[72] T. Horiuchi, H. Hidaka, T. Fukui, Y. Kubo, M. Horio, K. Suzuki, et al., Effect of added basic metal oxides on $\mathrm{CO} 2$ adsorption on alumina at elevated temperatures, Appl. Catal. A Gen. 167 (1998) 195-202.

[73] L. Li, X. Wen, X. Fu, F. Wang, N. Zhao, F. Xiao, et al., MgO/Al2O3 sorbent for $\mathrm{CO} 2$ capture, Energy and Fuels. 24 (2010) 5773-5780.

[74] G. Hu, L. Zhu, A. Jia, X. Hu, G. Xie, J. Lu, et al., CO2 Adsorption and Desorption on MgO/A12O3: An In Situ Diffuse Reflection Infrared Fourier Transform Spectroscopy (DRIFTS) Study, Appl. Spectrosc. 66 (2012) 122-127.

[75] C.J. Keturakis, F. Ni, M. Spicer, M.G. Beaver, H.S. Caram, I.E. Wachs, Monitoring Solid Oxide CO2 Capture Sorbents in Action, ChemSusChem. 7 (2014) 3459-3466.

[76] J. Szanyi, J.H. Kwak, Dissecting the steps of $\mathrm{CO} 2$ reduction: 1. The interaction of $\mathrm{CO}$ and CO2 with $\gamma$-A12O3: an in situ FTIR study., Phys. Chem. Chem. Phys. 16 (2014) 15117- 
15125 .

[77] J. V. Stark, D.G. Park, I. Lagadic, K.J. Klabunde, Nanoscale Metal Oxide Particles/Clusters as Chemical Reagents. Unique Surface Chemistry on Magnesium Oxide As Shown by Enhanced Adsorption of Acid Gases (Sulfur Dioxide and Carbon Dioxide) and Pressure Dependence, Chem. Mater. 8 (1996) 1904-1912.

[78] J. V Evans, T.L. Whateley, Infra-red study of adsorption of carbon dioxide and water on magnesium oxide, Trans. Faraday Soc. 63 (1967) 2769-2777.

[79] D.G. Rethwisch, J.A. Dumesic, Effect of metal-oxygen bond strength on properties of oxides. 1. Infrared spectroscopy of adsorbed carbon monoxide and carbon dioxide, Langmuir. 2 (1986) 73-79.

[80] J.A. Lercher, C. Colombier, H. Noller, Acid-base properties of alumina-magnesia mixed oxides. Part 4.-Infrared study of adsorption of carbon dioxide, J. Chem. Soc. Faraday Trans. 1 Phys. Chem. Condens. Phases. 80 (1984) 949-959.

[81] P. Gruene, A.G. Belova, T.M. Yegulalp, R.J. Farrauto, M.J. Castaldi, Dispersed Calcium Oxide as a Reversible and Efficient CO2 Sorbent at Intermediate Temperatures, Ind. Eng. Chem. Res. 50 (2011) 4042-4049.

[82] J. Rasko, F. Solymosi, Infrared spectroscopic study of the photoinduced activation of CO2 on $\mathrm{TiO} 2$ and $\mathrm{Rh} / \mathrm{TiO} 2$ catalysts, J. Phys. Chem. 98 (1994) 7147-7152.

[83] a Vimont, J.C. Lavalley, a Sahibed-Dine, C. Otero Arean, M. Rodríguez Delgado, M. Daturi, Infrared spectroscopic study on the surface properties of gamma-gallium oxide as compared to those of gamma-alumina., J. Phys. Chem. B. 109 (2005) 9656-9664.

[84] S.A. FitzGerald, J.M. Schloss, C.J. Pierce, B. Thompson, J.L.C. Rowsell, K. Yu, et al., Insights into the Anomalous Vibrational Frequency Shifts of CO2 Adsorbed to Metal Sites in Microporous Frameworks, J. Phys. Chem. C. 119 (2015) 5293-5300.

[85] C.P. Cabello, P. Rumori, G.T. Palomino, Carbon dioxide adsorption on MIL-100(M) (M = $\mathrm{Cr}, \mathrm{V}, \mathrm{Sc})$ metal-organic frameworks: IR spectroscopic and thermodynamic studies, Microporous Mesoporous Mater. 190 (2014) 234-239.

[86] P.L. Llewellyn, S. Bourrelly, C. Serre, A. Vimont, M. Daturi, L. Hamon, et al., High uptakes of $\mathrm{CO} 2$ and $\mathrm{CH} 4$ in mesoporous metal-organic frameworks MIL-100 and MIL101., Langmuir. 24 (2008) 7245-50.

[87] H. Leclerc, A. Vimont, J.-C. Lavalley, M. Daturi, A.D. Wiersum, P.L. Llwellyn, et al., Infrared study of the influence of reducible iron(iii) metal sites on the adsorption of CO, $\mathrm{CO} 2$, propane, propene and propyne in the mesoporous metal-organic framework MIL100, Phys. Chem. Chem. Phys. 13 (2011) 11748.

[88] J. Baltrusaitis, B. Mendoza-Sanchez, V. Fernandez, R. Veenstra, N. Dukstiene, A. Roberts, et al., Generalized molybdenum oxide surface chemical state XPS determination via informed amorphous sample model, Appl. Surf. Sci. 326 (2015) 151-161.

[89] N. Fairley, CasaXPS: Spectrum Processing Software for XPS, AES and SIMS (Version 2.3.13), (2006). 
[90] M.B. Jensen, L.G.M. Pettersson, O. Swang, U. Olsbye, CO2 sorption on $\mathrm{MgO}$ and $\mathrm{CaO}$ surfaces: A comparative quantum chemical cluster study, J. Phys. Chem. B. 109 (2005) 16774-16781.

[91] A.P. Scott, L. Radom, Harmonic Vibrational Frequencies: An Evaluation of Hartree-Fock, Møller-Plesset, Quadratic Configuration Interaction, Density Functional Theory, and Semiempirical Scale Factors, J. Phys. Chem. 100 (1996) 16502-16513.

[92] M.W. Wong, Vibrational frequency prediction using density functional theory, Chem. Phys. Lett. 256 (1996) 391-399.

[93] Y. Pan, C. Liu, D. Mei, Q. Ge, Effects of Hydration and Oxygen Vacancy on CO2 Adsorption and Activation on $\beta$-Ga2 O3 (100), Langmuir. 26 (2010) 5551-5558.

[94] D. Cornu, H. Guesmi, J.M. Krafft, H. Lauron-Pernot, Lewis acido-basic interactions between $\mathrm{CO} 2$ and $\mathrm{MgO}$ surface: DFT and DRIFT approaches, J. Phys. Chem. C. 116 (2012) 6645-6654.

[95] W.G. Reimers, M.A. Baltanás, M.M. Branda, $\mathrm{CO}, \mathrm{CO} 2$ and $\mathrm{H} 2$ adsorption on $\mathrm{ZnO}, \mathrm{CeO}$, and $\mathrm{ZnO} / \mathrm{CeO} 2$ surfaces: DFT simulations, J. Mol. Model. 20 (2014) 2270.

[96] L. Mino, G. Spoto, A.M. Ferrari, CO2 Capture by TiO2 Anatase Surfaces : A Combined DFT and FTIR Study, J. Phys. Chem. C. (2014) 25016-25026.

[97] D.C. Sorescu, J. Lee, W.A. Al-Saidi, K.D. Jordan, Coadsorption properties of CO2 and H2O on TiO2 rutile (110): A dispersion-corrected DFT study, J. Chem. Phys. 137 (2012) 074704.

[98] J. Ye, C. Liu, Q. Ge, DFT Study of CO2 Adsorption and Hydrogenation on the In2O3 Surface, J. Phys. Chem. C. 116 (2012) 7817-7825.

[99] D.D. Do, Adsorption Analysis: Equilibria and Kinetics Series on Chemical Engineering: Volume 2, Imperial College Press, 1998.

[100] M. Kontny, G. Zografi, Sorption of Water by Solids, in: Phys. Charact. Pharm. Solids, CRC Press, 1995: pp. 387-418.

[101] H.T. Schaef, J.S. Loring, V.-A. Glezakou, Q.R.S. Miller, J. Chen, A.T. Owen, et al., Competitive sorption of $\mathrm{CO} 2$ and $\mathrm{H} 2 \mathrm{O}$ in 2:1 layer phyllosilicates, Geochim. Cosmochim. Acta. 161 (2015) 248-257.

[102] S. Muraoka, Y. Kiyohara, H. Oue, S. Higashimoto, A CO2 Sensor Using a Quartz Crystal Microbalance Coated with a Sensitive Membrane, Electron. Commun. Japan. 97 (2014) 60-66.

[103] H.T. Schaef, V.-A. Glezakou, A.T. Owen, S. Ramprasad, P.F. Martin, B.P. McGrail, Surface Condensation of CO2 onto Kaolinite, Environ. Sci. Technol. Lett. 1 (2014) 142145.

[104] C.J. Thompson, P.F. Martin, J. Chen, P. Benezeth, H.T. Schaef, K.M. Rosso, et al., Automated high-pressure titration system with in situ infrared spectroscopic detection., Rev. Sci. Instrum. 85 (2014) 044102.

[105] J.R. Bargar, J.D. Kubicki, R. Reitmeyer, J.A. Davis, ATR-FTIR spectroscopic 
characterization of coexisting carbonate surface complexes on hematite, Geochim. Cosmochim. Acta. 69 (2005) 1527-1542.

[106] M. Villalobos, J.O. Leckie, Surface Complexation Modeling and FTIR Study of Carbonate Adsorption to Goethite., J. Colloid Interface Sci. 235 (2001) 15-32.

[107] M. Villalobos, J.O. Leckie, Carbonate adsorption on goethite under closed and open CO2 conditions, Geochim. Cosmochim. Acta. 64 (2000) 3787-3802.

[108] A. Villegas-Jimenez, R.M. Hazen, D.A. Sverjensky, Novel insights into the ion sorption properties of calcite in aqueous solutions using cavity ring-down spectroscopy, Mineral. Mag. (2011) 2091.

[109] A.A. Novitskiy, J. Ke, G. Comak, M. Poliakoff, M.W. George, A modified golden gate attenuated total reflection (ATR) cell for monitoring phase transitions in multicomponent fluids at high temperatures., Appl. Spectrosc. 65 (2011) 885-891.

[110] B.E. Koel, C. Panja, J. Kim, E. Samano, Molecular polyatomic adsorbates on metals and semiconductors, in: H.P. Bonzel (Ed.), Adsorbed Layers Surfaces. Part 5 Adsorpt. Mol. Met. Semicond. Oxide Surfaces, 42A5 ed., Springer Materials, Heidelberg, 2006: pp. $170-240$.

[111] E. Vesselli, L. De Rogatis, X. Ding, A. Baraldi, L. Savio, L. Vattuone, et al., Carbon Dioxide Hydrogenation on Ni(110), J. Am. Chem. Soc. 130 (2008) 11417-11422.

[112] R.J. Behm, C.R. Brundle, On the formation and bonding of a surface carbonate on Ni(100), Surf. Sci. Lett. 255 (1991) A513.

[113] S.S. Fu, G. a. Somorjai, Interactions of O2, CO, CO2, and D2 with the stepped CU(311) crystal face: Comparison to CU(110), Surf. Sci. 262 (1992) 68-76.

[114] I. a. Bönicke, W. Kirstein, F. Thieme, A study on CO2 dissociation on a stepped (332) copper surface, Surf. Sci. 307-309 (1994) 177-181.

[115] M. Pohl, a Otto, Adsorption and reaction of carbon dioxide on pure and alkali-metal promoted cold-deposited copper films, Surf. Sci. 406 (1998) 125-137.

[116] A.F. Carley, M.W. Roberts, J. Strutt, Activation of Carbon Monoxide and Carbon Dioxide at Cesium-Promoted $\mathrm{Cu}(110)$ adn $\mathrm{Cu}(110)-O$ Surfaces, J. Phys. Chem. 98 (1994) 91759181.

[117] P.J. Godowski, J. Onsgaard, S. V Ho, The coadsorption of hydrogen and carbon dioxide versus adsorption of formic acid on Cs-dosed $\mathrm{Cu}$ ( 110 ), Vacuum. 63 (2001) 257-266.

[118] E.. Thomsen, B. Jørgensen, J. Onsgaard, Adsorption and reactivity of CO2 on the $\mathrm{K} / \mathrm{Cu}(110)$ interface and the effect of photon irradiation, Surf. Sci. 304 (1994) 85-97.

[119] J. Onsgaard, L. Thomsen, S. V. Hoffmann, P.J. Godowski, Surface reactions between $\mathrm{CO} 2$ and $\mathrm{H}$ over K-modified $\mathrm{Cu}(00$ 1), Vacuum. 81 (2006) 25-31.

[120] J. Onsgaard, S. V. Hoffmann, P. Møller, P.J. Godowski, J.B. Wagner, G. Paolucci, et al., Adsorption of $\mathrm{CO} 2$ and coadsorption of $\mathrm{H}$ and $\mathrm{CO} 2$ on potassium-promoted $\mathrm{Cu}(115)$, ChemPhysChem. 4 (2003) 466-473. 
[121] J. Onsgaard, J. Storm, S.V. Christensen, J. Nerlov, P.J. Godowski, P. Morgen, et al., The interaction of $\mathrm{CO} 2$ with potassium-promoted $\mathrm{Cu}(100)$ : adsorption, reactions and radiation induced dissociation of CO2, Surf. Sci. 336 (1995) 101-112.

[122] Z.M. Liu, Y. Zhou, F. Solymosi, J.M. White, Spectroscopic study of K-induced activation of CO2 on Pt(111), Surf. Sci. Lett. 245 (1991) A142.

[123] J.M. Ricart, M.P. Habas, A. Clotet, D. Curulla, F. Illas, Theoretical study of CO2 activation on $\mathrm{Pt}(111)$ induced by coadsorbed K atoms, Surf. Sci. 460 (2000) 170-181.

[124] J. Llorca, N. Homs, J. Ara a , J. Sales, P. Ram rez de la Piscina, FTIR study of the interaction of CO and CO2 with silica-supported PtSn alloy, Appl. Surf. Sci. 134 (1998) 217-224.

[125] J. Rodriguez, R. a. Campbell, D. Wayne Goodman, Adsorption of CO, H2, O2 and CO2 on clean and Cu-covered $\operatorname{Re}(0001)$ : an XPS study, Surf. Sci. Lett. 244 (1991) A114.

[126] F. Solymosi, The bonding, structure and reactions of $\mathrm{CO} 2$ adsorbed on clean and promoted metal surfaces, J. Mol. Catal. 65 (1991) 337-358.

[127] W.H. Weinberg, Why CO2 does not dissociate on Rh at low temperature, Surf. Sci. 128 (1983) L224-L230.

[128] L.H. Dubois, G.A. Somorjai, The chemisorption of CO and CO2 on Rh(111) studied by high resolution electron energy loss spectroscopy, Surf. Sci. 91 (1980) 514-532.

[129] F. Solymosi, G. Klivenyi, HREELS study on the formation of CO2-, on a K-promoted Rh( 111) surface, Surf. Sci. 315 (1994) 255-268.

[130] M.F.H. van Tol, a. Gielbert, R.M. Wolf, a. B.K. Lie, B.E. Nieuwenhuys, The striking difference in the behaviour of $\mathrm{Rh}$ and $\mathrm{Pt}$ towards their interaction with $\mathrm{CO} 2$, Surf. Sci. Lett. 287-288 (1993) A378.

[131] C.-C. Chang, J.-J. Ho, Dissociation of $\mathrm{CO}_{2}$ on rhodium nanoclusters $\left(\mathrm{Rh}_{13}\right)$ in various structures supported on unzipped graphene oxide - a DFT study, Phys. Chem. Chem. Phys. 17 (2015) 11028-11035.

[132] R. Brosseau, T.H. Ellis, H. Wang, The influence of water on the chemisorption of CO2 onto Pd(110), Chem. Phys. Lett. 177 (1991) 118-122.

[133] G. Heß, C. Baumgartner, A. Petkova, H. Froitzheim, The determination of binding energies and preexponential factors: a time resolved HREELS study on $\mathrm{Fe}(111) / \mathrm{CO} 2$, Surf. Sci. 572 (2004) 355-365.

[134] T. Seyller, D. Borgmann, G. Wedler, Interaction of CO2 with Cs-promoted Fe(110) as compared to $\mathrm{Fe}(110) / \mathrm{K}+\mathrm{CO} 2$, Surf. Sci. 400 (1998) 63-79.

[135] G. Meyer, D. Borgmann, G. Wedler, Interaction of carbon dioxide with potassiumpromoted Fe(110): II. Temperature-dependent reactions, Surf. Sci. 320 (1994) 123-133.

[136] G. Meyer, E. Reinhart, D. Borgmann, G. Wedler, Interaction of carbon dioxide with potassium-promoted $\mathrm{Fe}(110) \mathrm{I}$. Dependence on potassium coverage and carbon dioxide exposure at $85 \mathrm{~K}$, Surf. Sci. 320 (1994) 110-122. 
[137] X.-C. Guo, R.J. Madix, Adsorption of oxygen and carbon dioxide on cesiumreconstructed $\operatorname{Ag}(110)$ surface, Surf. Sci. 550 (2004) 81-92.

[138] A. Sandell, A.J. Jaworowski, A. Beutler, M. Wiklund, Adsorption and reactions on a surface alloy: CO , NO, O and, Surf. Sci. 421 (1999) 116-134.

[139] C. Stampfl, M. Scheffler, Anomalous Behavior of Ru for Catalytic Oxidation: A Theoretical Study of the Catalytic Reaction $\mathrm{CO}+12 \mathrm{O} 2 \rightarrow \mathrm{CO} 2$, Phys. Rev. Lett. 78 (1997) 1500-1503.

[140] X.C. Guo, R.J. Madix, CO2 + O on Ag(110): Stoichiometry of carbonate formation, reactivity of carbonate with $\mathrm{CO}$, and reconstruction-stabilized chemisorption of $\mathrm{CO} 2, \mathrm{~J}$. Phys. Chem. B. 105 (2001) 3878-3885.

[141] I. Stensgaard, E. Lægsgaard, F. Besenbacher, The reaction of carbon dioxide with an oxygen precovered Ag(110) surface, J. Chem. Phys. 103 (1995) 9825-9831.

[142] K.J. Maynard, M. Moskovits, A surface enhanced Raman study of carbon dioxide coadsorption with oxygen and alkali metals on silver surfaces, J. Chem. Phys. . 90 (1989) 6668-6679.

[143] X. Guo, R.J. Madix, Carbonate on Ag (110): a complex system clarified by STM, Surf. Sci. 489 (2001) 37-44.

[144] A.F. Carley, P.R. Davies, E.M. Moser, M.W. Roberts, Facile hydrogenation of carbon dioxide at A1(111) surfaces: The role of coadsorbed water, Surf. Sci. 364 (1996) 563-567.

[145] G. Zhuang, Y. Chen, P.N. Ross, The reaction of lithium with carbon dioxide studied by photoelectron spectroscopy, Surf. Sci. 418 (1998) 139-149.

[146] M.A. Aramendia, V. Borau, C. Jimenez, J.M. Marinas, A. Porras, F.J. Urbano, Synthesis and characterization of various $\mathrm{MgO}$ and related systems, J. Mater. Chem. 6 (1996) 1943.

[147] C. Luo, Y. Zheng, Y. Xu, N. Ding, Q. Shen, C. Zheng, Wet mixing combustion synthesis of CaO-based sorbents for high temperature cyclic CO2 capture, Chem. Eng. J. 267 (2015) 111-116.

[148] Z. Sun, C. Xu, S. Chen, W. Xiang, Improvements of CaO-based sorbents for cyclic CO 2 capture using a wet mixing process, Chem. Eng. J. (2015).

[149] D.K. Aswal, K.P. Muthe, S. Tawde, S. Chodhury, N. Bagkar, A. Singh, et al., XPS and AFM investigations of annealing induced surface modifications of $\mathrm{MgO}$ single crystals, $\mathrm{J}$. Cryst. Growth. 236 (2002) 661-666.

[150] a. Chakradhar, U. Burghaus, Carbon dioxide adsorption on $\mathrm{MgO}(001)-\mathrm{CO} 2$ kinetics and dynamics, Surf. Sci. 616 (2013) 171-177.

[151] F. Voigts, F. Bebensee, S. Dahle, K. Volgmann, W. Maus-Friedrichs, The adsorption of $\mathrm{CO} 2$ and $\mathrm{CO}$ on $\mathrm{Ca}$ and $\mathrm{CaO}$ films studied with MIES, UPS and XPS, Surf. Sci. 603 (2009) 40-49.

[152] E.P. Reddy, P.G. Smirniotis, High-temperature sorbents for $\mathrm{CO} 2$ made of alkali metals doped on $\mathrm{CaO}$ supports, J. Phys. Chem. B. 108 (2004) 7794-7800. 
[153] W.F. Schneider, Qualitative Differences in the Adsorption Chemistry of Acidic (CO2, SOx) and Amphiphilic (NOx) Species on the Alkaline Earth Oxides, J. Phys. Chem. B. 108 (2004) 273-282.

[154] M. Tutuianu, O.R. Inderwildi, W.G. Bessler, J. Warnatz, Competitive Adsorption of NO, NO_2, CO_2, and $\mathrm{H} \_2 \mathrm{O}$ on $\mathrm{BaO}(100)$ : A Quantum Chemical Study, J. Phys. Chem. B. 110 (2006) 17484-17492.

[155] G. Pacchioni, J.J.M. Ricart, F. Illas, Ab Initio Cluster Model Calculations on the Chemisorption of $\mathrm{CO} 2$ and SO2 Probe Molecules on $\mathrm{MgO}$ and $\mathrm{CaO}$ (100) Surfaces . A Theoretical Measure of Oxide Basicity, J. Am. Chem. Soc. 116 (1994) 10152-10158.

[156] G. Kresse, J. Furthmüller, Efficiency of ab-initio total energy calculations for metals and semiconductors using a plane-wave basis set, Comput. Mater. Sci. 6 (1996) 15-50.

[157] R.. Dovesi, R.. Orlando, B.. Civalleri, C.. Roetti, V.R.. Saunders, C.M. Zicovich-Wilson, CRYSTAL: a computational tool for the ab initio study of the electronic properties of crystals, Z. Krist. 220 (2005) 571-573.

[158] J. Baltrusaitis, C. Hatch, R. Orlando, Periodic DFT Study of Acidic Trace Atmospheric Gas Molecule Adsorption on Ca- and Fe-Doped MgO(001) Surface Basic Sites, J. Phys. Chem. A. 116 (2012) 7950-7958.

[159] J. Deer, W. A.; Howie, R. A.; Zussman, An Introduction to the Rock-Forming Minerals, 2nd ed., Prentice Hall, New York, 1996.

[160] M.D. Segall, P.J.D. Lindan, M.J. Probert, C.J. Pickard, P.J. Hasnip, S.J. Clark, et al., Firstprinciples simulation: ideas, illustrations and the CASTEP code, J. Phys. Condens. Matter. 14 (2002) 2717.

[161] E.I. Vovk, A. Turksoy, V.I. Bukhtiyarov, E. Ozensoy, Interactive Surface Chemistry of $\mathrm{CO} 2$ and NO2 on Metal Oxide Surfaces: Competition for Catalytic Adsorption Sites and Reactivity, J. Phys. Chem. C. 117 (2013) 7713-7720.

[162] S. Wang, S. Yan, X. Ma, J. Gong, Recent Advances in Capture of Carbon Dioxide using Alkali Metal-based Oxides, Energy Environ. Sci. 4 (2011) 3805.

[163] Y. Duan, D.C. Sorescu, Density functional theory studies of the structural, electronic, and phonon properties of $\mathrm{Li} 2 \mathrm{O}$ and Li2CO3: Application to $\mathrm{CO} 2$ capture reaction, Phys. Rev. B - Condens. Matter Mater. Phys. 79 (2009) 1-18.

[164] N. Koura, S. Kohara, K. Takeuchi, S. Takahashi, L.A. Curtiss, M. Grimsditch, et al., Alkali carbonates: Raman spectroscopy, ab initio calculations, and structure, J. Mol. Struct. 382 (1996) 163-169.

[165] H. a Mosqueda, C. Vazquez, P. Bosch, H. Pfeiffer, Chemical Sorption of Carbon Dioxide (CO2) on Lithium Oxide (Li2O), Chem. Mater. 18 (2006) 2307-2310.

[166] K. Essaki, K. Nakagawa, M. Kato, H. Uemoto, CO2 Absorption by Lithium Silicate at Room Temperature, J. Chem. Eng. Japan. 37 (2004) 772-777.

[167] M. Kato, S. Yoshikawa, K. Nakagawa, Carbon dioxide absorption by lithium orthosilicate in a wide range of temperature and carbon dioxide concentrations, J. Mater. Sci. Lett. 21 
(2002) 485-487.

[168] S.M. Amorim, M.D. Domenico, T.L.P. Dantas, H.J. José, R.F.P.M. Moreira, Lithium orthosilicate for $\mathrm{CO} 2$ capture with high regeneration capacity: Kinetic study and modeling of carbonation and decarbonation reactions, Chem. Eng. J. 283 (2016) 388-396.

[169] Z. Yong, V. Mata, a Rodrigues, Adsorption of carbon dioxide at high temperature-a review, Sep. Purif. Technol. 26 (2002) 195-205.

[170] K.B. Lee, M.G. Beaver, H.S. Caram, S. Sircar, Chemisorption of carbon dioxide on sodium oxide promoted alumina, AIChE J. 53 (2007) 2824-2831.

[171] F. Prinetto, M. Manzoli, S. Morandi, F. Frola, G. Ghiotti, L. Castoldi, et al., Pt-K / Al2O3 NSR Catalysts : Characterization of Morphological , Structural and Surface Properties, J. Phys. Chem. C. (2010) 1127-1138.

[172] J. Baltrusaitis, V.H. Grassian, Carbonic Acid Formation from Reaction of Carbon Dioxide and Water Coordinated to $\mathrm{Al}(\mathrm{OH}) 3$ : A Quantum Chemical Study, J. Phys. Chem. A. 114 (2010) 2350-2356.

[173] X. Lin, Y. Yoon, N.G. Petrik, Z. Li, Z. Wang, V. Glezakou, et al., Structure and Dynamics of CO2 on Rutile TiO2 ( 110 )-1×1, J. Phys. Chem. C. 116 (2012) 26322-26334.

[174] S. Tan, Y. Zhao, J. Zhao, Z. Wang, C. Ma, A. Zhao, et al., CO2 activated through electron attachment on the reduced rutile TiO2 (110)-1x1 surface, Phys. Rev. B. 84 (2011) 155418.

[175] H. Noei, C. Wöll, M. Muhler, Y. Wang, Activation of carbon dioxide on ZnO nanoparticles studied by vibrational spectroscopy, J. Phys. Chem. C. 115 (2011) 908-914.

[176] M. Buchholz, P.G. Weidler, F. Bebensee, A. Nefedov, C. Wöll, Carbon dioxide adsorption on a $\mathrm{ZnO}(101$ [combining macron] $)$ substrate studied by infrared reflection absorption spectroscopy., Phys. Chem. Chem. Phys. 16 (2014) 1672-8.

[177] S. Fujita, M. Usui, H. Ito, N. Takezawa, Mechanisms of Methanol Synthesis from Carbon Dioxide and from Carbon Monoxide at Atmospheric Pressure over Cu/ZnO, J. Catal. 157 (1995) 403-413.

[178] A. Gutierrez-Sosa, S. Crook, S. Haq, R. Lindsay, S. Ludviksson, Audunn Parker, C.T. Campbell, et al., Influence of $\mathrm{Cu}$ overlayers on the interaction of $\mathrm{CO}$ and $\mathrm{CO} 2$ with $\mathrm{ZnO}(0001)-\mathrm{O}$, Faraday Discuss. 105 (1996).

[179] D. Esken, H. Noei, Y. Wang, C. Wiktor, S. Turner, G. Van Tendeloo, et al., ZnO@ZIF-8: stabilization of quantum confined $\mathrm{ZnO}$ nanoparticles by a zinc methylimidazolate framework and their surface structural characterization probed by $\mathrm{CO} 2$ adsorption, $\mathrm{J}$. Mater. Chem. 21 (2011) 5907.

[180] S.A.S. Farias, E. Longo, R. Gargano, J.B.L. Martins, CO2 adsorption on polar surfaces of ZnO, J. Mol. Model. 19 (2013) 2069-2078.

[181] T. Hikov, A. Rittermeier, M.-B. Luedemann, C. Herrmann, M. Muhler, R. a. Fischer, Preparation of $\mathrm{ZnO}$ colloids by pyrolysis of [MeZnOiPr] 4 in the presence of hexadecylamine and probing the surface chemistry of the nanoparticles by $\mathrm{CO} / \mathrm{CO} 2$ adsorption studies followed by FTIR, J. Mater. Chem. 18 (2008) 3325-3331. 
[182] Q.L. Tang, Q.H. Luo, Adsorption of CO2 at ZnO: A surface structure effect from DFT+ U Calculations, J. Phys. Chem. C. 117 (2013) 22954-22966.

[183] J. Koßmann, G. Roßmller, C. Hättig, Prediction of vibrational frequencies of possible intermediates and side products of the methanol synthesis on $\mathrm{ZnO}(0001)$ by ab initio calculations, J. Chem. Phys. 136 (2012) 0-12.

[184] J. Wang, U. Burghaus, Structure - activity relationship : the case of CO2 adsorption on H / $\mathrm{Zn}-\mathrm{ZnO}$ (0001), Surf. Sci. 403 (2005) 42-46.

[185] G. Dutta, A.A. Sokol, C.R.A. Catlow, T.W. Keal, P. Sherwood, Activation of carbon dioxide over zinc oxide by localised electrons., Chemphyschem. 13 (2012) 3453-6.

[186] J.P. Perdew, K. Burke, M. Ernzerhof, Generalized Gradient Approximation Made Simple, Phys. Rev. Lett. 77 (1996) 3865-3868.

[187] R. Ahlrichs, M. Bär, M. Häser, H. Horn, C. Kölmel, Electronic structure calculations on workstation computers: The program system turbomole, Chem. Phys. Lett. 162 (1989) $165-169$.

[188] M.W. Abee, S.C. York, D.F. Cox, CO2 Adsorption on alfa-Cr2O3 (101) Surfaces, J. Phys. Chem. B. 3 (2001) 7755-7761.

[189] O. Seiferth, K. Wolter, H. Kuhlenbeck, H.-J. Freund, CO2 adsorption on Na precovered Cr2O3(), Surf. Sci. 505 (2002) 215-224.

[190] H. Tsuneoka, K. Teramura, T. Shishido, T. Tanaka, Adsorbed Species of CO2 and H2 on Ga2O3 for the Photocatalytic Reduction of CO2, J. Phys. Chem. C. 114 (2010) 88928898.

[191] J. Baltrusaitis, J.D. Schuttlefield, E. Zeitler, J.H. Jensen, V.H. Grassian, Surface Reactions of Carbon Dioxide at the Adsorbed Water-Oxide Interface, J. Phys. Chem. C. 111 (2007) 14870-14880.

[192] D.B. Hausner, N. Bhandari, A.M. Pierre-Louis, J.D. Kubicki, D.R. Strongin, Ferrihydrite reactivity toward carbon dioxide, J. Colloid Interface Sci. 337 (2009) 492-500.

[193] X. Song, J.F. Boily, Carbon Dioxide Binding at Dry FeOOH Mineral Surfaces: Evidence for Structure-Controlled Speciation, Environ. Sci. Technol. 47 (2013) 9241-9248.

[194] A.K. Mishra, S. Ramaprabhu, Magnetite decorated graphite nanoplatelets as cost effective CO2 adsorbent, J. Mater. Chem. 21 (2011) 7467-7471.

[195] A.K. Mishra, S. Ramaprabhu, Enhanced CO2 capture in Fe3O4-graphene nanocomposite by physicochemical adsorption, J. Appl. Phys. 116 (2014) 064306.

[196] J. a. Hinojosa, A. Antony, C. Hakanoglu, A. Asthagiri, J.F. Weaver, Adsorption of CO 2 on a PdO(101) Thin Film, J. Phys. Chem. C. 116 (2012) 3007-3016.

[197] A.-M. Pierre-Louis, D.B. Hausner, N. Bhandari, W. Li, J. Kim, J.D. Kubicki, et al., Adsorption of carbon dioxide on Al/Fe oxyhydroxide., J. Colloid Interface Sci. 400 (2013) $1-10$.

[198] W. Broecker, The Carbon Cycle and Climate Change: Memoirs of my 60 years in 
Science, Geochemical Perspect. 1 (2012) 221-340.

[199] F.T. Mackenzie, A.J. Andersson, The Marine Carbon System and Ocean Acidification during Phanerozoic Time, Geochemical Perspect. 2 (2013) 1-227.

[200] J.P. Allen, A. Marmier, S.C. Parker, Atomistic Simulation of Surface Selectivity on Carbonate Formation at Calcium and Magnesium Oxide Surfaces, J. Phys. Chem. C. 116 (2012) 13240-13251.

[201] S.-C. Kwon, W.-R. Lee, H.-N. Lee, J.-H. Kim, H.-L. Lee, Competitive Adsorption of CO 2 and $\mathrm{H} 2 \mathrm{O}$ Molecules on the $\mathrm{BaO}$ (100) Surface: A First-Principle Study, Bull. Korean Chem. Soc. 32 (2011) 988-992.

[202] D.C. Sorescu, S. Civiš, K.D. Jordan, Mechanism of Oxygen Exchange between CO2 and TiO2(101) Anatase, J. Phys. Chem. C. 118 (2014) 1628-1639.

[203] S. Civiš, M. Ferus, M. Zukalová, A. Zukal, L. Kavan, K.D. Jordan, et al., Oxygen Atom Exchange between Gaseous CO2 and TiO2 Nanoclusters, J. Phys. Chem. C. 119 (2015) 3605-3612.

[204] A.L. Goodman, E.T. Bernard, V.H. Grassian, Spectroscopic Study of Nitric Acid and Water Adsorption on Oxide Particles: Enhanced Nitric Acid Uptake Kinetics in the Presence of Adsorbed Water, J. Phys. Chem. A. 105 (2001) 6443-6457.

[205] C. Su, D.L. Suarez, In Situ Infrared Speciation of Adsorbed Carbonate on Aluminum and Iron Oxides, Clays Clay Miner. 45 (1997) 814-825.

[206] M.A. Henderson, Evidence for bicarbonate formation on vacuum annealed TiO2(110) resulting from a precursor-mediated interaction between $\mathrm{CO} 2$ and $\mathrm{H} 2 \mathrm{O}$, Surf. Sci. 400 (1998) 203-219.

[207] R.W. Stevens, R. V Siriwardane, J. Logan, In Situ Fourier Transform Infrared (FTIR) Investigation of CO2 Adsorption onto Zeolite Materials, Energy \& Fuels. 22 (2008) 30703079 .

[208] T. Montanari, G. Busca, On the mechanism of adsorption and separation of CO2 on LTA zeolites: An IR investigation, Vib. Spectrosc. 46 (2008) 45-51.

[209] R.S. Pillai, S.A. Peter, R. V. Jasra, Adsorption of carbon dioxide, methane, nitrogen, oxygen and argon in NaETS-4, Microporous Mesoporous Mater. 113 (2008) 268-276.

[210] A. Zukal, C.O. Arean, M.R. Delgado, P. Nachtigall, A. Pulido, J. Mayerová, et al., Combined volumetric, infrared spectroscopic and theoretical investigation of $\mathrm{CO} 2$ adsorption on Na-A zeolite, Microporous Mesoporous Mater. 146 (2011) 97-105.

[211] M.R. Delgado, C.O. Arean, Carbon monoxide, dinitrogen and carbon dioxide adsorption on zeolite H-Beta: IR spectroscopic and thermodynamic studies, Energy. 36 (2011) 52865291.

[212] A. Pulido, M.R. Delgado, O. Bludsky, M. Rubes, P. Nachtigall, C.O. Arean, Combined DFT/CC and IR spectroscopic studies on carbon dioxide adsorption on the zeolite H-FER, Energy Environ. Sci. 2 (2009) 1187-1195.

[213] R. Bulánek, K. Frolich, E. Frýdová, P. Čičmanec, Microcalorimetric and FTIR Study of 
the Adsorption of Carbon Dioxide on Alkali-Metal Exchanged FER Zeolites, Top. Catal. 53 (2010) 1349-1360.

[214] C.O. Arean, G.F. Bibiloni, M.R. Delgado, FT-IR spectroscopic and thermodynamic study on the adsorption of carbon dioxide and dinitrogen in the alkaline zeolite K-L, Appl. Surf. Sci. 259 (2012) 367-370.

[215] T.D. Pham, Q. Liu, R.F. Lobo, Carbon Dioxide and Nitrogen Adsorption on CationExchanged SSZ-13 Zeolites, Langmuir. 29 (2013) 832-839.

[216] E. Díaz, E. Muñoz, A. Vega, S. Ordóñez, Enhancement of the CO2 Retention Capacity of Y Zeolites by $\mathrm{Na}$ and $\mathrm{Cs}$ Treatments: Effect of Adsorption Temperature and Water Treatment, Ind. Eng. Chem. Res. 47 (2008) 412-418.

[217] C.O. Areán, M.R. Delgado, Variable-temperature FT-IR studies on the thermodynamics of carbon dioxide adsorption on a faujasite-type H-Y zeolite, Appl. Surf. Sci. 256 (2010) 5259-5262.

[218] F. Yagi, H. Tsuji, H. Hattori, IR and TPD (temperature-programmed desorption) studies of carbon dioxide on basic site active for 1-butene isomerization on alkali-added zeolite $\mathrm{X}$, Microporous Mater. 9 (1997) 237-245.

[219] N. Hiyoshi, K. Yogo, T. Yashima, Adsorption characteristics of carbon dioxide on organically functionalized SBA-15, Microporous Mesoporous Mater. 84 (2005) 357-365.

[220] H. Tominaga, M. Nagai, Density functional theory of water-gas shift reaction on molybdenum carbide, J. Phys. Chem. B. 109 (2005) 20415-20423.

[221] L. Duan, Q. Ma, Z. Chen, Fabrication and CO2 capture performance of silicon carbide derived carbons from polysiloxane, Microporous Mesoporous Mater. 203 (2015) 24-31.

[222] M.D. Porosoff, X. Yang, J.A. Boscoboinik, J.G. Chen, Molybdenum Carbide as Alternative Catalysts to Precious Metals for Highly Selective Reduction of $\mathrm{CO}_{2}$ to $\mathrm{CO}$, Angew. Chemie Int. Ed. 53 (2014) 6705-6709.

[223] J.-L. Dubois, K. Sayama, H. Arakawa, CO2 Hydrogenation over Carbide Catalysts, Chem. Lett. 21 (1992) 5-8.

[224] S. Posada-Pérez, F. Viñes, P.J. Ramirez, A.B. Vidal, J. a Rodriguez, F. Illas, The bending machine: $\mathrm{CO} 2$ activation and hydrogenation on $\delta$-MoC $(001)$ and $\beta-\mathrm{Mo} 2 \mathrm{C}(001)$ surfaces., Phys. Chem. Chem. Phys. 16 (2014) 14912-21.

[225] J. Ren, C.-F. Huo, J. Wang, Z. Cao, Y.-W. Li, H. Jiao, Density functional theory study into the adsorption of $\mathrm{CO} 2, \mathrm{H}$ and $\mathrm{CHx}(\mathrm{x}=0-3)$ as well as $\mathrm{C} 2 \mathrm{H} 4$ on $\alpha-\mathrm{Mo} 2 \mathrm{C}(0001)$, Surf. Sci. 600 (2006) 2329-2337.

[226] J.A. Rodriguez, P. Liu, D.J. Stacchiola, S.D. Senanayake, M.G. White, J.G. Chen, Hydrogenation of CO 2 to Methanol: Importance of Metal-Oxide and Metal-Carbide Interfaces in the Activation of CO 2, ACS Catal. 6706 (2015) 6696-6706.

[227] A.B. Vidal, L. Feria, J. Evans, Y. Takahashi, P. Liu, K. Nakamura, et al., CO 2 activation and methanol synthesis on novel $\mathrm{Au} / \mathrm{TiC}$ and $\mathrm{Cu} / \mathrm{TiC}$ catalysts, J. Phys. Chem. Lett. 3 (2012) 2275-2280. 
[228] S.Y. Wu, J.J. Ho, Adsorption, dissociation, and hydrogenation of CO 2 on WC(0001) and WC-Co alloy surfaces investigated with theoretical calculations, J. Phys. Chem. C. 116 (2012) 13202-13209.

[229] H. Choi, Y.C. Park, Y. Kim, Y.S. Lee, Ambient Carbon Dioxide Capture by Boron-Rich Boron Nitride Nanotube, J. Am. Chem. Soc. (2011) 2084-2087.

[230] Y. Jiao, A. Du, Z. Zhu, V. Rudolph, G.Q. (Max) Lu, S.C. Smith, A density functional theory study on $\mathrm{CO} 2$ capture and activation by graphene-like boron nitride with boron vacancy, Catal. Today. 175 (2011) 271-275.

[231] P. Shao, X.Y. Kuang, L.P. Ding, J. Yang, M.M. Zhong, Can CO2 molecule adsorb effectively on Al-doped boron nitride single walled nanotube?, Appl. Surf. Sci. 285 (2013) 350-356.

[232] I. Carrillo, E. Rangel, L.F. Magaña, Adsorption of carbon dioxide and methane on graphene with a high titanium coverage, Surf. Sci. 47 (2009) 2758-2760.

[233] A. Manzi, T. Simon, C. Sonnleitner, M. Döblinger, R. Wyrwich, O. Stern, et al., LightInduced Cation Exchange for Copper Sulfide Based CO 2 Reduction, J. Am. Chem. Soc. 137 (2015) 14007-14010.

[234] T. Osaki, H. Taoda, T. Horiuchi, H. Yamakita, Tungsten Disulfide Prepared from Ammonium Tetrathiotungstate as a catalyst with high performance for the selective hydrogenation of CO2 to CO, React. Kinet. Catal. Lett. 51 (1993) 39.

[235] T. Osaki, T. Horiuchi, K. Suzuki, T. Mori, Catalyst performance of MoS2 and WS2 for the CO2-reforming of CH4 Suppression of carbon deposition, Appl. Catal. A Gen. 155 (1997) 229-238.

[236] M.A. Karolewski, R.G. Cavell, SIMS Study OF Cs/MoS,(0001) II. Chemisorption of O2, H2O, HCOOH, Surf. Sci. 219 (1989) 261-276.

[237] M. Wdowin, W. Franus, R. Panek, Preliminary Results of Usage Possibilities of Carbonate and Zeolitic Sorbents in CO2 Capture, Fresenius Environ. Bull. 21 (2011) 3726-3734.

[238] P. Giesting, S. Guggenheim, A.F.K. van Groos, A. Busch, Interaction of carbon dioxide with Na-exchanged montmorillonite at pressures to 640 bars: Implications for $\mathrm{CO} 2$ sequestration, Int. J. Greenh. Gas Control. 8 (2012) 73-81.

[239] P. Giesting, S. Guggenheim, A.F.K. van Groos, A. Busch, X-ray Diffraction Study of Kand Ca-Exchanged Montmorillonites in CO2 Atmospheres, Environ. Sci. Technol. 46 (2012) 5623-5630.

[240] V.N. Romanov, Evidence of irreversible CO2 intercalation in montmorillonite, Int. J. Greenh. Gas Control. 14 (2013) 220-226.

[241] M. Makaremi, K.D. Jordan, G.D. Guthrie, E.M. Myshakin, Multiphase Monte Carlo and Molecular Dynamics Simulations of Water and CO2 Intercalation in Montmorillonite and Beidellite, J. Phys. Chem. C. 119 (2015) 15112-15124.

[242] L. Michels, J.O. Fossum, Z. Rozynek, H. Hemmen, K. Rustenberg, P.A. Sobas, et al., 
Intercalation and Retention of Carbon Dioxide in a Smectite Clay promoted by Interlayer Cations, Sci. Rep. 5 (2015).

[243] S. Bachu, W.D. Gunter, E.H. Perkins, Aquifer disposal of CO2 - hydrodynamic and mineral trapping, Energy Convers. Manag. 35 (1994) 269-279.

[244] S.M. Benson, T. Surles, Carbon dioxide capture and storage: An overview with emphasis on capture and storage in deep geological formations, Proc. IEEE. 94 (2006) 1795-1805.

[245] D.J. DePaolo, D.R. Cole, Geochemistry of Geologic Carbon Sequestration: An Overview, in: D.J. and C. DePaolo DR and Navrotsky, A and Bourg, IC (Ed.), Geochemistry Geol. CO2 Sequestration, Mineralogical Society America, Chantilly, VA, 2013: pp. 1-14.

[246] P.R. Jeon, J. Choi, T.S. Yun, C.-H. Lee, Sorption equilibrium and kinetics of CO2 on clay minerals from subcritical to supercritical conditions: $\mathrm{CO} 2$ sequestration at nanoscale interfaces, Chem. Eng. J. 255 (2014) 705-715.

[247] M.-S. Lee, B.P. McGrail, V.-A. Glezakou, Microstructural Response of Variably Hydrated Ca-rich Montmorillonite to Supercritical CO2, Environ. Sci. Technol. 48 (2014) 8612-8619.

[248] J.S. Loring, E.S. Ilton, J. Chen, C.J. Thompson, P.F. Martin, P. Benezeth, et al., In Situ Study of CO2 and $\mathrm{H} 2 \mathrm{O}$ Partitioning between Na-Montmorillonite and Variably Wet Supercritical Carbon Dioxide, Langmuir. 30 (2014) 6120-6128.

[249] C.M. Tenney, R.T. Cygan, Molecular Simulation of Carbon Dioxide, Brine, and Clay Mineral Interactions and Determination of Contact Angles, Environ. Sci. Technol. 48 (2014) 2035-2042.

[250] T.-B. Hur, J.P. Baltrus, B.H. Howard, W.P. Harbert, V.N. Romanov, Carbonate formation in Wyoming montmorillonite under high pressure carbon dioxide, Int. J. Greenh. Gas Control. 13 (2013) 149-155.

[251] J.S. Loring, C.J. Thompson, Z. Wang, A.G. Joly, D.S. Sklarew, H.T. Schaef, et al., In Situ Infrared Spectroscopic Study of Forsterite Carbonation in Wet Supercritical CO2, Environ. Sci. Technol. 45 (2011) 6204-6210.

[252] J.S. Loring, J. Chen, P. Benezeth, O. Qafoku, E.S. Ilton, N.M. Washton, et al., Evidence for Carbonate Surface Complexation during Forsterite Carbonation in Wet Supercritical Carbon Dioxide, Langmuir. 31 (2015) 7533-7543.

[253] C.J. Thompson, J.S. Loring, K.M. Rosso, Z. Wang, Comparative reactivity study of forsterite and antigorite in wet supercritical CO2 by in situ infrared spectroscopy, Int. J. Greenh. Gas Control. 18 (2013) 246-255.

[254] Q.R.S. Miller, C.J. Thompson, J.S. Loring, C.F. Windisch, M.E. Bowden, D.W. Hoyt, et al., Insights into silicate carbonation processes in water-bearing supercritical $\mathrm{CO} 2$ fluids, Int. J. Greenh. Gas Control. 15 (2013) 104-118.

[255] Z. Wang, A.R. Felmy, C.J. Thompson, J.S. Loring, A.G. Joly, K.M. Rosso, et al., Nearinfrared spectroscopic investigation of water in supercritical $\mathrm{CO} 2$ and the effect of $\mathrm{CaCl} 2$, Fluid Phase Equilib. 338 (2013) 155-163. 
[256] H.T. Schaef, Q.R.S. Miller, C.J. Thompson, J.S. Loring, M.S. Bowden, B.W. Arey, et al., Silicate Carbonation in Supercritical CO2 Containing Dissolved H2O: An in situ High Pressure X-Ray Diffraction and Infrared Spectroscopy Study, in: T. and Y. Dixon K (Ed.), GHGT-11, 2013: pp. 5892-5896.

[257] J.S. Loring, H.T. Schaef, C.J. Thompson, R. V Turcu, Q.R. Miller, J. Chen, et al., Clay hydration/dehydration in dry to water-saturated supercritical CO2: Implications for caprock integrity, in: T. and Y. Dixon K (Ed.), GHGT-11, 2013: pp. 5443-5448.

[258] J.S. Loring, H.T. Schaef, R.V.F. Turcu, C.J. Thompson, Q.R.S. Miller, P.F. Martin, et al., In Situ Molecular Spectroscopic Evidence for CO2 Intercalation into Montmorillonite in Supercritical Carbon Dioxide, LANGMUIR. 28 (2012) 7125-7128.

[259] A. Busch, S. Alles, Y. Gensterblum, D. Prinz, D.N. Dewhurst, M.D. Raven, et al., Carbon dioxide storage potential of shales, Int. J. Greenh. GAS Control. 2 (2008) 297-308.

[260] S. Kerisit, E.J. Bylaska, A.R. Felmy, Water and carbon dioxide adsorption at olivine surfaces, Chem. Geol. 359 (2013) 81-89.

[261] E.S. Ilton, H.T. Schaef, O. Qafoku, K.M. Rosso, A.R. Felmy, In Situ X-ray Diffraction Study of $\mathrm{Na}+$ Saturated Montmorillonite Exposed to Variably Wet Super Critical CO2, Environ. Sci. Technol. 46 (2012) 4241-4248.

[262] A. Botan, B. Rotenberg, V. Marry, P. Turq, B. Noetinger, Carbon Dioxide in Montmorillonite Clay Hydrates: Thermodynamics, Structure, and Transport from Molecular Simulation, J. Phys. Chem. C. 114 (2010) 14962-14969.

[263] N. Yang, X. Yang, Molecular simulation of swelling and structure for Na-Wyoming montmorillonite in supercritical CO2, Mol. Simul. 37 (2011) 1063-1070.

[264] R.T. Cygan, V.N. Romanov, E.M. Myshakin, Molecular Simulation of Carbon Dioxide Capture by Montmorillonite Using an Accurate and Flexible Force Field, J. Phys. Chem. C. 116 (2012) 13079-13091.

[265] R.T. Cygan, J.-J. Liang, A.G. Kalinichev, Molecular Models of Hydroxide, Oxyhydroxide, and Clay Phases and the Development of a General Force Field, J. Phys. Chem. B. 108 (2004) 1255-1266.

[266] D.R. Cole, A.A. Chialvo, G. Rother, L. Vlcek, P.T. Cummings, Supercritical fluid behavior at nanoscale interfaces: Implications for CO2 sequestration in geologic formations, Philos. Mag. 90 (2010) 2339-2363.

[267] H.A. Al-Hosney, V.H. Grassian, Water, sulfur dioxide and nitric acid adsorption on calcium carbonate: A transmission and ATR-FTIR study, Phys. Chem. Chem. Phys. 7 (2005) 1266-1276.

[268] J. Baltrusaitis, V.H. Grassian, Calcite surface in humid environments, Surf. Sci. 603 (2009) L99-L104.

[269] T.A. Kendall, S.T. Martin, Water-Induced Reconstruction that Affects Mobile Ions on the Surface of Calcite, J. Phys. Chem. A. 111 (2007) 505-514.

[270] R.A. Walker, K. Wilson, A.F. Lee, J. Woodford, V.H. Grassian, J. Baltrusaitis, et al., 
Preservation of York Minster historic limestone by hydrophobic surface coatings, Sci. Rep. 2 (2012) 880.

[271] S.L. Stipp, M.F. Hochella, Structure and bonding environments at the calcite surface as observed with X-ray photoelectron spectroscopy (XPS) and low energy electron diffraction (LEED), Geochim. Cosmochim. Acta. 55 (1991) 1723-1736.

[272] S.L.S. Stipp, W. Gutmannsbauer, T. Lehmann, The dynamic nature of calcite surfaces in air, Am. Mineral. 81 (1996) 1-8.

[273] V.H. Grassian, Surface science of complex environmental interfaces: Oxide and carbonate surfaces in dynamic equilibrium with water vapor, Surf. Sci. 602 (2008) 2955-2962.

[274] J. Baltrusaitis, V.H. Grassian, Atomic Force Microscopy and X-ray Photoelectron Spectroscopy Study of NO2 Reactions on CaCO3 (1014) Surfaces in Humid Environments, J. Phys. Chem. A. 116 (2012) 9001-9009.

[275] J. Baltrusaitis, C.R. Usher, V.H. Grassian, Reactions of sulfur dioxide on calcium carbonate single crystal and particle surfaces at the adsorbed water carbonate interface, Phys. Chem. Chem. Phys. 9 (2007) 3011-3024.

[276] T.A. Kendall, S.T. Martin, Mobile ions on carbonate surfaces, Geochim. Cosmochim. Acta. 69 (2005) 3257-3263.

[277] C. Na, T.A. Kendall, S.T. Martin, Surface-Potential Heterogeneity of Reacted Calcite and Rhodochrosite, Environ. Sci. Technol. 41 (2007) 6491-6497.

[278] D.B. Hausner, R.J. Reeder, D.R. Strongin, Humidity-induced restructuring of the calcite surface and the effect of divalent heavy metals., J. Colloid Interface Sci. 305 (2007) 10110 .

[279] O.W. Duckworth, S.T. Martin, Role of molecular oxygen in the dissolution of siderite and rhodochrosite, Geochim. Cosmochim. Acta. 68 (2004) 607-621.

[280] Y.-S. Jun, T.A. Kendall, S.T. Martin, C.M. Friend, J.J. Vlassak, Heteroepitaxial Nucleation and Oriented Growth of Manganese Oxide Islands on Carbonate Minerals under Aqueous Conditions, Environ. Sci. Technol. 39 (2005) 1239-1249.

[281] C.R. Usher, A.E. Michel, V.H. Grassian, Reactions on Mineral Dust, Chem. Rev. 103 (2003) 4883-4940.

[282] C. Tullin, G. Nyman, S. Ghardashkhani, Direct sulfation of calcium carbonate: the influence of carbon dioxide partial pressure, Energy \& Fuels. 7 (1993) 512-519.

[283] M.J.H. Snow, J.P. Longwell, A.F. Sarofim, Direct sulfation of calcium carbonate, Ind. Eng. Chem. Res. 27 (1988) 268-273.

[284] M.R. Hajaligol, J.P. Longwell, A.F. Sarofim, Analysis and modeling of the direct sulfation of calcium carbonate, Ind. Eng. Chem. Res. 27 (1988) 2203-2210.

[285] G. Van Houte, L. Rodrique, M. Genet, B. Delmon, Kinetics of the reaction of calcium sulfite and calcium carbonate with sulfur dioxide and oxygen in the presence of calcium chloride, Environ. Sci. Technol. 15 (1981) 327-332. 
[286] A. Laskin, M.J. Iedema, A. Ichkovich, E.R. Graber, I. Taraniuk, Y. Rudich, Direct observation of completely processed calcium carbonate dust particles, Faraday Discuss. 130 (2005) 453-468.

[287] J. Baltrusaitis, D.M. Cwiertny, V.H. Grassian, Adsorption of sulfur dioxide on hematite and goethite particle surfaces, Phys. Chem. Chem. Phys. 9 (2007) 5542-5554.

[288] A. Putnis, Why Mineral Interfaces Matter, Sci. . 343 (2014) 1441-1442.

[289] K. Maher, C.P. Chamberlain, Hydrologic Regulation of Chemical Weathering and the Geologic Carbon Cycle, Sci. . 343 (2014) 1502-1504.

[290] O. Hoegh-Guldberg, P.J. Mumby, A.J. Hooten, R.S. Steneck, P. Greenfield, E. Gomez, et al., Coral Reefs Under Rapid Climate Change and Ocean Acidification, Sci. . 318 (2007) 1737-1742.

[291] J.C. Orr, V.J. Fabry, O. Aumont, L. Bopp, S.C. Doney, R.A. Feely, et al., Anthropogenic ocean acidification over the twenty-first century and its impact on calcifying organisms, Nature. 437 (2005) 681-686.

[292] K. Caldeira, M.E. Wickett, Oceanography: Anthropogenic carbon and ocean pH, Nature. 425 (2003) 365.

[293] C. Marutschke, D. Walters, J. Cleveland, I. Hermes, R. Bechstein, A. Kühnle, Threedimensional hydration layer mapping on the (10.4) surface of calcite using amplitude modulation atomic force microscopy, Nanotechnology. 25 (2014) 335703.

[294] A. Ridgwell, R. Zeebe, The role of the global carbonate cycle in the regulation and evolution of the Earth system, Earth Planet. Sci. Lett. 234 (2005) 299-315.

[295] I. Kurtz, J. Kraut, V. Ornekian, M.K. Nguyen, Acid-base analysis: a critique of the Stewart and bicarbonate-centered approaches., Am. J. Physiol. Renal Physiol. 294 (2008) F1009-F1031.

[296] N. Spycher, K. Pruess, J. Ennis-King, CO2-H2O mixtures in the geological sequestration of CO2. I. Assessment and calculation of mutual solubilities from 12 to $100^{\circ} \mathrm{C}$ and up to 600 bar, Geochim. Cosmochim. Acta. 67 (2003) 3015-3031.

[297] T.S. Bowers, H.C. Helgeson, FORTRAN programs for generating fluid inclusion isochores and fugacity coefficients for the system $\mathrm{H} 2 \mathrm{O}-\mathrm{CO} 2-\mathrm{NaCl}$ at high pressures and temperatures, Comput. Geosci. 11 (1985) 203-213.

[298] Z. Duan, N. Møller, J.H. Weare, Equation of state for the NaCl-H2O-CO2 system: prediction of phase equilibria and volumetric properties, Geochim. Cosmochim. Acta. 59 (1995) 2869-2882.

[299] J. Dubessy, A. Tarantola, J. Sterpenich, Modelling of Liquid-Vapour Equilibria in the H 2 O-CO 2 -Nacl and H 2 O-H 2 S-NaCl Systems to $270^{\circ} \mathrm{C}$, Oil Gas Sci. Technol. 60 (2005) 339-355.

[300] N. Spycher, K. Pruess, CO2-H2O mixtures in the geological sequestration of CO2. II. Partitioning in chloride brines at $12-100^{\circ} \mathrm{C}$ and up to 600 bar, Geochim. Cosmochim. Acta. 69 (2005) 3309-3320. 
[301] Z. Duan, J. Hu, A new cubic equation of state and its applications to the modeling of vapor-liquid equilibria and volumetric properties of natural fluids, Geochim. Cosmochim. Acta. 68 (2004) 2997-3009.

[302] Z. Duan, N. Møller, J.H. Weare, An equation of state for the CH4-CO2-H2O system: II. Mixtures from 50 to $1000^{\circ} \mathrm{C}$ and 0 to 1000 bar, Geochim. Cosmochim. Acta. 56 (1992) 2619-2631.

[303] G.K. Jacobs, D.M. Kerrick, Methane: An equation of state with application to the ternary system H2O-CO2-CH4, Geochim. Cosmochim. Acta. 45 (1981) 607-614.

[304] D.-Y. Peng, D.B. Robinson, A New Two-Constant Equation of State, Ind. Eng. Chem. Fundam. 15 (1976) 59-64.

[305] O. Redlich, J.N.S. Kwong, On the Thermodynamics of Solutions. V. An Equation of State. Fugacities of Gaseous Solutions., Chem. Rev. 44 (1949) 233-244.

[306] L.W. Diamond, N.N. Akinfiev, Solubility of $\mathrm{CO} 2$ in water from -1.5 to $100{ }^{\circ} \mathrm{C}$ and from 0.1 to $100 \mathrm{MPa}$ : evaluation of literature data and thermodynamic modelling, Fluid Phase Equilib. 208 (2003) 265-290.

[307] N.N. Akinfiev, L.W. Diamond, Thermodynamic model of aqueous $\mathrm{CO} 2-\mathrm{H} 2 \mathrm{O}-\mathrm{NaCl}$ solutions from -22 to $100^{\circ} \mathrm{C}$ and from 0.1 to $100 \mathrm{MPa}$, Fluid Phase Equilib. 295 (2010) $104-124$.

[308] Z. Duan, J. Hu, D. Li, S. Mao, Densities of the CO2-H2O and CO2-H2O-NaCl Systems Up to $647 \mathrm{~K}$ and $100 \mathrm{MPa}$, Energy \& Fuels. 22 (2008) 1666-1674.

[309] C.S. Patterson, R.H. Busey, R.E. Mesmer, Second ionization of carbonic acid in $\mathrm{NaCl}$ media to $250^{\circ} \mathrm{C}$, J. Solution Chem. 13 (1984) 647-661.

[310] S. Park, H. Kim, K. Kim, J. Lee, D. Lho, Spectroscopic measurement of the acid dissociation constant of 2-naphthol and the second dissociation constant of carbonic acid at elevated temperatures, Phys. Chem. Chem. Phys. 1 (1999) 1893-1898.

[311] C.. Patterson, G.. Slocum, R.. Busey, R.. Mesmer, Carbonate equilibria in hydrothermal systems: First ionization of carbonic acid in $\mathrm{NaCl}$ media to $300^{\circ} \mathrm{C}$, Geochim. Cosmochim. Acta. 46 (1982) 1653-1663.

[312] L.N.N. Plummer, E. Busenberg, The solubilities of calcite, aragonite and vaterite in CO2$\mathrm{H} 2 \mathrm{O}$ solutions between 0 and $90^{\circ} \mathrm{C}$, and an evaluation of the aqueous model for the system CaCO3-CO2-H2O, Geochim. Cosmochim. Acta. 46 (1982) 1011-1040.

[313] R.N. Roy, L.N. Roy, K.M. Vogel, C. Porter-Moore, T. Pearson, C.E. Good, et al., The dissociation constants of carbonic acid in seawater at salinities 5 to 45 and temperatures 0 to $45^{\circ} \mathrm{C}$, Mar. Chem. 44 (1993) 249-267.

[314] K. Lee, F.J. Millero, Thermodynamic studies of the carbonate system in seawater, Deep Sea Res. Part I Oceanogr. Res. Pap. 42 (1995) 2035-2061.

[315] F.J. Millero, Thermodynamics of the carbon dioxide system in the oceans, Geochim. Cosmochim. Acta. 59 (1995) 661-677.

[316] F.J. Millero, D. Pierrot, K. Lee, R. Wanninkhof, R. Feely, C.L. Sabine, et al., Dissociation 
constants for carbonic acid determined from field measurements, Deep Sea Res. Part I Oceanogr. Res. Pap. 49 (2002) 1705-1723.

[317] F.J. Millero, T.B. Graham, F. Huang, H. Bustos-Serrano, D. Pierrot, Dissociation constants of carbonic acid in seawater as a function of salinity and temperature, Mar. Chem. 100 (2006) 80-94.

[318] H.C. Helgeson, D.H. Kirkham, G.C. Flowers, Theoretical Prediction of the Thermodynamic Behavior of Aqueous Electrolytes by High Pressures and Temperatures, IV; Calculation of Activity Coefficients, Osmotic Coefficients, and Apparent Molal and Standard Relative Partial Molal Properties to 600 Degre, Am. J. Sci. 281 (1981) 12491516.

[319] J.C. Tanger, H.C. Helgeson, Calculation of the thermodynamic and transport properties of aqueous species at high pressures and temperatures; revised equations of state for the standard partial molal properties of ions and electrolytes, Am. J. Sci. 288 (1988) 19-98.

[320] E.L. Shock, H.C. Helgeson, D.A. Sverjensky, Calculation of the thermodynamic and transport properties of aqueous species at high pressures and temperatures: Standard partial molal properties of inorganic neutral species, Geochim. Cosmochim. Acta. 53 (1989) 2157-2183.

[321] E.L. Shock, H.C. Helgeson, Calculation of the thermodynamic and transport properties of aqueous species at high pressures and temperatures: Standard partial molal properties of organic species, Geochim. Cosmochim. Acta. 54 (1990) 915-945.

[322] D. Li, Z. Duan, The speciation equilibrium coupling with phase equilibrium in the H2O$\mathrm{CO} 2-\mathrm{NaCl}$ system from 0 to $250{ }^{\circ} \mathrm{C}$, from 0 to 1000 bar, and from 0 to 5 molality of $\mathrm{NaCl}$, Chem. Geol. 244 (2007) 730-751.

[323] A.P. dos Santos, A. Diehl, Y. Levin, Surface Tensions, Surface Potentials, and the Hofmeister Series of Electrolyte Solutions, Langmuir. 26 (2010) 10778-10783.

[324] W. Hua, A.M. Jubb, H.C. Allen, Electric Field Reversal of Na2SO4, (NH4)2SO4, and $\mathrm{Na} 2 \mathrm{CO} 3$ Relative to $\mathrm{CaCl} 2$ and $\mathrm{NaCl}$ at the Air/Aqueous Interface Revealed by Heterodyne Detected Phase-Sensitive Sum Frequency, J. Phys. Chem. Lett. 2 (2011) 2515-2520.

[325] M.A. Brown, M.-T. Lee, A. Kleibert, M. Ammann, J.B. Giorgi, Ion Spatial Distributions at the Air- and Vacuum-Aqueous K2CO3 Interfaces, J. Phys. Chem. C. 119 (2015) 49764982.

[326] A. Stirling, I. Pápai, H2CO3 Forms via HCO3- in Water, J. Phys. Chem. B. 114 (2010) 16854-16859.

[327] A. Laio, M. Parrinello, Escaping Free-Energy Minima, Proc. Natl. Acad. Sci. U. S. A. 99 (2002) 12562-12566.

[328] M. Galib, G. Hanna, The Role of Hydrogen Bonding in the Decomposition of H2CO3 in Water: Mechanistic Insights from Ab Initio Metadynamics Studies of Aqueous Clusters, J. Phys. Chem. B. 118 (2014) 5983-5993.

[329] M. Galib, G. Hanna, Molecular dynamics simulations predict an accelerated dissociation 
of H2CO3 at the air-water interface, Phys. Chem. Chem. Phys. 16 (2014) 25573-25582.

[330] R.K. Lam, A.H. England, J.W. Smith, A.M. Rizzuto, O. Shih, D. Prendergast, et al., The hydration structure of dissolved carbon dioxide from X-ray absorption spectroscopy, Chem. Phys. Lett. 633 (2015) 214-217.

[331] P.P. Kumar, A.G. Kalinichev, R.J. Kirkpatrick, Hydrogen-Bonding Structure and Dynamics of Aqueous Carbonate Species from Car-Parrinello Molecular Dynamics Simulations, J. Phys. Chem. B. 113 (2009) 794-802.

[332] S. Yamabe, N. Kawagishi, A computational study on the relationship between formation and electrolytic dissociation of carbonic acid, Theor. Chem. Acc. 130 (2011) 909-918.

[333] G.A. Gallet, F. Pietrucci, W. Andreoni, Bridging Static and Dynamical Descriptions of Chemical Reactions: An ab Initio Study of CO2 Interacting with Water Molecules, J. Chem. Theory Comput. 8 (2012) 4029-4039.

[334] M. Galib, G. Hanna, Mechanistic Insights into the Dissociation and Decomposition of Carbonic Acid in Water via the Hydroxide Route: An Ab Initio Metadynamics Study, J. Phys. Chem. B. 115 (2011) 15024-15035.

[335] S.K. Reddy, S. Balasubramanian, Carbonic acid: molecule, crystal and aqueous solution, Chem. Commun. 50 (2014) 503-514.

[336] M. Eigen, K. Kusti, G. Maass, Die Geschwindigkeit der Hydratation von SO2 in wäßriger Lösung, Zeitschrift Für Phys. Chemie. 30 (1961) 130-136.

[337] M. Eigen, Proton Transfer, Acid-Base Catalysis, and Enzymatic Hydrolysis. Part I: Elementary Processes, Angew. Chemie Int. Ed. English. 3 (1964) 1-19.

[338] Y. Pocker, D.W. Bjorkquist, Stopped-flow studies of carbon dioxide hydration and bicarbonate dehydration in water and water-d2. Acid-base and metal ion catalysis, J. Am. Chem. Soc. 99 (1977) 6537-6543.

[339] X. Wang, W. Conway, R. Burns, N. McCann, M. Maeder, Comprehensive Study of the Hydration and Dehydration Reactions of Carbon Dioxide in Aqueous Solution, J. Phys. Chem. A. 114 (2010) 1734-1740.

[340] K. Adamczyk, M. Prémont-Schwarz, D. Pines, E. Pines, E.T.J. Nibbering, Real-Time Observation of Carbonic Acid Formation in Aqueous Solution, Sci. . 326 (2009) 16901694.

[341] H. Falcke, S.H. Eberle, Raman spectroscopic identification of carbonic acid, Water Res. 24 (1990) 685-688.

[342] K.F. Wissbrun, D.M. French, A. Patterson, The True Ionization Constant of Carbonic Acid in Aqueous Solution from 5 to 45, J. Phys. Chem. 58 (1954) 693-695.

[343] A.L. Soli, R.H. Byrne, CO2 system hydration and dehydration kinetics and the equilibrium $\mathrm{CO} 2 / \mathrm{H} 2 \mathrm{CO} 3$ ratio in aqueous $\mathrm{NaCl}$ solution, Mar. Chem. 78 (2002) 65-73.

[344] X. Liu, X. Lu, R. Wang, H. Zhou, In Silico Calculation of Acidity Constants of Carbonic Acid Conformers, J. Phys. Chem. A. 114 (2010) 12914-12917. 
[345] A.H. England, A.M. Duffin, C.P. Schwartz, J.S. Uejio, D. Prendergast, R.J. Saykally, On the hydration and hydrolysis of carbon dioxide, Chem. Phys. Lett. 514 (2011) 187-195.

[346] B. Wang, Z. Cao, How water molecules modulate the hydration of CO2 in water solution: Insight from the cluster-continuum model calculations, J. Comput. Chem. 34 (2013) $372-$ 378.

[347] J. Cuny, A.A. Hassanali, Ab Initio Molecular Dynamics Study of the Mechanism of Proton Recombination with a Weak Base, J. Phys. Chem. B. 118 (2014) 13903-13912.

[348] F. Bruneval, D. Donadio, M. Parrinello, Molecular Dynamics Study of the Solvation of Calcium Carbonate in Water, J. Phys. Chem. B. 111 (2007) 12219-12227.

[349] E. Escamilla-Roa, C.I. Sainz-D az, F.J. Huertas, A. Hernández-Laguna, Adsorption of Molecules onto (1014) Dolomite Surface: An Application of Computational Studies for Microcalorimetry, J. Phys. Chem. C. 117 (2013) 17583-17590.

[350] A. Villegas-Jiménez, A. Mucci, O.S. Pokrovsky, J. Schott, Defining reactive sites on hydrated mineral surfaces: Rhombohedral carbonate minerals, Geochim. Cosmochim. Acta. 73 (2009) 4326-4345.

[351] E. Tertre, C. Beaucaire, A. Juery, J. Ly, Methodology to obtain exchange properties of the calcite surface--application to major and trace elements: $\mathrm{Ca}(\mathrm{II}), \mathrm{HCO} 3-$, and $\mathrm{Zn}(\mathrm{II})$., J. Colloid Interface Sci. 347 (2010) 120-6.

[352] O.S. Pokrovsky, J.A. Mielczarski, O. Barres, J. Schott, Surface Speciation Models of Calcite and Dolomite/Aqueous Solution Interfaces and Their Spectroscopic Evaluation, Langmuir. 16 (2000) 2677-2688.

[353] M. Ricci, P. Spijker, F. Stellacci, J.-F. Molinari, K. Voïtchovsky, Direct visualization of single ions in the Stern layer of calcite., Langmuir. 29 (2013) 2207-16.

[354] D.V. Okhrimenko, K.N. Dalby, L.L. Skovbjerg, N. Bovet, J.H. Christensen, S.L.S. Stipp, The surface reactivity of chalk (biogenic calcite) with hydrophilic and hydrophobic functional groups, Geochim. Cosmochim. Acta. 128 (2014) 212-224.

[355] Y.-S. Jun, S.K. Ghose, T.P. Trainor, P.J. Eng, S.T. Martin, Structure of the Hydrated (1014) Surface of Rhodochrosite (MnCO 3 ), Environ. Sci. Technol. 41 (2007) 39183925.

[356] A. Villegas-Jiménez, A. Mucci, M.A. Whitehead, Theoretical insights into the hydrated (10.4) calcite surface: structure, energetics, and bonding relationships., Langmuir. 25 (2009) 6813-24.

[357] O.S. Pokrovsky, J. Schott, F. Thomas, Processes at the magnesium-bearing carbonates/solution interface. I. a surface speciation model for magnesite, Geochim. Cosmochim. Acta. 63 (1999) 863-880.

[358] F. Heberling, T.P. Trainor, J. Lützenkirchen, P. Eng, M.A. Denecke, D. Bosbach, Structure and reactivity of the calcite-water interface., J. Colloid Interface Sci. 354 (2011) 843-857.

[359] M.D. Vinson, R.S. Arvidson, A. Luttge, Kinetic inhibition of calcite (104) dissolution by 
aqueous manganese(II), J. Cryst. Growth. 307 (2007) 116-125.

[360] O. Ozdemir, C. Karaguzel, A.V. Nguyen, M.S. Celik, J.D. Miller, Contact angle and bubble attachment studies in the flotation of trona and other soluble carbonate salts, Miner. Eng. 22 (2009) 168-175.

[361] N. Gence, Wetting behavior of magnesite and dolomite surfaces, Appl. Surf. Sci. 252 (2006) 3744-3750.

[362] N. Laanait, E.B.R. Callagon, Z. Zhang, N.C. Sturchio, S.S. Lee, P. Fenter, X-ray-driven reaction front dynamics at calcite-water interfaces, Sci. . 349 (2015) 1330-1334.

[363] R.A. Berner, The role of magnesium in the crystal growth of calcite and aragonite from sea water, Geochim. Cosmochim. Acta. 39 (1975) 489-504.

[364] P. Fenter, Z. Zhang, C. Park, N.C. Sturchio, X.M. Hu, S.R. Higgins, Structure and reactivity of the dolomite (104)-water interface: New insights into the dolomite problem, Geochim. Cosmochim. Acta. 71 (2007) 566-579.

[365] O.S. Pokrovsky, J. Schott, Surface Chemistry and Dissolution Kinetics of Divalent Metal Carbonates, Environ. Sci. Technol. 36 (2002) 426-432.

[366] F. Heberling, V.L. Vinograd, R. Polly, J.D. Gale, S. Heck, J. Rothe, et al., A thermodynamic adsorption/entrapment model for selenium(IV) coprecipitation with calcite, Geochim. Cosmochim. Acta. 134 (2014) 16-38.

[367] E.J. Elzinga, A.A. Rouff, R.J. Reeder, The long-term fate of $\mathrm{Cu} 2+, \mathrm{Zn} 2+$, and $\mathrm{Pb} 2+$ adsorption complexes at the calcite surface: An X-ray absorption spectroscopy study, Geochim. Cosmochim. Acta. 70 (2006) 2715-2725.

[368] R.J. Reeder, E.J. Elzinga, C.D. Tait, K.D. Rector, R.J. Donohoe, D.E. Morris, Site-specific incorporation of uranyl carbonate species at the calcite surface, Geochim. Cosmochim. Acta. 68 (2004) 4799-4808.

[369] J. Paquette, R.J. Reeder, Relationship between surface structure, growth mechanism, and trace element incorporation in calcite, Geochim. Cosmochim. Acta. 59 (1995) 735-749.

[370] V.G. Alexandratos, E.J. Elzinga, R.J. Reeder, Arsenate uptake by calcite: Macroscopic and spectroscopic characterization of adsorption and incorporation mechanisms, Geochim. Cosmochim. Acta. 71 (2007) 4172-4187.

[371] Y.J. Lee, R.J. Reeder, The role of citrate and phthalate during Co(II) coprecipitation with calcite, Geochim. Cosmochim. Acta. 70 (2006) 2253-2263.

[372] M.P. Andersson, C.P. Hem, L.N. Schultz, J.W. Nielsen, C.S. Pedersen, K.K. Sand, et al., Infrared Spectroscopy and Density Functional Theory Investigation of Calcite, Chalk, and Coccoliths_-Do We Observe the Mineral Surface?, J. Phys. Chem. A. 118 (2014) 1072010729.

[373] P. Fenter, P. Geissbühler, E. DiMasi, G. Srajer, L.B. Sorensen, N.C. Sturchio, Surface speciation of calcite observed in situ by high-resolution X-ray reflectivity, Geochim. Cosmochim. Acta. 64 (2000) 1221-1228.

[374] A. Villegas-Jimenez, A. Mucci, J. Paquette, Proton/calcium ion exchange behavior of 
calcite, Phys. Chem. Chem. Phys. 11 (2009) 8895-8912.

[375] A. Villegas-Jiménez, A. Mucci, O.S. Pokrovsky, J. Schott, Acid-Base Behavior of the Gaspeite (NiCO3(s)) Surface in NaCl Solutions, Langmuir. 26 (2010) 12626-12639.

[376] F. Heberling, P. Eng, M.A. Denecke, J. Lutzenkirchen, H. Geckeis, Electrolyte layering at the calcite(104)-water interface indicated by $\mathrm{Rb}+$ - and $\mathrm{Se}(\mathrm{vi}) \mathrm{K}$-edge resonant interface diffraction, Phys. Chem. Chem. Phys. 16 (2014) 12782-12792.

[377] P. Fenter, S. Kerisit, P. Raiteri, J.D. Gale, Is the Calcite-Water Interface Understood? Direct Comparisons of Molecular Dynamics Simulations with Specular X-ray Reflectivity Data, J. Phys. Chem. C. 117 (2013) 5028-5042.

[378] B.D. Lee, M.R. Walton, J.L. Megio, Biological and chemical interactions with U(VI) during anaerobic enrichment in the presence of iron oxide coated quartz., Water Res. 39 (2005) 4363-74.

[379] J. Luetzenkirchen, Influence of impurities on acid-base data for oxide minerals - Analysis of Observable, Croat. Chem. ACTA. 80 (2007) 333-343.

[380] M. Villalobos, M.A. Trotz, J.O. Leckie, Variability in goethite surface site density: evidence from proton and carbonate sorption, J. Colloid Interface Sci. 268 (2003) 273287.

[381] O.S. Pokrovsky, J. Schott, Kinetics and mechanism of forsterite dissolution at $25^{\circ} \mathrm{C}$ and pH from 1 to 12, Geochim. Cosmochim. Acta. 64 (2000) 3313-3325.

[382] A. López-Valdivieso, A. Robledo-Cabrera, A. Uribe-Salas, Flotation of celestite with the anionic collector sodium dodecyl sulfate. Effect of carbonate ions, Int. J. Miner. Process. 60 (2000) 79-90.

[383] M. Villalobos, M.A. Trotz, J.O. Leckie, Surface Complexation Modeling of Carbonate Effects on the Adsorption of $\mathrm{Cr}(\mathrm{VI}), \mathrm{Pb}(\mathrm{II})$, and U(VI) on Goethite, Environ. Sci. Technol. 35 (2001) 3849-3856.

[384] P. Roonasi, A. Holmgren, An ATR-FTIR study of carbonate sorption onto magnetite, Surf. Interface Anal. 42 (2010) 1118-1121.

[385] I. V Chernyshova, S. Ponnurangam, P. Somasundaran, Linking interfacial chemistry of $\mathrm{CO} 2$ to surface structures of hydrated metal oxide nanoparticles: hematite, Phys. Chem. Chem. Phys. 15 (2013) 6953-6964.

[386] T. Hiemstra, R. Rahnemaie, W.H. van Riemsdijk, Surface complexation of carbonate on goethite: IR spectroscopy, structure and charge distribution, J. Colloid Interface Sci. 278 (2004) 282-290.

[387] R. Rahnemaie, T. Hiemstra, W.H. van Riemsdijk, Carbonate adsorption on goethite in competition with phosphate, J. Colloid Interface Sci. 315 (2007) 415-425.

[388] T. Hiemstra, W.H. VanRiemsdijk, A surface structural approach to ion adsorption: The charge distribution (CD) model, J. Colloid Interface Sci. 179 (1996) 488-508.

[389] H. Wijnja, C. Schulthess, Interaction of carbonate and organic anions with sulfate and selenate adsorption on an aluminum oxide, Soil Sci. Soc. Am. J. 64 (n.d.) 898-908. 
[390] M. Biver, M. Krachler, W. Shotyk, The desorption of antimony(V) from sediments, hydrous oxides, and clay minerals by carbonate, phosphate, sulfate, nitrate, and chloride., J. Environ. Qual. 40 (2011) 1143-52.

[391] T.H. Yoon, S.B. Johnson, C.B. Musgrave, G.E. Brown, Adsorption of organic matter at mineral/water interfaces: I. ATR-FTIR spectroscopic and quantum chemical study of oxalate adsorbed at boehmite/water and corundum/water interfaces, Geochim. Cosmochim. Acta. 68 (2004) 4505-4518.

[392] K. Müller, H. Foerstendorf, V. Brendler, A. Rossberg, K. Stolze, A. Gröschel, The surface reactions of $\mathrm{U}(\mathrm{VI})$ on $\gamma$-A12O3 - In situ spectroscopic evaluation of the transition from sorption complexation to surface precipitation, Chem. Geol. 357 (2013) 75-84.

[393] S. Kerisit, C. Liu, Molecular dynamics simulations of uranyl and uranyl carbonate adsorption at aluminosilicate surfaces., Environ. Sci. Technol. 48 (2014) 3899-907.

[394] S. Doudou, D.J. Vaughan, F.R. Livens, N.A. Burton, Atomistic simulations of calcium uranyl(VI) carbonate adsorption on calcite and stepped-calcite surfaces., Environ. Sci. Technol. 46 (2012) 7587-94.

[395] Q.-J. Pan, S.O. Odoh, A.M. Asaduzzaman, G. Schreckenbach, Adsorption of uranyl species onto the rutile (110) surface: a periodic DFT study., Chemistry. 18 (2012) 145866.

[396] M.M. Fernandes, T. Stumpf, B. Baeyens, C. Walther, M.H. Bradbury, Spectroscopic identification of ternary Cm-carbonate surface complexes., Environ. Sci. Technol. 44 (2010) 921-7.

[397] A.Y. Teterin, K.I. Maslakov, Y.A. Teterin, S.N. Kalmykov, K.E. Ivanov, L. Vukcevic, et al., Interaction of neptunyl with goethite $(\alpha-\mathrm{FeOOH})$, maghemite $(\gamma-\mathrm{Fe} 2 \mathrm{O} 3)$, and hematite $(\alpha-\mathrm{Fe} 2 \mathrm{O} 3)$ in water as probed by X-ray photoelectron spectroscopy, Russ. J. Inorg. Chem. 51 (2006) 1937-1944.

[398] C. Alliot, L. Bion, F. Mercier, P. Toulhoat, Effect of aqueous acetic, oxalic, and carbonic acids on the adsorption of europium(III) onto alpha-alumina., J. Colloid Interface Sci. 298 (2006) 573-81.

[399] P.M. Fox, J.A. Davis, J.M. Zachara, The effect of calcium on aqueous uranium(VI) speciation and adsorption to ferrihydrite and quartz, Geochim. Cosmochim. Acta. 70 (2006) 1379-1387.

[400] A. Křepelová, S. Sachs, G. Bernhard, Uranium(VI) sorption onto kaolinite in the presence and absence of humic acid, Radiochim. Acta. 94 (2006) 825-833.

[401] J.G. Catalano, G.E. Brown, Uranyl adsorption onto montmorillonite: Evaluation of binding sites and carbonate complexation, Geochim. Cosmochim. Acta. 69 (2005) 29953005 .

[402] J.R. Bargar, R. Reitmeyer, J.A. Davis, Spectroscopic Confirmation of Uranium(VI)-Carbonato Adsorption Complexes on Hematite, Environ. Sci. Technol. 33 (1999) 2481-2484.

[403] J.A. Greathouse, R.J. O’Brien, G. Bemis, R.T. Pabalan, Molecular Dynamics Study of 
Aqueous Uranyl Interactions with Quartz (010), J. Phys. Chem. B. 106 (2002) 1646-1655.

[404] J.A. Greathouse, R.T. Cygan, Molecular dynamics simulation of uranyl(VI) adsorption equilibria onto an external montmorillonite surface., Phys. Chem. Chem. Phys. 7 (2005) 3580-6.

[405] P. Zhou, B. Gu, Extraction of Oxidized and Reduced Forms of Uranium from Contaminated Soils: Effects of Carbonate Concentration and pH, Environ. Sci. Technol. 39 (2005) 4435-4440.

[406] X. Liu, L. Wang, Z. Zheng, M. Kang, C. Li, C. Liu, Molecular dynamics simulation of the diffusion of uranium species in clay pores., J. Hazard. Mater. 244-245 (2013) 21-8.

[407] S. Kerisit, C. Liu, Diffusion and adsorption of uranyl carbonate species in nanosized mineral fractures., Environ. Sci. Technol. 46 (2012) 1632-40.

[408] F. Heberling, A.C. Scheinost, D. Bosbach, Formation of a ternary neptunyl(V) biscarbonato inner-sphere sorption complex inhibits calcite growth rate., J. Contam. Hydrol. 124 (2011) 50-6.

[409] G.Y. Zhang, Y.F. Hu, R.K. Xu, J.J. Dynes, R.I.R. Blyth, L.M. Kozak, et al., Carbonateinduced structural perturbation of Al hydroxides, Clays Clay Miner. 57 (2009) 795-807.

[410] J.F. Boily, J. Szanyi, A.R. Felmy, A combined FTIR and TPD study on the bulk and surface dehydroxylation and decarbonation of synthetic goethite, Geochim. Cosmochim. Acta. 70 (2006) 3613-3624.

[411] S. Garcia, R.J. Rosenbauer, J. Palandri, M.M. Maroto-Valer, Sequestration of non-pure carbon dioxide streams in iron oxyhydroxide-containing saline repositories, Int. J. Greenh. Gas Control. 7 (2012) 89-97.

[412] C.J. Yapp, H. Poths, Productivity of Pre-vasular Continetal Biota Inferred from the Fe (CO3)OH Content of Goethite, Nature. 368 (1994) 49-51.

[413] N.J. Tabor, C.J. Yapp, Incremental vacuum dehydration-decarbonation experiments on a natural gibbsite $(\alpha-\mathrm{Al}(\mathrm{OH} 3))$ : $\mathrm{CO} 2$ abundance and $\delta 13 \mathrm{C}$ values, Geochim. Cosmochim. Acta. 69 (2005) 519-527.

[414] W. Feng, C.J. Yapp, Paleoenvironmental implications of concentration and 13C/12C ratios of $\mathrm{Fe}(\mathrm{CO} 3) \mathrm{OH}$ in goethite from a mid-latitude Cenomanian laterite in southwestern Minnesota, Geochim. Cosmochim. Acta. 73 (2009) 2559-2580.

[415] N.J. Tabor, C.J. Yapp, Coexisting goethite and gibbsite from a high-paleolatitude $\left(55^{\circ} \mathrm{N}\right)$ Late Paleocene laterite: Concentration and 13C/12C ratios of occluded $\mathrm{CO} 2$ and associated organic matter, Geochim. Cosmochim. Acta. 69 (2005) 5495-5510.

[416] P. Stathi, K.C. Christoforidis, A. Tsipis, D.G. Hela, Y. Deligiannakis, Effects of Dissolved Carboxylates and Carbonates on the Adsorption Properties of Thiuram Disulfate Pesticides, Environ. Sci. Technol. 40 (2006) 221-227.

[417] J. Zhuang, Y. Jin, Interactions between viruses and goethite during saturated flow: effects of solution pH, carbonate, and phosphate., J. Contam. Hydrol. 98 (2008) 15-21.

[418] C. Hogue, Success Of Climate Deal Will Hinge On Chemistry, Chem. Eng. News. (2016). 
